LA-14052-T

Thesis

Approved for public release;

distribution is unlimited.

Reduction of the Radiotoxicity of

Spent Nuclear Fuel Using a Two-Tiered

System Comprising Light Water Reactors and

Accelerator-Driven Systems

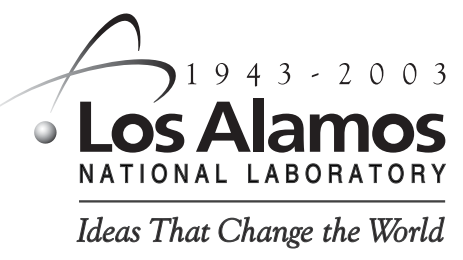


This thesis was accepted by the Chemical and Nuclear Engineering Department, University of New Mexico, Albuquerque, New Mexico, in partial fulfillment of the requirements for the degree of Doctor of Philosophy. The text and illustrations are the independent work of the author and only the front matter has been edited by the IM-1 Writing and Editing Staff to conform with Department of Energy and Los Alamos National Laboratory publication policies.

Los Alamos National Laboratory, an affirmative action/equal opportunity employer, is operated by the University of California for the United States Department of Energy under contract W-7405-ENG-36.

This report was prepared as an account of work sponsored by an agency of the United States Government. Neither the Regents of the University of California, the United States Government nor any agency thereof, nor any of their employees make any warranty, express or implied, or assume any legal liability or responsibility for the accuracy, completeness, or usefulness of any information, apparatus, product, or process disclosed, or represent that its use would not infringe privately owned rights. Reference herein to any specific commercial product, process, or service by trade name, trademark, manufacturer, or otherwise does not necessarily constitute or imply its endorsement, recommendation, or favoring by the Regents of the University of California, the United States Government, or any agency thereof. The views and opinions of authors expressed herein do not necessarily state or reflect those of the Regents of the University of California, the United States Government, or any agency thereof. Los Alamos National Laboratory strongly supports academic freedom and a researcher's right to publish; as an institution, however, the Laboratory does not endorse the viewpoint of a publication or guarantee its technical correctness. 
LA-14052-T

Issued: June 2003

Reduction of the Radiotoxicity of

Spent Nuclear Fuel Using a Two-Tiered

System Comprising Light Water Reactors and

Accelerator-Driven Systems

Holly R. Trellue

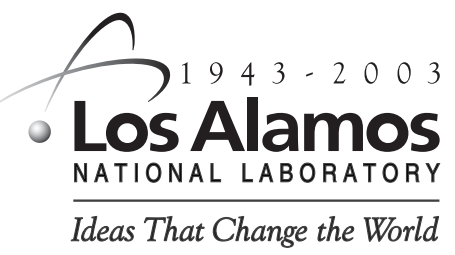





\section{Table of Contents}

Table of Contents ........................................................................................................................... v

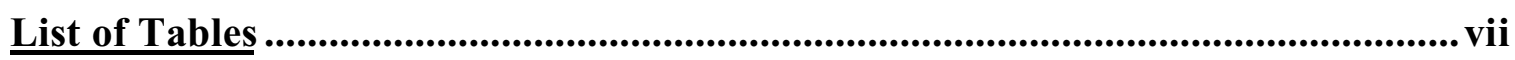

List of Figures............................................................................................................ii

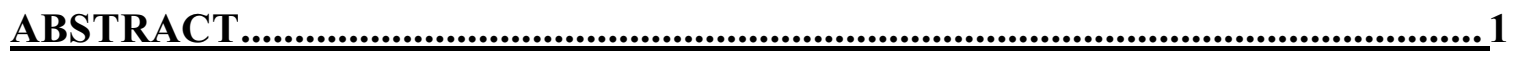

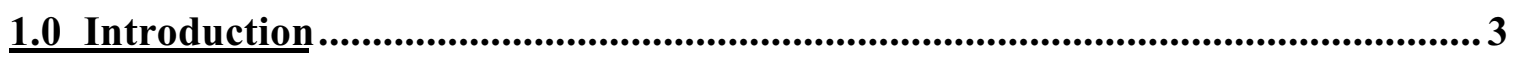

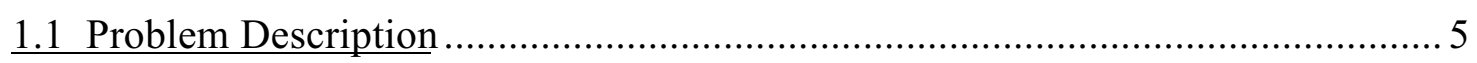

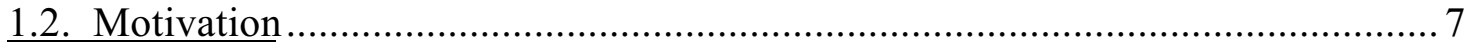

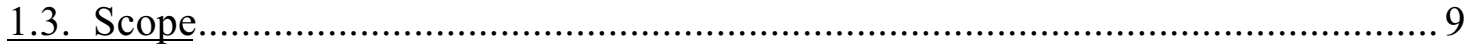

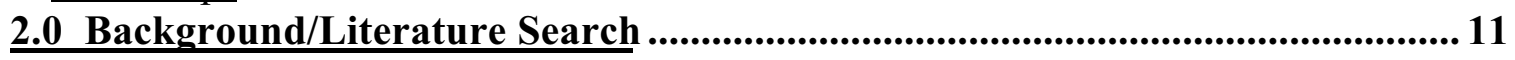

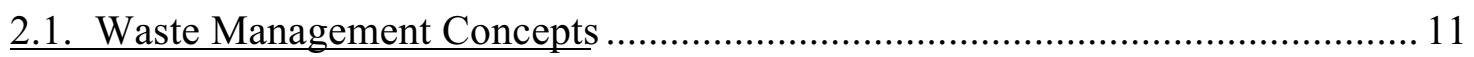

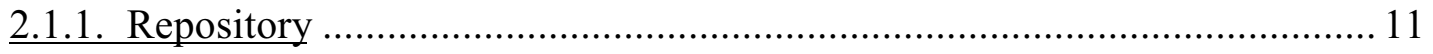

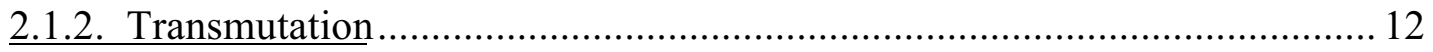

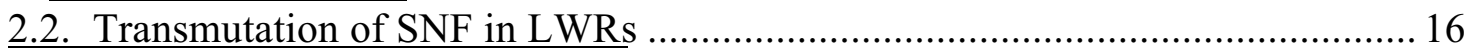

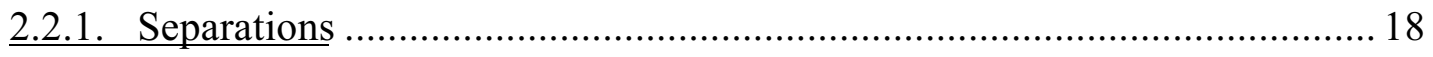

2.2.2. Relicensing/Logistics of U.S. Reactor Irradiation ......................................... 19

2.2.3. MOX Fuel Irradiation and Multiple Recycling ............................................2 20

2.2.4. Full Cores of MOX Fuel ................................................................... 23

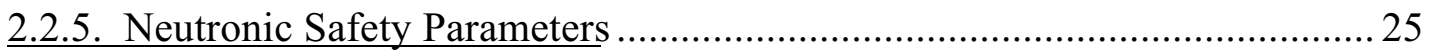

2.3. Accelerator-Driven Transmutation Systems ……….......................................... 30

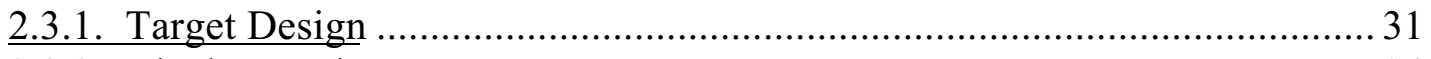

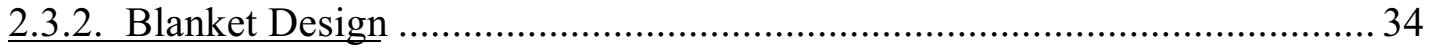

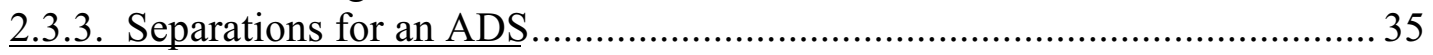

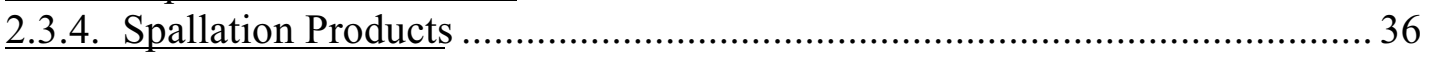

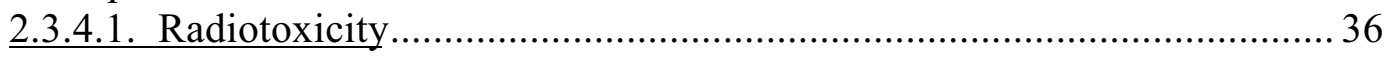

2.3.4.2. Radiotoxicity of Spallation Products ................................................... 38

3.0 Methodology ………….................................................................................................. 41

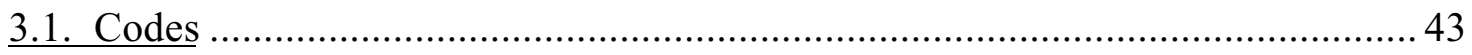

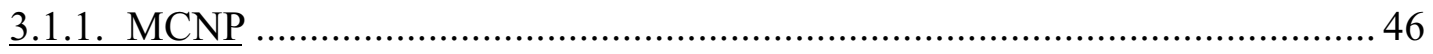

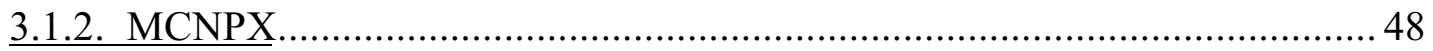

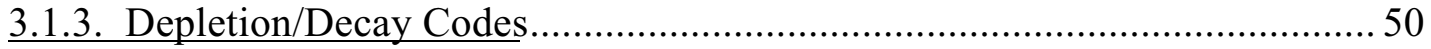

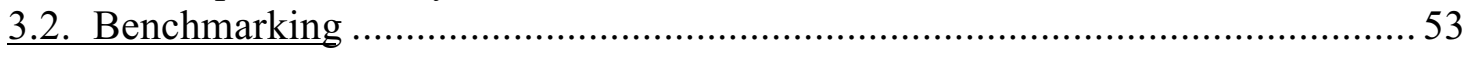

3.2.1. Expansion of Previous Benchmarking ...................................................... 54

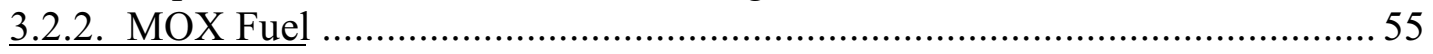

3.2.2.1. Benchmarks for MOX Fuel Irradiation to Other Codes.......................... 56

3.2.2.1.1. Pin-Cell with Poor Quality Plutonium ……….................................. 57

3.2.2.1.2. Pin Cell with Good Quality Plutonium............................................. 58

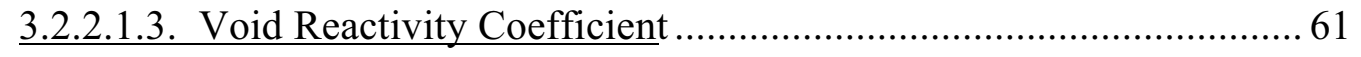

3.2.2.2. MOX Fuel Benchmarks to Experimental Data........................................ 62

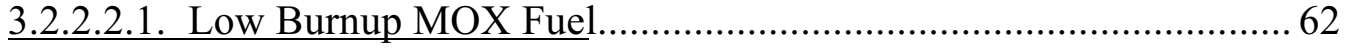

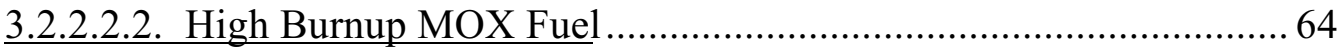

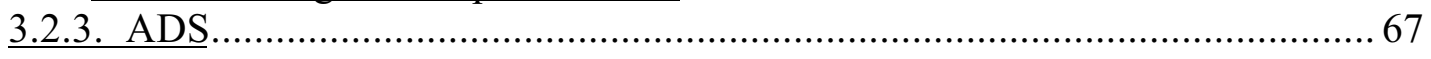




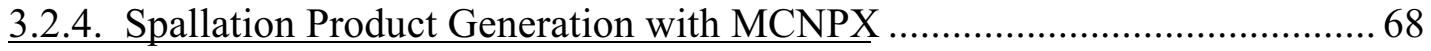

3.3. Assumptions and Specific Techniques ......................................................... 70

3.3.1. Full Cores of MOX Fuel in an LWR ...................................................... 72

3.3.1.1. MOX Fuel Irradiation Calculations with Pure Plutonium Stream.......... 77

3.3.1.2 MOX Fuel Irradiation Calculations with Heavy Metal Other Than

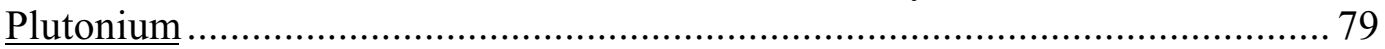

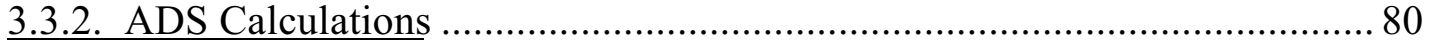

3.3.3. Neutronic Safety Calculations for a Full Core of MOX fuel ........................ 84

3.3.3.1. Verification of Calculation of Neutronic Safety Parameters...................86

3.3.4. Spallation Product Radiotoxicity ..................................................... 88

4.0 Results ............................................................................................................... 91

4.1. Multi-recycling of MOX Fuel ................................................................. 91

4.2. Addition of Actinide Material Other Than Plutonium to MOX.......................... 99

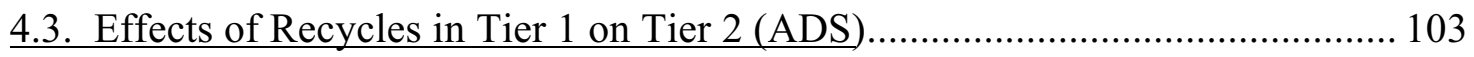

4.4. Summary/Conclusions for First Three Objectives ...................................... 106

5.0 Implementation/Safety Calculations .................................................................. 109

5.1. Safety Conditions for a Full Core of MOX Fuel in an LWR ........................... 109

5.1.1. Neutronic Safety Results with Plutonium ............................................. 109

5.1.2. Use of Materials in MOX Fuel Other Than Plutonium and Uranium ......... 117

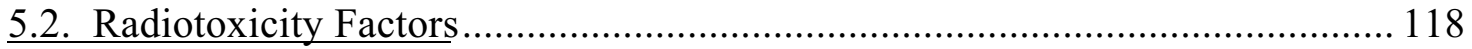

6.0 Conclusions and Future Work ............................................................................... 127

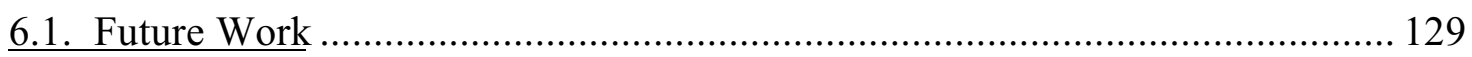

Appendix A. Sample MCNP Input File for 1/8 Core ............................................... 135

Appendix B. Sample Main Monteburns Input File for Reactor Calculations ........ 145

Appendix C. Sample Monteburns Feed File for Reactor Calculations at

Equilibrium ................................................................................................. 149

Appendix D. Excerpts from Sample Monteburns Output File for First Pass of MOX

Fuel with Pu Only ................................................................................................ 153

Appendix E. Sample MCNP Input File for ADS............................................ 159

Appendix F. Sample Main Monteburns Input File for ADS .................................... 181

Appendix G. Sample Monteburns Feed File for ADS (Concatenated to 15 Steps) 187

Appendix H. Excerpts from Sample Monteburns Output File for an ADS............ 193

Appendix I. FORTRAN77 Program Used to Generate MCNP Input Files for Safety

Calculations

Appendix J. FORTRAN77 Program Used to Calculate Radiotoxicity of Spallation

Products from CINDER90 Output ........................................................................ 203

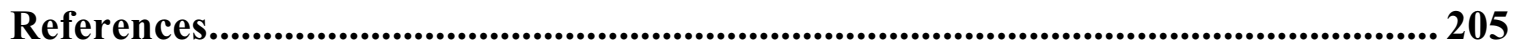




\section{List of Tables}

Table 2-1. Effective One-Group Cross Sections for Actinides in Representative Thermal

$(\mathrm{LWR})$ and Fast (ADS) System ................................................................ 13

Table 2-2. Utilities with CE System 80 s or Westinghouse $17 \times 17$ s and Relative Long

Current Lifetimes Proposed for Transmutation of SNF ........................................ 21

Table 2-3. Spallation Products of Concern............................................................ 40

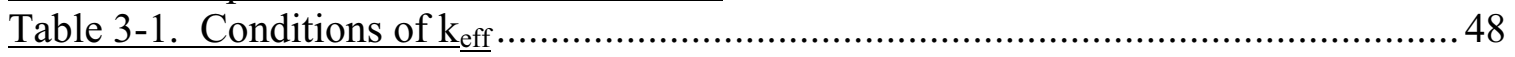

Table 3-2. Benchmark of Monteburns to Experimental Data for PWR Burnup

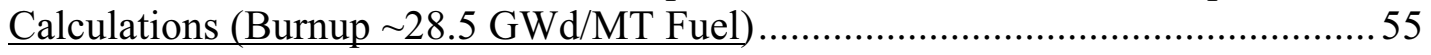

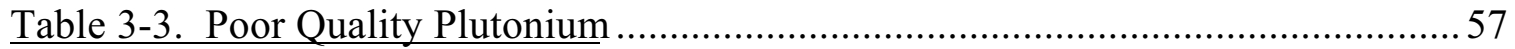

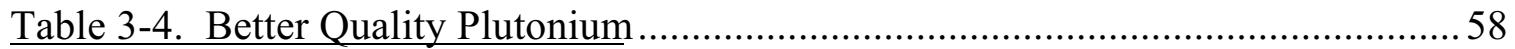

Table 3-5. Fission Product and Cross Section Sensitivities ..........................................59

Table 3-6. Delta $\mathrm{k}_{\infty}$ (Reactivity Change) between Moderated and Voided Cases........... 62

Table 3-7. Benchmark of Monteburns to Experimental MOX Data............................... 63

Table 3-8. Benchmark Results Using a Comprehensive Three-Dimensional Model for

Irradiation of MOX Fuel to High Burnup ( $55 \mathrm{GWd}$ /MTHM) ..............................6 65

Table 3-9. Results from Spallation (and Fission) Product Benchmark at High Energies

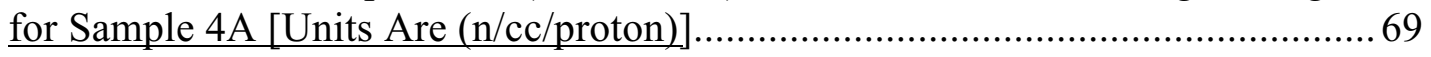

Table 3-10. Values of Parameters Used in LWR Irradiation Calculations ..................... 74

Table 3-11. Isotopic Plutonium Vector for MOX Calculations.................................... 76

Table 3-12. Geometric Parameters for H.B. Robinson Assembly ................................. 77

Table 3-13. Basic Neutronic Safety Results ............................................................. 87

Table 4-1. Activity and Heatload of Eight Assemblies of SNF as a Function of Time... 92

Table 4-2. Heatload (W) of Various Isotopes in MOX after Seven Years vs. Extended

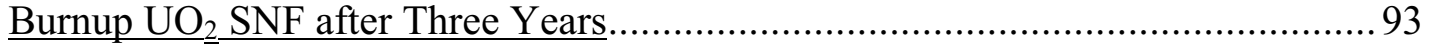

Table 4-3. Weight Percent Plutonium in Transuranic Material as a Function of Decay

Time after Irradiation through One Pass of MOX Fuel........................................ 94

Table 4-4. Detailed Results for Each Plutonium Recycle as MOX ...............................95

Table 4-5. Activity and Heatload of Eight Assemblies of Spent MOX Fuel as a Function

of Cooling Time ...................................................................................... 96

Table 4-6. Comparison of Plutonium Depletion and Minor Actinide Buildup for One

Pass with Different Starting Plutonium Vectors ............................................... 98

Table 4-7. Comparison of Burnup and Final Isotopic Vector (in Weight Fraction) of

$15 \times 15$ and 17x17 PWR Models for One Pass of MOX Fuel ................................. 99

Table 4-8. Activity and Heatload of MOX Cases (Eight Assemblies) with MAs or

Fission Products as a Function of Cooling Time ............................................. 101

Table 4-9. Comparison of Pu Depletion and MA Buildup Per Pass When Fission

Products or Minor Actinides Are Added to Pu in MOX ..................................... 101

Table 4-10. Isotopic Vector Entering ADS and Resulting Reactivity Swing ............... 104

Table 5-1. Neutronic Safety Calculations for Varying Degrees of Plutonium

Concentation in MOX Fuel........................................................................... 110

Table 5-2. Boron Efficiencies and Control and Shutdown Rod Worths with

Overmoderated Systems ......................................................................... 112

Table 5-3. Boron Efficiency as Enrichment of Boron Changes for Medium Pu case ... 113

Table 5-4. Comparison of Safety Features of $17 \times 17$ and $15 \times 15$ PWR Assemblies ...... 114 
Table 5-5. Neutronic Safety Cases for Multi-Recycling of Pu..... 115

Table 5-6. Neutronic Safety Results for Weapons-Grade vs. Reactor-Grade Plutonium 116

Table 5-7. Neutronic Safety Calculations for the Three Multi-Recycling Cases .......... 118

\section{List of Figures}

Fig. 1-1. High-Level Waste Ingestion Radiotoxicity Relative to Natural Uranium Ore ... 4

Fig. 1-2. Change in Reactivity as a Function of Time for Pure Minor Actinide Feed....... 7

Fig. 2-1. Fission-to-Capture Ratios in Fast vs. Thermal Systems ................................ 13

Fig. 2-2. Radiotoxicity of SNF that is Irradiated Only through Tier 1 ......................... 17

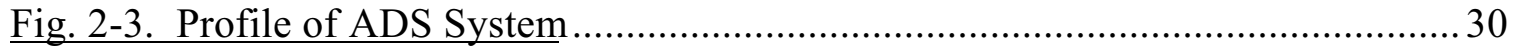

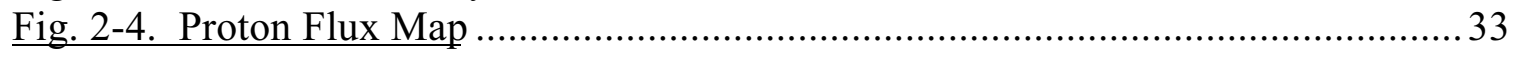

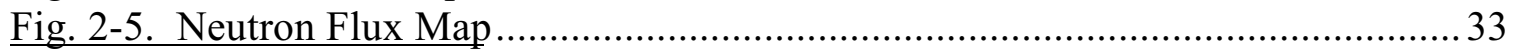

Fig. 3-1. Flow Chart for Monteburns ............................................................. 44

Fig. 3-2. PWR Assembly Design Used in This Research (H. B. Robinson Unit 2) ........54

Fig. 3-3. Comparison of Monteburns and REBUS3 Results for an Accelerator-Driven

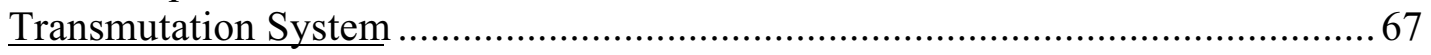

Fig. 3-4. One-Eighth Core Model of a PWR (Cross Section) ..................................... 73

Fig. 3-5. Detailed Cross-Sectional Layout of ADS .................................................. 82

Fig. 3-6. Location of Control/Shutdown Rods in Core ................................................ 86

Fig. 4-1. Depletion of Pu and Accumulation of Minor Actinides for Multi-Recycling of

$\mathrm{Pu}$ as MOX Fuel in LWRs ............................................................................... 95

Fig. 4-2. Change in Actinide Isotopes as the Number of Passes Increased.....................97

Fig. 4-3. Isotopic Composition of Actinides in MOX Fuel with $\mathrm{Pu}+\mathrm{MA}$ Stream....... 102

Fig. 4-4. Feed Rate as a Function of Cycle in the ADS ........................................... 104

Fig. 5-1. Ingestion Radiotoxicity Relative to Natural U Ore for an LBE Target .......... 120

Fig. 5-2. Inhalation Radiotoxicity Relative to Natural U Ore for a Tungsten Target.... 120

Fig. 5-3. Ingestion Radiotoxicity of Spallation Products Compared to SNF ................. 122

Fig. 5-4. Inhalation Radiotoxicity of Spallation Products Compared to SNF............... 122

Fig. 5-5. Comparison of Radiotoxicity as a Function of Proton Beam Energy.............. 123

Fig. 5-6. Ingestion Radiotoxicity for Each Target by Isotope ...................................... 126

Fig. 5-7. Inhalation Radiotoxicity for Each Target by Isotope ................................... 126 


\title{
Reduction of the Radiotoxicity of Spent Nuclear Fuel Using a Two-Tiered System \\ Comprising Light Water Reactors and Accelerator-Driven Systems
}

\author{
by \\ Holly R. Trellue \\ B.S., Nuclear Engineering, University of New Mexico, 1997 \\ M.S., Nuclear Engineering, University of New Mexico, 1998 \\ Ph.D., Engineering, University of New Mexico, 2003
}

\begin{abstract}
Two main issues regarding the disposal of spent nuclear fuel from nuclear reactors in the United States in the geological repository Yucca Mountain are: 1) Yucca Mountain is not designed to hold the amount of fuel that has been and is proposed to be generated in the next few decades, and 2) the radiotoxicity (i.e., biological hazard) of the waste (particularly the actinides) does not decrease below that of natural uranium ore for hundreds of thousands of years. One solution to these problems may be to use transmutation to convert the nuclides in spent nuclear fuel to ones with shorter half-lives. Both reactor and accelerator-based systems have been examined in the past for transmutation; there are advantages and disadvantages associated with each. By using existing Light Water Reactors (LWRs) to burn a majority of the plutonium in spent nuclear fuel and Accelerator-Driven Systems (ADSs) to transmute the remainder of the actinides, the benefits of each type of system can be realized. The transmutation process then becomes more efficient and less expensive. This research searched for the best
\end{abstract}


combination of LWRs with multiple recycling of plutonium and ADSs to transmute spent nuclear fuel from past and projected nuclear activities (assuming little growth of nuclear energy). The neutronic design of each system is examined in detail although thermal hydraulic performance would have to be considered before a final system is designed. The results are obtained using the Monte Carlo burnup code Monteburns, which has been successfully benchmarked for MOX fuel irradiation and compared to other codes for ADS calculations. The best combination of systems found in this research includes 41 LWRs burning mixed oxide fuel with two recycles of plutonium ( $\sim 40$ years operation each) and $53 \mathrm{ADSs}$ to transmute the remainder of the actinides from spent nuclear fuel over the course of 60 years of operation. 


\subsection{Introduction}

Currently one of the greatest challenges in the nuclear industry is to determine what should be done with spent nuclear fuel (SNF), which consists of cylindrical, lowenriched uranium dioxide fuel rods surrounded by a stainless steel or zircaloy cladding. A symmetrical combination of approximately two hundred rods is called an assembly, and water flows around these rods to cool each assembly during reactor operation. After irradiation in a reactor, a majority of the uranium dioxide remains, but fission products and other actinides that are more radioactive build in, which makes the fuel "hotter" (both in activity and heatload). Currently the irradiated SNF assemblies are moved to a pool of water where isotopes with short half-lives decay to more safe levels and the internal heat generation drops, at which point they can be put in "dry" storage facilities. Eventually, SNF is to be disposed in a geological repository at Yucca Mountain.

However, even with the availability of a permanent geological repository, there are still issues about the volume of waste that can be stored and how to minimize release of radioactive material to the environment. One option that would reduce the amount of radiation escaping to the environment from SNF rods is vitrification, which involves mixing the wastes within a ceramic or glass material. However, this option is costly and still does not change the total amount of SNF in existence. Currently, the only process that can actually reduce the amount of high-level waste and minimize environmental release is transmutation.

Transmutation is the process of bombarding a material with particles (typically neutrons) to form new atoms with higher masses and/or to fission the material into atoms with smaller masses. In principle, transmutation can convert those isotopes in SNF that 


\section{LA-14052-T}

pose a radiological hazard to humans to isotopes that pose less of a hazard. It can reduce the mass, volume, activity, heatload, and/or radiotoxicity of waste that must be sent to a repository. Transmutation can also reduce the "attractiveness" of the material to a proliferator who may want to obtain nuclear material for nonpeaceful purposes.

One of the reasons that the transmutation of SNF has been pursued is that the ingestion radiotoxicity of SNF does not decrease below that of natural uranium (U) ore for hundreds of thousands of years (see Fig. 1-1). Although fission products comprise a significant portion of the radiotoxicity risk for the first few hundred years, the primary contributors over thousands of years are actinides. ${ }^{1}$ In this figure, radiotoxicities are shown relative to that of five tons of natural uranium ore plus all its daughter products (i.e., thorium, radium, radon) because this is the amount required to fabricate about one ton of $3.6 \mathrm{w} \%$ enriched uranium fuel $(5 * 0.72$ (natural uranium enrichment $)=3.6)$.

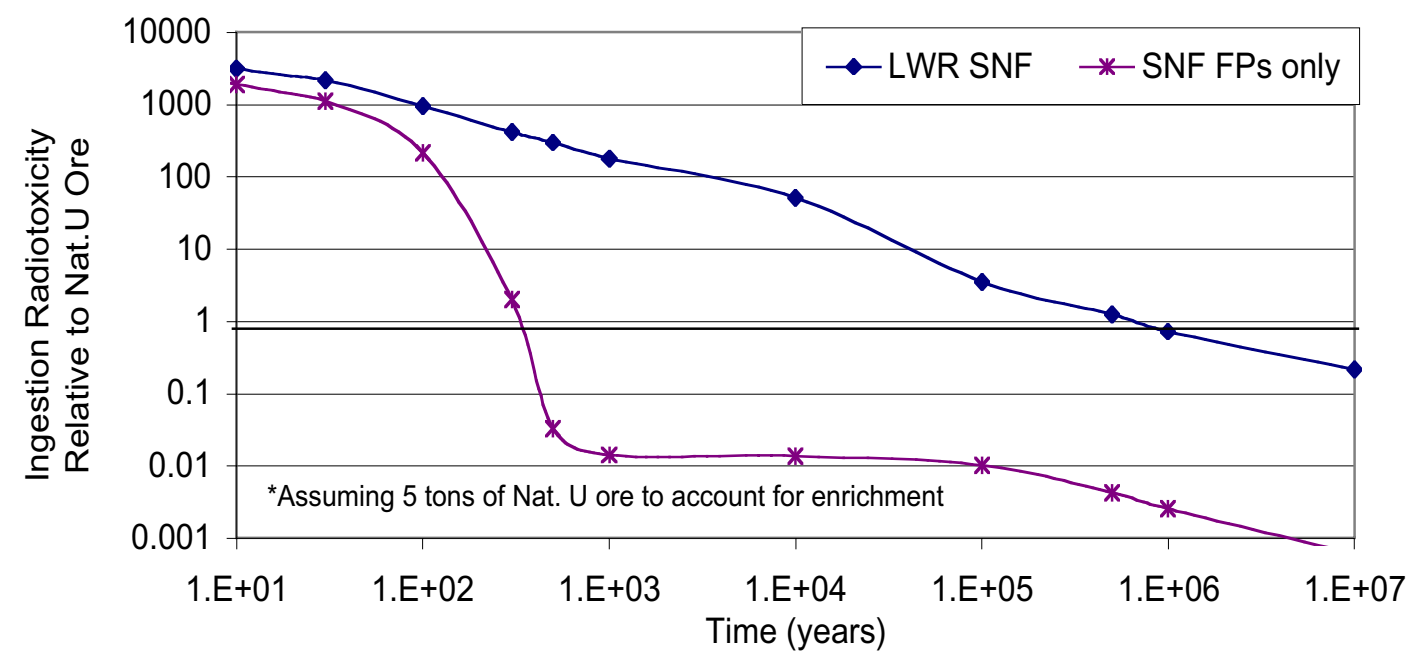

Fig. 1-1. High-Level Waste Ingestion Radiotoxicity Relative to Natural Uranium Ore 


\subsection{Problem Description}

The use of reactors (both thermal and fast) for transmutation has been explored, with safety issues limiting the use of existing Light Water Reactors (LWRs) and political barriers currently preventing new reactors (such as fast reactors) from being built in the United States (U.S.). The use of accelerator-driven systems (ADSs) comprised of subcritical assemblies of material driven by the spallation process (i.e., a proton beam hitting a target and undergoing $(\mathrm{p}, \mathrm{n})$ reactions to produce neutrons) has also been proposed. In either case, transmutation systems are typically distinguished by their neutron energy spectrum; in particular, whether they are fast or thermal. There are advantages and disadvantages to each spectrum when applied to waste transmutation. Fast spectrum systems are beneficial because the fission-to-capture ratios of actinides are large in them, leading to more efficient nuclide destruction by fission compared to buildup from capture reactions (absorption of neutrons and subsequent decay to higher actinides). No fast spectrum systems currently exist (such as a fast reactor), but the most popularly proposed ADSs are fast spectrum systems.

In contrast, the advantage of a thermal spectrum is that a majority of the plutonium $(\mathrm{Pu})$ isotopes have large fission cross sections, and thermal LWRs are already in operation in the U.S. and the rest of the world. The concept of burning at least the plutonium from SNF in existing LWRs is attractive for both of these reasons, as well as for the fact that LWRs produce reliable electricity (compared to ADSs). For burning plutonium in LWRs, mixed oxide (MOX) fuel, a mixture of uranium and plutonium dioxides, is the current choice (i.e., several countries already use MOX fuel). Using 
MOX fuel for the transmutation of SNF in an LWR takes advantage of existing knowledge, which helps decrease implementation time and cost.

While a thermal spectrum system is suitable for reducing masses of plutonium, it actually increases the mass of total actinides in the system because it builds in (through neutron captures and subsequent beta decay) isotopes of americium, curium, and elements with higher numbers (which along with neptunium, comprise minor actinides (MAs)). Irradiating MAs in a thermal spectrum is not attractive because they have large thermal absorption cross sections that decrease the fission-to-capture ratio of the material and cause a significant quantity of higher elements to be produced. MAs are more efficiently burned in a dedicated fast spectrum system, such as recently proposed ADSs, where fission-to-capture ratios are larger. ADSs can be used to burn all legacy plutonium and minor actinides, but the reactivity swing (change in value of $\mathrm{k}_{\mathrm{eff}}$ between the beginning and end of a cycle) is relatively large as is discussed in the next section. The larger the reactivity swing in an ADS, the more expensive the accelerator; because as $\mathrm{k}_{\mathrm{eff}}$ decreases in a power-producing ADS, the current of the proton beam must increase to make up for the neutrons not created by fission.

If some plutonium is burned elsewhere (i.e., in an LWR) and just minor actinides are sent to an ADS, then performance in the ADS is enhanced because the reactivity swing per cycle is smaller. ${ }^{2}$ The concept of using both a reactor and an accelerator is part of a recent multi-tier transmutation study in the U.S. ${ }^{3}$ This research focuses on finding the best combination of LWR and ADS (Tiers 1 and 2 respectively) transmutation that destroys the most actinides while maintaining system safety and reducing costs. 


\subsection{Motivation}

In initial studies involving the Accelerator Transmutation of Waste (ATW), the entire mixture of actinides plus long-lived fission products in commercial SNF was to be sent to an ADS for transmutation. However, the use of an ADS for the entire mission began to appear impractical due to the large reactivity swings (change in $\mathrm{k}_{\mathrm{eff}}$ ) seen using all material and the demands these swings place upon the accelerator. Improving the performance of the ADS by reducing the reactivity swings requires reducing the fissile quality (i.e., primarily plutonium) of its contents. ${ }^{2}$ This reduction is the motivation for burning the plutonium first in an LWR. However, putting only minor actinides in the ADS actually increases the reactivity over the course of the first several cycles instead of decreasing it (see Fig. 1-2).

An increase in reactivity may be undesirable from a safety standpoint, so some plutonium would also be needed in the system to decrease the reactivity over the course of a cycle. Finding the amount of plutonium that should be irradiated in the ADS versus the LWR to allow the best performance in the ADS is one of the goals of this research.

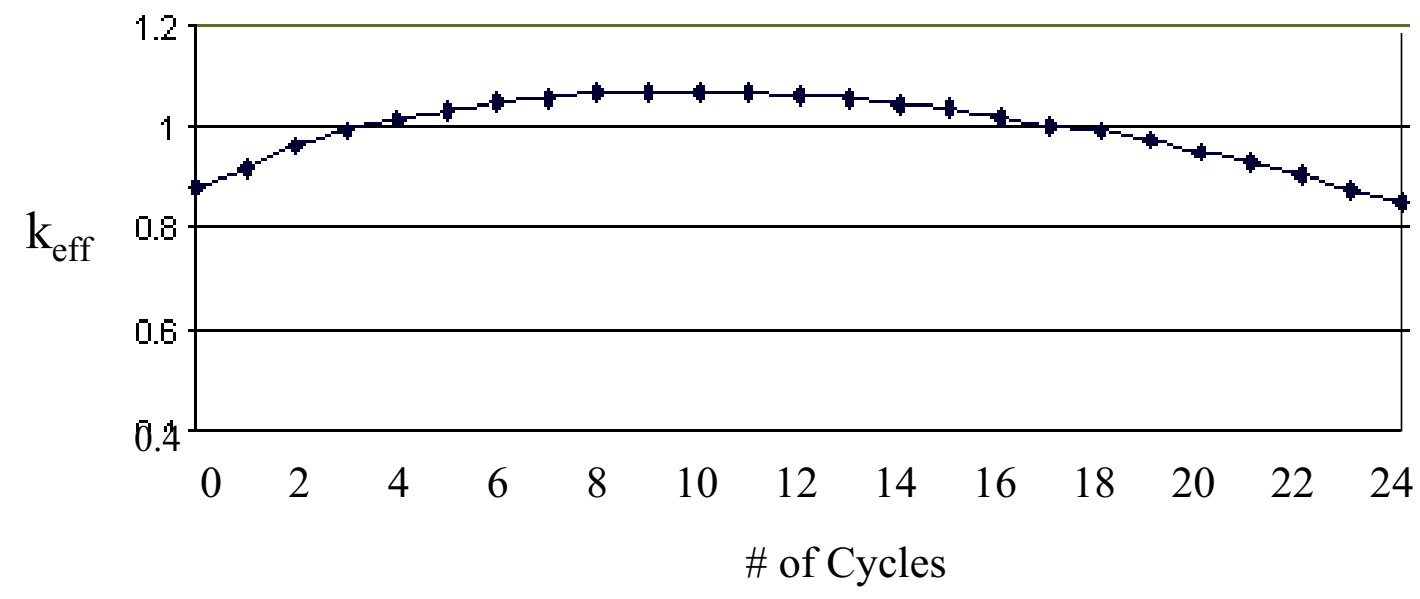

Fig. 1-2. Change in Reactivity as a Function of Time for Pure Minor Actinide Feed 
This goal involves determining how much plutonium must be present to keep the reactivity swing negative while also reducing the magnitude of the reactivity swing in the ADS.

The technique proposed for decreasing the amount of plutonium going to an ADS is to irradiate some of it using MOX fuel in existing LWRs. Current MOX-fueled reactors consist of partial cores (30 to $50 \%$ ) of $\mathrm{MOX}$ fuel with the majority being $\mathrm{UO}_{2}$ fuel. However, using full cores of MOX fuel would allow a greater plutonium burnup per reactor and would require fewer reactors to be re-licensed. Such a system has not been fully designed or licensed, so part of this research is to develop a technique for the irradiation of MOX fuel that meets neutronic safety conditions for an LWR. However, to burn a significant amount of plutonium from SNF in an LWR, multiple cycles are necessary. Keeping the elemental structure (i.e., Pu vs. U) of the MOX fuel fairly consistent in these multiple recycles is also considered important for facilitating licensing of the fuel itself. Assuming multi-recycling of plutonium and license extensions/modifications for existing LWRs, a majority of all legacy plutonium (that from existing and predicted future SNF) can be burned to about $50 \%$ in the near future (i.e., none of the plutonium can be completely burned in an LWR). ${ }^{4}$

Another limiting factor in the use of ADSs for transmutation is that as a result of the spallation process, some fission and spallation products are produced that pose radiotoxicity hazards. Both Japanese and Russian studies have shown that the radiotoxicity resulting from several alpha-emitting rare-earth isotopes can indeed be significant. ${ }^{5}$ The final goal of this research is to show that using an ADS for any part of the transmutation mission does not create more radiotoxic waste than it destroys. 


\subsection{Scope}

In summary, this research comprises five major design areas that are essential to implementation of a two-tiered transmutation system using LWRs and ADSs. In particular, the actual research includes:

1. Assessing the benefits of multiple recycling of the plutonium in MOX fuel to help determine the number of recycles that can be performed in the LWR and still meet safety conditions (both in the LWR and ADS);

2. Considering a different composition of MOX fuel to decrease some of the proliferation concerns associated with having pure plutonium available; such streams consist of plutonium contaminated with other materials (such as minor actinides and the fission products strontium (Sr) and cesium (Cs));

3. Comparing transmutation performance in the ADS (i.e., feed rate and reactivity swing) of the different resulting feed materials from the LWR and SNF itself to determine the best combination of LWRs and ADSs that keeps the current requirements in the $\mathrm{ADS}$ to less than about a factor of two increase during a six month cycle;

4. Developing a strategy to perform irradiation of at least half the plutonium from legacy SNF in a full core of MOX fuel and still meet neutronic safety and fabrication limits in an LWR; and

5. Calculating the radiotoxicity of spallation products for various targets and incident proton beam energies and comparing the results to the radiotoxicity of other materials in the fuel cycle. 
LA-14052-T

Background material and methodogies used in this research are given in Sections 2 and 3. Results of calculations involving the first three objectives are presented in Section 4, and results from the remaining two objectives are discussed in Section 5. Finally, Section 6 presents conclusions and future work suggestions. 


\subsection{Background/Literature Search}

Initial development of nuclear power as an energy source did not focus on what should be done with the fuel rods after they are irradiated in power reactors. After removal from a reactor, these rods are currently placed in spent fuel pools and/or dry storage facilities so that short-lived fission products can decay to more stable isotopes in a controlled environment. Many countries (e.g., France and Japan) then take these fuel rods, reprocess them (i.e., separating the fission products and the reusable plutonium and/or uranium), and use the plutonium along with depleted and/or natural uranium to make MOX fuel, which is reused as fuel in nuclear reactors. Reprocessing has not been a viable alternative in the U.S. the past few decades. ${ }^{6}$ Nonetheless, SNF still contains many long-lived fission products and actinides that remain radioactive hundreds of thousands of years into the future.

\subsection{Waste Management Concepts}

To assure that SNF does not pose a threat for future generations, the material should either be placed safely in a geological repository or should be transmuted to convert some of the more harmful isotopes to less harmful products. Either way, at least one repository for SNF and/or its transmutation products is required.

\subsubsection{Repository}

Once material is placed in a repository, the goal is for it to remain there until it can naturally decay to safe levels. Repositories are designed to pose the smallest risk to humans possible. However, it is always possible for water to infiltrate the site or for 


\section{LA-14052-T}

future earth beings to intrude upon it, so that the radioactive material can still cause potential biological hazards. Another concern in a repository is criticality risk from fissile material being absorbed into ground water and transported into a region in which it can form a critical mass, but studies have shown that this risk is minimal. ${ }^{7,8}$ In addition, the repository proposed to house SNF, Yucca Mountain, currently is not designed to contain all material projected to be created. ${ }^{9}$ Radionuclides of most concern according to the Yucca Mountain Total System Performance Assessment in terms of dose are: ${ }^{237} \mathrm{~Np}$ (most important over 1 million years), ${ }^{129} \mathrm{I},{ }^{99} \mathrm{Tc},{ }^{14} \mathrm{C}$ (in a 10,000 year period), ${ }^{239} \mathrm{Pu}$, ${ }^{242} \mathrm{Pu},{ }^{79} \mathrm{Se},{ }^{234} \mathrm{U}$, and ${ }^{231} \mathrm{~Pa} .{ }^{10}$

\subsubsection{Transmutation}

Although only transmutation of neptunium (and the americium that decays into it), technetium, and iodine can significantly reduce the environmental risk associated with SNF, transmutation of the plutonium and/or minor actinides could decrease the actinide mass that has to go into a repository. Additionally, it can reduce the criticality and proliferation risks associated with having plutonium in a geological repository.

Many different technologies have been examined for transmutation, including a variety of reactors and ADSs. ${ }^{11}$ These systems are primarily distinguished by whether they have fast or thermal neutron energy spectrums. Representative cross sections (probabilities that various interactions such as scatter, capture, and fission will occur) and fission-to-capture ratios for non-uranium actinides in these systems are given in Table 2-1 and Fig. 2-1. Fast spectrum systems are advantageous for actinide transport from the standpoint that actinide fission-to-capture ratios are high in them, so the most efficient 
Table 2-1. Effective One-Group Cross Sections for Actinides in Representative Thermal (LWR) and Fast (ADS) System

\begin{tabular}{|c|c|c|c|c|}
\hline & \multicolumn{2}{|c|}{ Capture Cross Section (b) } & \multicolumn{2}{c|}{ Fission Cross Section (b) } \\
\hline & Thermal & Fast & Thermal & Fast \\
\hline${ }^{234} \mathrm{U}$ & 15.3 & 0.641 & 0.616 & 0.319 \\
\hline${ }^{235} \mathrm{U}$ & 3.91 & 0.598 & 11.6 & 1.95 \\
\hline${ }^{236} \mathrm{U}$ & 6.63 & 0.593 & 0.342 & 0.0891 \\
\hline${ }^{238} \mathrm{U}$ & 0.774 & 0.391 & 0.128 & 0.0311 \\
\hline${ }^{237} \mathrm{~Np}$ & 17.1 & 1.59 & 0.634 & 0.32 \\
\hline${ }^{238} \mathrm{Pu}$ & 7.57 & 0.803 & 1.83 & 1.12 \\
\hline${ }^{239} \mathrm{Pu}$ & 11.2 & 0.577 & 20.2 & 1.91 \\
\hline${ }^{240} \mathrm{Pu}$ & 20.8 & 0.588 & 0.686 & 0.355 \\
\hline${ }^{241} \mathrm{Pu}$ & 8.13 & 0.479 & 26.2 & 2.55 \\
\hline${ }^{242} \mathrm{Pu}$ & 10.3 & 0.474 & 0.534 & 0.25 \\
\hline${ }^{241} \mathrm{Am}$ & 27.5 & 1.47 & 0.808 & 0.265 \\
\hline${ }^{242 \mathrm{~m}} \mathrm{Am}$ & 22.6 & 0.434 & 119 & 4.2 \\
\hline${ }^{243} \mathrm{Am}$ & 1.38 & 0.0703 & 0.544 & 0.207 \\
\hline${ }^{242} \mathrm{Cm}$ & 3.18 & 0.35 & 0.467 & 0.135 \\
\hline${ }^{243} \mathrm{Cm}$ & 5.89 & 0.272 & 45.9 & 2.77 \\
\hline${ }^{244} \mathrm{Cm}$ & 9.8 & 0.884 & 0.977 & 0.407 \\
\hline
\end{tabular}

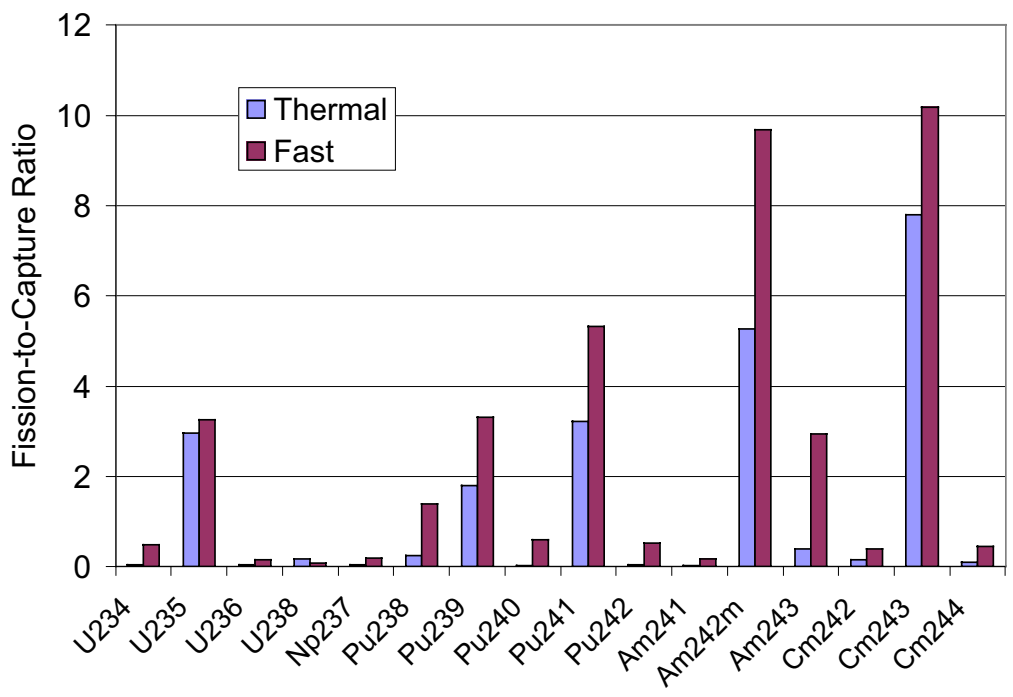

Fig. 2-1. Fission-to-Capture Ratios in Fast vs. Thermal Systems 
destruction of actinides occurs while building up the fewest minor actinides (i.e., fewer captures occur relative to fission). Thermal spectrum systems, however, actually have higher values of fission cross sections, which is beneficial in power production.

Examples of fast spectrum systems are fast reactors and some proposed subcritical ADSs. However, none are actually operating commercially today or in the U.S. at all. Fast reactors are neutronically favored for transmutation because they can generate reliable power (i.e., they have positive economic attributes) and transmute plutonium mixed with minor actinides from SNF efficiently. ${ }^{12}$ Unfortunately, there are safety and political issues associated with building a fast reactor that may not be resolved for several decades. ADSs can be designed to have a fast neutron energy spectrum, and they are subcritical so safety issues can be considered less significant than in a fast reactor. This feature may decrease implementation time compared to a fast reactor (particularly for licensing) but would still require at least 10-20 years to be built. Another advantage of ADSs is that they can burn mixtures of material that would not maintain criticality in a reactor. However, they are plagued by problems associated with large reactivity swings, so improving their performance capability by supplementing them with an additional system to burn plutonium (i.e., a thermal one) is one goal of this research. Thermal systems capable of transmutation include LWRs operating today, some new reactors being proposed, and a molten salt ADS examined for transmutation in the past. ${ }^{13}$ LWR technology is the most advanced of the thermal spectrum systems proposed, so that is why they are focused on in this research. LWRs can efficiently burn plutonium, but they accumulate a significant portion of minor actinides in the process. 
One disadvantage of fast spectrum ADSs is that they depend on accelerator reliability to provide energy to a power grid because the beam must operate continuously to produce constant power. With beam trips and interruptions, it would be difficult for ADSs to provide the steady, reliable electricity source provided by reactors. Additionally, most ADSs are associated with significant reactivity swings over the course of a cycle (e.g., the beginning of cycle $\mathrm{k}_{\mathrm{eff}}$ for an ADS is 0.97 , but $\mathrm{k}_{\mathrm{eff}}$ can decrease to as low as 0.90 over a 6-month cycle as fissile material is burned). ${ }^{14}$ The ADS must create neutrons to compensate for those not produced in fission to produce continuous power. At a $\mathrm{k}_{\mathrm{eff}}$ of $0.97,3 \%$ of the neutrons must be provided by an external source (in this case, spallation) because only $97 \%$ of the neutron flux is maintained by fission reactions. If the $\mathrm{k}_{\mathrm{eff}} \mathrm{drops}$ even to 0.94 , spallation neutron generation must double (i.e., to $6 \%$ ), which is expensive because it requires the beam power and current to double as well; an end of cycle $\mathrm{k}_{\text {eff }}$ of 0.90 causes it to more than triple. The technology base for ADS is not yet great enough to overcome the above two problems for full-scale transmutation purposes, but the ADS still shows promise if the power demands are less and/or if the incoming material composition for the system is modified such that the reactivity swing is smaller. This occurs when the plutonium composition in the ADS feed is reduced. However, it is assumed that not all plutonium could be burned in a reactor, so the ADS would probably always start with some fraction of plutonium (although too little plutonium leads to concerns of $\mathrm{k}_{\mathrm{eff}}$ being greater than or equal to 1.0 at some point). At an actinide fissionto-capture ratio of $0.8, \mathrm{k}_{\text {eff }}$ even remains relatively constant over a 6 -month period. The third objective of this research is to determine what the ideal amount of plutonium to be burned in the ADS is. 
To reduce the amount of plutonium going to an ADS, some of it must be burned in another system. LWRs are a good option for plutonium irradiation because they have already been built, licensed, and operated worldwide, and plutonium from SNF is already being burned in them in the form of MOX fuel in many countries. They are a critical part of the fuel cycle in countries like Japan and France, and the existing database of knowledge about them could be applied to implement them relatively quickly here in the U.S. if policy issues are resolved. ${ }^{15}$

\subsection{Transmutation of SNF in LWRs}

Reactors were the first systems proposed for transmutation because they are a known technology and provide electricity while burning SNF. However, declining interest in nuclear power and opposition to reprocessing in the U.S. has made them a less attractive option. LWRs are particularly attractive for burning plutonium because the technology already exists and many reactors throughout the world already burn plutonium. There are over 100 LWRs currently in operation in the U.S., and they already possess the ability to provide reliable electricity to an energy grid. MOX fuel is used to burn plutonium in LWRs in many countries, and this knowledge and experience would reduce the learning curve and potentially the time required to implement transmutation in LWRs in the U.S.

This option would probably require four pieces (see Sections 2.2.1 through 2.2.4 respectively). First, reprocessing/separations would have to occur to split the plutonium and/or minor actinides from SNF and to recycle the plutonium burned in LWRs to obtain the desired burnups $(>50 \%)$. Second, at least some existing LWRs would have to be re- 
licensed to accept a new fuel type (note that the Combustion Engineering (CE) System 80 reactors were designed to irradiate MOX fuel and several Duke Power Pressurized Water Reactors (PWRs) are proposed to burn MOX fuel for the Department of Energy's Materials Disposition (MD) project). ${ }^{16}$ Third, MOX fuel irradiation and multi-recycling of MOX fuel would have to become possible in the U.S. Finally, to burn a majority of plutonium from current inventories of SNF, a design that handles full cores of MOX fuel would have to be developed. Neutronic safety parameters examined in these studies are described in Section 2.2.5.

Even with reactor-based transmutation, the concurrent development of ADSs to burn minor actinides is essential for complete (>99\%) destruction of actinides from SNF. The reason an ADS (or comparable Tier 2 system) is still required is that even if about $50 \%$ of the material is burned in an LWR (or comparable Tier 1 system), the radiotoxicity of the resulting mixture does not decrease below that of natural uranium ore for hundreds of thousands of years (see Fig. 2-2).

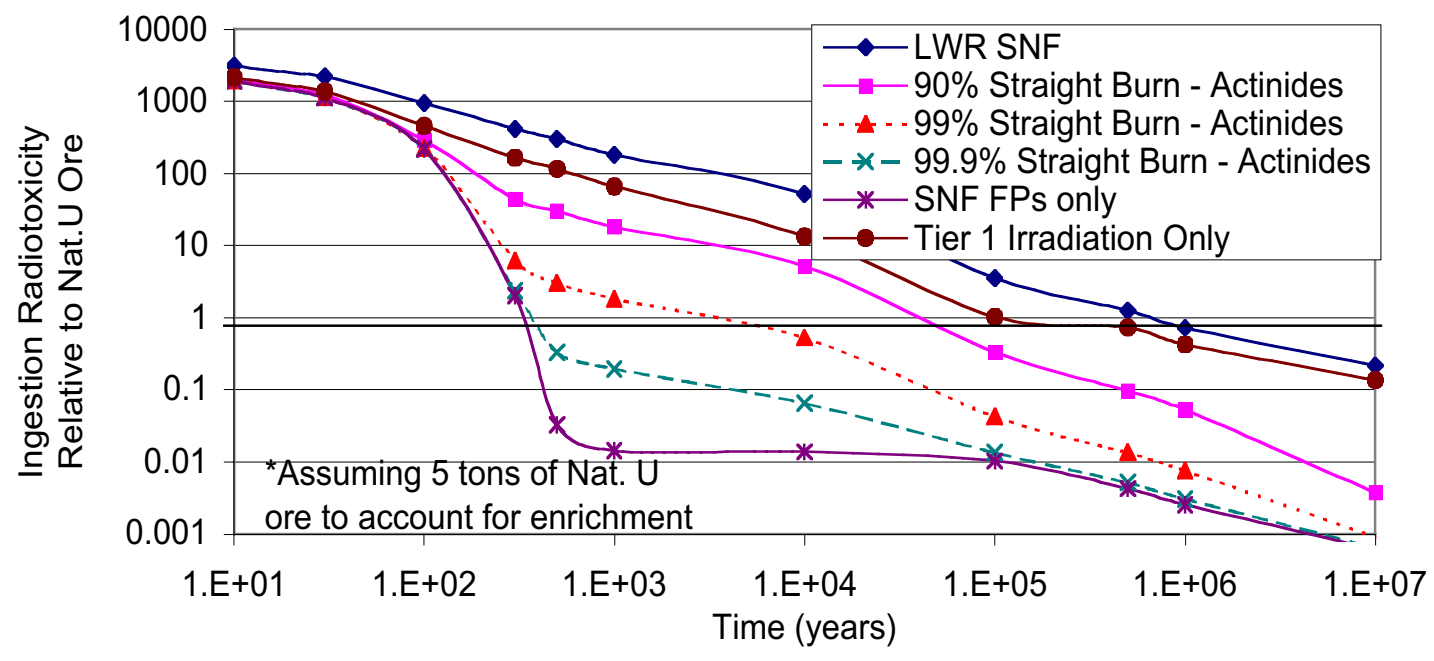

Fig. 2-2. Radiotoxicity of SNF that is Irradiated Only through Tier 1 
The ingestion radiotoxicities of fission products and fission products plus $0.1,1$, and $10 \%$ of the starting actinides from SNF (corresponding to $99.9,99$, and $90 \%$ actinide destruction rates respectively) are also shown in Fig. 2-2. Transmutation would reduce the mass of minor actinides that must be placed in a repository, but to reduce the radiotoxicity (see Section 2.3.4.1 for a description of radiotoxicity) significantly, more complete transmutation is required.

\subsubsection{Separations}

Before transmutation can occur, a large-scale separations capability must be created to remove the plutonium and/or minor actinides from SNF. SNF currently consists of about $96 \%$ uranium, $1 \%$ minor actinides and plutonium, and $3 \%$ fission products. Any type of separation, such as reprocessing, is currently unfavorable in the 7U.S. primarily because of the large proliferation risk it could present by making the plutonium and other actinides more "attractive" (i.e., removing radiation barriers such as fission products). However, reprocessing of SNF is performed daily in other countries (e.g., France, Great Britain, Germany, and Japan), so technically, separations could be easily implemented.

Reprocessing is typically performed using an aqueous solvent extraction process similar to UREX, but the process also has the potential to remove plutonium and/or minor actinides as well, being named PUREX. ${ }^{17}$ PUREX could be used at a large-scale separations facility to obtain the $1 \%$ of SNF that is of interest in transmutation processes: the plutonium and minor actinides. It is assumed that uranium and fission products would be sent to low-level nuclear waste sites (most of the fission products decay over 
the course of hundreds of years anyway) and/or the depleted uranium could be used in enriching/fabricating MOX and/or $\mathrm{UO}_{2}$ fuel. Long-lived fission products such as ${ }^{99} \mathrm{Tc}$ and ${ }^{129}$ I could also be separated so that they could be transmuted in a dedicated facility.

One issue that must be addressed for multi-recycling of plutonium is how the difference in spent MOX versus spent $\mathrm{UO}_{2}$ fuel changes reprocessing and subsequent fuel fabrication. Spent MOX fuel consists of more plutonium, and the presence of plutonium creates an increase in activity and heatload (depending on how long it is cooled first). In general, the difference between spent $\mathrm{UO}_{2}$ and spent MOX fuel does not influence reprocessing significantly, but spent MOX fuel yields a different dissolubility in nitric acid, increased criticality risk, and a slight increase in alpha, gamma, and neutron doses. ${ }^{18}$ The increased heatload of the resulting plutonium does, however, influences MOX fabrication facilities, which require at least the use of gloveboxes with special neutron shielding and/or hot cells if the ${ }^{238} \mathrm{Pu}$ content is high enough (note that these are probably required for extended burnup $\mathrm{UO}_{2}$ fuel anyway). ${ }^{19}$ One study claims that decay heat and radioactivity immediately after reactor shutdown are not much different for MOX than $\mathrm{UO}_{2}$ spent fuel, but in the long-term (i.e., years of cooling time) it can become significant because the higher actinides in MOX take longer to decay. ${ }^{20}$

\subsubsection{Relicensing/Logistics of U.S. Reactor Irradiation}

LWR license extensions would not only benefit the U.S. by making transmutation of SNF more realistic, but it would also benefit the U.S. in allowing continued electricity production without the reliance on middle eastern countries for fossil fuels to produce energy. This research does not assume that all LWRs in the U.S. would be converted to 
burning MOX fuel; in fact, a majority would likely continue with their current missions. Once all legacy plutonium is depleted, if a certain percentage of LWRs burn the plutonium produced by the others as MOX fuel, then an equal plutonium production/destruction state can be achieved. In particular, based on a 4-year cycle irradiation time, six years of cooling after each irradiation (10 years total), and multirecycling of the plutonium, all plutonium from legacy SNF could be burned to at least $50 \%$ assuming (each pass only burns about $30 \%$ ) the use of one of the following:

- All WE 17x17 PWRs and CE System 80s (35 Reactors total, three of which are CE System $80 \mathrm{~s}$ ) with $8.5 \mathrm{w} \% \mathrm{Pu}$, one license extension and one recycle; or

- All WE 17x17 PWRs and CE System 80s with 7w\% Pu, two license extensions and two recycles; or

- All WE 17x17 PWRs and CE System 80s with 11w\% Pu, one license extension and two recycles; or

- Seventeen reactors with three license extensions, $9 \mathrm{w} \% \mathrm{Pu}$, and two recycles (see Table 2-2); or

- Eleven reactors with three license extensions, $11 \mathrm{w} \% \mathrm{Pu}$, and one recycle. ${ }^{2}$

\subsubsection{MOX Fuel Irradiation and Multiple Recycling}

MOX fuel consists of plutonium (and/or other transuranics) and uranium oxides mixed together. Currently, MOX-fueled reactors typically consist of partial cores (30 to $50 \%$ ) of MOX fuel with the rest being pure $\mathrm{UO}_{2}$ fuel to meet safety margins. ${ }^{21}$ MOX itself usually has a plutonium content in heavy metal of less than $12 \%$ (typically it is from 5.25 to $8.2 \%$ ), the remainder being depleted or even natural uranium. ${ }^{22}$ Keeping a larger 


\section{LA-14052-T}

$(>90 \%)$ fraction of uranium in the system helps licensing issues because it more closely resembles the low-enriched uranium oxide fuel currently used in commercial LWRs.

Table 2-2. Utilities with CE System 80 s or Westinghouse $17 \times 17$ s and Relative Long Current Lifetimes Proposed for Transmutation of SNF

\begin{tabular}{|c|c|c|c|c|}
\hline Utility & Reactor & $\begin{array}{l}\text { Current year of } \\
\text { proposed } \\
\text { shutdown }\end{array}$ & $\begin{array}{l}\text { Years available assuming } \\
\text { startup in } 2015 \text { and three } \\
\text { license extensions }\end{array}$ & Type of reactor \\
\hline \multirow{3}{*}{$\begin{array}{l}\text { Arizona Public } \\
\text { Service Company }\end{array}$} & Palo Verde 1 & 2024 & 69 & CE System 80 \\
\hline & Palo Verde 2 & 2025 & 70 & CE System 80 \\
\hline & Palo Verde 3 & 2027 & 72 & CE System 80 \\
\hline $\begin{array}{l}\text { Carolina Power and } \\
\text { Light Company }\end{array}$ & Harris 1 & 2026 & 71 & WE $17 \times 17$ \\
\hline \multirow{4}{*}{$\begin{array}{l}\text { Commonwealth } \\
\text { Edison Company }\end{array}$} & Braidwood 1 & 2028 & 73 & WE $17 \times 17$ \\
\hline & Braidwood 2 & 2028 & 73 & WE 17x17 \\
\hline & Byron 1 & 2025 & 70 & WE $17 \times 17$ \\
\hline & Byron 2 & 2027 & 72 & WE $17 \times 17$ \\
\hline $\begin{array}{l}\text { Kansas Gas and } \\
\text { Electric Company }\end{array}$ & Wolf Creek 1 & 2025 & 70 & WE $17 \times 17$ \\
\hline $\begin{array}{l}\text { North Atlantic Energy } \\
\text { Service Corporation }\end{array}$ & Seabrook & 2030 & 75 & WE $17 \times 17$ \\
\hline $\begin{array}{l}\text { Northeast Utilities } \\
\text { Service Company }\end{array}$ & Millstone 3 & 2025 & 70 & WE $17 \times 17$ \\
\hline TU Electric & Comanche Peak 1 & 2030 & 75 & WE $17 \times 17$ \\
\hline & Comanche Peak 2 & 2033 & 78 & WE $17 \times 17$ \\
\hline $\begin{array}{l}\text { South Carolina } \\
\text { Electric and Gas Co. }\end{array}$ & Summer & 2035 & 80 & WE $17 \times 17$ \\
\hline Tennessee Valley & Sequoyah 1 & 2020 & 65 & WE $17 \times 17$ \\
\hline & Sequoyah 2 & 2021 & 66 & WE $17 \times 17$ \\
\hline & Watts Bar 1 & 2035 & 80 & WE $17 \times 17$ \\
\hline
\end{tabular}

* Note that this is just a proposed set of reactors that could be used for the mission; none of these have indicated interest nor are others excluded for any purpose other than demonstration 


\section{LA-14052-T}

However, because it contains a large fraction of uranium, it also breeds plutonium and other minor actinides, decreasing the overall efficiency of the plutonium depletion.

The use of MOX fuel is assumed in this research; however, there is another fuel type that could potentially irradiate plutonium in an LWR more efficiently - nonfertile fuel (NFF). Although licensing of MOX fuel may be easier than a new fuel type, the burnup rate of plutonium and minor actinides in MOX fuel is $<30 \%$ per pass compared to the $70 \%$ to $80 \%$ obtainable with uranium-free cores. ${ }^{23}$ Thus, plutonium would be burned more efficiently as NFF so a majority of neutron interactions would destroy the plutonium, not produce it. ${ }^{24}$ NFF is a revolutionary new fuel type proposed within the last decade and typically consists of plutonium stabilized in an inert matrix (such as $\mathrm{ZrO}_{2}$, $\mathrm{CeO}_{2}, \mathrm{MgO}, \mathrm{Al}_{2} \mathrm{O}_{3}$ ) with burnable poison (most commonly erbium) to control reactivity and power peaking. ${ }^{25}$ The partial use of NFF in typical LWR assemblies has also been examined for plutonium destruction. One design contains assemblies with $\mathrm{NFF}\left(\mathrm{PuO}_{2}\right.$ mixed with $\mathrm{CeO}_{2}$ ) within thick (larger than average) annular fuel rods surrounded by standard $\mathrm{UO}_{2}$ rods (the Advanced Plutonium Fuel Assembly concept). ${ }^{26}$ The idea of using evolutionary mixed oxide-fueled reactors (with a fraction of the cores as MOX and the rest as NFF) has also been explored. ${ }^{27}$ Although research on uranium-free fuels is forthcoming and they represent an efficient technique for transmutation, their implementation is many decades away because so little is known about them. Thus, for this research, it is assumed that using the existing database of knowledge and experience in MOX fuels would lead to the most rapid implementation and most acceptable alternative for transmutation. 
Worldwide, the French and Japanese have been using MOX fuel for decades and are always trying to find ways to improve the efficiency of their fuel cycle. Being able to perform multiple recycles of plutonium would be beneficial by burning as much of it as possible. However, in the past it has been found that after one or more recycles, the fissile quality of the plutonium is so poor that to account for the loss in reactivity, changes to the system must be made that can compromise safety. In many previous studies, the plutonium content (relative to uranium) has been increased so that the fissile fraction of material in the core remains constant (the uranium is solely comprised of depleted or natural uranium, for which the fissile content is small). ${ }^{28,29}$

In contrast, other studies have shown that increasing the fissile content of uranium $\left({ }^{235} \mathrm{U}\right)$ instead of the fraction of the plutonium in MOX with multiple recycles (the MIX concept) reduces safety concerns and makes licensing easier (by keeping the fraction of plutonium in heavy metal in MOX the same with each recycle). ${ }^{30}$ Such studies have been performed by increasing the initial enrichment of uranium in the MOX so that the reactivity at the end of each cycle (not the beginning) is consistent (i.e., around 1.0). ${ }^{31}$ Previous research has shown that up to $27.5 \%$ of the original plutonium can be depleted the first cycle, and about one-half to one percent less of the starting plutonium each recycle thereafter. ${ }^{32}$ Objectives one and two of this research involve the multi-recycling of plutonium and plutonium plus minor actinides respectively as MOX fuel in LWRs.

\subsubsection{Full Cores of MOX Fuel}

One of the reasons that $30 \%$ cores of MOX fuel are more easily licensed than full cores is that as the plutonium content in the reactor increases, the soluble boron and 


\section{LA-14052-T}

control/shutdown rod worth decreases (these are discussed more in Section 5.1). This is because the high absorption cross section of the plutonium present in MOX fuel causes a reduced thermal flux. ${ }^{20}$ It is also primarily why licenses to burn MOX fuel in France limit the MOX content to $30 \%$ and the plutonium concentration to less than or equal to $5.3 \mathrm{w} \%$. To meet safety conditions, the boron concentration in the reactor is increased to help control reactivity, and control rods are inserted at various lengths/rates throughout burnup. ${ }^{33}$ In addition, MOX assemblies are generally only kept in the reactor for three cycles as opposed to four cycles as with $\mathrm{UO}_{2}$ assemblies.

Although $30 \%$ cores of MOX fuel are feasible and can burn plutonium, to increase the burnup of plutonium in licensed reactors even further, it would be desirable to use full cores of MOX fuel. To do this, a technique for improving safety parameters would have be developed. One way to do this is to use an over-moderated reactor design. ${ }^{34}$ Previous studies have shown that such an increase in the hydrogen-to-heavy metal ratio can meet neutronic safety constraints. ${ }^{35}$ Replacing some symmetrically positioned fuel rods with water holes increases the moderating ratio from about 2.0 to 2.5 and leads to a higher boron efficiency and/or control/shutdown rod worth. ${ }^{36}$ Preliminary thermal hydraulic analyses of such an assembly show less than 5\% variance from traditional performance. ${ }^{37}$ In addition, when compared to standard MOX assemblies, the buildup of minor actinides is reduced with extra moderation. ${ }^{38}$

Finally, instead of having only a fraction of reactors in the country burn MOX and the others burn $\mathrm{UO}_{2}$ as is suggested in this research, another recent idea for MOX irradiation in LWRs is to have a self-sustaining fuel assembly that burns as much plutonium as it produces (this is termed the CORAIL concept). This concept consists of 
MOX fuel rods surrounding the periphery of the assembly and $\mathrm{UO}_{2}$ rods in the middle, also using an enriched uranium support to maintain desired reactivity levels as a function

of multi-recycling. ${ }^{39}$ Although novel, it is assumed in this research that this concept is a less practical application of an enriched uranium support because it requires: 1) all LWRs to be re-licensed, and 2) bundling of both $\mathrm{UO}_{2}$ and $\mathrm{MOX}$ fuel rods together, which may not be possible at current facilities. This is because plutonium fuel requires more secure fabrication facilities than large-scale uranium ones. The idea of burning as much plutonium as is produced within each assembly would definitely be beneficial to future fuel cycles but is not as directly applicable to burning legacy plutonium as full cores of MOX fuel would be. If the safety issues of burning a full core of MOX fuel can be resolved by combining over-moderated LWR assemblies with an enriched uranium support, then only a fraction of LWRs would have to be re-licensed for full cores of MOX fuel. Additionally, most uranium fabrication and bundling facilities could remain the same; an additional facility(ies) would have to be built for the MOX assemblies. The dedicated MOX reactors would initially burn all the legacy plutonium, and eventually, the MOX burning reactors could be arranged to burn all the plutonium being produced by $\mathrm{UO}_{2}$-burning LWRs as well.

\subsubsection{Neutronic Safety Parameters}

The most significant parameters in neutronic safety calculations include the Doppler reactivity coefficient, the moderator temperature coefficient, soluble boron efficiency, void reactivity coefficient, and control/shutdown rod worth. The Doppler reactivity coefficient (termed simply Doppler coefficient throughout the rest of the paper) 


\section{LA-14052-T}

is the change in the multiplication of the system $\left(\mathrm{k}_{\mathrm{eff}}\right)$ caused by variations in the fuel cross sections due to temperature. The Doppler coefficient should be negative, which means that $\mathrm{k}_{\mathrm{eff}}$ decreases as the fuel temperature increases. This negativity would be beneficial in an accident scenario in which the core overheats and the fuel temperature rises; it is nice to have the $\mathrm{k}_{\mathrm{eff}}$ of the system decrease instead of increase and potentially go supercritical. The reason it is termed Doppler coefficient instead of "fuel" temperature coefficient is that broadening of the resonances with temperature is called the Doppler effect and is seen primarily in the fuel (particularly actinides) of a reactor system. The moderator temperature coefficient is similar to the Doppler coefficient in that it represents how the multiplication $\mathrm{k}_{\mathrm{eff}}$ of the system changes as the temperature of the moderator increases. Both the decrease in density and the change in the cross section of the material are accounted for in this research.

The void reactivity coefficient (see benchmark in Section 3.2.2.1.3) represents the effect that a decrease in the water/moderator (such as a loss of coolant accident) has on the reactivity of the system. A decrease of $25 \%$ percent of water in the system is considered for this study. All reactivity coefficients are measured in terms of change in $\mathrm{k}_{\text {eff }}\left(1 \mathrm{pcm}=10^{-5} \mathrm{k}_{\mathrm{eff}}\right)$ per degree $\mathrm{C}($ or $\mathrm{K})$ change in temperature. Temperature changes are modeled by changing the cross section of the fuel or moderator material in MCNP.

One of the ways that reactivity is controlled as a function of irradiation in a PWR is by adding soluble boron to the water. Typically measured parameters for neutronic safety calculations include the critical boron concentration and the soluble boron efficiency. Critical boron concentration is the amount of boron required to keep the system exactly critical at the beginning of a cycle. It is typically measured in units of 
parts per million (ppm), which is milligrams of boron per kilograms of water. Critical boron concentration should not be greater than $2500 \mathrm{ppm}$ because it could lead to recrystallization, and it is usually less than 1500 ppm. ${ }^{30}$ Soluble boron efficiency represents how well insertions of boron decrease the reactivity of the reactor. Boron efficiency is calculated in terms of the change in reactivity $(\mathrm{pcm})$ per ppm boron added or removed from the water. It should be at least $4 \mathrm{pcm} / \mathrm{ppm}$ to assure adequate control measures in the reactor.

The last measure is the worth of the control and shutdown rods. In a reactor, control rods are used to help keep the system critical throughout a cycle (i.e., with a $\mathrm{k}_{\text {eff }}$ of $\sim 1.03$ at the beginning of each cycle, control rods may be used to reduce reactivity). Shutdown rods are used to make the reactor subcritical (i.e., cease operation) either at the end of an operating period or in case of an emergency. In a typical LWR with $\mathrm{UO}_{2}$ fuel, control rods are typically comprised of silver-indium-cadmium, and shutdown rods are boron carbide $\left(\mathrm{B}_{4} \mathrm{C}\right)$, which is an even stronger neutron absorber.

Safety concerns associated with the use and/or subsequent multi-recycling of MOX fuel are:

- Plutonium hardens the neutron spectrum due to competition between the fuel and the moderator, leading to a shorter neutron lifetime, better fast neutron utilization, and a lower delayed neutron fraction, which could allow the reactor to go prompt critical faster; ${ }^{40}$

- The moderator void coefficient can become positive at plutonium contents greater than about $10-15 \mathrm{w} \%$ in heavy metal; ${ }^{29}$ 
- A harder neutron spectrum leads to increased absorption rates (especially of ${ }^{238} \mathrm{U},{ }^{240} \mathrm{Pu}$, and $\left.{ }^{242} \mathrm{Pu}\right)$ and decreased fission-to-capture ratios of the actinides at thermal energies;

- Control material (i.e., control rods, soluble boron, gadolinium, xenon) becomes less efficient;

- Larger (negative) Doppler and moderator temperature coefficients occur (requiring additional shutdown capacity), especially with a high hydrogen-toheavy metal ratio; and

- Hot Spots/Power peaking concerns exist, especially with one-third cores of MOX because of the larger fission cross sections of MOX compared to $\mathrm{UO}_{2}$ fuel, which create more flux depressions from resonance self-shielding across assemblies.

Because the plutonium content is higher in a full core of MOX fuel than in a $30 \%$ MOX reactor, several parameters may be have modified. For example, the boron enrichment may have to be increased (up to $90 \mathrm{w} \% \mathrm{~B}-10$ ) because the maximum boron concentration in the water is limited to $2500 \mathrm{ppm}$ (parts per million); above that, recrystallization might occur in auxiliary circuits. ${ }^{30}$ With a full core of MOX fuel at high plutonium concentrations, values above $2500 \mathrm{ppm}$ might be required with natural boron. Additionally, boron efficiency should be greater than $4 \mathrm{pcm} / \mathrm{ppm}$ (i.e., the change in $\mathrm{k}_{\mathrm{eff}}$ should be at least $4 * 10^{-5}$ for each ppm change in boron concentration), and in full cores of MOX fuel, this limit may not be met without modifications. One way to resolve both these issues is to use boron enriched in ${ }^{10} \mathrm{~B}$. Similarly, the shutdown safety margin 
should be at least $5000 \mathrm{pcm}^{30}$ To reach this limit, additional shutdown rods may be necessary or the control rod composition may have to be changed (i.e., from AgInCd to $\mathrm{B}_{4} \mathrm{C}$ ) to become more effective. The shutdown margin in a partial core of MOX fuel is larger than that for a full core and can usually make use of the existing control and shutdown rod materials, which is another reason why partial cores have been more easily licensed in the past. ${ }^{41}$ The fourth objective involves the design of a full core of MOX fuel to meet all these safety conditions.

When the use of MOX fuel in an LWR was initially studied, another concern was that the use of plutonium could lead to a positive temperature reactivity coefficient. However, hot criticality tests showed that reactivity is only marginally influenced by temperature, so this issue has not become a major concern. ${ }^{42}$ Other concerns in the use of MOX fuel include the fact that the thermal conductivity of MOX fuel is lower than that of $\mathrm{UO}_{2}$ fuel (by about 10\%), which leads to a higher operating temperature of the fuel, which is important in analyzing accident scenarios. In addition, MOX fuel can be associated with a larger fission gas release during operation, internal fuel rod pressure, thermal gap conductivity, and fuel swelling than $\mathrm{UO}_{2}$, which may lead to differences in reactivity initiated accidents (RIAs). Nonetheless, another study showed that behavior under RIAs (control rod ejection as a realistic case and fuel melting as a severe case) is better for MOX fuel at high burnups (30 and $60 \mathrm{GWd} / \mathrm{MTHM}$ ) than for $\mathrm{UO}_{2}$ fuel although it is worse for fresh MOX than fresh $\mathrm{UO}_{2}$ fuel. ${ }^{43}$ Overall, safety aspects of plutonium reload calculations have been explored but not in enough detail yet for implementation of full cores. $^{44}$ 


\subsection{Accelerator-Driven Transmutation Systems}

One of the perceived advantages of using ADSs for actinide transmutation is the current public and political resistance to the use and expansion of nuclear reactors. The advantages of ADSs are: 1) they can be considered safer than reactors because they have a $\mathrm{k}_{\mathrm{eff}}$ less than 1.0 , and 2) they can burn material combinations that do not have a sufficiently high fission-to-capture ratio to maintain criticality in a reactor. An accelerator is used to produce a steady stream of protons that hit a target and undergo $(\mathrm{p}, \mathrm{n})$ interactions to produce spallation neutrons. Commonly used targets include lead, lead-bismuth eutectic (LBE), and tungsten. ${ }^{13,15,45}$ These targets allow a proton to enter the nucleus of an atom and one or more neutrons to leave. Spallation neutrons are used to transmute actinides and/or fission products contained in the blanket surrounding the target (see Fig. 2-3).

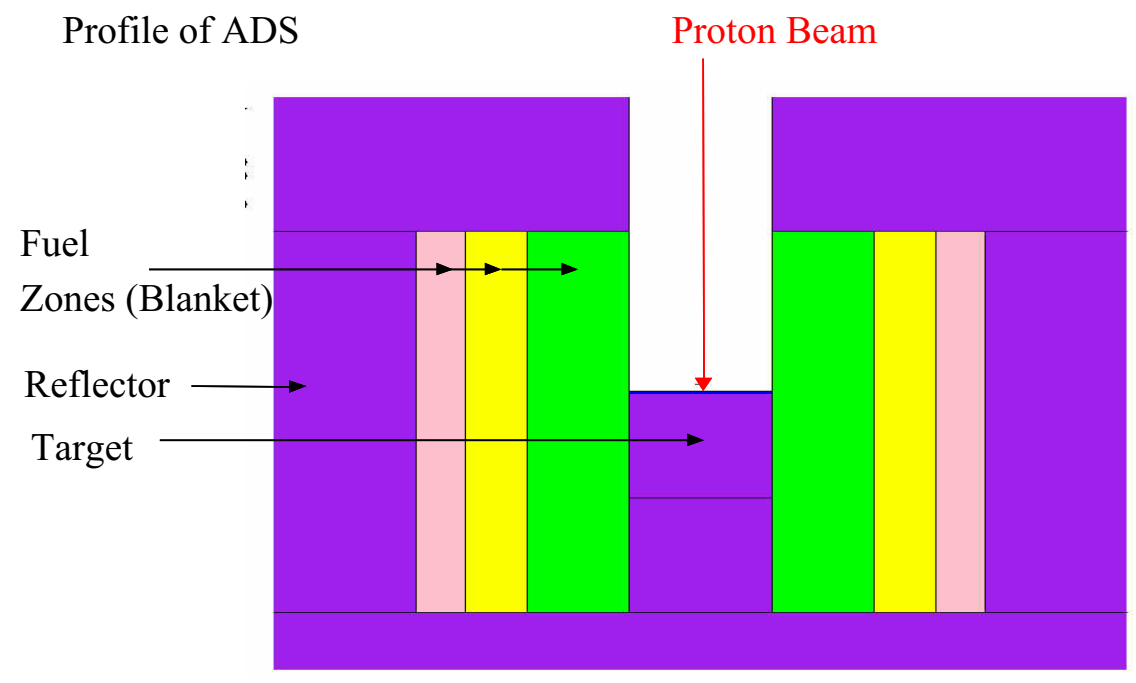

Fig. 2-3. Profile of ADS System 
The blanket consists of several regions of actinide fuel material encompassed by an appropriate coolant. A cycle of irradiation is considered to be the time over which no fuel is added, removed, or rotated. ADSs designed for transmuting both plutonium and minor actinides from SNF have a $\mathrm{k}_{\mathrm{eff}}$ at the beginning of the cycle less than 0.97 and a $\mathrm{k}_{\mathrm{eff}}$ at the end-of-cycle greater than 0.90 , which is the case if the cycle length is about six months. Between cycles, irradiated rods are removed from the system, uranium and fission products are separated from the actinides and fuel matrix, and enough new actinides are added at the beginning of each cycle to achieve a $k_{\text {eff }}$ of 0.97 . Over the first few cycles, significant quantities of minor actinides build up because they are not removed with the uranium and fission products. The actinide inventory of the system increases because the amount of fuel added at the beginning of each cycle (the feed rate) is larger than that added at equilibrium to account for this buildup. After 20-30 cycles, a near equilibrium situation is reached where the same amount of minor actinides of transuranic material is both added and burned each cycle (this equilibrium feed is 2-3 times smaller than the initial feed rate and the actinide inventory now remains constant). At equilibrium, about $1 \mathrm{~kg} /$ day of the cycle is added for each $\mathrm{GW}_{\mathrm{t}}$ of power produced by the system. Background information on targets, blanket design, separations techniques, and spallation product generation is given in Sections 2.3.1, 2.3.2, 2.3.3, and 2.3.4 respectively.

\subsubsection{Target Design}

It is assumed for the ADS studies presented here that the target is cylindrical and located in the middle of the system, and the beam enters from the top. The target is 
bombarded with a proton beam of up to $1 \mathrm{GeV}$ and creates about 20-30 spallation neutrons per proton. Some of these neutrons are captured in the actinides or other materials in the system; others go on to produce fissions (and subsequent chain reactions), which contribute about 400 fissions per source proton with a $\mathrm{k}_{\mathrm{eff}} \approx 0.97 .{ }^{13}$ The currently proposed $840-\mathrm{MW}_{\mathrm{t}}$ system requires a proton current of $\sim 13 \mathrm{~mA}$, as given in Equation 1.9

$$
\mathrm{I}=\frac{\mathrm{v} * \mathrm{P} * 1.602 \times 10^{-19} \mathrm{C} / \text { proton }}{\mathrm{S} * \mathrm{k}_{\mathrm{eff}} /\left(1-\mathrm{k}_{\mathrm{eff}}\right) * \mathrm{Q}_{\mathrm{ave}}}
$$

where

$$
\begin{aligned}
& \mathrm{I}=\text { the beam current }(\text { amps }), \\
& v=\text { the average number of neutrons produced per fission }(\approx 2.9), \\
& \mathrm{P}=\text { the power produced by the blanket }\left(\approx 840 \mathrm{MW}_{\mathrm{t}}\right), \\
& \mathrm{S}=\text { the number of neutrons leaking from the target into the blanket } \\
& \quad(\approx 30 \text { spallation neutrons/source proton }), \\
& \mathrm{k}_{\mathrm{eff}}=\text { the effective multiplication factor obtained by MCNP }(\approx 0.97), \\
& \mathrm{k}_{\mathrm{eff}} /\left(1-\mathrm{k}_{\mathrm{eff}}\right)=\text { the number of fission neutrons to the number of spallation } \\
& \quad \text { neutrons, and } \\
& \mathrm{Q}_{\text {ave }}=\text { the average recoverable energy released per fission } \\
& \quad\left(\sim 200 \mathrm{MeV} \text {, or } 3.2 \times 10^{-11} \mathrm{~J}\right) \text {. }
\end{aligned}
$$

A proton flux map showing the distribution of protons in the system is given in Fig. 2-4, and a corresponding neutron flux map is given in Fig. 2-5. The target (with a 
radius of $18 \mathrm{~cm}$ and length around $60 \mathrm{~cm}$ ) starts at an axial location of $4 \mathrm{~cm}$, with the proton beam striking the top of the target. The maximum proton flux is $\sim 4{ }_{-} 10^{14}$ protons $/ \mathrm{cm}^{2}$-s, and the peak neutron flux in the blanket is $\sim 4{ }_{-} 10^{15}$ neutrons $/ \mathrm{cm}^{2}-\mathrm{s}$.

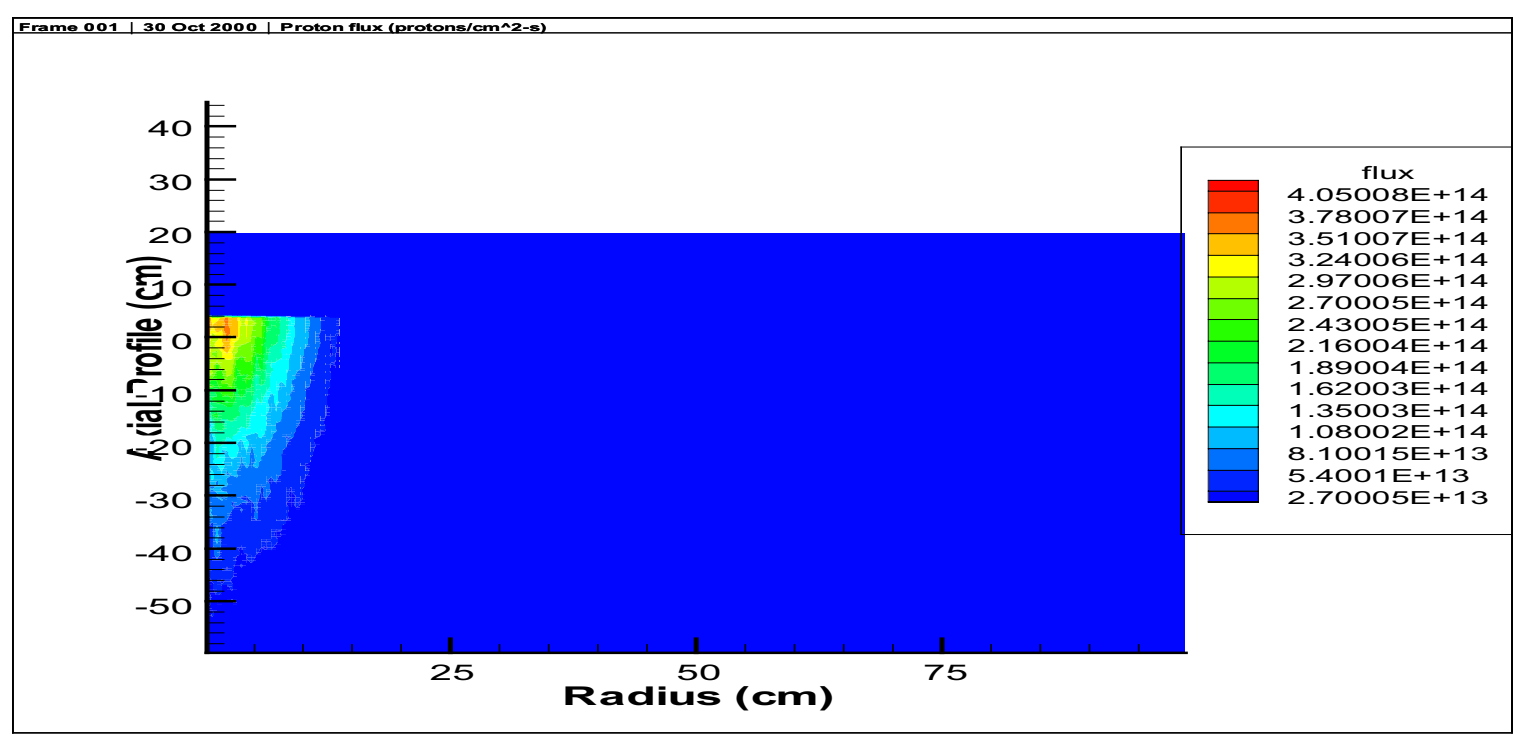

Fig. 2-4. Proton Flux Map

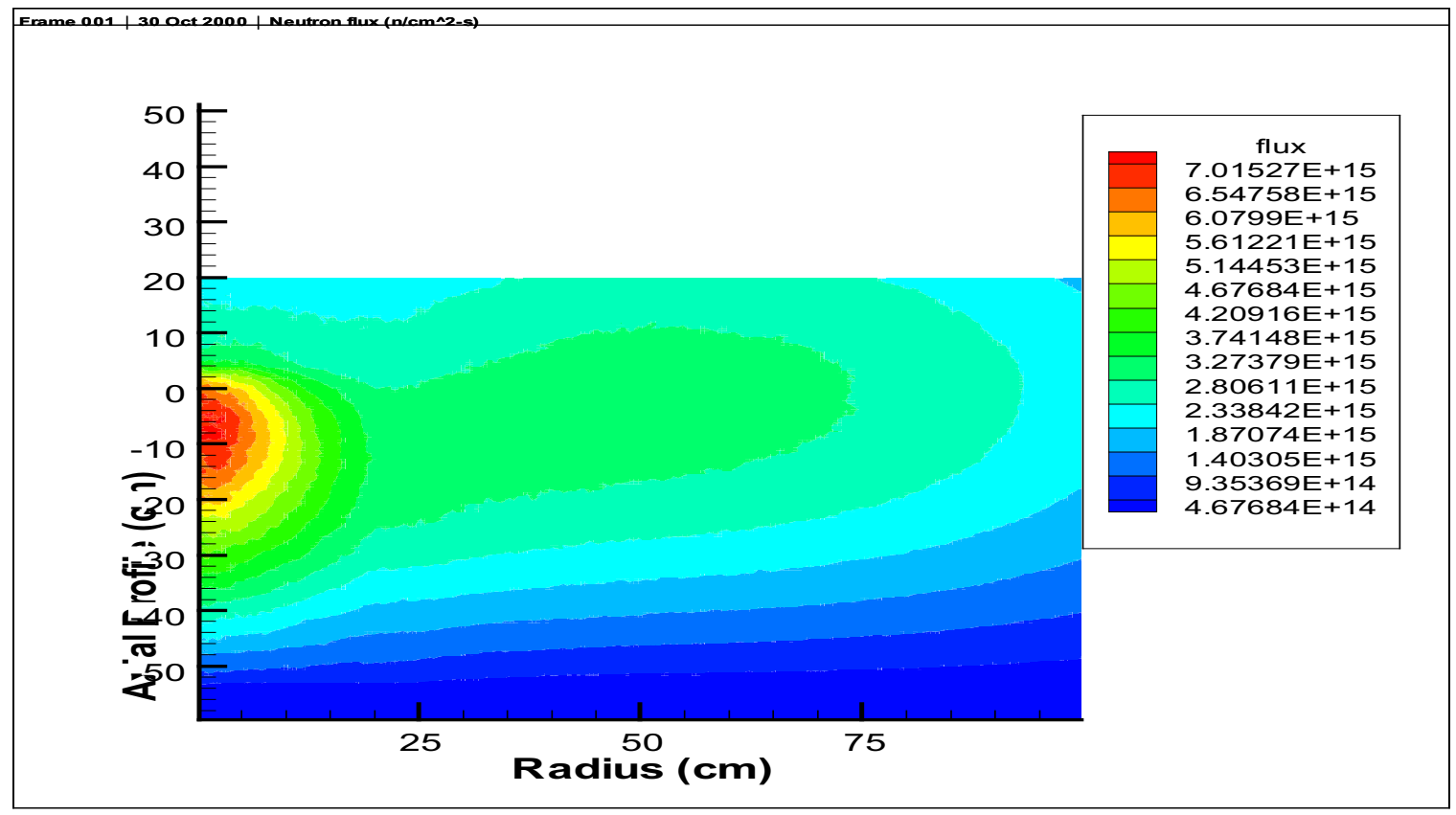

Fig. 2-5. Neutron Flux Map 


\subsubsection{Blanket Design}

Two main types of blankets can be used in an ADS, and like reactors, they are distinguished by neutron energy spectrum. Previous ADS studies for transmutation focused on the use of a molten salt thermal spectrum system that allowed the continuous feed of actinide material and removal of fission products and a constant value of $\mathrm{k}_{\mathrm{eff} .}{ }^{13}$ However beneficial continuous feed and removal may be, the molten salt ADSs lead to a large accumulation of higher actinides because of the thermal spectrum. Fast spectrum systems generally yield higher actinide fission-to-capture ratios than thermal ones, so they are currently the more popular option and are the type examined in this research.

The fast spectrum ADSs currently proposed use a liquid coolant (either LBE or sodium) and metallic (zirconium) or nitride fuel. The fuel is fabricated into pins or particles that are placed in the blanket. There are typically multiple regions of this actinide fuel, each region consisting of appropriate actinide concentrations designed to flatten the flux profile in the system. One approach to such a design is to start with fresh fuel (i.e., that with the largest actinide fraction) in the outer region, then once it is irradiated for one cycle, rotate it inward one region for further irradiation and so on. ${ }^{46}$ After several rotations, the oldest fuel is in the innermost region. Once the irradiation cycle finishes there, the fuel is removed and sent to separations, during which the uranium and most fission products are removed (with the exception of long-lived fission products such as ${ }^{99} \mathrm{Tc}$ and ${ }^{129} \mathrm{I}$, which may remain in the blanket for transmutation). The actinides are then mixed with fresh fuel and placed back into the system in the outermost region. 
Other designs do not include shuffling of the material after each cycle; instead there are several regions with different actinides concentrations, and a fraction of the fuel rods in each region is removed each cycle (and sent to separations) and replaced with fresh fuel rods. ${ }^{47}$ The reason this design is beneficial is that fuel handling is not simple for these pool systems with liquid metal coolant. Limiting the number of fuel handling steps and using long cycle partial reload fuel management strategies is advantageous. Furthermore, detailed loading patterns are not required to limit local power peaks in a fast reactor as needed for a thermal reactor system (there is a smaller local heterogeneity effect corresponding to a longer neutron mean free path). Thus, fuel management schemes which require multiple assembly movements are generally avoided, so a system without shuffling is used in this research.

\subsubsection{Separations for an $A D S$}

The separations technique proposed for intermediate processing in the ADS is called pyroprocessing. A typical fast spectrum ADS only burns about $30 \%$ of the starting material per pass (several cycles of irradiation in the system), so to achieve burnups up to the desired $99.75 \%$, much recycling must be done (i.e., obtain the reusable plutonium and minor actinides each cycle and mix them with "fresh fuel" for the next cycle). Pyrochemical techniques provide the most efficient separation of uranium and transuranic elements from the irradiated metallic rods and fission products. $^{48}$ Note that pyroprocessing can also be used for large-scale SNF separations instead of PUREX, but it is expensive and best suited for smaller-scale separations of fuel between cycles in an 
ADS $^{49}$ It is hoped that separations efficiencies as great as $99.999 \%$ can be achieved per pass so that a $99.75 \%$ overall transmutation is possible.

\subsubsection{Spallation Products}

Spallation products (SPs) are the radionuclides produced in a target after a proton beam hits it and emits neutrons. Numerous studies have been performed on the longterm radiotoxicity of transuranics and fission products (both within SNF and those generated from the transmutation process). However, since the concept of using an ADS is relatively new, there has not been as much research on the radiotoxicity of the radionuclides generated during the spallation process.

\subsubsection{Radiotoxicity}

To determine the biological hazard that a particular material represents to humans, a measure must be developed to quantify the risk. Radiotoxicity is a widely accepted measure for this hazard because it gives the probability that a material will cause harm if ingested or inhaled. The International Commission on Radiological Protection (ICRP) represents radiotoxicity in terms of the estimated number of cancer deaths that might result following the ingestion or inhalation of a set of radionuclides, or effective dose. ${ }^{50}$ Effective dose is calculated by obtaining the weighted sum of committed dose equivalents multiplied by appropriate weighting factors for relevant organs and tissues. The ICRP reports fractional absorption and the summed effective dose for many radionuclides. ${ }^{51}$ For ingestion, it is assumed that radionuclides are incorporated either into the food or water a person is eating or drinking and are readily absorbed in the 
gastrointestional tract. Inhalation radiotoxicity values include retention of deposited activity in various respiratory tract regions with clearance from the regions by breathing out, movement of the particles to the GI tract and lymph nodes, and absorption into body fluids. Values are reported for fast, moderate, and slow absorption, but the highest of the three is used in these calculations. Effective dose is given separately for ingestion and inhalation in units of dose per activity (Sieverts per Bequerel (Sv/Bq)) for the isotope of interest. $^{52}$ Effective doses are reported for ages ranging from three months (representing an infant) to an adult, but the adult values are used in this study if an average is not available.

The Code of Federal Regulations (CFR) citation written by the Nuclear Regulatory Commission (NRC) expresses radiotoxicity in units of annual limit on intake (ALI). ALI is defined as the greatest value for annual intake (represented by I and usually in terms of $\mu \mathrm{Ci}$ ) that satisfies the two conditions below (where $\mathrm{H}_{50, \mathrm{~T}}$ is the committed dose equivalent per unit activity of intake $(\mathrm{Sv} / \mathrm{Bq})$ in tissue $\mathrm{T}$ from the radionuclide and $\mathrm{w}_{\mathrm{T}}$ is the weighting fraction for that tissue $):{ }^{53}$

$$
\begin{aligned}
& I \sum w_{T} \hat{H}_{50, T} \leq 0.05 S v \\
& \hat{H}_{50, T} \leq 0.5 S v
\end{aligned}
$$

The committed dose equivalent is the dose equivalent resulting from the intake of a radionuclide over a subsequent 50-year period. The inhalation ALIs reported in the CFR represent an aerosol with an activity median aerodynamic diameter of 1 micron for retention periods of days (for halflives less than 10 days), weeks (for halflives between 


\section{LA-14052-T}

10 and 100 days), and years (for halflives greater than 100 days) in the pulmonary region of the lung. Other ALIs for airborne and liquid effluents and discharges to sanitary sewer systems (i.e., from ingestion) are also reported. ${ }^{54}$ However, neither the ICRP nor the CFR report values for all radionuclides of interest. For this reason, the Japanese developed their own set of radiotoxicity data for about 300 radionuclides not listed in the ICRP. ${ }^{55}$

In a repository, ingestion toxicity may be considered to be more important than inhalation radiotoxicity because the potential biological hazard to humans occurs when the isotope is absorbed in nearby ground water or brine and transported from the repository to potential human receptors through drinking water. Inhalation radiotoxicity is important to analyze in case of a breach of containment inside the accelerator facility and/or for short-term (i.e., above-ground) storage concerns. It may also become important in case of intrusion upon the repository site and release of radioactive elements to the air. Sufficient barriers would be designed to protect this material in any case.

\subsubsection{Radiotoxicity of Spallation Products}

A majority of the common fission products are beta-emitters, but some of the radionuclides generated during spallation are alpha-emitters, which means that they may pose more significant inhalation hazards than typical fission products. Previous studies involving heavy liquid metal spallation targets show that important contributors to the radiotoxicity of a LBE target are: ${ }^{208} \mathrm{Po},{ }^{210} \mathrm{Po},{ }^{202} \mathrm{~Pb},{ }^{207} \mathrm{Bi},{ }^{193} \mathrm{Pt}$, and rare earth isotopes such as ${ }^{146} \mathrm{Sm},{ }^{148} \mathrm{Gd},{ }^{150} \mathrm{Gd}$, and ${ }^{154} \mathrm{Dy} .{ }^{5,56}$ One comparison shows that the resulting radiotoxicity from an $\mathrm{ADS}$ is indeed higher than that from a comparable reactor due to 
the accumulation of spallation products, and it takes about 300 years for their radiotoxicity to decrease below that of natural uranium ore. ${ }^{56}$ Another study compares the radiotoxicity of three different targets: lead, tungsten, and tin. ${ }^{5}$ This study shows that initial radiotoxicities (primarily inhalation) of products generated from a lead target are higher than those from either a tungsten or tin target because of the accumulation of ${ }^{90} \mathrm{Sr}$, ${ }^{60} \mathrm{Co},{ }^{194} \mathrm{Hg}$, and ${ }^{148} \mathrm{Gd}$. However, at equilibrium, the tungsten target has a significantly higher radiotoxicity than either lead or tin because the isotopes ${ }^{146} \mathrm{Sm},{ }^{148} \mathrm{Gd},{ }^{150} \mathrm{Gd}$, and ${ }^{154}$ Dy (see Table $2-3$ for half-lives) contribute significantly $(\sim 90 \%)$ to the radiotoxicity per incident proton. ${ }^{5}$ These isotopes are alpha-emitters and are associated with high inhalation radiotoxicities, making the equilibrium radiotoxicity of the tungsten target significantly higher than that of lead. Using a smaller incident proton beam energy decreases the radiotoxicity as does the use of a deuterium beam instead of a proton beam. However, reaching equilibrium concentrations in the target requires thousands if not millions of years, so such an approach is unrealistic. Reasonable target lifetimes are $\sim 1$ year for solid target materials (i.e., tungsten and tantalum), and 10-100 years for liquid target materials (i.e., mercury and LBE). It is assumed that spallation products may contribute significantly to overall radiotoxicity immediately upon removal from the ADS, but even those isotopes that pose problems decay within 1000 years. Long-term effects on the repository from spallation products are negligible compared to those from SNF itself. 
Table 2-3. Spallation Products of Concern

\begin{tabular}{|c|c|c|}
\hline Isotope & Half-Life $^{57}$ & Decay Mode \\
\hline${ }^{3} \mathrm{H}$ & 12.32 years & $\beta^{-}$ \\
\hline${ }^{22} \mathrm{Na}$ & 2.604 years & $\beta^{+}$ \\
\hline${ }^{60} \mathrm{Co}$ & 5.271 years & $\beta^{-}$ \\
\hline${ }^{90} \mathrm{Sr}$ & 28.78 years & $\alpha$ \\
\hline${ }^{146} \mathrm{Sm}$ & $1.03 \mathrm{e}+8$ years & $\alpha$ \\
\hline${ }^{148} \mathrm{Gd}$ & 75 years & $\alpha$ \\
\hline${ }^{150} \mathrm{Gd}$ & $1.8 \mathrm{e}+6$ years & $\alpha$ \\
\hline${ }^{154} \mathrm{Dy}$ & $3 \mathrm{e}+6$ years & $\varepsilon$ \\
\hline${ }^{193} \mathrm{Pt}$ & 60 years & $\varepsilon$ \\
\hline${ }^{194} \mathrm{Hg}$ & 520 years & $\beta^{-}$ \\
\hline${ }^{202} \mathrm{~Pb}$ & $5.3 \mathrm{e}+4$ years & $\varepsilon, \beta^{+}$ \\
\hline${ }^{204} \mathrm{Tl}$ & 3.78 years & $\alpha$ \\
\hline${ }^{207} \mathrm{Bi}$ & 32 years & $\alpha$ \\
\hline${ }^{208} \mathrm{Po}$ & 2.898 years & $\alpha$ \\
\hline${ }^{209} \mathrm{Po}$ & 102 years & $\alpha$ \\
\hline${ }^{210 \mathrm{~m}} \mathrm{Bi}$ & $3.0 \mathrm{e}+6$ years & \\
\hline${ }^{210} \mathrm{Po}$ & 138.38 days & \\
\hline & & \\
\hline & & \\
\hline
\end{tabular}

$\alpha=$ alpha decay

$\beta^{-}=$beta (electron) decay

$\beta^{+}=$positron decay

$\varepsilon=$ electron capture 


\subsection{Methodology}

The first two objectives in this research involve performing irradiation calculations for a full core of MOX fuel in an LWR. Doing this type of calculation requires a burnup code that can handle the geometry of an LWR and can perform spectrum-dependent isotope generation calculations. The major requirement of these calculations is that the code be able to obtain and/or use cross sections representative of the system (i.e., a full core of MOX fuel). Discrete ordinates codes can be used for burnup calculations, but cross sections often only exist for particular systems, which makes them limited because it is preferred to get cross sections as a function of burnup for a variety of systems. The more energy groups the flux and/or cross sections are given as, the better the results (continuous energy is most preferable).

A flexible burnup code is also necessary for the calculations associated with the third objective, ADS neutronic performance. Again, using correct cross sections is essential in capturing neutronic details about a system, and little data and/or cross sections currently exist for a fast spectrum ADS and/or minor actinide irradiation. Even with little data, it is still desired to obtain as much spectrum-dependent information (cross sections, fluxes) as possible for this little-known system. Thus, the code required for this calculation must have a wide range of flexibility.

Safety conditions for both the LWR and the ADS (objectives four and five) are also important. The ability to calculate changes in reactivity under different operating conditions in an LWR is essential to proving that a full core of MOX fuel can be designed and licensed. Again, appropriate cross sections must be used to perform such calculations. Finally, the ability to obtain spallation product yields and representative 
target radiotoxicity is also required for this research. In particular, the probability of generation for various radionuclides must be obtained, and then these radionuclides must be irradiated and/or decayed appropriately to represent what actually occurs in an ADS target over time.

The results presented in this research are purely calculational; thus, this section primarily focuses on the codes used to perform analyses for the five research objectives. The Monte Carlo transport code MCNP is used to obtain spectrum-averaged cross sections for any nuclear system from a continuous energy data set, and the isotope generation and depletion code ORIGEN2.1 uses one-group cross sections and fluxes from MCNP for system-dependent burnup calculations. ${ }^{58,59}$ As part of nuclear waste transmutation research at Los Alamos National Laboratory, a code that links MCNP to ORIGEN2.1 was developed. Called Monteburns, this code is used for the calculations associated with the first three objectives in this research. ${ }^{60}$

Neutronic safety calculations do not require the use of a burnup code; thus, just the code MCNP is used to calculate the changes in reactivity under differing conditions in the core. Spallation product generation (for the fifth objective) can be obtained using the code LAHET along with MCNP, the combination of which has been built into a code called MCNPX. ${ }^{61,62}$ The radionuclide yields from MCNPX are processed into a format for use by another isotope generation and depletion code, CINDER90. ${ }^{63}$ Monteburns is again used to transfer information between the two codes (in this case MCNPX and CINDER90) and obtain isotopic results as a function of both irradiation and decay over a specified period of time. 
A typical method used to perform calculational research is to 1) obtain and learn to use applicable codes, 2) benchmark those codes to make sure the calculations are being done correctly, and 3) produce the actual information desired using those codes and/or additional data. Step one (i.e., developing a code) was performed prior to this research, and the result of this, Monteburns, and its sister codes are discussed in Section 3.1. Monteburns has been benchmarked in the past for $\mathrm{UO}_{2}$ fuel irradiation calculations, but only limited benchmark calculations had been done for MOX fuel, ADS design, and spallation product generation. Thus, more complete benchmarking efforts are performed in this research and are discussed in Section 3.2. Finally, specific assumptions and techniques used to perform the calculations in this research are presented in Section 3.3.

\subsection{Codes}

One of the reasons that studies involving the transmutation of SNF in LWRs have been limited in the past is that accounting for cross section and spectral changes as a function of burnup for less known materials such as recycled plutonium can be difficult and computationally expensive. ${ }^{31}$ However, with the latest developments in computational power and codes, calculating irradiation with such detailed information is less difficult. One new code developed at Los Alamos National Laboratory by the author is called Monteburns. ${ }^{60}$ Monteburns uses the well-known Monte Carlo transport code MCNP or the related code MCNPX to calculate system- and burnup-dependent cross sections and fluxes and links the resulting information to a depletion code; the current options for which are either ORIGEN2.1 or CINDER90 (see Fig. 3-1). The depletion code then provides material compositions halfway through each burnup step with initial 


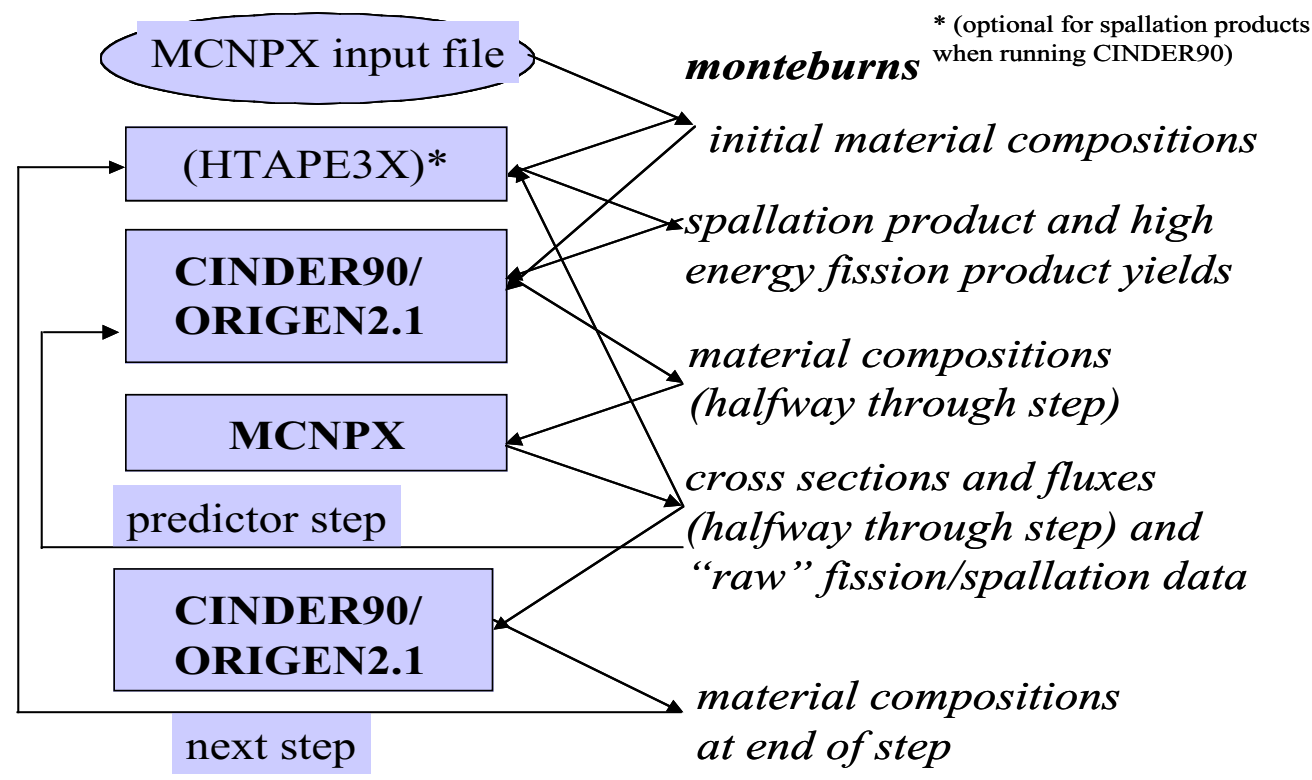

Fig. 3-1. Flow Chart for Monteburns

cross section and flux information, and these compositions are used to generate onegroup cross sections and fluxes in MCNP that represent the entire burnup step (assuming it is not too long, a parameter that must be analyzed using the results produced by Monteburns on a system by system basis). ORIGEN2.1 (or CINDER90) then uses these cross sections and fluxes to calculate material compositions at the end of each burnup step before proceeding to the next step.

Having the capability to get detailed, system-dependent results and the flexibility to do automated feed and removal of material in multiple cycles is one of the major benefits of Monteburns. This feature of Monteburns is especially important in this research because actinide cross sections for MOX fuel do vary as a function of burnup, the number of recycles, and with varying initial MOX fuel compositions (i.e., with heavy 
metal other than plutonium and uranium). The code itself consists of FORTRAN77 for calculations and an interactive Perl script to transfer information between the transport and depletion codes. The input includes information about the system including material volumes, power for a reactor or current for an ADS, default ORIGEN2.1 libraries to be used (cross sections from these are used for isotopes not tracked in MCNP), a list of isotopes to be tracked for each burnup material, and an importance fraction for isotopes that should be tracked if they contribute significantly to the mass, atom composition, absorption, and/or fission rates compared to other isotopes in the system. Once an isotope is deemed "important," its cross section is always calculated in MCNP, and it is also listed in the intermediate input files and further tracked so that detailed information can be obtained for it. Monteburns also allows the user to input changes in temperaturedependent cross sections as a function of burnup step, and any removal or addition of material either between or during steps. It outputs information about the transport history of each material tracked by the code. Note that the material does not have to be burned; for example, soluble boron that flows through a reactor is processed by Monteburns so that the density and boron concentration can be modified as a function of burnup step, but it is not irradiated because it is continually being replaced in a reactor system. Monteburns also outputs cross sections, beginning and ending compositions of the material, production/depletion rates, and burnup step.

For more detailed information, MCNP is discussed in Section 3.1.1, MCNPX in Section 3.1.2, and ORIGEN2.1 and CINDER90 in Section 3.1.3. 


\subsection{1. $M C N P$}

MCNP is a transport code that uses the Monte Carlo technique. ${ }^{58}$ The Monte Carlo technique is a statistical method in which estimations for particle characteristics are obtained through multiple computer simulations of the behavior of individual particles in a system. The probability that a particle behaves in a certain manner (scatters, absorbs, fissions) is obtained from the cross sections for the material(s) with which the particle interacts. For example, if a material is a pure absorber, then the probability that a particle interacting with this material is absorbed is $100 \%$. If the material is both an absorber and a scatterer, then the probability of absorption is equal to the ratio of the absorption cross section to the total cross section (absorption plus scatter). It follows that the probability of scatter is equal to the ratio of the scattering cross section to the total cross section. After a particle has undergone a scatter, it remains in the system to undergo another interaction. A Monte Carlo code keeps track of the position of each particle before and after it scatters and/or is absorbed, as well as any neutrons produced from fission interactions. If a particle travels outside the system, then it is considered to have "leaked." The "life" of the particle end either when it leaks from the system or when it is absorbed in a material. In the case of a neutron being absorbed in fissile material and causing a fission, the location and number of new neutrons created is recorded.

A Monte Carlo code generates a statistical history for a particle based on random samples from probability distributions used in calculations to determine 1) the type of interaction the particle undergoes at each point in its life, 2) the resulting energy of the particle if it scatters, and/or 3) the number of neutrons it produces if it causes a fission. Thus, a Monte Carlo code models the series of events that occur in the lives of a large 
number of particles to determine the flux of different types of particles in various locations in the system. The particles of most interest in criticality/burnup calculations are neutrons because they interact with fissile materials to produce energy as well as more neutrons.

MCNP is used to model the events in the lives of neutrons, photons, and/or electrons. The cross sections for the particles are obtained from numerous material cross section libraries containing a number of isotopes at various operating temperatures. MCNP uses these libraries in a continuous-energy fashion, which means that it obtains the specific cross section for a given energy rather than looking at grouped cross section sets, in which the cross sections represent an average of a particular range of energies. The code NJOY can be used to produce temperature-dependent cross sections for numerous isotopes in a format that can be read by MCNP. ${ }^{64}$ After running NJOY, an identifier is placed in the "xsdir" file used by MCNP, the Monteburns "mbxs.inp" file, and the MCNP input file to recognize the new cross section.

MCNP can also calculate the effective multiplication factor $\left(\mathrm{k}_{\mathrm{eff}}\right)$ for a system, which is the number of neutrons produced in one generation divided by the number of neutrons that existed in the previous generation, indicating how close the system is to being critical ( $\mathrm{k}_{\text {eff }}$ of 1.0$)$. The conditions represented by different values of $\mathrm{k}_{\mathrm{eff}}$ are listed in Table 3-1. ADSs operate at a $\mathrm{k}_{\mathrm{eff}}$ of less than 1.0, or in a subcritical condition, and reactors operate at critical, or a $\mathrm{k}_{\mathrm{eff}}$ of 1.0 . 
Table 3-1. Conditions of $\mathrm{k}_{\mathrm{eff}}$

\begin{tabular}{|c|c|}
\hline Value of $\mathrm{k}_{\mathrm{eff}}$ & Condition \\
\hline $\mathrm{k}_{\mathrm{eff}}<1.0$ & Subcritical \\
\hline $\mathrm{k}_{\mathrm{eff}}=1.0$ & Critical \\
\hline $\mathrm{k}_{\mathrm{eff}}>1.0$ & Supercritical \\
\hline
\end{tabular}

MCNP is a valuable tool in that it helps in designing a system to operate at a certain condition. MCNP was developed by personnel at Los Alamos National Laboratory (LANL), serves a large number of government and institutional organizations, and has been well maintained, benchmarked, and updated.

\subsection{2. $M C N P X$}

Three main types of codes are needed to calculate spallation product yields in a material over a period of time. First, a code is required to model the spallation yields that result from a proton (or similar) beam impinging upon a target. Then a transport code (such as MCNP) is needed to transport the resulting particles from the target to the blanket and back. Finally, a decay/buildup code is desired to determine what happens to them as a function of time (both during irradiation and after removal from the system (decay)). One popular code used to model the spallation reaction and its stages is the LAHET Code System (LCS). ${ }^{62}$ Recently MCNP and LCS have been combined to perform charged particle transport for proton beam systems such as an ADS. The name of the combined code is MCNPX, and this code is used to calculate the spallation product inventories presented in this research. ${ }^{61}$ The third calculation that must be performed is for irradiation and/or subsequent decay of the target. CINDER90 is desirable for this 


\section{LA-14052-T}

purpose because it can take the results from MCNPX and a further processing code called HTAPE3X (which comes with MCNPX) and calculate the buildup and decay of spallation products as a function of time. ${ }^{63}$ In this research, Monteburns is used to link MCNPX with CINDER90.

There are several stages to a spallation reaction in MCNPX: intranuclear cascade, preequilibrium, evaporation and/or fission, and final residual deexcitation. ${ }^{61}$ The basis of intranuclear cascade is that a particle (i.e., a proton) incident on a nucleus interacts with individual nucleons, creating a high energy particle cascade (i.e., protons, neutrons, pions leaking from the nucleus), leaving the nucleus in an excited state. Next, the preequilibrium stage accounts for subsequent de-excitation of the residual nucleus after the intranuclear cascade phase. Preequilibrium ends once an equilibrium exciton number is reached, and evaporation (for elements with atomic mass numbers between 18 and 71), Fermi-Breakup (for atomic mass numbers less than or equal to 17), or fission (for atomic numbers greater than 71) takes place next (as modeled in MCNPX). Spallation neutrons are primarily comprised of the low-energy neutrons resulting either from the intranuclear cascade or evaporation phases. Higher energy neutrons can undergo subsequent spallation interactions to create additional spallation neutrons. ${ }^{65}$

Traditional reactor physics calculations have involved the use of lower energy $(<14 \mathrm{MeV})$ neutron physics and cross sections, primarily because thermal neutrons are more likely to be absorbed in nuclei and fission than higher energy ones. However, intermediate and higher energy physics becomes more important when dealing with proton beams and spallation neutron production. The energy of the proton beam is typically on the order of hundreds of $\mathrm{MeV}$ to $\mathrm{GeV}$, and the resulting neutrons have 


\section{LA-14052-T}

energies on that order down to thermal energies (in the eV range). Cross section data has been tabulated and is commonly used for the low energy portions, but this data is neither abundant nor verified in the energy ranges of 20-150 MeV to several GeV. Thus, intermediate energy physics packages must be used instead to calculate fission and spallation product inventories. The intranuclear cascade model CEM2k in MCNPX is used to calculate spallation product inventories in this research.

\subsubsection{Depletion/Decay Codes}

Almost any burnup/depletion code can be used to calculate the results of irradiation (and/or subsequent decay) in an LWR, so it is up to the user to select the code that will yield the most accurate results. ORIGEN2.1 and CINDER90 are both codes that can perform burnup/decay calculations and are linked through Monteburns to MCNP or MCNPX to provide better accuracy for irradiation calculations. ORIGEN2.1 is an isotope generation and depletion code that uses one-group cross sections and fluxes to calculate the concentration of radionuclides as a function of irradiation and/or decay time. ${ }^{59}$ ORIGEN2.1 is not designed to calculate spallation product inventories as a function of irradiation and/or decay (although one can modify it to do so). CINDER90 is a burnup code developed at LANL specifically for unique applications (such as accelerators) because it tracks both fission and spallation products as a function of time. ${ }^{63}$ In addition, it uses multi-group (63-group) fluxes and cross sections instead of the simplified one-group ones used by ORIGEN2.1. Commercial discrete ordinates codes can be used for burnup, but they are expensive and/or difficult to obtain. Thus, Monteburns has been developed to provide detailed system information and perform 
burnup calculations without the large overhead associated with a complex commercial code.

ORIGEN2.1 is a version of the ORIGEN computer code, which is an isotope generation and depletion code used for performing radioactive decay and burnup analyses in a material. ORIGEN2.1 calculates the concentration of nuclides at numerous points throughout a decay or irradiation using primarily the matrix exponential method of equation solving. ORIGEN2.1 treats the full isotopic matrix of materials generated through irradiation by considering time-dependent formulation, destruction, and decay concurrently. Sometimes difficulties occur in generating accurate values using the matrix exponential method, and either the Bateman equations or the Gauss-Seidel iterative technique may be applied. The number of nuclides removed from the transition matrix and processed using the Bateman nuclide chain equations is determined by how many have half-lives (both absorption and fission) less than $10 \%$ of the time interval being investigated. Thus, having a shorter time interval in ORIGEN2.1 allows the Bateman equations to be used in directly solving for the concentrations of a larger number of isotopes. This can be advantageous in that it often allows more accurate results to be obtained but requires more time.

The input required for ORIGEN2.1 consists of three parts: cross section libraries, information about each decay/irradiation step, and initial material compositions. First, ORIGEN2.1 contains over 40 different data sets with one-group cross sections for various energy/system spectra. The user must decide which one to use, and transfer both the ORIGEN2.1 decay library and that cross section library to a file that can be read by ORIGEN2.1. The user must then enter identifiers for these libraries in the main 
ORIGEN2.1 input file. Second, this main ORIGEN2.1 input file must also contain detailed information required to run the code, including the length(s) of each decay and/or irradiation, the flux or power associated with each irradiation, and a description of what output parameters (and units of these parameters) are desired. Finally, the initial composition of the material being irradiated must be entered. This can either be part of the main ORIGEN2.1 input file, or it can be self-contained in its own file (as is done in Monteburns to allow flexibility of material stream processing). ORIGEN2.1 has recently been upgraded to ORIGEN2.2 with minor modifications, but the same files and methodology are used in the new version. The use of ORIGEN2.1 combined with Monteburns for reactor calculations has been proven extensively, and some of this benchmarking is presented in the next section.

CINDER90 similarly solves the set of coupled differential Bateman equations corresponding to depletion and decay for various isotopes using the Markov method. It follows transmutation for chains of isotopes based upon the starting nuclide of the chain. CINDER90 follows over 1300 different nuclides and more metastable states than does ORIGEN2.1, which is why it is used for spallation product calculations in this research. It is not used for reactor calculations at this time because only recently has a version come out that calculates actinide inventories correctly.

CINDER90 requires four to five different input files. These are: a general library file with 63-group cross sections that can be applied to any problem of interest with 63group fluxes, a material file that specifies the atom density and isotopic composition of each material of interest (this may vary depending on whether input concentrations are obtained from a previous run or not), a fluxes file that lists the 63-group fluxes for each 
region of interest in the system, and an input file that specifies the irradiation rate and time. Optional fifth and sixth input files contain information about all the spallation products generated during a given spallation reaction and cross sections, respectively, specific to the problem of interest. Such a file is obtained by running the module HTAPE3X that comes with MCNPX and processes the detailed particle history file “histp" produced during a MCNPX run.

\subsection{Benchmarking}

Monteburns takes the cross sections and fluxes from MCNP or MCNPX and uses them to calculate the concentrations of all relevant isotopes as a function of time (i.e., over a million years) using either ORIGEN2.1 or CINDER90. The benchmarking of Monteburns using the isotope generation and depletion code ORIGEN2.1 was performed in the past for several test cases that modeled LWRs: uranium and plutonium isotopic concentrations as a function of burnup, a simple fuel pin, an infinitely reflected PWR assembly, power distributions of pins in a BWR lattice assembly, and the activity of MOX fuel after it is removed from a reactor. ${ }^{66}$ These benchmarks show fairly close agreement (within 10\%) for most uranium and plutonium isotopes. However, benchmarking is needed for the use of a one-eighth core reactor model (as is used in this research) instead of an infinite assembly, the irradiation of MOX fuel compared to experimental data (both burnup and safety parameters), burnup in an ADS, and/or the use of MCNPX for spallation product inventories. This benchmarking is addressed in this section. 


\subsubsection{Expansion of Previous Benchmarking}

Previous benchmarking efforts were only performed with an infinite assembly of fuel rods. This limited model made it difficult to perform safety calculations with sufficient accuracy to determine if a full core of MOX fuel is safe without representing all assemblies and control/safety rods in a reactor core. Thus, to model the exact effects of fuel with varying burnups during irradiation, a more comprehensive model for an infinitely reflected one-eighth core of a PWR is used with the same assembly design as the previous benchmark (see Fig. 3-2) ${ }^{67}$

The results for this comprehensive model are compared to the previously published results for an infinitely reflected assembly in Table 3-2. A comparison of ORIGEN2.2 to ORIGEN2.1 is also shown for the infinite assembly. Relative error is calculated using Equation 3, while the remaining results are compared with each other.

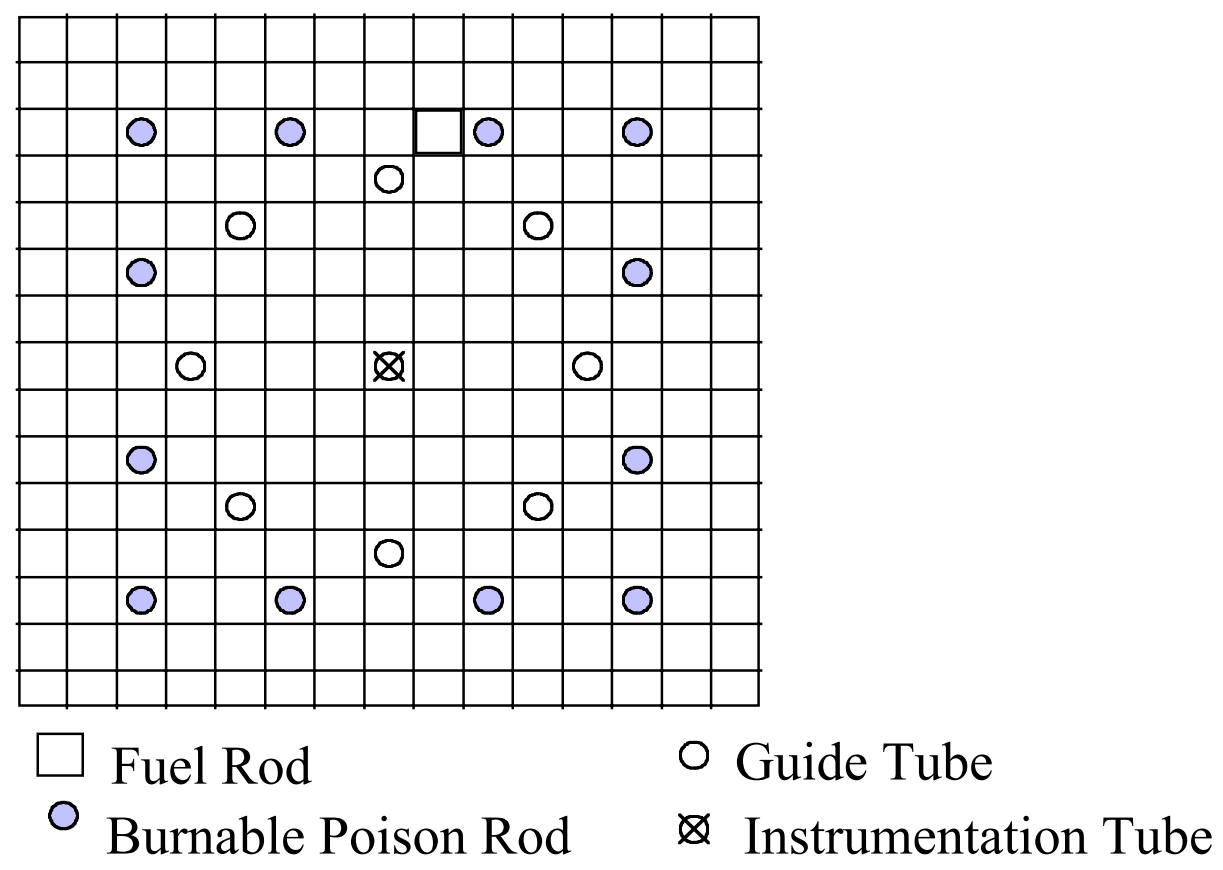

Fig. 3-2. PWR Assembly Design Used in This Research (H. B. Robinson Unit 2) 
$\%$ Error $=($ Calculated $/$ Measured -1$) * 100 \%$

Table 3-2. Benchmark of Monteburns to Experimental Data for PWR Burnup Calculations (Burnup $28.5 \mathrm{GWd} / \mathrm{MT}$ fuel)

\begin{tabular}{|l|c|c|c|c|c|}
\hline Isotope & $\begin{array}{c}\text { Published } \\
\left(\mathrm{g} / \mathrm{g} \mathrm{UO}_{2}\right)\end{array}$ & $\begin{array}{c}\text { One Assembly } \\
\text { w/ORIGEN2.1 }\end{array}$ & \% error & $1 / 8$ Core & $\begin{array}{c}\text { One Assembly } \\
\text { w/ORIGEN2.2 }\end{array}$ \\
\hline${ }^{235} \mathrm{U}$ & 0.00618 & 0.00603 & -2.44 & 0.00603 & 0.00592 \\
\hline${ }^{236} \mathrm{U}$ & 0.00282 & 0.00285 & 1.24 & 0.00280 & 0.00277 \\
\hline${ }^{238} \mathrm{U}$ & 0.834 & 0.838 & 0.54 & 0.841 & 0.840 \\
\hline${ }^{238} \mathrm{Pu}$ & $1.14 \mathrm{E}-04$ & $1.06 \mathrm{E}-04$ & -7.01 & $8.511 \mathrm{e}-5$ & $8.354 \mathrm{e}-5$ \\
\hline${ }^{239} \mathrm{Pu}$ & 0.00439 & 0.00431 & -1.77 & 0.00407 & 0.00417 \\
\hline${ }^{240} \mathrm{Pu}$ & 0.00197 & 0.00199 & 1.14 & 0.00182 & 0.00225 \\
\hline${ }^{241} \mathrm{Pu}$ & $6.81 \mathrm{E}-04$ & $6.49 \mathrm{E}-04$ & -4.72 & $6.74 \mathrm{e}-4$ & $5.47 \mathrm{e}-4$ \\
\hline${ }^{237} \mathrm{~Np}$ & $3.04 \mathrm{E}-04$ & $3.11 \mathrm{E}-04$ & 2.45 & $2.70-4$ & $2.99 \mathrm{e}-4$ \\
\hline
\end{tabular}

Using a one-eighth core model does not yield any more or less accuracy than an infinitely reflected assembly (i.e., it is better for some isotopes and worse for others), so it is apparent that either one will work for further calculations. Additionally, the variances observed from measured values when ORIGEN2.2 is used instead of ORIGEN2.1 are, as a general rule, not significantly different. ORIGEN2.1 is used for the results given in this paper.

\subsubsection{MOX Fuel}

Two different types of benchmarks for MOX fuel are performed: benchmarks to other codes, and benchmarks to experimental data. Both types of benchmarks are 
important in determining how well Monteburns performs irradiation calculations for MOX fuel.

\subsubsection{Benchmarks for MOX Fuel Irradiation to Other Codes}

There is a limited amount of experimental data available for MOX fuel irradiation; thus, the Europeans developed a set of benchmark problems involving reactor physics that simulate irradiation calculations for multiple recycles of MOX fuel. ${ }^{68}$ The purpose of the Organization for Economic Co-operation and Development (OECD) exercise was to compare results obtained by well-known neutronics/burnup codes for MOX fuel in several different types of reactors using different isotopic compositions of plutonium (corresponding to different recycles). The results obtained from the different codes are not as close as was desired, but they indicate that existing codes and nuclear data can indeed be used for calculations involving multiple recycling of plutonium. ${ }^{69}$ By simulating PWR irradiation with Monteburns, several benchmarks of the code for MOX fuel calculations have been performed. Although these benchmarks do not directly compare Monteburns results to experimental data, they do represent a valid test of the data and techniques used by Monteburns for problems involving multi-recycling of MOX. There are three different problems in these exercises applicable to PWRs: 1) a pin-cell irradiation with poor quality plutonium (recycled five times or "fifth generation"), 2) a pin-cell irradiation with good quality plutonium (i.e., obtained directly from spent nuclear fuel or "first generation"), and 3) an exercise calculating void reactivity effects. 


\subsection{Pin-Cell with Poor Quality Plutonium}

The first problem uses poor quality plutonium in an infinitely reflected pin of MOX fuel surrounded by water and irradiated to $50 \mathrm{MWd} / \mathrm{kg}$. The results using Monteburns compared to the range of values calculated by other codes are given in Table 3-3 for three different default ORIGEN2.1 cross section libraries, orig23, orig24, and orig32, each of which is described shortly.

Table 3-3. Poor Quality Plutonium

$($ Error $\sim+/-0.002)$

\begin{tabular}{|c|c|c|c|c|}
\hline $\begin{array}{c}\text { Burnup } \\
(\mathrm{GWd} / \mathrm{MT})\end{array}$ & $\begin{array}{c}\text { Published } \mathrm{k}_{\infty} \\
\text { range }\end{array}$ & $\begin{array}{l}\mathrm{k}_{\infty} \text { using } \\
\text { orig23 }\end{array}$ & $\begin{array}{l}\mathrm{k}_{\infty} \text { using } \\
\text { orig24 }\end{array}$ & $\begin{array}{l}\mathrm{k}_{\infty} \text { using } \\
\text { orig32 }\end{array}$ \\
\hline 0 & 1.1043 to 1.1396 & 1.1325 & 1.1313 & 1.1325 \\
\hline 10 & 1.0398 to 1.0777 & 1.0784 & 1.0692 & 1.0697 \\
\hline 33 & 0.9645 to 1.0081 & 1.0132 & 0.9961 & 1.0017 \\
\hline 42 & 0.9405 to 0.9833 & 0.9947 & 0.9819 & 0.9855 \\
\hline 50 & 0.9208 to 0.9641 & 0.9820 & 0.9569 & 0.9640 \\
\hline
\end{tabular}

This calculation shows that the accuracy of the results does indeed depend on the choice of default ORIGEN2.1 cross section library in Monteburns. When the library designed for $\mathrm{UO}_{2}$ fuel in a partial-MOX-burning reactor (orig23) is used, the resulting $\mathrm{k}_{\infty}$ is larger than the range of values calculated by other codes in the plutonium recycle exercise at all non-zero burnup steps. However, when the MOX-based plutonium recycle library for PWRs is used (orig24), $\mathrm{k}_{\infty}$ falls within the published range for all steps. In addition, when the plutonium recycle library for BWRs (orig32) is used (for comparison), the end-of-cycle calculated value of $\mathrm{k}_{\infty}$ falls within the range calculated by other codes, 
but one of the intermediate calculations does not. This exercise shows that using the library that best simulates the problem is important and that Monteburns can be used to calculate burnup correctly for plutonium that has been recycled multiple times with an accurate default cross section library for ORIGEN2.1. The MOX-based plutonium recycle library (orig24) for PWRs is used for all subsequent calculations unless otherwise noted.

\subsection{Pin Cell with Good Quality Plutonium}

The second benchmark to data from other codes is for better-quality, firstgeneration plutonium. All the results are again within the published range for this plutonium stream (see Table 3-4), which means that Monteburns results for basic plutonium recycle and irradiation as MOX fuel in a PWR are comparable to those from other codes.

In these OEDC benchmarks, it is specified that a number of fission products should be tracked: ${ }^{95} \mathrm{Zr},{ }^{95} \mathrm{Mo},{ }^{106} \mathrm{Pd},{ }^{144} \mathrm{Ce},{ }^{147} \mathrm{Pm},{ }^{148} \mathrm{Pm},{ }^{148 \mathrm{~m}} \mathrm{Pm},{ }^{149} \mathrm{Sm},{ }^{150} \mathrm{Sm},{ }^{151} \mathrm{Sm}$, ${ }^{152} \mathrm{Sm},{ }^{153} \mathrm{Eu},{ }^{154} \mathrm{Eu},{ }^{155} \mathrm{Eu},{ }^{155} \mathrm{Gd},{ }^{156} \mathrm{Gd},{ }^{157} \mathrm{Gd},{ }^{99} \mathrm{Tc},{ }^{109} \mathrm{Ag},{ }^{113} \mathrm{Cd},{ }^{115} \mathrm{In},{ }^{129} \mathrm{I},{ }^{131} \mathrm{Xe},{ }^{131} \mathrm{Cs}$,

Table 3-4. Better Quality Plutonium

\begin{tabular}{|c|c|c|}
\hline $\begin{array}{c}\text { Burnup } \\
(\mathrm{GWd} / \mathrm{MT})\end{array}$ & Published $\mathrm{k}_{\infty}$ range & $\begin{array}{c}\mathrm{k}_{\infty} \text { using orig24 } \\
\text { (error } \sim+/-0.002)\end{array}$ \\
\hline 0 & 1.1744 to 1.1926 & 1.1821 \\
\hline 10 & 1.0824 to 1.1026 & 1.0861 \\
\hline 33 & 0.9730 to 0.9956 & 0.9890 \\
\hline 42 & 0.9367 to 0.9604 & 0.9535 \\
\hline 50 & 0.9070 to 0.9312 & 0.9254 \\
\hline
\end{tabular}


${ }^{137} \mathrm{Cs},{ }^{143} \mathrm{Nd},{ }^{145} \mathrm{Nd},{ }^{148} \mathrm{Nd}$, and four additional fission product groups into which the remaining fission products are combined. The Monteburns benchmark calculations are performed with most of the isotopes listed above except that MCNP-compatible cross sections do not exist for three of the isotopes included by the other codes $\left({ }^{115} \mathrm{In},{ }^{148 \mathrm{~m}} \mathrm{Pm}\right.$, and ${ }^{131} \mathrm{Cs}$ ), so they are neglected. Such neglect could be one of the reasons that $\mathrm{k}_{\infty}$ is still on the high side of the range of values reported. Calculational results with both ENDFBVI and JEF2.2 cross sections processed into MCNP-compatible temperature-dependent cross sections using the code NJOY are compared in Table 3-5. Most burnup calculations performed in the U.S. (and the ones performed in this research) are performed with ENDFB-VI cross section libraries although most of the cross sections used in the OEDC study were JEF2.2, which is why they are included here.

Table 3-5. Fission Product and Cross Section Sensitivities

\begin{tabular}{|c|c|c|c|c|}
\hline $\begin{array}{c}\text { Burnup } \\
(\mathrm{GWd} / \mathrm{MT}) \\
\text { for poor } \\
\text { quality } \mathrm{Pu}\end{array}$ & $\begin{array}{c}\mathrm{k}_{\infty} \text { using only } \\
\text { temperature- } \\
\text { dependent cross } \\
\text { sections for all FPs } \\
\text { with an importance } \\
\text { fraction of } 0.00001 \\
\text { using ENDFB-VI } \\
\text { libraries } \\
\text { (error } \sim+/-0.0007 \text { ) }\end{array}$ & $\begin{array}{c}\mathrm{k}_{\infty} \text { using only } \\
\text { temperature- } \\
\text { dependent cross } \\
\text { sections for an } \\
\text { importance } \\
\text { fraction of } \\
0.0001 \\
\text { (error } \sim+/- \\
0.0007)\end{array}$ & $\begin{array}{c}\mathrm{K}_{\infty} \text { using } \\
\text { temperature- } \\
\text { dependent } \\
\text { cross sections } \\
\text { for only } \\
\text { "important" } \\
\text { FPs } \\
\text { (error } \sim+/- \\
0.002)\end{array}$ & $\begin{array}{c}\mathrm{k}_{\infty} \text { using } \\
\text { temperature- } \\
\text { dependent } \\
\text { cross sections } \\
\text { for all FPs } \\
\text { using JEF-2.2 } \\
\text { libraries } \\
\text { (error } \sim+/- \\
0.002)\end{array}$ \\
\hline 0 & 1.1344 & 1.1344 & 1.1344 & 1.1313 \\
\hline 10 & 1.0716 & 1.0713 & 1.0725 & 1.0692 \\
\hline 33 & 1.0027 & 1.0022 & 1.0047 & 0.9961 \\
\hline 42 & 0.9817 & 0.9808 & 0.9821 & 0.9819 \\
\hline 50 & 0.9629 & 0.9638 & 0.9675 & 0.9569 \\
\hline
\end{tabular}


Another important parameter that must be determined when using Monteburns is how many fission products should be tracked, and of those tracked, how many beyond the ones defined in the problem should be associated with temperature-dependent cross section libraries. The importance fraction in Monteburns represents how much an isotope may contribute to absorption, fission, mass, or atom fraction before its cross section is calculated each step with MCNP. When the first benchmark case (for poor quality plutonium) is run with an importance fraction of 0.0001 , the ending $k_{\infty}$ is $\sim 0.9638+/-$ 0.0007 , but when run with an importance fraction of 0.00001 , the resulting $\mathrm{k}_{\infty}$ is $\sim 0.9629$ +/- 0.0007 (see Table 3-5). Both ending values fall into the range calculated by the other codes, but the 0.00001 case includes a few more fission products and actinides and falls more easily into the range of those calculated by other codes (especially when JEF2.2 libraries and an importance fraction of 0.00001 are used). Thus, the MOX fuel calculations performed in this research use an importance fraction of 0.00001 .

Additionally, one run of Monteburns only included temperature-dependent cross sections for those fission products explicitly tracked (i.e., the list above), not others that are built up and deemed "important". The comparisons are again in Table 3-5. Although the differences are not large, $\mathrm{k}_{\infty}$ is, on average, smaller when more temperature-dependent cross section libraries are used and falls into the range of calculated values for the final burnup step whereas the case run with the exclusion of a few fission products does not. Thus, temperature-dependent cross section libraries have been generated for all fission products deemed "important" in this study and used for the MOX fuel calculations performed in this research. 


\subsection{Void Reactivity Coefficient}

The final problem addresses the calculation of void reactivity coefficients for neutronic safety calculations of MOX fuel. The void reactivity coefficient represents the change in multiplication with a decrease in the amount of water (moderator) in the system. The two geometries proposed for the void coefficient problems analyzed here are that of an infinitely reflected pincell (consisting of a fuel rod surrounded by water) and that of a macrocell consisting of an outer zone of $\mathrm{UO}_{2}$ fuel and an inner zone comprised of either $\mathrm{UO}_{2}$ or $\mathrm{MOX}$ fuel with one of three different plutonium compositions (corresponding to $\mathrm{H}, \mathrm{M}$, and $\mathrm{L}$, which is a high, medium and low plutonium enrichment respectively within the MOX). Each case is analyzed both fully moderated and voided in the inner region. The difference in $\mathrm{k}_{\infty}$ between the moderated and voided cases using MCNP is compared to the results calculated by other codes in Table 3-6 (Monteburns is not used here because there is no burnup involved).

ENDFB-VI libraries were not available when the OECD study was performed, and a majority of the codes used ENDFB-V data libraries for this benchmark. In this research, benchmarking is performed using both libraries to show that 1) results using the old data are comparable to those calculated by other codes, and 2) using the new data for calculations does indeed make a difference. The results obtained using ENDFB-V data are within the range of calculated values for both the pin and macrocell geometries (except for the pincell $\mathrm{UO}_{2}$ case which is considered an anomaly), showing that the data and technique for calculating void reactivity coefficient in this research is sufficient for further safety analyses. However, the results using ENDFB-VI data are slightly outside 
the range for the MOX cases in the pincell geometry. Because it is the most recent, the ENDFB-VI data library is used for the remainder of the calculations in this research.

Table 3-6. Delta $\mathrm{k}_{\infty}$ (Reactivity Change) between Moderated and Voided Cases (Calculated Error +/- 0.0006)

\begin{tabular}{|c|c|c|c|}
\hline $\begin{array}{c}\text { Fuel } \\
\text { Type }\end{array}$ & Pincell (published) & $\begin{array}{c}\text { Pincell (calculated) } \\
\text { w/ENDF-V }\end{array}$ & $\begin{array}{c}\text { Pincell (calculated) } \\
\text { w/ENDF-VI }\end{array}$ \\
\hline $\mathrm{UO}_{2}$ & -0.7246 to -0.7436 & -0.7610 & -0.7315 \\
\hline $\mathrm{H}-\mathrm{MOX}$ & 0.0500 to 0.0768 & 0.0562 & 0.0809 \\
\hline M-MOX & -0.1233 to -0.1901 & -0.1489 & -0.1197 \\
\hline L-MOX & -0.3709 to -0.4456 & -0.3978 & -0.3702 \\
\hline \hline Fuel & Macrocell (published) & Macrocell (calculated) & Macrocell (calculated) \\
Type & & w/ENDF-V & w/ENDF-VI \\
\hline UO 2 & -0.0138 to -0.0164 & -0.0145 & 0.01455 \\
\hline H-MOX & 0.0004 to 0.0067 & 0.0042 & 0.00568 \\
\hline M-MOX & -0.0005 to 0.0057 & 0.0042 & 0.0002 \\
\hline L-MOX & -0.0043 to 0.0026 & 0.0017 & \\
\hline
\end{tabular}

\subsubsection{MOX Fuel Benchmarks to Experimental Data}

Along with the OEDC benchmark study on multi-recycling of plutonium, two other benchmarks are performed with measured (experimental) MOX fuel data. One is associated with a low burnup, and the other is a more comprehensive model that calculates MOX fuel irradiation to a higher burnup.

\subsubsection{Low Burnup MOX Fuel}

The first set of experimental data is for the San Onofre PWR, which burned MOX fuel samples in the 1970 s to low burnups $(\sim 20 \mathrm{GWd} / \mathrm{MTHM}) .{ }^{70}$ Data for one assembly is 
given in the reference, and using an infinitely reflected assembly model, the burnup of the sample is calculated using Monteburns. The resulting isotopic compositions are decayed for the appropriate cooling time to be comparable to the measured results. The differences in composition between the measured and calculated data (using Monteburns) for sample 079 are given in Table 3-7 using the two different default ORIGEN2.1 PWR cross section libraries examined in the previous problem, orig23 and orig24.

Table 3-7. Benchmark of Monteburns to Experimental MOX Data

\begin{tabular}{|c|c|c|c|c|c|}
\hline Isotope & $\begin{array}{c}\text { Measured } \\
(\mathrm{mg} / \mathrm{gHM})\end{array}$ & $\begin{array}{c}\text { Calculated } \\
\text { values with } \\
\text { orig23 }\end{array}$ & $\begin{array}{c}\text { Calculated } \\
\text { values with } \\
\text { orig24 }\end{array}$ & $\begin{array}{c}\text { \%error } \\
\text { w/orig23 }\end{array}$ & $\begin{array}{c}\text { \%error } \\
\text { w/orig24 }\end{array}$ \\
\hline${ }^{235} \mathrm{U}$ & 4.400 & 4.544 & 4.550 & 3.27 & 3.40 \\
\hline${ }^{236} \mathrm{U}$ & 0.489 & 0.480 & 0.482 & -1.92 & -1.32 \\
\hline${ }^{238} \mathrm{U}$ & 943.2 & 941.5 & 941.5 & -0.18 & -0.18 \\
\hline${ }^{238} \mathrm{Pu}$ & 0.282 & 0.087 & 0.087 & -69.11 & -69.32 \\
\hline${ }^{239} \mathrm{Pu}$ & 16.49 & 17.25 & 17.31 & 4.62 & 4.97 \\
\hline${ }^{240} \mathrm{Pu}$ & 7.677 & 7.661 & 7.661 & -0.21 & -0.21 \\
\hline${ }^{241} \mathrm{Pu}$ & 3.656 & 3.877 & 3.865 & 6.05 & 5.73 \\
\hline${ }^{242} \mathrm{Pu}$ & 0.897 & 0.854 & 0.854 & -4.79 & -4.79 \\
\hline${ }^{148} \mathrm{Nd}$ & 0.227 & 0.234 & 0.234 & 3.04 & 3.04 \\
\hline
\end{tabular}

The percent error seen for most of the isotopes is less than $5 \%$ but is much greater (i.e., almost $70 \%$ ) for ${ }^{238} \mathrm{Pu}$ for both libraries. Because that large an error is not seen in Monteburns for the other MOX fuel benchmarks, it is assumed that the measured, not the calculated, data is incorrect. Performance is slightly better using the library orig24, so again, it is chosen for the remainder of the MOX fuel calculations in this research. 


\subsubsection{High Burnup MOX Fuel}

Additionally, as part of this dissertation, a comprehensive benchmark of Monteburns has been performed for high burnup irradiation of MOX fuel in a PWR. The ARIANE (Actinides Research In A Nuclear Element) project was initiated by Belgonucleaire with cooperation from nuclear organizations across the world to address irradiation properties of plutonium and higher actinides built into MOX fuel in a true reactor environment. ${ }^{71}$ A detailed irradiation history is provided for the system, including power and temperature profiles, water density, and boron concentrations at 93 separate irradiation and cooling steps. The two fuel samples actually comprise only 7.2 and 3.8 $\mathrm{cm}$ each of a $302.3 \mathrm{~cm}$ fuel rod. This rod is modeled in an infinitely reflected assembly model with extensive axial detail in the fuel rod and the rods surrounding it (16 and 12 regions respectively). The differences between the burnups calculated by Monteburns for the three-dimensional model and those measured are only $2.83 \%$ and $4.62 \%$ for each segment respectively. The variances in isotopic concentrations for the more highly burned segment between the calculated and measured values are, for the most part, also in close agreement (see Table 3-8). Results are also compared to the $2 \sigma$ errors associated with the measurements.

One of the largest differences is seen for ${ }^{239} \mathrm{Pu}$. The cause of this error is that too much depletion of ${ }^{238} \mathrm{U}$ occurs, leading to a large accumulation of ${ }^{239} \mathrm{Pu}(0.11$ grams too much of ${ }^{238} \mathrm{U}$ depleted and 0.07 grams too much of ${ }^{239} \mathrm{Pu}$ built up). The large absorption cross section of ${ }^{238} \mathrm{U}$ can be attributed to: 1) the spectrum for the infinitely reflected assembly is not at critical throughout the cycle, and although Monteburns corrects for 


\section{LA-14052-T}

Table 3-8. Benchmark Results Using a Comprehensive Three-Dimensional Model for Irradiation of MOX Fuel to High Burnup ( $55 \mathrm{GWd} / \mathrm{MTHM})$

\begin{tabular}{|c|c|c|c|c|c|}
\hline Isotope & $\%$ error & $\begin{array}{c}\text { Experimental. } 2 \sigma \\
\text { error }\end{array}$ & Isotope & $\%$ error & $\begin{array}{c}\text { Experimental } \\
2 \sigma \text { error }\end{array}$ \\
\hline${ }^{234} \mathrm{U}$ & $-0.39 \%$ & $9.19 \%$ & ${ }^{147} \mathrm{Pm}$ & $1.75 \%$ & $14.89 \%$ \\
\hline${ }^{235} \mathrm{U}$ & $0.87 \%$ & $2.05 \%$ & ${ }^{147} \mathrm{Sm}$ & $6.06 \%$ & $1.34 \%$ \\
\hline${ }^{236} \mathrm{U}$ & $-5.67 \%$ & $4.54 \%$ & ${ }^{148} \mathrm{Sm}$ & $-4.07 \%$ & $1.09 \%$ \\
\hline${ }^{238} \mathrm{U}$ & $-0.27 \%$ & $0.45 \%$ & ${ }^{149} \mathrm{Sm}$ & $14.21 \%$ & $6.17 \%$ \\
\hline${ }^{237} \mathrm{~Np}$ & $-4.19 \%$ & $0.43 \%$ & ${ }^{150} \mathrm{Sm}$ & $1.66 \%$ & $1.15 \%$ \\
\hline${ }^{238} \mathrm{Pu}$ & $-5.36 \%$ & $3.05 \%$ & ${ }^{151} \mathrm{Sm}$ & $3.67 \%$ & $1.54 \%$ \\
\hline${ }^{239} \mathrm{Pu}$ & $13.86 \%$ & $0.57 \%$ & ${ }^{152} \mathrm{Sm}$ & $2.47 \%$ & $1.27 \%$ \\
\hline${ }^{240} \mathrm{Pu}$ & $-4.04 \%$ & $0.57 \%$ & ${ }^{154} \mathrm{Sm}$ & $1.51 \%$ & $1.46 \%$ \\
\hline${ }^{241} \mathrm{Pu}$ & $-9.33 \%$ & $0.57 \%$ & ${ }^{151} \mathrm{Eu}$ & $-24.36 \%$ & $2.06 \%$ \\
\hline${ }^{242} \mathrm{Pu}$ & $-9.26 \%$ & $0.57 \%$ & ${ }^{153} \mathrm{Eu}$ & $-3.83 \%$ & $0.63 \%$ \\
\hline${ }^{244} \mathrm{Pu}$ & $-44.11 \%$ & $50.00 \%$ & ${ }^{154} \mathrm{Eu}$ & $18.81 \%$ & $2.77 \%$ \\
\hline${ }^{241} \mathrm{Am}$ & $27.47 \%$ & $2.79 \%$ & ${ }^{155} \mathrm{Eu}$ & $-33.73 \%$ & $6.80 \%$ \\
\hline${ }^{242 \mathrm{~m}} \mathrm{Am}$ & $-0.25 \%$ & $4.76 \%$ & ${ }^{155} \mathrm{Gd}$ & $-32.87 \%$ & $4.45 \%$ \\
\hline${ }^{243} \mathrm{Am}$ & $10.77 \%$ & $2.84 \%$ & ${ }^{90} \mathrm{Sr}$ & $-1.24 \%$ & $13.54 \%$ \\
\hline${ }^{242} \mathrm{Cm}$ & $0.71 \%$ & $3.46 \%$ & ${ }^{95} \mathrm{Mo}$ & $-2.88 \%$ & $3.61 \%$ \\
\hline${ }^{243} \mathrm{Cm}$ & $-24.87 \%$ & $10.60 \%$ & ${ }^{99} \mathrm{Tc}$ & $5.33 \%$ & $4.42 \%$ \\
\hline${ }^{244} \mathrm{Cm}$ & $-0.48 \%$ & $3.61 \%$ & ${ }^{101} \mathrm{Ru}$ & $12.59 \%$ & $10.20 \%$ \\
\hline${ }^{245} \mathrm{Cm}$ & $-3.15 \%$ & $3.41 \%$ & ${ }^{106} \mathrm{Ru}$ & $-84.92 \%$ & $11.96 \%$ \\
\hline${ }^{246} \mathrm{Cm}$ & $-18.11 \%$ & $4.68 \%$ & ${ }^{103} \mathrm{Rh}$ & $12.04 \%$ & $6.28 \%$ \\
\hline${ }^{144} \mathrm{Ce}$ & $13.56 \%$ & $26.12 \%$ & ${ }^{109} \mathrm{Ag}$ & $83.78 \%$ & $11.49 \%$ \\
\hline${ }^{142} \mathrm{Nd}$ & $8.46 \%$ & $7.03 \%$ & ${ }^{125} \mathrm{Sb}$ & $27.50 \%$ & $5.64 \%$ \\
\hline${ }^{143} \mathrm{Nd}$ & $3.41 \%$ & $0.56 \%$ & ${ }^{129} \mathrm{I}$ & $68.51 \%$ & $11.24 \%$ \\
\hline${ }^{144} \mathrm{Nd}$ & $-0.58 \%$ & $0.56 \%$ & ${ }^{133} \mathrm{Cs}$ & $3.28 \%$ & $2.14 \%$ \\
\hline${ }^{145} \mathrm{Nd}$ & $1.19 \%$ & $0.56 \%$ & ${ }^{134} \mathrm{Cs}$ & $-4.56 \%$ & $3.25 \%$ \\
\hline${ }^{146} \mathrm{Nd}$ & $1.95 \%$ & $0.56 \%$ & ${ }^{135} \mathrm{Cs}$ & $-0.29 \%$ & $2.09 \%$ \\
\hline${ }^{148} \mathrm{Nd}$ & $2.99 \%$ & $0.56 \%$ & ${ }^{137} \mathrm{Cs}$ & $-2.17 \%$ & $3.05 \%$ \\
\hline${ }^{150} \mathrm{Nd}$ & $3.21 \%$ & $0.58 \%$ & - & - & - \\
\hline
\end{tabular}


variances in $\mathrm{k}_{\mathrm{eff}}$ from 1.0 , it does not adjust the spectrum appropriately; 2) the error associated with cross section calculations in Monteburns is still around 10\%, so statistics may still be affecting the results; and 3) errors either in the ENDFB-VI cross section used in the calculations or in the way the code NJOY has been run to get temperaturedependent cross sections for each burn step.

The MCNPX calculations in Monteburns were performed using 50 active cycles with 50,000 starting neutron histories per cycle and a continuously updated source file. To achieve reasonable execution times, the simulation was carried out in parallel on a LINUX cluster at PSI using PVM Version 3.3 and fifteen $1.4 \mathrm{GHz}$ processors. Even with these systems, the run still took about one week to complete. Increasing accuracy (to $<10 \%$ ) is an option for future runs but would require a significant increase in computer run-time.

The comparison of calculated and measured results for most minor actinides and fission products show agreement within 5\%. These include key burnup indicators like $\mathrm{Nd}$ and Cs and most of the strongly absorbing Sm isotopes. However, significant deviations are observed for some minor actinides $\left({ }^{241} \mathrm{Am}\right.$ and $\left.{ }^{246} \mathrm{Cm}\right)$, other strong neutron absorbers (Eu and $\mathrm{Gd}$ ), and other fission products $\left({ }^{106} \mathrm{Ru},{ }^{109} \mathrm{Ag}\right.$, and $\left.{ }^{129} \mathrm{I}\right)$. Nonetheless, as a whole the results obtained using the detailed burnup history and Monteburns are found to be more accurate than the results from either CASMO-4 or BOXER, well known 2-D discrete ordinates burnup codes. 


\subsection{3. $A D S$}

Experimental benchmarks have not been performed for ADS irradiation calculations using Monteburns in systems containing a significant fraction of minor actinides because the experimental data does not exist. Instead, as a calculational benchmark, results from Monteburns are compared to calculations with the codes DIF3D/REBUS3 at ANL for a representative ADS proposed for transmutation of SNF (see Fig. 3-3). ${ }^{3}$ This particular ADS design irradiates all plutonium and minor actinides from SNF (i.e., assumes no use of a Tier 1).

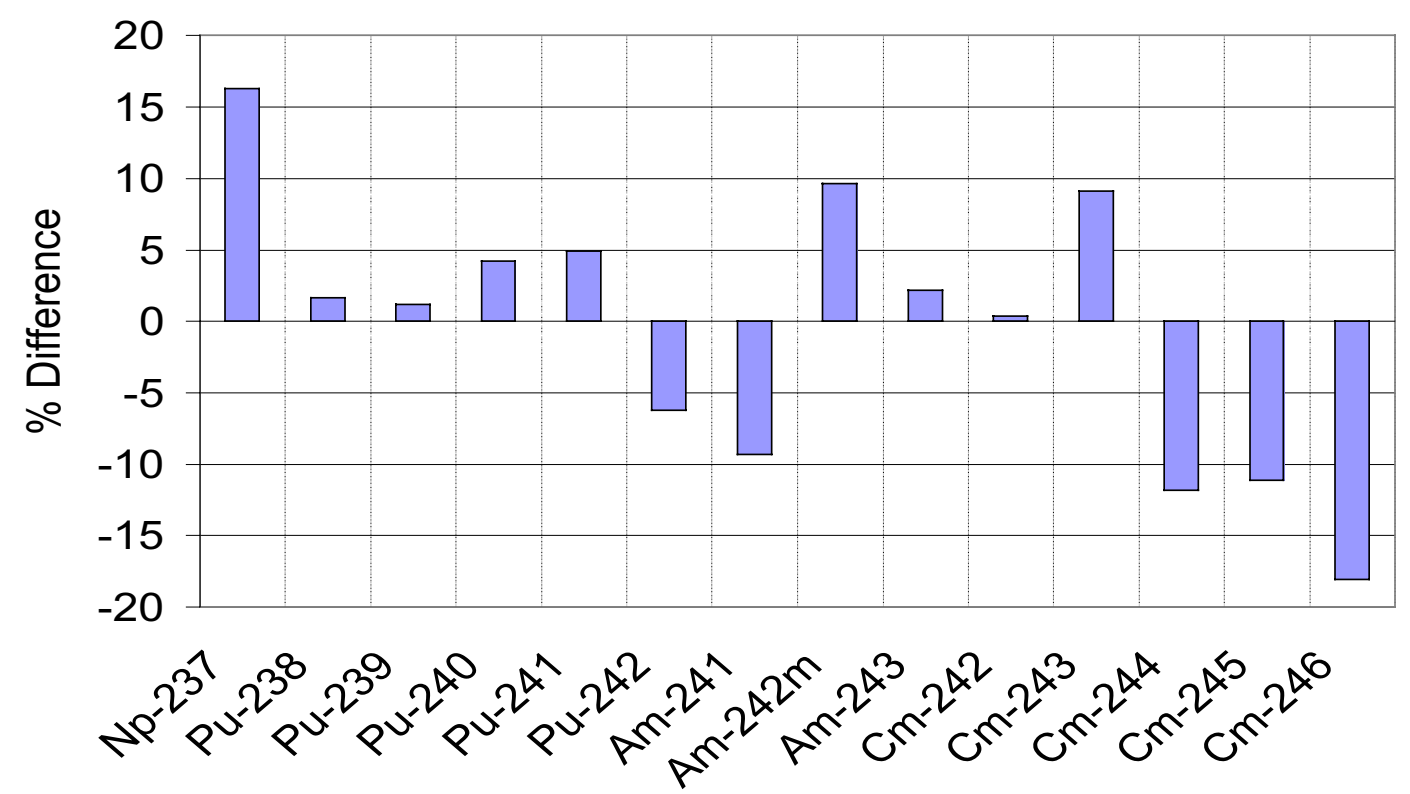

Fig. 3-3. Comparison of Monteburns and REBUS3 Results for an Accelerator-Driven Transmutation System

There are three main reasons for the differences in results. First, the solution methods used for each of the calculations are different. However, this is just a function of using two different burnup codes. Second, REBUS3 uses an equilibrium system model in which the same amount of material is added and burned each cycle, and 
Monteburns models the system from the first cycle as it builds up to a near-equilibrium state. Finally, with the uncertainty associated with cross sections of minor actinides (which also varied between the codes), the differences seen in this comparison ( $\sim 5$ to $\sim 30 \%$ for most isotopes) are not considered to be significant. Fission product yields may also have varied between the two codes, contributing to the results.

\subsubsection{Spallation Product Generation with MCNPX}

MCNPX has been developed from both MCNP and the LAHET Code System (LCS). MCNP is currently used worldwide and has been benchmarked extensively. LCS has been validated with experimental data both with and without the subsequent use of CINDER90 for depletion and buildup at both high and low energies. ${ }^{72}$ The CEM2k and other modules within MCNPX have also been benchmarked for spallation product generation. ${ }^{73}$ As part of this research, the combination of MCNPX and CINDER90 in the form of Monteburns is further benchmarked for spallation product generation. In particular, Monteburns is used to simulate spallation product generation in a past experiment at LANSCE at LANL. ${ }^{74}$ This experiment involved the irradiation of several lead and tungsten foils by a high energy $(800 \mathrm{MeV})$ proton beam, spallation, and then decay of the resulting products from the point at which the beam stopped and they were removed until they could be measured. The results calculated are for the lead foil in position 4A, associated with an irradiation time of about 45 minutes and a decay time of 5 minutes. $^{75}$ The results obtained in this benchmark do not always correspond with the experimental ones, but they are, however, typically close to results using LAHET and CINDER90 in a previous calculation. The spallation products yields calculated from the CEM2k module in MCNPX are presented in Table 3-9 for the end of irradiation (i.e., no 
decay time) as are the measured results. The measurement values in bold are distinguished because they represent "independent" rather than "cumulative" yields. The agreement for most isotopes is fairly good, with the differences being a result of inaccuracies either in the modeling technique (i.e., spallation product yield) or the measurement technique and decay assumptions applied to the measured results (which are not clear in the literature).

Table 3-9. Results from Spallation (and Fission) Product Benchmark at High Energies for Sample 4A [Units Are (n/cc/proton)]

\begin{tabular}{|c|c|c|c|c|c|c|c|}
\hline Isotope & Calculated & Measured & $\begin{array}{l}\text { Previous } \\
\text { LAHET }\end{array}$ & Isotope & Calculated & Measured & $\begin{array}{l}\text { Previous } \\
\text { LAHET }\end{array}$ \\
\hline${ }^{82} \mathrm{Br}$ & $4.28 \mathrm{E}-06$ & $1.42 \mathrm{E}-05$ & $4.18 \mathrm{E}-06$ & ${ }^{190} \mathrm{Hg}$ & $1.26 \mathrm{E}-04$ & $2.86 \mathrm{E}-04$ & $1.04 \mathrm{E}-04$ \\
\hline${ }^{87} \mathrm{Y}$ & $1.11 \mathrm{E}-05$ & $1.21 \mathrm{E}-05$ & $6.13 \mathrm{E}-06$ & ${ }^{191} \mathrm{Pt}$ & $2.00 \mathrm{E}-05$ & $3.21 \mathrm{E}-04$ & $1.29 \mathrm{E}-05$ \\
\hline${ }^{89} \mathrm{Zr}$ & $9.12 \mathrm{E}-06$ & $1.01 \mathrm{E}-05$ & $1.03 \mathrm{E}-05$ & ${ }^{191} \mathrm{Hg}$ & $2.16 \mathrm{E}-04$ & $1.98 \mathrm{E}-04$ & $9.48 \mathrm{E}-04$ \\
\hline${ }^{96} \mathrm{Tc}$ & $2.15 \mathrm{E}-06$ & $6.22 \mathrm{E}-06$ & 5.09E-06 & ${ }^{192} \mathrm{Hg}$ & $2.35 \mathrm{E}-04$ & $5.51 \mathrm{E}-05$ & $7.77 \mathrm{E}-05$ \\
\hline${ }^{121} \mathrm{Te}$ & $2.52 \mathrm{E}-06$ & $2.52 \mathrm{E}-06$ & $1.57 \mathrm{E}-06$ & ${ }^{193} \mathrm{Hg}$ & $1.74 \mathrm{E}-04$ & 1.19E-04 & $1.01 \mathrm{E}-04$ \\
\hline${ }^{127} \mathrm{Xe}$ & $7.11 \mathrm{E}-08$ & $3.43 \mathrm{E}-06$ & $6.53 \mathrm{E}-07$ & ${ }^{193} \mathrm{~Pb}$ & $1.38 \mathrm{E}-05$ & $9.63 \mathrm{E}-05$ & $1.95 \mathrm{E}-05$ \\
\hline${ }^{169} \mathrm{Lu}$ & $4.03 \mathrm{E}-05$ & $3.56 \mathrm{E}-05$ & $2.56 \mathrm{E}-05$ & ${ }^{194} \mathrm{Au}$ & $2.89 \mathrm{E}-05$ & 5.22E-05 & $1.91 \mathrm{E}-05$ \\
\hline${ }^{170} \mathrm{Lu}$ & $4.44 \mathrm{E}-07$ & 4.19E-05 & $1.28 \mathrm{E}-05$ & ${ }^{195} \mathrm{Hg}$ & $1.48 \mathrm{E}-04$ & $9.40 \mathrm{E}-05$ & $8.20 \mathrm{E}-05$ \\
\hline${ }^{170} \mathrm{Hf}$ & $3.34 \mathrm{E}-05$ & $6.58 \mathrm{E}-06$ & $3.32 \mathrm{E}-05$ & ${ }^{196} \mathrm{Au}$ & $1.69 \mathrm{E}-05$ & $2.44 E-05$ & $7.70 \mathrm{E}-06$ \\
\hline${ }^{171} \mathrm{Lu}$ & $7.07 \mathrm{E}-07$ & $6.21 \mathrm{E}-05$ & $1.10 \mathrm{E}-05$ & ${ }^{198} \mathrm{Tl}$ & $2.03 \mathrm{E}-04$ & $4.57 \mathrm{E}-04$ & $1.04 \mathrm{E}-04$ \\
\hline${ }^{175} \mathrm{Ta}$ & $1.68 \mathrm{E}-05$ & $1.01 \mathrm{E}-04$ & $1.59 \mathrm{E}-05$ & ${ }^{199} \mathrm{Tl}$ & $1.68 \mathrm{E}-04$ & $3.84 \mathrm{E}-04$ & $1.28 \mathrm{E}-04$ \\
\hline${ }^{176} \mathrm{Ta}$ & $1.07 \mathrm{E}-05$ & $1.19 \mathrm{E}-04$ & $7.83 \mathrm{E}-06$ & ${ }^{200} \mathrm{Tl}$ & $1.62 \mathrm{E}-04$ & $5.74 \mathrm{E}-04$ & $8.81 \mathrm{E}-05$ \\
\hline${ }^{178} \mathrm{Re}$ & $5.16 \mathrm{E}-05$ & $1.23 \mathrm{E}-04$ & $4.66 \mathrm{E}-05$ & ${ }^{201} \mathrm{Tl}$ & $1.62 \mathrm{E}-04$ & $2.41 \mathrm{E}-04$ & $1.01 \mathrm{E}-04$ \\
\hline${ }^{181} \mathrm{Re}$ & $1.82 \mathrm{E}-04$ & $1.71 \mathrm{E}-03$ & $1.45 \mathrm{E}-05$ & ${ }^{201} \mathrm{~Pb}$ & $1.53 \mathrm{E}-04$ & $2.64 \mathrm{E}-04$ & $1.60 \mathrm{E}-04$ \\
\hline${ }^{182} \mathrm{Re}$ & $3.31 \mathrm{E}-06$ & $2.26 \mathrm{E}-05$ & $4.96 \mathrm{E}-06$ & ${ }^{202} \mathrm{Tl}$ & $1.25 \mathrm{E}-04$ & $1.68 \mathrm{E}-04$ & $8.42 \mathrm{E}-05$ \\
\hline${ }^{182} \mathrm{Ir}$ & $8.25 \mathrm{E}-05$ & $3.14 \mathrm{E}-05$ & $7.14 \mathrm{E}-05$ & ${ }^{203} \mathrm{~Pb}$ & $2.21 \mathrm{E}-04$ & $3.74 \mathrm{E}-04$ & $2.16 \mathrm{E}-04$ \\
\hline${ }^{183} \mathrm{Os}$ & $5.42 \mathrm{E}-05$ & $1.09 \mathrm{E}-04$ & $2.17 \mathrm{E}-05$ & ${ }^{203} \mathrm{Bi}$ & $8.05 \mathrm{E}-05$ & $6.96 \mathrm{E}-05$ & $6.88 \mathrm{E}-05$ \\
\hline${ }^{186} \mathrm{Ir}$ & $2.93 \mathrm{E}-05$ & $1.13 \mathrm{E}-04$ & $1.74 \mathrm{E}-05$ & ${ }^{204} \mathrm{Bi}$ & $7.28 \mathrm{E}-05$ & 6.89E-05 & $5.66 \mathrm{E}-05$ \\
\hline${ }^{188} \mathrm{Pt}$ & $2.08 \mathrm{E}-04$ & 3.09E-04 & $4.14 \mathrm{E}-05$ & ${ }^{205} \mathrm{Bi}$ & $8.43 \mathrm{E}-05$ & 8.18E-05 & $6.13 \mathrm{E}-05$ \\
\hline${ }^{189} \mathrm{Pt}$ & $1.23 \mathrm{E}-04$ & 4.79E-04 & $3.51 \mathrm{E}-05$ & ${ }^{206} \mathrm{Bi}$ & $7.19 \mathrm{E}-05$ & $5.38 \mathrm{E}-05$ & $4.46 \mathrm{E}-05$ \\
\hline
\end{tabular}




\subsection{Assumptions and Specific Techniques}

To perform this research, assumptions are made about various steps in the nuclear fuel cycle. These general assumptions are listed below, with the objective to which they relate given in parentheses:

- A second repository is needed to house what cannot currently fit in Yucca Mountain (1-5);

- Separated uranium can go to low-level waste disposal as can short-lived fission products after they decay appropriately (1-3);

- Reprocessing SNF (separations) can occur using the PUREX process with at least 99.9\% efficiency (1);

- License extensions for most LWRs can be obtained (1);

- MOX fabrication will be implemented (1);

- Full cores of MOX fuel can be licensed in numerous LWRs with fractions of plutonium in heavy metal as high as $8-9 \mathrm{w} \%(1)$;

- The irradiation periods between recycles are called passes (the initial irradiation is the first pass and so on) (1);

- Licensing for multi-recycling MOX fuel is easier if $\mathrm{U} / \mathrm{Pu}$ ratio stays constant (1);

- Spent MOX fuel can be reprocessed in $<10$ years cooling time (additional radiation barriers, remote handling, and/or hot cells may be required to do so) (1);

- Addition of MAs or FPs to MOX fuel is possible to reduce proliferation risk (2);

- Commercial uranium enrichment plants cannot enrich uranium above 5w\% (2);

- The actinide material separated from SNF but not burned in the LWR is sent directly to ADS fuel fabrication (3); 
- Fast spectrum ADSs can be designed and licensed in the next few decades (3);

- Separations technologies for ADS fuel (pyroprocessing for metallic fuel) can be developed with efficiencies around $99.999 \%$ for separating actinides from the remaining metal, FPs, and uranium (for $99.75 \%$ overall after $>100$ recycles) (3);

- Economically, the power of proton beam can double but not triple over the course of one cycle (3);

- $\quad$ Shuffling in the ADS is not practical (3);

- Reactivity control in an ADS is easier if $\mathrm{k}_{\mathrm{eff}}$ decreases as a function of time during a cycle and the required feed rate decreases as the number of cycles increases (3);

- Control rod material can be changed from $\mathrm{AgInCd}$ to boron carbide $\left(\mathrm{B}_{4} \mathrm{C}\right)(4)$;

- Soluble boron coolant can be enriched in ${ }^{10} \mathrm{~B}(4)$;

- Neutronic safety conditions are met if boron efficiency is greater than $4 \mathrm{pcm} / \mathrm{ppm}$ and total rod worth is less than 5000 pcm (4);

- Radiotoxicity is only important if it is greater than that of natural uranium ore (5); and

- Facilities can accommodate material with short-term high radiotoxicities (i.e., storage of spallation targets after irradiation) (5).

Using these general assumptions, specific techniques can be applied to perform calculations associated with each of the five objectives. These methodologies are described in Sections 3.3.1 through 3.3.4 (the first two objectives are combined into one section as the methodologies for each are similar). Results from the first three objectives 
are given in Section 4, and safety parameters (i.e., the last two objectives) are discussed in Section 5.

\subsubsection{Full Cores of MOX Fuel in an LWR}

Using a geometric MCNP model of a one-eighth core of an LWR containing MOX fuel is more accurate and can provide more information (in particular, control and shutdown rod worth as will be discussed in Section 3.3.3) than an infinitely reflected assembly. Details about the Monteburns model are discussed below, and Table 3-10 lists the specific parameters used for the burnup calculations:

- The one-eighth core MCNP model of an LWR consists of three regions of fuel with eight assemblies per region (plus one-eighth of one in the center for 193assemblies) reflected on both sides to simulate a full core;

- One region contains fresh fuel (3.2 w\% enriched uranium dioxide), one represents fuel irradiated for one cycle, and one is comprised of fuel depleted for two cycles (fuel regions 3, 2, and 1 respectively in Fig. 3-4);

- The once and twice irradiated assemblies are moved (shuffled) to different locations (regions 2 and 1 respectively) at the end of each cycle so that fresh fuel is always added to the same assembly region, simulating a true core;

- The center assembly of the reactor is replaced with a thrice-irradiated fuel assembly, but it influences the results little because it is only one of 193 assemblies in the entire core;

- The initial composition of the material irradiated multiple cycles is estimated based on results from previous runs, but it is assumed that by the fourth cycle, 
the core is fairly representative to that seen in a reactor at equilibrium. Monteburns is thus used to run the problem for a total of four cycles even though each fuel rod is only irradiated for three;

- The results reported in this research are associated with the fresh fuel added at the beginning of cycle two and followed through the system until it is removed at the end of cycle four; and

- The fuel, water, and burnable poison rods in each of the three regions are followed through each irradiation cycle. Half the boron concentration is removed halfway through each cycle to simulate the fact that boron concentration is adjusted many times throughout a typical reactor cycle.

\section{Fuel Region 1}

Fuel Region 2

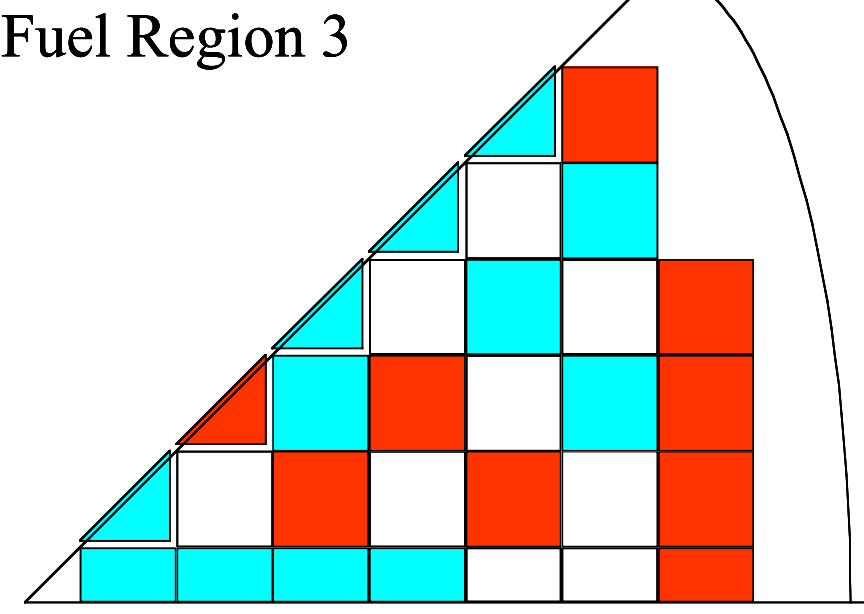

Fig. 3-4. One-Eighth Core Model of a PWR (Cross Section)

Appendices A-C display the actual files used for the first pass of plutonium as MOX fuel in the one-eighth core, and Appendix D gives excerpts from a sample output file. 
Table 3-10. Values of Parameters Used in LWR Irradiation Calculations

\begin{tabular}{|c|c|c|}
\hline Parameter & Value & Justification \\
\hline Burnup & $50 \mathrm{GWd} / \mathrm{MTHM}$ & $\begin{array}{l}\text { Consistent with present-day European } \\
\text { reactors burning MOX fuel }\end{array}$ \\
\hline $\begin{array}{l}\text { Average soluble } \\
\text { boron } \\
\text { concentration }\end{array}$ & $\begin{array}{l}920 \mathrm{ppm} 1^{\text {st }} \text { half } \\
460 \mathrm{ppm} 2^{\text {nd }} \text { half }\end{array}$ & $\begin{array}{l}\text { Keeps initial boron concentration less than } \\
2500 \text { ppm and is similar to what is used in } \\
\text { LWRs today }\end{array}$ \\
\hline $\begin{array}{l}\text { Uranium } \\
\text { enrichment }\end{array}$ & $\begin{array}{l}\text { Modified each pass } \\
\text { so EOC } \mathrm{k}_{\mathrm{eff}}<\sim 1.00\end{array}$ & $\begin{array}{l}\text { Other studies simply adjust the BOC value } \\
\text { of } \mathrm{k}_{\mathrm{eff}} \text {, which is not accurate. During } \\
\text { operation, boron concentration is increased } \\
\text { or control rods are added to keep } \mathrm{k}_{\mathrm{eff}}=1.0 \text {. }\end{array}$ \\
\hline $\begin{array}{l}\text { Plutonium content } \\
\text { in heavy metal }\end{array}$ & $\begin{array}{l}8.3 \mathrm{w} \% \text { for } \mathrm{Pu} \text {-only } \\
12.55 \mathrm{w} \% \text { for } \mathrm{Pu}+\mathrm{MA}\end{array}$ & $\begin{array}{l}8-9 \mathrm{w} \% \mathrm{Pu} \text { required to implement mission } \\
\text { (Section 2.2.2); 6w\% is highest used today } \\
\text { but design must be redone for full core } \\
\text { anyway; additional } \mathrm{Pu} \text { does not influence } \\
\text { design much (see Section 5.1) }\end{array}$ \\
\hline Cycle length & $\begin{array}{l}\text { 203-day burn } \\
\text { 39-day cooling time, } \\
\text { 203-day burn again, } \\
\text { 64-day cooling time }\end{array}$ & $\begin{array}{l}\text { Reactors may run } 18 \text {-month cycles today, } \\
\text { but it is assumed here that one month of } \\
\text { that is devoted to routine maintenance. } \\
\text { Shorter cooling times are also possible, but } \\
\text { 64-days between cycles is used here. The } \\
\text { most irradiated assemblies are removed and } \\
\text { fresh ones are added between each cycle. }\end{array}$ \\
\hline $\begin{array}{l}\text { Number of } \\
\text { histories/cycles }\end{array}$ & $\begin{array}{l}1000 \text { histories/cycle } \\
100 \text { active cycles }\end{array}$ & $\begin{array}{l}\text { Statistics are }<\sim 5 \% \text { for major cross } \\
\text { sections }\end{array}$ \\
\hline $\begin{array}{l}\text { Separations } \\
\text { efficiencies }\end{array}$ & $\begin{array}{l}99.9 \% \text { for } \mathrm{Pu} \\
95 \% \text { for } \mathrm{Am} \text { and } \mathrm{Cm}\end{array}$ & $\begin{array}{l}99.9 \% \text { of plutonium is removed from } \\
\text { uranium and fission products with PUREX; } \\
95 \% \text { of } \mathrm{Am} \text { and } \mathrm{Cm} \text { is removed in } \\
\text { calculations with the contaminated } \mathrm{Pu} \\
\text { stream }\end{array}$ \\
\hline
\end{tabular}


The first step in determining how much plutonium can be burned per pass in an LWR is to define a representative isotopic vector of plutonium from SNF for transmutation. As the burnup of $\mathrm{UO}_{2}$ fuel increases, the quantity of fissile ${ }^{239} \mathrm{Pu}$ relative to other plutonium isotopes decreases. SNF can have a variety of different burnups depending on the power of the reactor and how long the fuel is irradiated. The fissile plutonium $\left({ }^{239} \mathrm{Pu}\right.$ and $\left.{ }^{241} \mathrm{Pu}\right)$ burns the fastest, so the most conservative plutonium vector to consider for the smallest plutonium consumption in the LWR would be one with the least amount of ${ }^{239} \mathrm{Pu}$ and ${ }^{241} \mathrm{Pu}$. This vector is probably associated with a high burnup case, such as extended burnup for an LWR fueled with $\mathrm{UO}_{2}$ (i.e., $\sim 60 \mathrm{GWd} / \mathrm{MTU}$ ). One of the safety cases examined in this research is for such an extended burnup (see Section 5.1), so the plutonium composition at the end of this burn is assumed as input for the MOX fuel calculations done here. Much SNF within the U.S. resulted from much lower burnups and has been sitting in spent fuel pools and/or dry storage for decades; thus, the fissile content is smaller. Others that have been recently removed from reactors would probably accumulate in storage while older SNF rods are reprocessed, so it may be decades after discharge before any SNF is reprocessed and fabricated into MOX fuel. Once all plutonium from legacy SNF is transmuted, then newer SNF rods could potentially be reprocessed within three to four years after removal from the reactor. A cooling time of one decade is thus assumed for these calculations to account for the average between older and newer SNF rods. The resulting plutonium vector appears in Table 3-11. Older SNF has a higher ${ }^{239} \mathrm{Pu}$ content than that examined here, but it also has a lower ${ }^{241} \mathrm{Pu}$ content because 1 ) it decays with a half-life of 14.4 years, and 2) less of it is built in to begin with. It is assumed that the plutonium vector used in this research is 
fairly representative of average SNF, but it probably does contribute to less plutonium consumption and MA buildup per pass in the LWR than is seen in other vectors. Results with this assumed vector are compared to results from other applicable plutonium vectors in Section 4.1. Specific assumptions associated with pure plutonium are discussed in Section 3.3.1.1, and those for the inclusion of minor actinides or fission products is discussed in Section 3.3.1.2 using the same plutonium vector and the corresponding minor actinide and fission product concentrations from the same run in which these are obtained.

Table 3-11. Isotopic Plutonium Vector for MOX Calculations

\begin{tabular}{|c|c|}
\hline Pu Isotope & Weight Fraction in $\mathrm{Pu}$ \\
\hline${ }^{238} \mathrm{Pu}$ & 0.038229 \\
\hline${ }^{239} \mathrm{Pu}$ & 0.500503 \\
\hline${ }^{240} \mathrm{Pu}$ & 0.259054 \\
\hline${ }^{241} \mathrm{Pu}$ & 0.100855 \\
\hline${ }^{242} \mathrm{Pu}$ & 0.101358 \\
\hline
\end{tabular}

The next design decision involves defining a fuel assembly to use for LWR calculations. Benchmarking calculations assumed the use of a 15x15 assembly design (see Table 3-12 for fuel rods parameters), so that same design is used throughout this research. Results are compared to those in a $17 \times 17$ assembly in Section 4.1. All calculations are performed using temperature-dependent cross sections generated by the cross section processing code NJOY. ${ }^{61}$ 
Table 3-12. Geometric Parameters for H.B. Robinson Assembly

\begin{tabular}{|l|c|}
\hline Parameter & Value \\
\hline Fuel rod density & $10 \mathrm{~g} / \mathrm{cc}$ \\
\hline Plutonium content (of heavy metal) in MOX & $8.2588 \mathrm{w} \%$ \\
\hline Fuel rod radius & $0.53595 \mathrm{~cm}$ \\
\hline Cladding thickness & $0.06175 \mathrm{~cm}$ \\
\hline Fuel pellet radius & $0.4647 \mathrm{~cm}$ \\
\hline Fuel rod height & $365.76 \mathrm{~cm}$ \\
\hline Assembly pitch (square) & $21.45 \mathrm{~cm}$ \\
\hline
\end{tabular}

\subsubsection{MOX Fuel Irradiation Calculations with Pure Plutonium Stream}

The next step in the calculation is to determine what percentage of plutonium in heavy metal to use in MOX fuel. In Section 2.2.2, it is stated that to meet implementation guidelines, $8-9 \mathrm{w} \%$ plutonium in the heavy metal of MOX fuel must be used. Thus, part of the challenge of this research is to design an LWR that accommodates a full core of MOX fuel with such a plutonium content and still meets the neutronic safety conditions required for an LWR. The safety results for different plutonium concentrations are given in Section 5.1 , but a plutonium quantity of $8.3 \mathrm{w} \%$ has been chosen for MOX irradiation calculations in this research both to follow the implementation guidelines and to meet safety conditions for full cores of MOX fuel. The design requires that twelve water holes replace fuel rods in a $15 \times 15$ assembly and that slightly enriched boron $\left(25 \%{ }^{10} \mathrm{~B}\right)$ is used in the water (see Section 5.1 for more details).

Unfortunately, plutonium depletion in a single pass is insufficient (i.e., less than even $50 \%$ ) to reduce the radiotoxicity of SNF sent to a repository. Thus, spent MOX fuel 


\section{LA-14052-T}

must be reprocessed and refabricated into fresh MOX fuel rods for further irradiation in a reactor to make a more significant impact. As the number of recycles of plutonium in MOX fuel increase, the quality (fissile content) of the plutonium decreases because the most fissile isotopes are slowly depleted so that the reactivity of the fuel at the end of MOX irradiation is much less than that at the beginning. If the plutonium is removed and directly refabricated into MOX fuel rods, the reactor cannot operate at critical with the same $\mathrm{Pu}$ concentration. Thus, the enrichment of uranium is increased each pass to met reactivity requirements.

In addition, some percentage of the plutonium is destroyed each pass, so unless the amount of plutonium in two reactors (or assemblies) can be combined into one reactor (assembly), the amount of plutonium needed for additional passes is insufficient. Requiring the number of reactors (or assemblies) needed for burning a select set of plutonium to decrease with the number of recycles would complicate licensing and logistics. It is more straightforward through mass conservation to have all plutonium from one reactor being burned in the same reactor through repeated passes. Thus, the mass of plutonium depleted (which includes fission plus capture to higher actinides) during each pass is replaced with the initial plutonium from spent nuclear fuel. Such replacement helps by making up the extra mass and increasing the fissile quality of the plutonium so that the uranium enrichment can be kept as low as possible. For example, if one starts with 100 grams of plutonium for MOX irradiation and 30\% of it is depleted, then after reprocessing, only about 70 grams remains. Thus, 30 grams of plutonium from legacy SNF is added to the 70 grams to again make 100 grams. If $30 \%$ of this plutonium is depleted, then 60 of 130 grams total of legacy plutonium is depleted over the two 
passes, which corresponds to a cumulative depletion rate of about $46 \%$ after the second "pass." However, the plutonium depletion rate per cycle actually decreases as the number of recycles increase because the fissile quality of the plutonium decreases.

\subsubsection{MOX Fuel Irradiation Calculations with Heavy Metal Other Than Plutonium}

The first problem that must be solved before any transmutation of SNF can take place is overcoming the political directive of the 1970s stating that no reprocessing will be performed in the United States. The motivation of this decision was to start a trend of getting rid of separated plutonium streams worldwide, starting with the U.S. However, most of the rest of the world chose not to follow this course of action. The current political atmosphere of the U.S., however, still does not favor (or even allow) separated plutonium as proposed in this research. It is less of a proliferation risk if the plutonium does not exist as a pure product anywhere in the fuel cycle. Assuming appropriate separation processes exist, the plutonium can be kept or combined with minor actinides and/or certain fission products from SNF instead. However, the presence of minor actinides in SNF decreases the amount of plutonium that can be burned each pass (in a thermal neutron spectrum), leads to significant Am and Cm buildup, and makes fuel more difficult to fabricate.

Alternatively, the fission products strontium-90 $\left({ }^{90} \mathrm{Sr}\right)$ and cesium-137 $\left({ }^{137} \mathrm{Cs}\right)$ have relatively high activities and half-lives on the order of only 30 years. Assuming appropriate separation processes exist, $\mathrm{Sr}$ and $\mathrm{Cs}$ can be combined with the plutonium from SNF to increase the activity of the MOX fuel, making it more attractive. Thus, a case is briefly considered in which plutonium is kept with the fission products $\mathrm{Sr}$ and Cs 
to increase the activity of the material stream, thereby reducing the proliferation attractiveness of this material. Plutonium contributes to $\sim 26 \%$ of the activity of SNF after 10 years, and ${ }^{90} \mathrm{Sr}$ and ${ }^{137} \mathrm{Cs}$ comprise $\sim 36 \%$ of the total radioactivity. By keeping these select fission products with the plutonium and doubling their presence from other

Sr and Cs sources, MOX fuel could have about same activity as SNF, which would represent an added nonproliferation benefit because it would meet the "spent fuel standard." The added activity does, however, make the fuel more difficult to fabricate, but with the use of hot cells and/or remote handling of the material (as may already be required for spent MOX fuel), such a proposal is not impossible. It is not known if a separations process capable of keeping the plutonium with Cs and Sr in SNF can be developed to limit proliferation risk throughout the entire cycle (the current PUREX process separates fission products first before the actinides), but they potentially can be combined in the separations facility to at least prevent transportation of separated plutonium.

\subsubsection{ADS Calculations}

The main question to answer for the third objective is: how does the number of recycles of plutonium in an LWR influence the value of the reactivity swing in the ADS? The more recycles that occur, the more plutonium is burned and the more minor actinides accumulate, making the fraction of plutonium in material going to an ADS smaller. The smaller the amount of plutonium that must go to an ADS, the smaller the reactivity swing in the ADS per unit time is. However, if too little plutonium starts in the ADS, $\mathrm{k}_{\text {eff }}$ may increase slightly as a function of time, or the quantity of material fed to the system at the 
beginning of each cycle may have to decrease to maintain subcriticality in the ADS. These effects occur because plutonium would actually build into the system until it reaches equilibrium, which could be considered a safety problem if $\mathrm{k}_{\mathrm{eff}}$ approaches unity. Additionally, the larger the number of recycles in an LWR, the longer Tier 1 must operate (e.g., it takes approximately 10 years per pass with irradiation and cooling time), which would require additional license extensions to be obtained or more reactors to be built. Thus, the benefit of multi-recycling plutonium in the LWR to the ADS must be determined.

Performance of five different material streams is analyzed in the ADS, which include: the remaining plutonium and minor actinides from three different Tier 1 irradiations with plutonium-only in MOX fuel combined with the initial minor actinides from SNF, the actinides remaining when plutonium and minor actinides are burned for one pass in the LWR, and the entire stream of plutonium and minor actinides from SNF by-passing Tier 1 and going directly to Tier 2 .

Monteburns is also used to model the time-dependent irradiation of material in an ADS. The ADS design used for the calculations in this research consists of an LBE target with a sodium-cooled blanket and produces about $840 \mathrm{MWt}$ of fission energy. It consists of two main regions of fuel, one on the outside with a higher actinide enrichment and one on the inside (i.e., closer to the target) with a lower actinide enrichment. Within each region, either seven or eight inner zones of fuel are modeled, one of which (the most irradiated) is replaced with fresh fuel between cycles (see Fig. 3-5). ${ }^{76}$ Monteburns is used to calculate burnup in each of these regions. 
The fuel rods are contained in hexagonal assemblies and consist of metallic zirconium-based fuel with an actinide volume fraction of less than $50 \%$. The cycle length is six months. Between cycles, irradiated fuel rods are removed, and fresh ones are added to one zone in each region. Between three and four years is required for any one fuel rod to complete irradiation, at which point it is removed from the system because the fast fluence limit on the cladding (a form of stainless steel) is about $4 * 10^{23} \mathrm{n} / \mathrm{cm}^{2}$. After appropriate cooling, the fuel is separated, and the actinides are retrieved, fabricated with the initial ADS actinide stream, and recycled in the ADS during a later cycle. The MCNP and Monteburns input files used for the ADS calculations are given in Appendices E-G with excerpts from the corresponding output file in Appendix H.

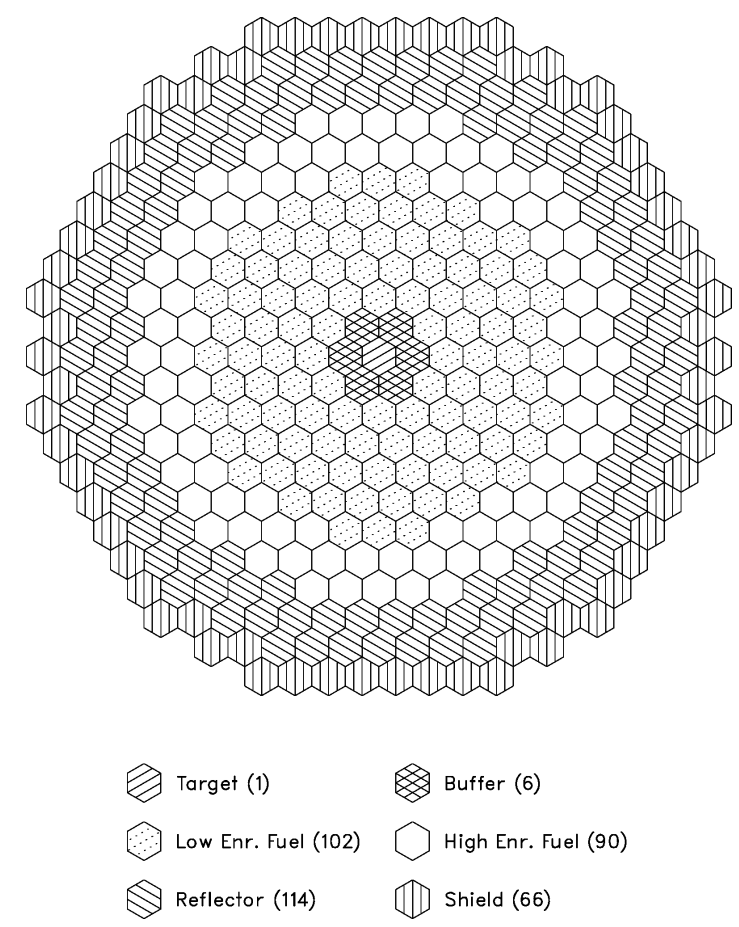

Fig. 3-5. Detailed Cross-Sectional Layout of ADS 
The trickiest part of performing ADS neutronics calculations is either generating a time-dependent depletion scenario or determining isotopic concentrations for an equilibrium case. Monteburns runs a time-dependent burnup problem, which means that when the system first starts up, the user must estimate the material composition in each zone because only the fresh fuel composition is known. Until a certain number of cycles are run, it is not known what the actual composition in each region really is (i.e., what minor actinides and fission products are present and in what composition). At equilibrium, the overall material composition in the system is fairly consistent from one cycle to the next, and approximately the same amount of each isotope that is added at the beginning of each cycle is depleted during the course of the cycle. Enough minor actinides (and/or plutonium in some cases) have already built up so that no new ones contribute significantly to the system. Thus, the amount of material that should be added is approximately equal to the fission rate, or about one gram per megawatt-day of irradiation. A thermal power production of $840 \mathrm{MWt}$ corresponds to a feed rate of about 840 grams/day. However, before equilibrium is attained and as higher actinides are built into the system, the feed rate per cycle for about the first ten cycles is much higher than at equilibrium because the actinide inventory of the system increases to account for the decreasing fission-to-capture ratio. It can take 10 to 20 cycles for an ADS to reach equilibrium, and the smaller the amount of plutonium in the feed material, the faster equilibrium is reached.

For each of the ADS cases examined, it is assumed that the uranium separations (from $\mathrm{Pu}$ and MAs) efficiency during initial PUREX and subsequent recycling in the LWR is $99.9 \%$. Therefore, as the number of recycles in the LWR increases, the uranium 
content in the feed for the ADS also increases. After the initial separations process, about $10 \%$ of the remaining material is still uranium, which is significant. More efficient separations processes reducing this uranium content would be beneficial.

\subsubsection{Neutronic Safety Calculations for a Full Core of MOX fuel}

Using full cores of MOX fuel instead of one-third cores as implemented in Europe would help to reduce the time and number of reactors required to burn all legacy plutonium. However, neutronic safety issues associated with operating a full core of MOX fuel and multi-recycling of plutonium in a LWR exist; additional design modifications are needed to meet these safety criteria. For a full core of MOX fuel to be implemented in an LWR in the U.S., certain safety conditions must be met. Although both neutronic and thermal hydraulic safety concerns exist, only the neutronic safety conditions are examined in this research. These calculations are done solely using the code MCNP to calculate $\mathrm{k}_{\mathrm{eff}}$ of the system with various modifications that simulate situations that may occur in the reactor. The material compositions at the beginning and end of relevant cycles are obtained using Monteburns (which saves intermediate MCNP input files for these further calculations).

The neutronic safety calculations performed in this research use the same reflected one-eighth core model of a PWR in MCNP used for burnup calculations and discussed in Section 3.3.1. Monteburns saves the MCNP input file at the beginning and end of a representative cycle for each burn defined by the user and are used further at this point. The MCNP input files for both the beginning and end of an average equilibrium step are then modified to provide the Doppler coefficient, moderator temperature 
coefficient, boron efficiency, void reactivity coefficient, control and shutdown rod worths. A short FORTRAN77 program named "safety" is used to perform these modifications, creating 10-11 different MCNP input files in the process, and it appears in Appendix I. The Doppler coefficient is calculated using Equation 4. The effective multiplication factors $\left(\mathrm{k}_{\mathrm{eff}}\right)$ are obtained by running two of these new MCNP input files and using cross sections that correspond to fuel temperatures 100 degrees $\mathrm{K}$ above and 100 degrees $\mathrm{K}$ below that of the default (base) case. The moderator temperature coefficient is calculated similarly; however, the change in temperature is only 50 degrees $\mathrm{K}$, and the density of the water is also slightly modified $(-/+0.002 \mathrm{~g} / \mathrm{cc}$ with every degree up or down in temperature respectively).

$$
100000 \frac{p c m}{\Delta k} *\left[\frac{\left(k_{\text {high }}-k_{\text {default }}\right)+\left(k_{\text {default }}-k_{\text {low }}\right)}{2}\right] \div \Delta(\operatorname{Temp}(K) / p p m B)
$$

The boron efficiency (which should exceed $4 \mathrm{pcm} / \mathrm{ppm}$ ) is calculated by changing the boron concentration to be $100 \mathrm{ppm}$ less and $100 \mathrm{ppm}$ greater than the default case in two different MCNP files. The void reactivity coefficient is calculated by obtaining the $\mathrm{k}_{\mathrm{eff}}$ from a case in which the density of the water is decreased by $25 \%$ and subtracting the $\mathrm{k}_{\mathrm{eff}}$ of the basecase from it. Initial boron concentration is also calculated for the beginning of an equilibrium cycle to make sure it does not exceed $2500 \mathrm{ppm}$.

Both control and shutdown rods are located in clusters, which in this case are comprised of nine rods each and occupy the guide tube locations of each assembly. The assemblies that have control or shutdown rod clusters (located in the nine guide tubes of the assembly) are given in Fig. 3-6. LWR assemblies in this research are designed so that the total worth of both the control and shutdown rods is at least $5000 \mathrm{pcm}^{30}$ The control 
and shutdown rod worths are obtained by calculating the $\mathrm{k}_{\text {eff }}$ when control and/or shutdown rod clusters are inserted into the reactor and subtracting it from the basecase $\mathrm{k}_{\text {eff. }}$ The total rod worth is that which occurs when both control and shutdown rods are inserted.

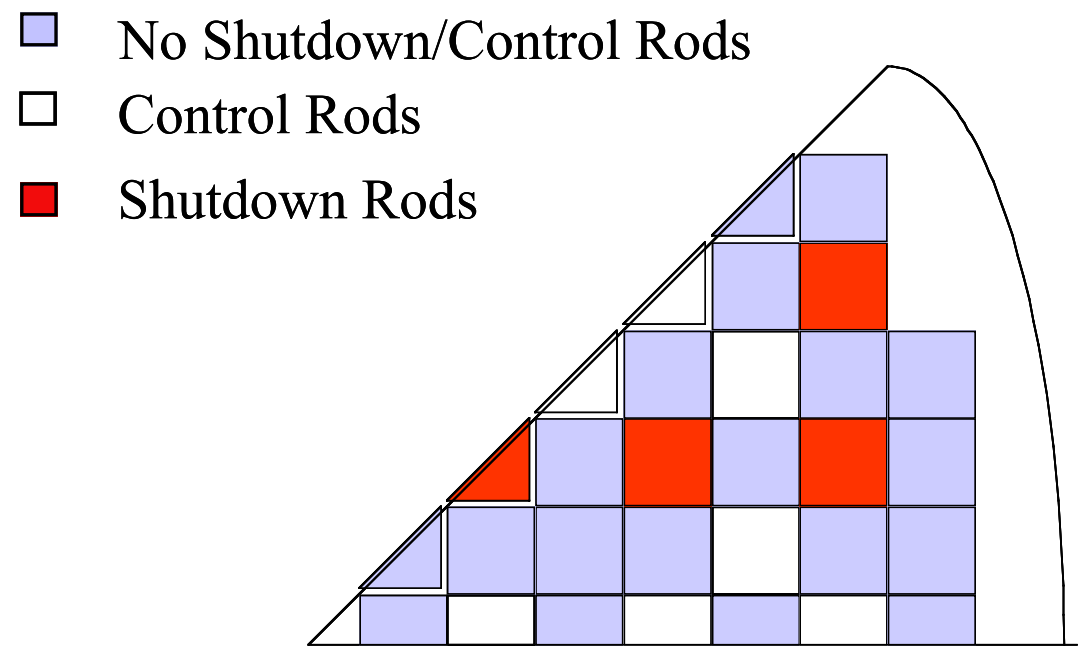

Fig. 3-6. Location of Control/Shutdown Rods in Core

\subsubsection{Verification of Calculation of Neutronic Safety Parameters}

The first step in performing safety calculations for multi-recycling of plutonium in a full core of MOX fuel is to make sure that Monteburns/MCNP calculates values similar to those seen in literature. The most knowledge exists about uranium oxide fuels, thus initial neutronic safety calculations are performed for standard and extended burnups of enriched $\mathrm{UO}_{2}$ fuel in an LWR. The standard case is considered to have a burnup of about $38 \mathrm{GWd} / \mathrm{MTU}$ with an initial enrichment of $3.2 \mathrm{w} \%$ uranium, which is common for the H.B. Robinson assembly design used in this research (see Fig. 3-2). The extended burnup cycle is considered to be a burnup of about $60 \mathrm{GWd} / \mathrm{MTU}$ with an initial 
enrichment of $4.2 \mathrm{w} \%$ uranium. A sample full core of MOX fuel case is also explored with a plutonium concentration of $8.3 \mathrm{w} \%$ heavy metal and the sample plutonium isotopics given in Table 3-11. The results for these three cases both at the beginning and end of a representative cycle (BOC and EOC respectively) appear in Table 3-13. Cases are also run at a xenon-saturated condition (after about 12 hours of irradiation in the LWR), and safety parameters are not significantly different for these than at the beginning or end of cycle.

Table 3-13. Basic Neutronic Safety Results

\begin{tabular}{|c|c|c|c|c|c|c|}
\hline & $\begin{array}{l}\text { Standard } \\
\text { BOC }\end{array}$ & $\begin{array}{l}\text { Standard } \\
\text { EOC }\end{array}$ & $\begin{array}{l}\text { Extended } \\
\text { BOC }\end{array}$ & $\begin{array}{l}\text { Extended } \\
\text { EOC }\end{array}$ & $\begin{array}{l}\text { MOX } \\
\text { BOC }\end{array}$ & $\begin{array}{l}\text { MOX } \\
\text { EOC }\end{array}$ \\
\hline $\begin{array}{c}\text { Doppler coefficient } \\
\text { (pcm/K) }\end{array}$ & -2.4 & -2.3 & -2.2 & -2.6 & -3.2 & -2.9 \\
\hline $\begin{array}{c}\text { Moderator coeffic. } \\
\text { (pcm/K) }\end{array}$ & -40 & -47 & -48 & -44 & -47 & -52 \\
\hline $\begin{array}{c}\text { Boron efficiency } \\
\text { (pcm/ppm) }\end{array}$ & 7.6 & 9.2 & 5.4 & 7.0 & 1.3 & 2.4 \\
\hline $\begin{array}{c}\text { Void coefficient } \\
\text { (pcm/25\% void) }\end{array}$ & -223 & -266 & -210 & -205 & -199 & -217 \\
\hline $\begin{array}{c}\text { Control rod worth } \\
\text { (pcm) }\end{array}$ & 4566 & 3631 & 3780 & 2837 & 2275 & 2305 \\
\hline $\begin{array}{c}\text { Shutdown rod } \\
\text { worth (pcm) }\end{array}$ & 2616 & 2011 & 2281 & 2320 & 1905 & 1843 \\
\hline $\begin{array}{c}\text { Total rod worth } \\
\text { (pcm) }\end{array}$ & 7640 & 5315 & 5454 & 5214 & 4111 & 4064 \\
\hline $\begin{array}{c}\text { Initial Critical } \\
\text { Boron Con- } \\
\text { centration (ppm) }\end{array}$ & 1600 & - & 1633 & - & 1700 & - \\
\hline
\end{tabular}


These basic neutronic safety calculations confirm the safety data results reported in literature, which indicates that they are being done correctly. The absolute values of the Doppler and moderator reactivity coefficients are larger (though still negative) for MOX fuel than for extended burnup $\mathrm{UO}_{2}$ fuel. This leads to smaller control and shutdown rod worth for MOX fuel, which is observed as well. In fact, the total rod worth is less than $5000 \mathrm{pcm}$ for a full core of MOX fuel, which is a major safety concern. The absolute value of the void reactivity coefficient is, as expected, smaller but not positive. The other noticeable safety problem for MOX fuel is that the efficiency of the soluble boron decreases significantly compared to that of traditional $\mathrm{UO}_{2}$ cases. This boron efficiency should be greater than $4 \mathrm{pcm} / \mathrm{ppm}$ to provide adequate safety in a system. The standard $\mathrm{UO}_{2}$ case has boron efficiencies well above the limit, while the extended LWR case almost reaches this lower limit but is still sufficient. However, the MOX case does not meet the designated safety criterion for boron efficiency either at the beginning or the end of a cycle. Thus, to implement a full core of MOX fuel, both the control/shutdown rod worth and the boron efficiency must be increased as discussed in Section 5.1.

\subsubsection{Spallation Product Radiotoxicity}

The final calculation involves determining the radiotoxicity of spallation products generated in an ADS target. For this calculation, the code MCNPX is used to produce a list of the probabilities that various residual nuclides are generated when a proton hits the spallation target of interest. ${ }^{77}$ Both the Bertini and CEM2k modules in MCNPX are used to calculate these yields. ${ }^{78}$ Through Monteburns, these probabilities, fluxes, and a normalization factor representing the number of protons per second that hit the target are passed to CINDER90, which calculates the production (and subsequent irradiation and 
decay) of many radionuclides. Proton energies of $800 \mathrm{MeV}, 1 \mathrm{GeV}$, and $1.6 \mathrm{GeV}$ are examined in this research, as well as spallation targets of tungsten, LBE, and lead. Both LBE and sodium are examined as coolants for the tungsten and lead targets. The results from CINDER90 are processed using a FORTRAN77 program (see Appendix J), which applies radiotoxicity factors to each isotope to get the overall ingestion and inhalation radiotoxicities from each target as well as from each radionuclide in the target.

Preliminary calculations used ICRP data only (not the latest Japanese (JAERI) data) and LBE coolant in all targets. ${ }^{79}$ However, in the calculations in this report, the coolant for the lead and tungsten targets is sodium because it was discovered that the LBE spallation products ${ }^{208} \mathrm{Po}$ and ${ }^{209} \mathrm{Po}$ contribute significantly to the radiotoxicity so a more inert coolant should be used. In addition, the ICRP data does not include all isotopes of interest. Thus, for the calculations presented in this research, the ICRP data is supplemented by JAERI data, which, among others, includes radiotoxicities for the alphaemitting rare earth isotopes ${ }^{150} \mathrm{Gd},{ }^{154} \mathrm{Dy},{ }^{208} \mathrm{Po}$, and ${ }^{209} \mathrm{Po}$ that have been shown to be important in spallation targets. ${ }^{56}$ 
LA-14052-T 


\subsection{Results}

The first objective of this research is to determine how much plutonium can be burned in an LWR as a function of cycle (pass) number. Results from this multirecycling study for plutonium irradiated as MOX fuel in LWRs are presented in Section

4.1. The next issue addressed in this research is how to reduce the proliferation risk associated with having a separated plutonium stream in the fuel cycle (i.e., going to MOX fuel fabrication). Thus, the inclusion of materials other than plutonium (i.e., minor actinides and certain fission products) in MOX fuel is explored in Section 4.2. The final, most important topic to be addressed is to determine the effect that burning some material in an LWR (Tier 1) has on Tier 2. Section 4.3 addresses the effect that various numbers of recycles in Tier 1 have on the ADS in Tier 2.

\subsection{Multi-recycling of MOX Fuel}

Calculations performed for MOX fuel recycling include: activity and heatload from irradiated assemblies, plutonium depletion as a function of multi-recycling, a comparison of performance for different incoming plutonium vectors, and a comparison of performance for varying assembly size. Plutonium from $\mathrm{UO}_{2} \mathrm{SNF}$ is recycled as MOX fuel in LWRs worldwide, but recycling MOX fuel is more complicated than recycling regular SNF because its heatload and activity is larger. Determining how long MOX fuel must reside in storage (either spent fuel pools or dry storage) before it can be recycled (i.e., cooling time) is the first parameter that is calculated. To recycle spent MOX fuel in similar processes as $\mathrm{UO}_{2} \mathrm{SNF}$, the activity and heatload should be less than or equal to the activity and heatload of spent $\mathrm{UO}_{2}$ fuel. Table 4-1 shows the activity and 
heatload of SNF from $\mathrm{UO}_{2}$ fuel with a standard burnup $(\sim 38 \mathrm{GWd} / \mathrm{MTU}$ with $3.2 \mathrm{w} \%$ enriched uranium), from $\mathrm{UO}_{2}$ with an extended burnup ( $\sim 60 \mathrm{GWd} / \mathrm{MTU}$ with $4.2 \mathrm{w} \%$ enriched uranium), and from MOX fuel with a burnup of $\sim 50 \mathrm{GWd} / \mathrm{MTHM}$.

Table 4-1 shows that after seven years of cooling, the activity of spent MOX fuel is about equal to that of $\mathrm{UO}_{2}$ fuel after three years (a commonly proposed cooling time in France), and the heatload is almost the same although still a little larger for MOX than $\mathrm{UO}_{2}$. Table 4-2 gives a breakdown of how different actinides contribute to the heatload.

Table 4-1. Activity and Heatload of Eight Assemblies of SNF as a Function of Time

\begin{tabular}{|c|c|c|c|c|c|c|}
\hline $\begin{array}{l}\text { Activity } \\
\text { (Ci) } \\
\text { \# years of } \\
\text { cooling }\end{array}$ & $\begin{array}{l}\text { Standard } \\
\text { Burnup for } \\
\mathrm{UO}_{2} \text { Fuel } \\
\text { Actinides }\end{array}$ & Total & $\begin{array}{l}\text { Extended } \\
\text { Burnup for } \\
\mathrm{UO}_{2} \text { Fuel } \\
\text { Actinides }\end{array}$ & Total & MOX Fuel & Total \\
\hline 0 & $9.17 \mathrm{E}+05$ & $5.27 \mathrm{E}+08$ & $1.07 \mathrm{E}+06$ & $5.20 \mathrm{E}+08$ & $5.58 \mathrm{E}+06$ & $5.46 \mathrm{E}+08$ \\
\hline 1 & $6.75 \mathrm{E}+05$ & $8.76 \mathrm{E}+06$ & $7.79 \mathrm{E}+05$ & $9.40 \mathrm{E}+06$ & $4.11 \mathrm{E}+06$ & $1.26 \mathrm{E}+07$ \\
\hline 3 & $5.67 \mathrm{E}+05$ & $3.90 \mathrm{E}+06$ & $6.53 \mathrm{E}+05$ & $4.41 E+06$ & $3.46 \mathrm{E}+06$ & $6.60 \mathrm{E}+06$ \\
\hline 5 & $5.16 \mathrm{E}+05$ & $2.68 \mathrm{E}+06$ & $5.95 \mathrm{E}+05$ & $3.12 \mathrm{E}+06$ & $3.16 \mathrm{E}+06$ & $4.99 \mathrm{E}+06$ \\
\hline 7 & $4.74 \mathrm{E}+05$ & $2.23 \mathrm{E}+06$ & $5.46 \mathrm{E}+05$ & $2.63 \mathrm{E}+06$ & $2.90 \mathrm{E}+06$ & $4.30 \mathrm{E}+06$ \\
\hline 10 & $4.16 \mathrm{E}+05$ & $1.90 \mathrm{E}+06$ & $4.80 \mathrm{E}+05$ & $2.25 \mathrm{E}+06$ & $2.56 \mathrm{E}+06$ & $3.70 \mathrm{E}+06$ \\
\hline $\begin{array}{c}\text { Heatload } \\
\text { (W) }\end{array}$ & Actinides & Total & Actinides & Total & Actinides & Total \\
\hline 0 & $1.24 \mathrm{E}+04$ & $5.05 \mathrm{E}+06$ & $1.53 \mathrm{E}+04$ & $5.03 \mathrm{E}+06$ & $7.85 \mathrm{E}+04$ & $5.43 \mathrm{E}+06$ \\
\hline 1 & $4.43 \mathrm{E}+03$ & $3.89 \mathrm{E}+04$ & $5.57 \mathrm{E}+03$ & $4.24 \mathrm{E}+04$ & $3.03 \mathrm{E}+04$ & $6.65 \mathrm{E}+04$ \\
\hline 3 & $2.33 \mathrm{E}+03$ & $1.51 \mathrm{E}+04$ & $3.01 \mathrm{E}+03$ & $1.75 \mathrm{E}+04$ & $1.72 \mathrm{E}+04$ & $2.93 \mathrm{E}+04$ \\
\hline 5 & $2.17 \mathrm{E}+03$ & $9.51 \mathrm{E}+03$ & $2.81 \mathrm{E}+03$ & $1.14 \mathrm{E}+04$ & $1.61 \mathrm{E}+04$ & $2.23 \mathrm{E}+04$ \\
\hline 7 & $2.11 \mathrm{E}+03$ & $7.58 \mathrm{E}+03$ & $2.72 \mathrm{E}+03$ & $9.25 \mathrm{E}+03$ & $1.56 \mathrm{E}+04$ & $1.99 E+04$ \\
\hline 10 & $2.03 \mathrm{E}+03$ & $6.39 \mathrm{E}+03$ & $2.61 \mathrm{E}+03$ & $7.85 \mathrm{E}+03$ & $1.49 \mathrm{E}+04$ & $1.82 \mathrm{E}+04$ \\
\hline
\end{tabular}


Table 4-2. Heatload (W) of Various Isotopes in MOX after Seven Years vs. Extended Burnup $\mathrm{UO}_{2} \mathrm{SNF}$ after Three Years

\begin{tabular}{|c|c|c|}
\hline & Spent MOX Fuel & Spent $\mathrm{UO}_{2}$ Fuel \\
\hline${ }^{238} \mathrm{Pu}$ & 4694 & 886 \\
\hline${ }^{239} \mathrm{Pu}$ & 130 & 38 \\
\hline${ }^{240} \mathrm{Pu}$ & 436 & 74 \\
\hline${ }^{241} \mathrm{Pu}$ & 76 & 18 \\
\hline${ }^{241} \mathrm{Am}$ & 1457 & 135 \\
\hline${ }^{243} \mathrm{Am}$ & 44 & 7.8 \\
\hline${ }^{242} \mathrm{Cm}$ & 19 & 120 \\
\hline${ }^{243} \mathrm{Cm}$ & 25 & 4.8 \\
\hline${ }^{244} \mathrm{Cm}$ & 8700 & 1728 \\
\hline
\end{tabular}

Along with ${ }^{238} \mathrm{Pu}$, the isotopes ${ }^{241} \mathrm{Am}$ and ${ }^{244} \mathrm{Cm}$ contribute significantly to the heatload of spent MOX fuel. ${ }^{244} \mathrm{Cm}$ only has a 18.1 year halflife, so a longer cooling time can reduce the heatload from this isotope. Nonetheless, the halflives of ${ }^{238} \mathrm{Pu}$ and ${ }^{241} \mathrm{Am}$ are about 90 and 430 years respectively, and it is impractical to wait that long for reprocessing to reduce the heatload significantly (i.e., the decay of ${ }^{244} \mathrm{Cm}$ is not enough of a heatload reduction by itself). It is also impractical to wait much longer than seven years for cooling because the ${ }^{241} \mathrm{Pu}$ rapidly decays to ${ }^{241} \mathrm{Am}$, increasing the plutonium destruction rate (see Table 4-3) but losing a valuable fissile plutonium isotope in the process. Therefore, a cooling time of seven years is chosen for all spent MOX recycles of plutonium in this research. 
Table 4-3. Weight Percent Plutonium in Transuranic Material as a Function of Decay Time After Irradiation Through One Pass of MOX Fuel

\begin{tabular}{|c|c|c|}
\hline Years of Cooling & Percent $\mathrm{Pu}$ & Percent Pu Built Up as MA \\
\hline 1 & 28.6 & 5.68 \\
\hline 3 & 29.6 & 6.05 \\
\hline 5 & 30.5 & 6.95 \\
\hline 7 & 31.3 & 7.80 \\
\hline 10 & 32.4 & 8.59 \\
\hline
\end{tabular}

For a cooling time of seven years, the destruction of plutonium in one "pass" of MOX fuel is about 30\%. Fig. 4-1 shows the cumulative percent of plutonium depleted each pass and the relative percent of minor actinides that accumulate as the number of passes increases. Table 4-4 gives more detailed information about each recycle, and Table 4-5 displays the activity and heatload as a function of cooling time for the second and third pass of MOX fuel relative to the first. Note that the uranium enrichment never increases above $3 \mathrm{w} \%$ for any pass, which is feasible in modern uranium enrichment plants. 


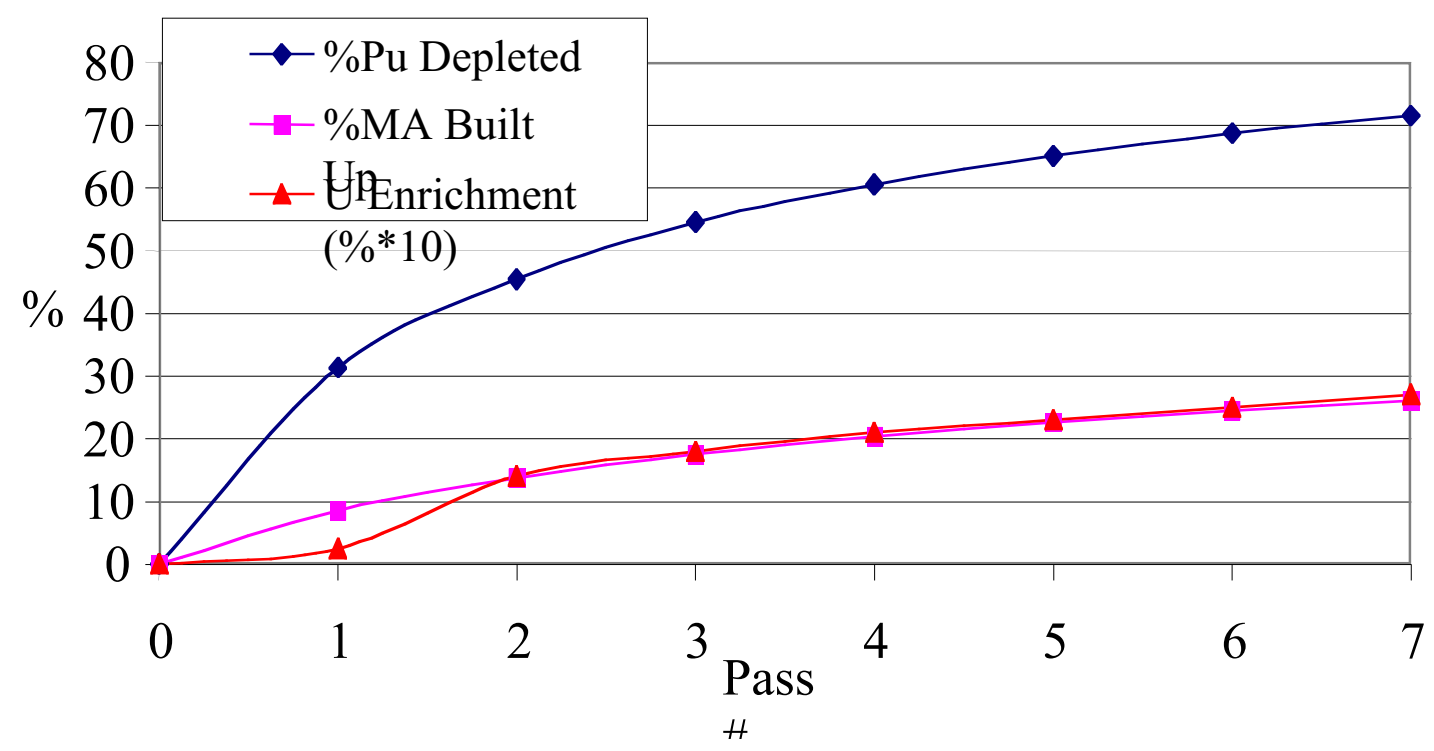

Fig. 4-1. Depletion of Pu and Accumulation of Minor Actinides for Multi-Recycling of $\mathrm{Pu}$ as MOX Fuel in LWRs

Table 4-4. Detailed Results For Each Plutonium Recycle as MOX

\begin{tabular}{|c|c|c|c|c|c|c|c|}
\hline Pass & $\begin{array}{c}\% \mathrm{Pu} \\
\text { number } \\
\text { depleted/ } / \\
\text { pass }\end{array}$ & $\begin{array}{c}\text { Cumulative } \\
\mathrm{Pu} \text { put into } \\
\text { system }\end{array}$ & $\begin{array}{c}\text { Cumulative } \\
\% \mathrm{Pu} \\
\text { depleted }\end{array}$ & $\begin{array}{c}\text { MAs built } \\
\text { up per } \\
\text { cycle (\%) }\end{array}$ & $\begin{array}{c}\text { Cumulative } \\
\% \text { MAs Built } \\
\text { Up }\end{array}$ & $\begin{array}{c}\text { Ratio of Pu } \\
\text { depleted to } \\
\text { MAs built up }\end{array}$ & $\begin{array}{c}\text { Uranium } \\
\text { enrichment } \\
\left(\%{ }^{235} \mathrm{U}\right)\end{array}$ \\
\hline 1 & 31.3 & 100 & 31.3 & 8.59 & 8.6 & 3.7 & 0.25 \\
\hline 2 & 28.3 & 131.3 & 45.4 & 9.43 & 13.7 & 3.3 & 1.4 \\
\hline 3 & 27.4 & 159.6 & 54.5 & 9.91 & 17.5 & 3.1 & 1.8 \\
\hline 4 & 26.2 & 187 & 60.5 & 9.99 & 20.3 & 3.0 & 2.1 \\
\hline 5 & 25.5 & 213.2 & 65.1 & 10.2 & 22.6 & 2.9 & 2.3 \\
\hline 6 & 25.3 & 238.7 & 68.7 & 10.3 & 24.5 & 2.9 & 2.5 \\
\hline 7 & 24.7 & 264 & 71.5 & 10.3 & 26.0 & 2.8 & 2.7 \\
\hline
\end{tabular}


Table 4-5. Activity and Heatload of Eight Assemblies of Spent MOX Fuel as a Function of Cooling Time

\begin{tabular}{|c|c|c|c|c|c|c|}
\hline $\begin{array}{l}\text { Activity } \\
\text { (Ci) } \\
\# \text { years }\end{array}$ & $\begin{array}{l}\text { First } \\
\text { Recycle } \\
\text { Actinides }\end{array}$ & Total & $\begin{array}{l}\text { Second } \\
\text { Recycle } \\
\text { Actinides }\end{array}$ & Total & $\begin{array}{l}\text { Third } \\
\text { Recycle } \\
\text { Actinides }\end{array}$ & Total \\
\hline 0 & $5.58 \mathrm{E}+06$ & $5.46 \mathrm{E}+08$ & $5.87 \mathrm{E}+06$ & $5.57 \mathrm{E}+08$ & $5.87 \mathrm{E}+06$ & $5.57 \mathrm{E}+08$ \\
\hline 1 & $4.11 \mathrm{E}+06$ & $1.26 \mathrm{E}+07$ & $4.31 \mathrm{E}+06$ & $1.27 \mathrm{E}+07$ & $4.31 \mathrm{E}+06$ & $1.28 \mathrm{E}+07$ \\
\hline 3 & $3.46 \mathrm{E}+06$ & $6.60 \mathrm{E}+06$ & $3.63 \mathrm{E}+06$ & $6.77 \mathrm{E}+06$ & $3.63 \mathrm{E}+06$ & $6.80 \mathrm{E}+06$ \\
\hline 5 & $3.16 \mathrm{E}+06$ & $4.99 \mathrm{E}+06$ & $3.31 \mathrm{E}+06$ & $5.17 \mathrm{E}+06$ & $3.31 \mathrm{E}+06$ & $5.20 \mathrm{E}+06$ \\
\hline 7 & $2.90 \mathrm{E}+06$ & $4.30 \mathrm{E}+06$ & $3.04 \mathrm{E}+06$ & $4.48 \mathrm{E}+06$ & $3.04 \mathrm{E}+06$ & $4.50 \mathrm{E}+06$ \\
\hline $\begin{array}{c}\text { Heatload } \\
\text { (W) }\end{array}$ & Actinides & Total & Actinides & Total & Actinides & Total \\
\hline 0 & $7.85 \mathrm{E}+04$ & $5.43 \mathrm{E}+06$ & $8.33 \mathrm{E}+04$ & $5.59 \mathrm{E}+06$ & $8.56 \mathrm{E}+04$ & $5.61 \mathrm{E}+06$ \\
\hline 1 & $3.03 \mathrm{E}+04$ & $6.65 \mathrm{E}+04$ & $3.23 \mathrm{E}+04$ & $6.80 \mathrm{E}+04$ & $3.41 \mathrm{E}+04$ & $6.99 \mathrm{E}+04$ \\
\hline 3 & $1.72 \mathrm{E}+04$ & $2.93 \mathrm{E}+04$ & $1.86 \mathrm{E}+04$ & $3.05 \mathrm{E}+04$ & $2.01 \mathrm{E}+04$ & $3.22 \mathrm{E}+04$ \\
\hline 5 & $1.61 \mathrm{E}+04$ & $2.23 \mathrm{E}+04$ & $1.74 \mathrm{E}+04$ & $2.36 \mathrm{E}+04$ & $1.88 \mathrm{E}+04$ & $2.51 \mathrm{E}+04$ \\
\hline 7 & $1.56 \mathrm{E}+04$ & $1.99 \mathrm{E}+04$ & $1.68 \mathrm{E}+04$ & $2.12 \mathrm{E}+04$ & $1.82 \mathrm{E}+04$ & $2.26 \mathrm{E}+04$ \\
\hline
\end{tabular}

Both the heatload and activity of spent MOX fuel increase with the number of recycles, but not significantly enough that reprocessing the second or third pass is much different than recycling the first pass of spent MOX fuel. Fig. 4-2 shows the isotopic composition of the actinides at the end of each pass. As expected, the concentration of ${ }^{239} \mathrm{Pu}$ decreases as the pass number increases, whereas the ${ }^{242} \mathrm{Pu}$ level increases significantly (i.e., builds in from ${ }^{241} \mathrm{Pu}$ ), causing an overall decrease in the fissile quality of the material. The ${ }^{238} \mathrm{Pu}$ content is around $4-5 \mathrm{w} \%$ for all passes, including the initial pass of plutonium from spent $\mathrm{UO}_{2}$ fuel, which exceeds the fabrication limit of $2.1 \mathrm{w} \%$ and requires hot cells or at least increased shielding for handling. ${ }^{28}$ 


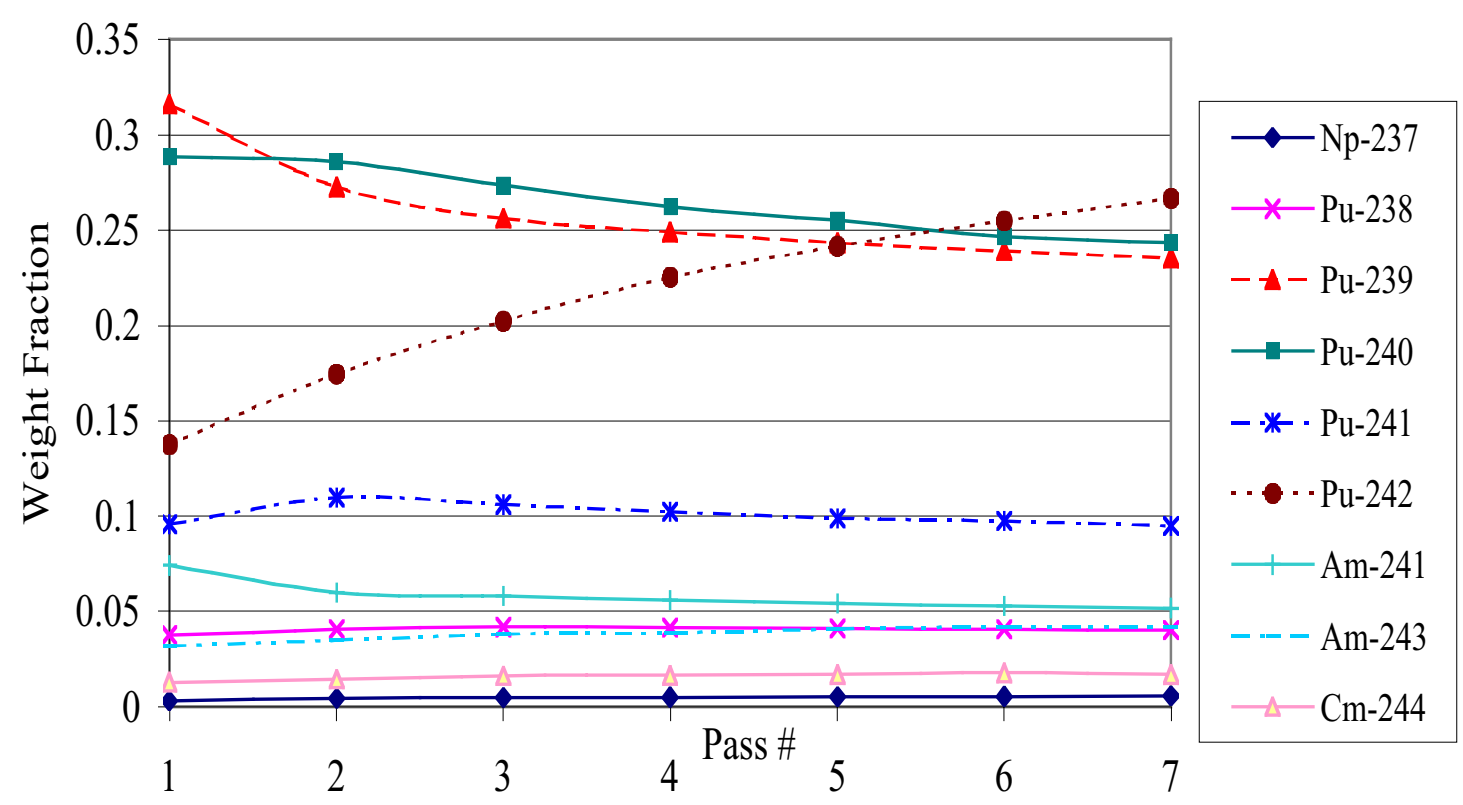

Fig. 4-2. Change in Actinide Isotopes as the Number of Passes Increased

Two other concerns exist for the implementation of MOX fuel irradiation of plutonium from SNF: what influence do changes in the initial plutonium vector have on the results, and are similar destruction rates observed for different reactor assemblies? Thus, the next calculation compares the amount of plutonium depleted and minor actinides built up for different initial plutonium streams followed by a comparison of burnup results for a $15 \times 15$ versus a $17 \times 17$ assembly.

Plutonium vectors from SNF with a burnup of $\sim 30 \mathrm{GWd} / \mathrm{MTHM}$ and a cooling time of 30 years and from SNF with a burnup of $\sim 50 \mathrm{GWd} / \mathrm{MTHM}$ and a cooling time of only three years are compared to the basecase, which is SNF burned to $\sim 60 \mathrm{GWd} / \mathrm{MTHM}$ with ten years of cooling in Table 4-6. Minor actinide buildup from the first case occurs mainly from cooling, not irradiation, because the burnup is relatively low and cooling time is relatively high. The second case has lower plutonium depletion, primarily 
Table 4-6. Comparison of Plutonium Depletion and Minor Actinide Buildup for One Pass with Different Starting Plutonium Vectors

\begin{tabular}{|c|c|c|}
\hline Case & Pu depletion & MA buildup \\
\hline $\begin{array}{c}30 \mathrm{GWd} / \mathrm{MTHM} \text { and } \\
30 \text { cooling years }\end{array}$ & $28.3 \%$ & $5.5 \%$ \\
\hline $\begin{array}{c}50 \mathrm{GWd} / \mathrm{MTHM} \text { and } \\
3 \text { cooling years }\end{array}$ & $27.8 \%$ & $4.6 \%$ \\
\hline $60 \mathrm{GWd} / \mathrm{MTHM}$ and \\
10 cooling years
\end{tabular}

because ${ }^{241} \mathrm{Pu}$ has not yet decayed. In both cases, the differences observed are not significant enough to influence the results of the multi-recycling calculations, so no further work is deemed necessary at this point.

Benchmarking efforts for Monteburns focused on a common H.B. Robinson 15x15 PWR design, but the implementation approaches presented in Section 2.2 are based upon the Materials Disposition program and assume that a majority of the existing LWRs that would be used to burn MOX fuel would be $17 \times 17$ PWRs. ${ }^{80}$ A brief comparison of a $15 \times 15$ to a $17 \times 17$ PWR assembly design is performed, and results comparing the isotopic compositions and plutonium depletion for each case with a common burnup are given in Table 4-7. The depletion of plutonium is slightly less for the $15 \times 15$ assembly, which is probably because the spectrum is a bit harder with the slightly larger heavy metal-to-hydrogen ratio in the $17 \times 17$ assembly. 
Table 4-7. Comparison of Burnup and Final Isotopic Vector (in Weight Fraction) of 15x15 and 17x17 PWR Models for One Pass of MOX Fuel

\begin{tabular}{|c|c|c|}
\hline & $15 \times 15$ & $17 \times 17$ \\
\hline${ }^{238} \mathrm{Pu}$ & 0.0431 & 0.0428 \\
\hline${ }^{239} \mathrm{Pu}$ & 0.3609 & 0.3697 \\
\hline${ }^{240} \mathrm{Pu}$ & 0.3295 & 0.3229 \\
\hline${ }^{241} \mathrm{Pu}$ & 0.1093 & 0.1095 \\
\hline${ }^{242} \mathrm{Pu}$ & 0.1573 & 0.1551 \\
\hline $\mathrm{Pu}$ depletion & 28.3 & 27.2 \\
\hline
\end{tabular}

The main decision that has to be made in this research is to determine the number of recycles of plutonium that best enhances performance in the ADS. With only two recycles (three passes), more than $50 \%$ of the plutonium is depleted, which is one goal of this research. Additional recycles increase the depletion rate of plutonium even more. Therefore, it must be determined whether any further recycles offer additional advantages to the ADS operations or not. This issue is explored later in this chapter.

\subsection{Addition of Actinide Material Other Than Plutonium to MOX}

The nonproliferation advantage of keeping minor actinides or fission products with the plutonium is that the activity and/or heatload of the MOX fuel increases, but this increase also makes MOX fabrication more complicated. The activity for the minor actinide case after ten years almost decreases to that of the plutonium-only case after seven years, but the heatload remains more than twice that of the plutonium-only case, as is shown in Table 4-8. The case with strontium and cesium retention has a much higher activity and a slightly higher heatload than the Pu-only case (which is the point of adding 


\section{LA-14052-T}

$\mathrm{Sr}$ and $\mathrm{Cs}$ in the first place). For subsequent calculations, it is assumed that the spent fuel with minor actinides is reprocessed after 10 years and the spent fuel with $\mathrm{Sr}$ and $\mathrm{Cs}$ is reprocessed after 7 years since the activity does not decrease for hundreds of years and the assumption is that hot cells are required anyway. Neutronic safety parameters for these cases are discussed in the next chapter.

The difference in the depletion rate of plutonium in MOX fuel both by itself and with minor actinides and $\mathrm{Cs} / \mathrm{Sr}$ is shown in Table 4-9. When $\mathrm{Cs}$ and $\mathrm{Sr}$ are added, little change is seen in plutonium depletion and minor actinide buildup, and it is assumed that additional passes behave similarly. However, when minor actinides become part of the MOX fuel, the plutonium depletion for the first pass decreases significantly (from about $28 \%$ to $15 \%$ ). Additional recycles have to be performed to achieve the same destruction of plutonium. For this case, minor actinides are being built up at a slower rate than they are being depleted during irradiation, so there is a net decrease. After seven years of

cooling, however, minor actinides do start building in, primarily from the decay of ${ }^{241} \mathrm{Pu}$ to ${ }^{241} \mathrm{Am}$ (with a 14.4 year halflife), and the same amount of minor actinide exists after seven years as initially.

Further calculations show that multiple recycling of Pu plus MAs in MOX fuel would be difficult. To meet reactivity requirements, the amount of actinide contained in the heavy metal of MOX fuel is raised to $12.55 \mathrm{w} \%$, which is shown to be the largest possible in previous calculations. ${ }^{3}$ In addition, even with the increase in actinide concentration, the uranium enrichment is still required to be $2.4 \mathrm{w} \%$ for the first pass. 
Table 4-8. Activity and Heatload of MOX Cases (Eight Assemblies) with MAs or Fission Products as a Function of Cooling Time

\begin{tabular}{|c|c|c|c|c|c|c|}
\hline $\begin{array}{c}\text { Activity } \\
\text { (Ci) } \\
\begin{array}{c}\text { of years } \\
\text { cooling }\end{array}\end{array}$ & $\begin{array}{c}\text { Pu only } \\
\text { in MOX } \\
1^{\text {st }} \text { pass } \\
\text { Actinides }\end{array}$ & Total & $\begin{array}{c}\text { Pu plus } \\
\text { MAs in } \\
\text { Actinides }\end{array}$ & Total & $\begin{array}{c}\text { Pu plus Sr } \\
\text { and Cs in } \\
\text { MOX } \\
\text { Actinides }\end{array}$ & Total \\
\hline 0 & $5.58 \mathrm{E}+06$ & $5.46 \mathrm{E}+08$ & $1.06 \mathrm{E}+07$ & $5.55 \mathrm{E}+08$ & $5.29 \mathrm{E}+06$ & $5.23 \mathrm{E}+08$ \\
\hline 1 & $4.11 \mathrm{E}+06$ & $1.26 \mathrm{E}+07$ & $6.32 \mathrm{E}+06$ & $1.46 \mathrm{E}+07$ & $3.94 \mathrm{E}+06$ & $3.50 \mathrm{E}+07$ \\
\hline 3 & $3.46 \mathrm{E}+06$ & $6.60 \mathrm{E}+06$ & $4.87 \mathrm{E}+06$ & $7.97 \mathrm{E}+06$ & $3.33 \mathrm{E}+06$ & $2.83 \mathrm{E}+07$ \\
\hline 5 & $3.16 \mathrm{E}+06$ & $4.99 \mathrm{E}+06$ & $4.45 \mathrm{E}+06$ & $6.29 \mathrm{E}+06$ & $3.04 \mathrm{E}+06$ & $2.58 \mathrm{E}+07$ \\
\hline 7 & $2.90 \mathrm{E}+06$ & $4.30 \mathrm{E}+06$ & $4.10 \mathrm{E}+06$ & $5.54 \mathrm{E}+06$ & $2.79 \mathrm{E}+06$ & $2.42 \mathrm{E}+07$ \\
\hline 10 & $2.56 \mathrm{E}+06$ & $3.70 \mathrm{E}+06$ & $3.65 \mathrm{E}+06$ & $4.83 \mathrm{E}+06$ & $2.46 \mathrm{E}+06$ & $2.23 \mathrm{E}+07$ \\
\hline \hline Heatload & & & & & & \\
\hline W) & & & & & & \\
\hline 0 & $7.85 \mathrm{E}+04$ & $5.43 \mathrm{E}+06$ & $2.35 \mathrm{E}+05$ & $5.70 \mathrm{E}+06$ & $7.19 \mathrm{E}+04$ & $5.05 \mathrm{E}+06$ \\
\hline 1 & $3.03 \mathrm{E}+04$ & $6.65 \mathrm{E}+04$ & $8.53 \mathrm{E}+04$ & $1.20 \mathrm{E}+05$ & $2.77 \mathrm{E}+04$ & $1.27 \mathrm{E}+05$ \\
\hline 3 & $1.72 \mathrm{E}+04$ & $2.93 \mathrm{E}+04$ & $4.51 \mathrm{E}+04$ & $5.66 \mathrm{E}+04$ & $1.58 \mathrm{E}+04$ & $8.94 \mathrm{E}+04$ \\
\hline 5 & $1.61 \mathrm{E}+04$ & $2.23 \mathrm{E}+04$ & $4.16 \mathrm{E}+04$ & $4.76 \mathrm{E}+04$ & $1.49 \mathrm{E}+04$ & $8.01 \mathrm{E}+04$ \\
\hline 7 & $1.56 \mathrm{E}+04$ & $1.99 \mathrm{E}+04$ & $3.99 \mathrm{E}+04$ & $4.42 \mathrm{E}+04$ & $1.44 \mathrm{E}+04$ & $7.52 \mathrm{E}+04$ \\
\hline & $1.49 \mathrm{E}+04$ & $1.82 \mathrm{E}+04$ & $3.76 \mathrm{E}+04$ & $4.10 \mathrm{E}+04$ & $1.38 \mathrm{E}+04$ & $6.98 \mathrm{E}+04$ \\
\hline
\end{tabular}

Table 4-9. Comparison of Pu Depletion and MA Buildup Per Pass When Fission Products or Minor Actinides Are Added to Pu in MOX

\begin{tabular}{|l|l|l|}
\hline Case & Pu Depletion & MA Buildup \\
\hline Plutonium Only & 28.3 & 5.68 \\
\hline Plutonium Plus Sr and Cs & 27.5 & 5.59 \\
\hline Plutonium Plus MAs & 15.2 & $-2.00^{\text {a }}$ \\
\hline
\end{tabular}

${ }^{a}$ The buildup of minor actinides after 7 years of decay is approximately equal to MA depletion during irradiation, so the initial depletion is included here instead 
By the second pass, the necessary uranium enrichment rises to $5.8 \mathrm{w} \%$ and significant safety conditions exist (see Section 5.1 for more information). Commercial uranium enrichment plants currently can only produce a product that is less than $\sim 5 \mathrm{w} \%$ ${ }^{235} \mathrm{U}$, although higher enrichments are technically feasible. Nonetheless, for the purpose of this research, it is assumed that the second pass is not economically achievable and that it is not possible to perform multi-recycling of the plutonium with minor actinides in MOX, so the remaining $80-85 \%$ of the plutonium $(\sim 80 \%$ with a cooling time of ten years) would be sent to the ADS in Tier 2. The ending isotopes after the first and second passes are displayed in Fig. 4-3. The ${ }^{238} \mathrm{Pu}$ concentration significantly increases in the second pass, which is what makes the heatload large. Additionally, the ${ }^{239} \mathrm{Pu}$ concentration decreases, which is why the uranium enrichment has to be increased to impractical levels.

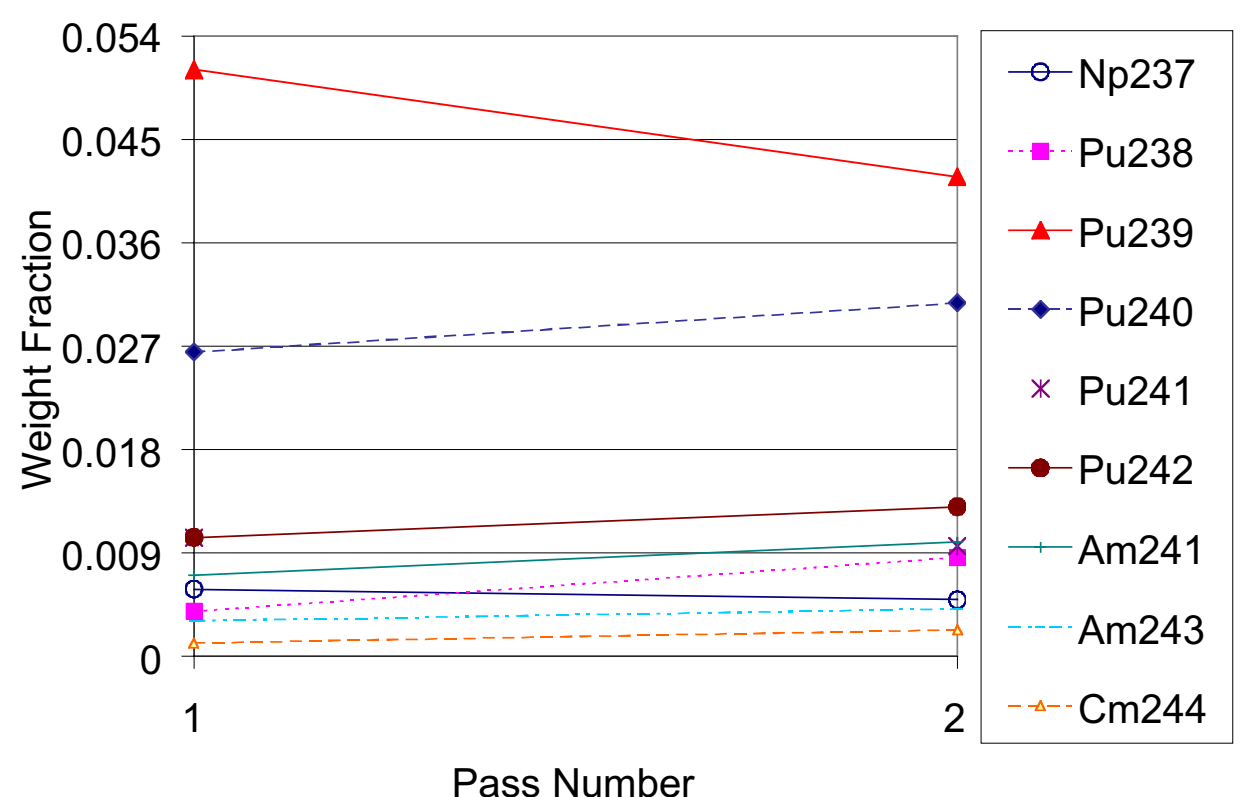

Fig. 4-3. Isotopic Composition of Actinides in MOX Fuel with $\mathrm{Pu}+\mathrm{MA}$ Stream 


\subsection{Effects of Recycles in Tier 1 on Tier 2 (ADS)}

The initial purpose of studying a two-tiered system was to find a way to decrease the reactivity swing per cycle in an ADS. The idea of burning only minor actinides in an ADS originated for this purpose. Keeping the difference between $\mathrm{k}_{\mathrm{eff}}$ and 1.0 to less than about a factor of two increase over the course of a cycle is the most practical limit for an ADS economically. However, reducing the reactivity swing infinitely requires that an impractically large amount of plutonium is burned in Tier 1. Even with six recycles of plutonium as MOX fuel, only $71.5 \%$ of the plutonium is burned. Three, four, or five passes of LWR irradiation is probably more practical, so the material remaining from these cases is added to the minor actinides from SNF, and the results from the performance with these feed material in an ADS is compared to the results with feed material consisting of all plutonium and minor actinides from SNF and the irradiated actinides when plutonium and minor actinides are burned together in one pass in a LWR.

Fig. 4-4 shows the feed rate as a function of the number of cycles for different feed compositions coming into the ADS. The feed rate represents the amount of actinide material added to the system between each cycle to increase the value of $\mathrm{k}_{\text {eff }}$ back to 0.97 (it also assumes that the zirconium and existing actinides are reused). Remember that for most cases, the starting feed rate is greater than the equilibrium one because minor actinides are being built in, but when the starting plutonium content is low enough (i.e., after four and five passes of plutonium burning in an LWR), the feed rate actually decreases before equilibrium is reached, which could make operations difficult as is discussed shortly. Table 4-10 shows the resulting reactivity swing at equilibrium for all five cases along with the actual isotopic vectors entering the ADS and the initial volume 
percent actinide in the most fissile fuel zone. This fraction increases as more feed is added until equilibrium is reached.

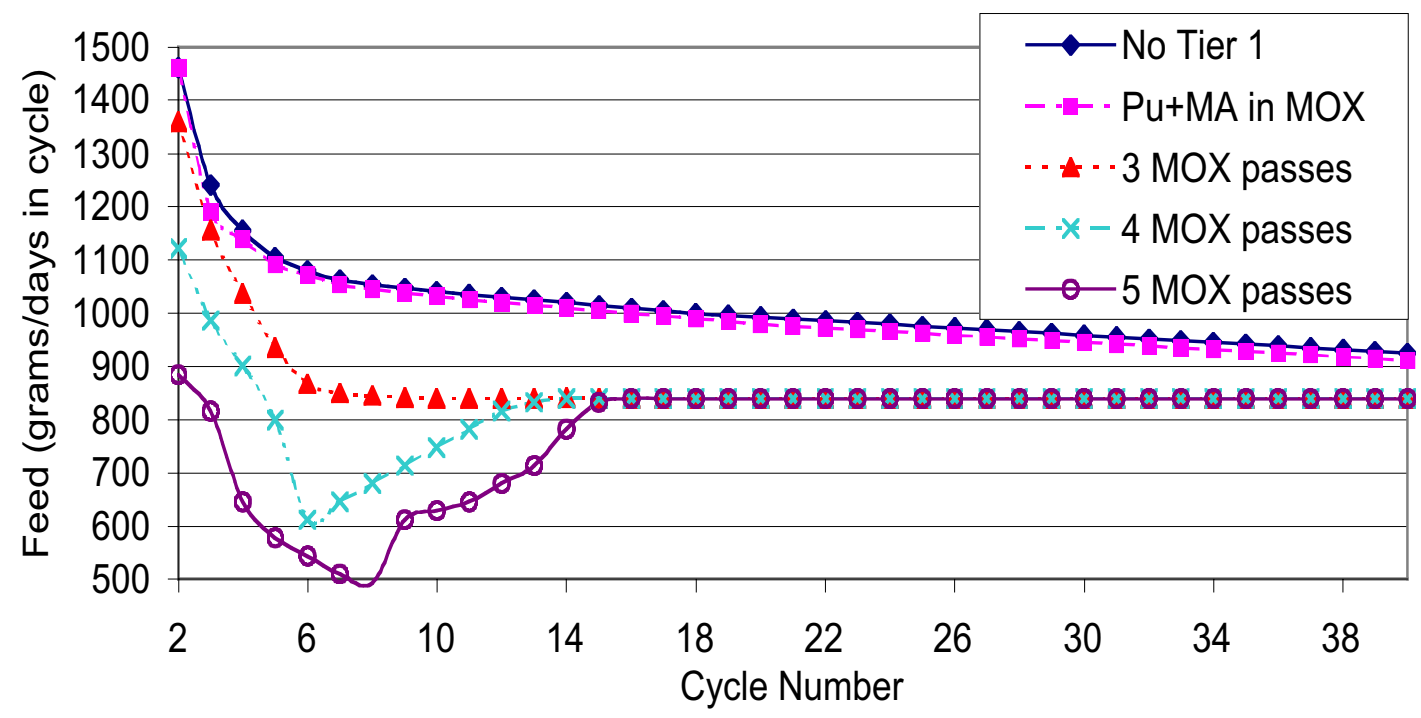

Fig. 4-4. Feed Rate as a Function of Cycle in the ADS

Table 4-10. Isotopic Vector Entering ADS and Resulting Reactivity Swing

\begin{tabular}{|c|c|c|c|c|c|}
\hline & No Tier 1 & Pu+MA MOX & 3 MOX passes & 4 MOX passes & MOX passes \\
\hline${ }^{238} \mathrm{U}$ & 0.064 & 0.081 & 0.109 & 0.116 & 0.121 \\
\hline${ }^{237} \mathrm{~Np}$ & 0.055 & 0.038 & 0.082 & 0.086 & 0.090 \\
\hline${ }^{238} \mathrm{Pu}$ & $\mathbf{0 . 0 3 0}$ & $\mathbf{0 . 0 6 5}$ & $\mathbf{0 . 0 2 4}$ & $\mathbf{0 . 0 2 1}$ & $\mathbf{0 . 0 1 9}$ \\
\hline${ }^{239} \mathrm{Pu}$ & $\mathbf{0 . 3 9 6}$ & $\mathbf{0 . 2 8 9}$ & $\mathbf{0 . 1 5 1}$ & $\mathbf{0 . 1 2 9}$ & $\mathbf{0 . 1 1 5}$ \\
\hline${ }^{240} \mathrm{Pu}$ & $\mathbf{0 . 2 0 5}$ & $\mathbf{0 . 2 2 9}$ & $\mathbf{0 . 1 5 7}$ & $\mathbf{0 . 1 3 6}$ & $\mathbf{0 . 1 1 9}$ \\
\hline${ }^{241} \mathrm{Pu}$ & $\mathbf{0 . 0 8 0}$ & $\mathbf{0 . 0 4 8}$ & $\mathbf{0 . 0 6 1}$ & $\mathbf{0 . 0 5 3}$ & $\mathbf{0 . 0 4 6}$ \\
\hline${ }^{242} \mathrm{Pu}$ & $\mathbf{0 . 0 8 0}$ & $\mathbf{0 . 0 9 7}$ & $\mathbf{0 . 1 1 2}$ & $\mathbf{0 . 1 1 2}$ & $\mathbf{0 . 1 1 0}$ \\
\hline${ }^{241} \mathrm{Am}$ & 0.055 & 0.098 & 0.174 & 0.194 & 0.209 \\
\hline${ }^{243} \mathrm{Am}$ & 0.024 & 0.033 & 0.088 & 0.103 & 0.115 \\
\hline${ }^{244} \mathrm{Cm}$ & 0.009 & 0.015 & 0.036 & 0.041 & 0.046 \\
\hline${ }^{245} \mathrm{Cm}$ & 0.001 & 0.004 & 0.005 & 0.005 & 0.006 \\
\hline Vol.\% Act. & 11 & 14.5 & 21.6 & 24.4 & 27 \\
\hline delta k-eff & 0.07 & 0.06 & 0.035 & 0.03 & 0.025 \\
\hline
\end{tabular}


From Fig. 4-4, it is apparent that an equilibrium feed rate is reached the fastest for the case that burns plutonium for three passes as MOX fuel before going to an ADS. Too much plutonium is present in the case without Tier 1 and that for only one pass of plutonium plus minor actinides in Tier 1, and too little plutonium comprises the cases where plutonium is burned for four and five passes in Tier 1 to reach an equilibrium actinide vector sooner. In the first two cases, so much plutonium exists initially that neutrons predominately contribute to fissions instead of captures, and it takes a while for an equilibrium concentration of minor actinides to build up and compete with the plutonium. Thus, the first feed rate is higher than that seen at the end, and it slowly decreases down to equilibrium in the middle. At a starting plutonium content of about $50 \%$ (actinide fission-to-capture ratio of about 0.8 ), equilibrium is reached the fastest because a ratio of Pu-to-MAs of about 1.0 is observed.

As expected, as reduced amounts of plutonium are fed to the ADS, the reactivity swing decreases. However, the cases associated with more than two recycles (three passes) of plutonium as MOX in the LWR have a small enough starting plutonium content that plutonium builds into the system during irradiation, increasing the fission-tocapture ratio, which is previously below the desired quantity of 0.8 . In fact, the feed rates over the first 15 or so cycles actually must be lower than the equilibrium feed rate to avoid having $\mathrm{k}_{\mathrm{eff}}$ rise to critical or above. These results are consistent with a similar study that indicated that a plutonium content above $60 \%$ or a ${ }^{235} \mathrm{U}$ content above $50 \%$ should be used within the fuel for a fast spectrum minor actinide burner to reduce safety concerns in the system. ${ }^{19}$ 


\subsection{Summary/Conclusions for First Three Objectives}

In Section 4.3, it is shown that no more than two recycles should be performed in an ADS, so three passes of MOX fuel to transmute plutonium is considered the best when the remainder of the material is sent to an ADS because it maximizes plutonium fissioning in the LWR without affecting the ADS significantly. For one region in oneeighth of an LWR core, the mass of initial plutonium used in this research is $278 \mathrm{~kg}$. The depletion rate of plutonium during the first pass is $31.3 \%$ and the second is $28.3 \%$, for a total of $\sim 60 \%$ of plutonium needing to be replaced, so 1.6 times the initial amount is needed altogether. Since the amount of plutonium burned each recycle is replaced with "fresh" SNF, the actual quantity of plutonium added in a one-eighth core during three passes is $278 \mathrm{~kg} * 1.6$, or $445 \mathrm{~kg}$, which comes to about 3.6 metric tons of legacy plutonium being depleted in a full core over three passes. Assuming each irradiation cycle is about 1.5 years and each rod is irradiated for 4.5 years followed by seven years of cooling and two years of fabrication time, it would take about 13.5 years after the first MOX fuel loading before that material would be ready to be loaded in the reactor again for another pass. Eight different first pass MOX loadings would be done in the meantime for a total of $9 * 3.6$ (or 32) metric tons of plutonium irradiated per reactor, which requires three passes and takes about 40 years assuming full capacity. To burn the approximately 1300 metric tons of plutonium from legacy SNF (110 kT SNF * 1.19\% Pu), about 41 reactors are required, which is slightly higher than that estimated in Section 2.2.2 because it assumes that each reactor only runs for 40 years (one license extension) with two recycles, and is thus not unreasonable. Fewer reactors could be used with additional license extensions if the cooling time between recycles is larger. 
Over the course of three passes, $54.5 \%$ of the legacy plutonium is depleted, during which $17.5 \%$ of it is converted to minor actinides (see Fig. 4-1). Thus, only about 37\% of the plutonium is actually destroyed and does not need to be processed in Tier 2 . Additionally, for every 100 kilograms of plutonium in SNF there are about 18 kilograms of minor actinides that are separated before Tier 1 and must be irradiated in Tier 2 . The amount of material sent to an ADS with two recycles of MOX fuel therefore amounts to:

$\sim 110,000$ tonnes $\mathrm{SNF} * 0.0119 \mathrm{Pu} / \mathrm{SNF} *(0.63$ (=fraction of Pu left after Tier 1$)+$

$$
\text { * } 0.18(\mathrm{MA} / \mathrm{Pu} \text { ratio in } \mathrm{SNF}))=1060 \text { tonnes. }
$$

The steady-state actinide inventory in the fast-spectrum ADS considered is about 2.2 tonnes, and the feed rate is about $840 \mathrm{~g} /$ day for a $840 \mathrm{MWt}$ system. Over the expected operation period of 60 years, about 20 tonnes of actinides can be burned in such a system, requiring around 53 ADSs to complete the mission. This can be compared to the 77 ADSs with higher costs required to destroy all Pu and MAs from SNF (i.e., without supplement of a LWR). Similar calculations show that if one more recycle can be performed in the LWR and meet reactivity limitations in the ADS, then 23 reactors would be required over 54 years and only 30 ADSs would be needed to supplement them. However, three passes are still recommended based on the results of this research.

Although the feed rate and change in reactivity as a function of cycle in the ADS is one general measure of system safety, specific safety parameters must still be addressed for full LWR cores burning MOX fuel the LWR and for determining if the ADS creates more radiotoxic waste in the form of spallation products than it destroys. These two issues are addressed in Section 5. 
LA-14052-T 


\subsection{Implementation/Safety Calculations}

The remainder of the objectives of this research is to show that both the Tier 1 and Tier 2 transmutation systems being proposed (LWRs with MOX fuel and ADSs) can be operated safety and efficiently under the proposed operating conditions. For LWRs, this means showing that full cores of MOX fuel can be irradiated and still meet all the neutronic safety conditions typically imposed on commercial LWRs. For ADSs, it means showing that spallation products do not cause a greater radiotoxicity concern than the SNF itself. These two issues are addressed in Sections 5.1 and 5.2 respectively.

\subsection{Safety Conditions for a Full Core of MOX Fuel in an LWR}

Examining neutronic safety conditions and designing an assembly for a full core of MOX fuel to meet those conditions in an LWR is the premise of all calculations performed in this research. Without the full core design, significant plutonium depletion becomes difficult in the U.S. unless new reactors are constructed. Neutronic safety conditions are examined for two different cases in this research: one with just plutonium in the MOX fuel, and one with plutonium plus minor actinides. These cases are described in Sections 5.1.1 and 5.1.2 respectively. Note that additional safety analyses primarily in the area of thermal hydraulics would be required for implementation.

\subsubsection{Neutronic Safety Results with Plutonium}

Several different neutronic safety cases are examined here, including the effects

of: 1) varying plutonium concentrations; 2) different types of overmoderated assembly designs, 3) soluble boron concentration and enrichment, 4) 15x15 versus 17x17 
assembly designs, 5) multi-recycling, and 6) reactor- versus weapons-grade plutonium. First, different plutonium concentrations in the MOX fuel lead to varying safety conditions. Calculations are performed for three different plutonium compositions in the MOX fuel: low, medium, and high (corresponding to 5.3, 8.3, and $12 \mathrm{w} \%$ plutonium respectively). The results are shown in Table 5-1.

Table 5-1. Neutronic Safety Calculations for varying degrees of plutonium concentation in MOX fuel

\begin{tabular}{|c|c|c|c|c|c|c|}
\hline $\begin{array}{c}\text { Doppler } \\
\text { coefficient } \\
\text { (pcm/K) }\end{array}$ & $\begin{array}{l}\text { Low Pu } \\
\text { BOC }\end{array}$ & $\begin{array}{l}\text { Low Pu } \\
\text { EOC }\end{array}$ & $\begin{array}{l}\text { Med. Pu } \\
\text { BOC }\end{array}$ & $\begin{array}{l}\text { Med. Pu } \\
\text { EOC }\end{array}$ & $\begin{array}{l}\text { High Pu } \\
\text { BOC }\end{array}$ & $\begin{array}{l}\text { High Pu } \\
\text { EOC }\end{array}$ \\
\hline $\begin{array}{c}\text { Moderator } \\
\text { coeffic. } \\
\text { (pcm/K) }\end{array}$ & -61 & -63 & -47 & -52 & -23 & -0.4 \\
\hline $\begin{array}{c}\text { Boron } \\
\text { efficiency } \\
\text { (pcm/ppm) }\end{array}$ & 2.9 & 3.8 & 1.3 & 2.4 & 2.6 & -32 \\
\hline $\begin{array}{c}\text { Void } \\
\text { coefficient } \\
\text { (pcm/25\%void) }\end{array}$ & -242 & -249 & -199 & -217 & -104 & -129 \\
\hline $\begin{array}{c}\text { Control rod } \\
\text { worth (pcm) }\end{array}$ & 2778 & 2245 & 2275 & 2305 & 2329 & 1832 \\
\hline $\begin{array}{c}\text { Shutdown rod } \\
\text { worth (pcm) }\end{array}$ & 2115 & 1948 & 1905 & 1843 & 1478 & \\
\hline $\begin{array}{c}\text { Total rod worth } \\
\text { (pcm) }\end{array}$ & 5142 & 4105 & 4111 & 4064 & 3935 & \\
\hline
\end{tabular}


The absolute values of the void and moderator reactivity coefficients decrease as the amount of plutonium in the MOX fuel increases but still remain negative. At a plutonium concentration of $12 \mathrm{w} \%$, the void coefficient is approximately half that at 8.3 $\mathrm{w} \%$, so the potential for the void reactivity coefficient to become positive at higher plutonium concentrations is as observed in other studies. The control and shutdown rod worths also decrease as the plutonium concentration increases, partly due to the fact that Doppler coefficient at the beginning of cycle increases and also because the spectrum hardens. The fact that the control and shutdown rod worths are smaller as the plutonium fraction increases shows that safety concerns of increasing plutonium content must be weighed against the benefit of burning as much material as possible each cycle.

The boron efficiency for a full core of MOX fuel is below the lower limit of 4 $\mathrm{pcm} / \mathrm{ppm}$ even for the $5.3 \mathrm{w} \%$ (the smallest plutonium fraction) case, which is probably why one-third cores are the only ones currently licensed. Thus, even to burn full cores of MOX fuel with only $5.3 \mathrm{w} \%$ plutonium, changes to the control system have to be made. Since design changes have to be made anyway, they are made for $8.3 \mathrm{w} \%$ plutonium case in this research to be able to meet the implementation guidelines (otherwise the mission could not be done with existing LWRs). Techniques to increase the control/shutdown rod worths and boron efficiencies for this case are thus further developed in this research. Note that the accuracy for the cases given in Table 5-1 is not as great as that presented elsewhere in Section 5.1 (i.e., 2000 histories per cycle and 200 active cycles instead of 5000 and 500 respectively as is used for the following tables), but the correct trends are realized nonetheless. 
A previous study shows that the absolute values of the reactivity coefficients decrease and the boron worth increases as the hydrogen-to-heavy metal ratio increases in the reactor. ${ }^{32}$ Thus, as more water is added relative to fuel, the neutronic safety margins should be easier to meet. The simplest way to increase the hydrogen-to-heavy metal ratio is to use water holes in place of approximately ten fuel rods per assembly although decreasing the fuel rod diameter while maintaining a constant pitch is also an option. Both options are examined here, but neither increase the total rod worth or the boron efficiency enough to meet the desired criteria (see Table 5-2).

Table 5-2. Boron Efficiencies and Control and Shutdown Rod Worths with Overmoderated Systems

\begin{tabular}{|c|c|c|c|c|c|c|}
\hline & $\begin{array}{l}5.3 \mathrm{w} \% \mathrm{Pu} \\
\text { at } \mathrm{BOC} \\
\text { (with water } \\
\text { holes) }\end{array}$ & $\begin{array}{l}5.3 \mathrm{w} \% \mathrm{Pu} \\
\text { at EOC } \\
\text { (with water } \\
\text { holes) }\end{array}$ & $\begin{array}{l}8.3 \mathrm{w} \% \mathrm{Pu} \\
\text { at BOC } \\
\text { (with water } \\
\text { holes) }\end{array}$ & $\begin{array}{l}8.3 \mathrm{w} \% \mathrm{Pu} \\
\text { at EOC } \\
\text { (with water } \\
\text { holes) }\end{array}$ & $\begin{array}{l}8.3 \mathrm{w} \% \mathrm{Pu} \\
\text { at BOC (w/ } \\
\text { a smaller } \\
\text { diameter) }\end{array}$ & $\begin{array}{l}8.3 \mathrm{w} \% \mathrm{Pu} \\
\text { at EOC (w/ } \\
\text { a smaller } \\
\text { diameter) }\end{array}$ \\
\hline $\begin{array}{l}\text { Boron Effic. } \\
(\mathrm{pcm} / \mathrm{ppm})\end{array}$ & 3.4 & 4.6 & 3.3 & 3.2 & 3.9 & 3.4 \\
\hline $\begin{array}{l}\text { Boron Effic. } \\
\mathrm{w} / 25 \mathrm{w} \%{ }^{10} \mathrm{~B} \\
(\mathrm{pcm} / \mathrm{ppm})\end{array}$ & & & 4.7 & 5.5 & & \\
\hline $\begin{array}{l}\text { Control Rod } \\
\text { Worth (pcm- } \\
\text { w/ AgCdIn) }\end{array}$ & 2561 & 2136 & 2258 & 2306 & 2885 & 2618 \\
\hline $\begin{array}{l}\text { Shutdown } \\
\text { Rod Worth } \\
\left(\mathrm{pcm}-\mathrm{w} / \mathrm{B}_{4} \mathrm{C}\right)\end{array}$ & 1879 & 1645 & 1737 & 1704 & 2214 & 1868 \\
\hline $\begin{array}{l}\text { Total Rod } \\
\text { Worth (pcm) }\end{array}$ & 4733 & 3912 & 4008 & 4223 & 4976 & 4572 \\
\hline $\begin{array}{l}\text { Rod worth w/ } \\
\text { all } \mathrm{B}_{4} \mathrm{C}(\mathrm{pcm})\end{array}$ & - & - & 5172 & 5243 & - & - \\
\hline
\end{tabular}


It is thus assumed that it would be easier to remove several fuel rods and let water flow through those locations than to fabricate rods of different sizes, so further design calculations are explored only for a system with extra water holes. To meet safety criteria, the first modification is to change the composition of the control rods from silver-indium-cadmium, which is commonly used, to $\mathrm{B}_{4} \mathrm{C}$ (the same composition as the shutdown rods) so they have a more significant impact. This increases the rod worth slightly, but not enough. The use of enriched boron in these rods (i.e., to $25 \%{ }^{10} \mathrm{~B}$ ) is also necessary to meet the total rod worth requirement of $5000 \mathrm{pcm}$. These changes do not increase the boron efficiency much, so the enrichment of the soluble boron in the water is increased as well. An enrichment of $90 \mathrm{w} \%$ B-10 produces boron efficiencies as high as $20 \mathrm{pcm} / \mathrm{ppm}$, so smaller enrichments such as $25-40 \mathrm{w} \% \mathrm{~B}-10$ are explored. With the extra water holes, only a slight B-10 enrichment (to $25 \%$ from $\sim 20 \%$ in natural boron) is needed to get a boron efficiency greater than $4 \mathrm{pcm} / \mathrm{ppm}$ both at the beginning and end of cycle (see Table 5-3). Thus, the baseline assembly design used in further MOX fuel irradiation calculations consists of 12 water holes instead of fuel rods, control and shutdown rods made of $\mathrm{B}_{4} \mathrm{C}$, and $25 \mathrm{w} \%{ }^{10} \mathrm{~B}$ enriched boron both in the water and control/shutdown rods.

Table 5-3. Boron Efficiency as Enrichment of Boron Changes for Medium Pu case

\begin{tabular}{|c|c|}
\hline Case & Boron Efficiency $(\mathrm{pcm} / \mathrm{ppm})$ \\
\hline $40 \mathrm{w} \%$ enriched BOC & 8.8 \\
\hline $40 \mathrm{w} \%$ enriched EOC & 7.1 \\
\hline $25 \mathrm{w} \%$ enriched BOC & 4.7 \\
\hline $25 \mathrm{w} \%$ enriched EOC & 5.5 \\
\hline
\end{tabular}


The ${ }^{10} \mathrm{~B}$ concentration in either the soluble boron or in the boron carbide of the control and shutdown rods can be increased if additional cases (such as additional recycles of spent MOX fuel) require. Another safety analysis examined involves comparing the differences in neutronic safety parameters between the $15 \times 15$ assembly used in the majority of this research and the Westinghouse 17x17 PWR assembly proposed for MOX fuel irradiation (see Section 4.1). The results of this comparison are shown in Table 5-4. Neutronic safety conditions do not appear to be that much different between the two cases; in fact, the total rod worth for the $17 \mathrm{x} 17$ assembly even met the $5000 \mathrm{pcm}$ limit without the use of enriched boron.

Table 5-4. Comparison of Safety Features of 17x17 and 15x15 PWR Assemblies

\begin{tabular}{|c|c|c|c|c|}
\hline & \multicolumn{2}{|c|}{$15 \times 15$} & \multicolumn{2}{c|}{$17 \times 17$} \\
\hline $\begin{array}{c}\text { Doppler coefficient } \\
(\mathrm{pcm} / \mathrm{K})\end{array}$ & BOC & EOC & BOC & EOC \\
\hline $\begin{array}{c}\text { Moderator coefficient } \\
(\mathrm{pcm} / \mathrm{K})\end{array}$ & -3.0 & -2.7 & -2.8 & -2.5 \\
\hline $\begin{array}{c}\text { Boron efficiency } \\
(\mathrm{pcm} / \mathrm{ppm})\end{array}$ & 4.7 & -47 & -41 & -49 \\
\hline $\begin{array}{c}\text { Void coefficient } \\
(\mathrm{pcm} / 25 \% \text { void })\end{array}$ & -169 & -194 & -171 & -199 \\
\hline Control rod worth (pcm) & 2258 & 2306 & 2386 & 2477 \\
\hline Shutdown rod worth (pcm) & 1737 & 1704 & 1723 & 1952 \\
\hline Total rod worth (pcm) & 4008 & 4223 & 4310 & 4391 \\
\hline $\begin{array}{c}\text { Total rod worth w/all B } 4 \text { C } \\
\text { rods (pcm) }\end{array}$ & 5172 & 5243 & 5213 & 5256 \\
\hline
\end{tabular}


As the number of recycles of plutonium increases, so does the enrichment of uranium to compensate for the decrease in fissile material. As a result, the boron efficiency slightly decreases but still meets the condition of $4 \mathrm{pcm} / \mathrm{ppm}$ for up to four recycles (neutronic safety results for passes one, three, and five are given in Table 5-5). The total rod worth requirement of $5000 \mathrm{pcm}$ is not met with the use of $25 \%$ enriched ${ }^{10} \mathrm{~B}$ in the boron carbide rods, so a slightly higher enrichment $(27.5 \%)$ is required for the total rod worth to be met after the first pass. The boron efficiency is still met with $25 \%{ }^{10} \mathrm{~B}$.

Table 5-5. Neutronic Safety Cases for Multi-Recycling of Pu

\begin{tabular}{|c|c|c|c|c|c|c|}
\hline & $\begin{array}{c}\text { Pu from } \\
\text { SNF }\end{array}$ & $\begin{array}{c}\text { (depleted } \\
\text { uranium) }\end{array}$ & $3^{\text {rd }}$ Pass & $\left(1.8 \%{ }^{235} \mathrm{U}\right)$ & $5^{\text {th }}$ Pass & $\left(2.3 \%{ }^{235} \mathrm{U}\right)$ \\
\hline $\begin{array}{c}\text { Dopp. coefficient } \\
(\mathrm{pcm} / \mathrm{K})\end{array}$ & -3.0 & -2.7 & -3.4 & -2.9 & -2.8 & -2.7 \\
\hline $\begin{array}{c}\text { Mod. coeffic. } \\
(\mathrm{pcm} / \mathrm{K})\end{array}$ & -40 & -47 & -38 & -45 & -37 & EOC \\
\hline $\begin{array}{c}\text { Boron efficiency } \\
(\mathrm{pcm} / \mathrm{ppm})\end{array}$ & 4.7 & 5.5 & 4.2 & 5.2 & 5.3 & 5.2 \\
\hline $\begin{array}{c}\text { Void coefficient } \\
\text { (pcm/25\%void) }\end{array}$ & -169 & -194 & -161 & -185 & -161 & -185 \\
\hline $\begin{array}{c}\text { Total rod worth } \\
(\mathrm{pcm})\end{array}$ & 4008 & 4223 & 4023 & 4056 & 4050 & 4057 \\
\hline $\begin{array}{c}\text { Total rod worth } \\
\text { w/enriched B4C } \\
(25 \% / 27.5 \%)\end{array}$ & 5172 & 5243 & 5109 & 5186 & 5185 & 5287 \\
\hline $\begin{array}{c}\text { Initial B con- } \\
\text { centration (ppm) }\end{array}$ & 1700 & - & 1600 & - & 1600 & - \\
\hline
\end{tabular}


One of the reasons that this research assumes that MOX fuel irradiation could be implemented in the U.S. is that a few commercial LWRs are currently being licensed to burn weapons-grade plutonium in the form of MOX fuel. The goal of the MD program is to irradiate some of the plutonium obtained from the dismantling of nuclear weapons. Hopefully, the infrastructure developed during this mission can be built upon for the transmutation of SNF in LWRs. However, one important question must be addressed: how do neutronic safety parameters vary for reactor-grade (plutonium from SNF) versus weapons-grade plutonium? Neutronic safety parameters are compared for the two cases in Table 5-6.

Table 5-6. Neutronic Safety Results for Weapons-Grade vs. Reactor-Grade Plutonium

\begin{tabular}{|c|c|c|c|c|}
\hline & \multicolumn{2}{|c|}{ Weapons Pu } & \multicolumn{2}{c|}{ Reactor Pu } \\
\hline $\begin{array}{c}\text { Doppler coefficient } \\
(\mathrm{pcm} / \mathrm{K})\end{array}$ & BOC & EOC & BOC & EOC \\
\hline $\begin{array}{c}\text { Moderator coeffic. } \\
(\mathrm{pcm} / \mathrm{K})\end{array}$ & -2.3 & -1.4 & -3.0 & -2.7 \\
\hline $\begin{array}{c}\text { Boron efficiency } \\
(\mathrm{pcm} / \mathrm{ppm})\end{array}$ & 4.2 & 5.5 & 4.7 & 5.5 \\
\hline $\begin{array}{c}\text { Void coefficient } \\
(\mathrm{pcm} / 25 \% \text { void })\end{array}$ & -153 & -210 & -169 & -194 \\
\hline $\begin{array}{c}\text { Control rod worth } \\
(\mathrm{pcm})\end{array}$ & 2154 & 2190 & 2258 & 2306 \\
\hline $\begin{array}{c}\text { Shutdown rod worth } \\
(\mathrm{pcm})\end{array}$ & 1867 & 1874 & 1737 & 1704 \\
\hline Total rod worth (pcm) & 4363 & 4119 & 4008 & 4223 \\
\hline
\end{tabular}


No significant differences appear although the Doppler and moderator coefficients are slightly larger for the weapons-grade plutonium due to a slightly harder spectrum, but this should make reactor-grade plutonium MOX irradiation even easier to implement than weapons-grade.

\subsubsection{Use of Materials in MOX Fuel Other Than Plutonium and Uranium}

To decrease the proliferation risk of a separated plutonium stream going to MOX fuel fabrication and then reactor irradiation, additional actinides and/or fission products may be added or retained in the plutonium stream going to the fabrication of MOX fuel. Reactivity effects from the inclusion of minor actinides and the fission products strontium and cesium are discussed in Section 4.2. The effect that such a change in the material composition has on neutronic safety parameters is shown in Table 5-7. The safety calculations show that the initial plutonium-only and the plutonium plus cesium and strontium cases do meet the requirements for safe operation. However, the case with plutonium and minor actinides does NOT meet the required safety margins. The enrichment of the soluble boron has to be increased to $33 \%$ to yield a boron efficiency greater than $4 \mathrm{pcm} / \mathrm{ppm}$ (shown in Table 5-7), and the addition of four more control rods per assembly is required to meet an acceptable (i.e., $>5000 \mathrm{pcm}$ ) total rod worth. In this case, all control rods consist of natural boron carbide. Another option is to enrich the boron in the control rods even further. 
Table 5-7. Neutronic Safety Calculations for the Three Multi-Recycling Cases

\begin{tabular}{|c|c|c|c|c|c|c|}
\hline & $\begin{array}{c}\text { Pu-only } \\
\text { BOC }\end{array}$ & $\begin{array}{c}\text { Pu-only } \\
\text { EOC }\end{array}$ & $\begin{array}{c}\text { Pu+Cs+Sr } \\
\text { BOC }\end{array}$ & $\begin{array}{c}\text { Pu+Cs+Sr } \\
\text { EOC }\end{array}$ & $\begin{array}{c}\text { Pu+MA } \\
\text { BOC } \\
\text { (modif.) }\end{array}$ & $\begin{array}{c}\text { Pu+MA } \\
\text { (modif.) }\end{array}$ \\
\hline $\begin{array}{c}\text { Doppler } \\
\text { coefficient } \\
\text { (pcm/K) }\end{array}$ & -3.0 & -2.7 & -2.7 & -2.7 & -2.1 & -1.8 \\
\hline $\begin{array}{c}\text { Moderator } \\
\text { coeffic. } \\
\text { (pcm/K) }\end{array}$ & -40 & -47 & -38 & -48 & -39 & -66 \\
\hline $\begin{array}{c}\text { Boron } \\
\text { efficiency } \\
\text { (pcm/ppm) }\end{array}$ & 4.7 & 5.5 & 5.37 & 5.44 & 5.2 & 4.8 \\
\hline $\begin{array}{c}\text { Void } \\
\text { coefficient } \\
\text { (pcm/25\%void) }\end{array}$ & -169 & -194 & -169 & -189 & -153 & -170 \\
\hline $\begin{array}{c}\text { Control rod } \\
\text { worth (pcm) }\end{array}$ & 2258 & 2306 & 2379 & 2205 & 1616 & 1875 \\
\hline $\begin{array}{c}\text { Shutdown rod } \\
\text { worth (pcm) }\end{array}$ & 1737 & 1704 & 1795 & 1730 & 1477 & \\
\hline $\begin{array}{c}\text { Total rod worth } \\
\text { (pcm) }\end{array}$ & 4008 & 4223 & 4205 & 4134 & 2870 & \\
\hline $\begin{array}{c}\text { Modified rod } \\
\text { worth (pcm) }\end{array}$ & 5172 & 5243 & 5171 & 5244 & 4007 & \\
\hline
\end{tabular}

\subsection{Radiotoxicity Factors}

Finally, the radiotoxicity of several different irradiated ADS spallation targets driven by various proton beam energies and with two different coolants are also calculated in this research. Previous studies involving heavy liquid-metal spallation 


\section{LA-14052-T}

targets have shown that important contributors to the radiotoxicity of an LBE-cooled target can yield higher radiotoxicities than fission products can. ${ }^{56}$ Isotopes of concern for the LBE target (or any LBE-cooled target) include ${ }^{208} \mathrm{Po},{ }^{210} \mathrm{Po},{ }^{202} \mathrm{~Pb},{ }^{207} \mathrm{Bi}$, and ${ }^{193} \mathrm{Pt}$ and, for both the LBE and tungsten targets, rare earth isotopes such as ${ }^{146} \mathrm{Sm},{ }^{148} \mathrm{Gd}$, ${ }^{150} \mathrm{Gd}$, and ${ }^{154} \mathrm{Dy} .{ }^{5}$

The results of these radiotoxicity calculations are dependent upon the source of the radiotoxicity factors and the MCNPX module used in the calculations. Results using the CEM2k versus Bertini modules are compared for representative ingestion and inhalation radiotoxicity cases (LBE and Tungsten) in Figs. 5-1 and 5-2 respectively. CEM2k is the more recent physics module, which is why it yields slightly higher results for LBE (i.e., it produces additional isotopes) and is used in the remainder of the calculations for this research. Results using ICRP versus ICRP plus JAERI data are also compared in these two figures. When the JAERI data is used with LBE coolant, polonium, which comes from LBE in either the target or the coolant, dominates the results. The presence of polonium, which contributes significantly to radiotoxicity, is not representative of the lead and tungsten targets themselves, so these two targets are analyzed with sodium as the coolant instead in the remainder of the calculations. Additionally, radiotoxicities for the isotopes ${ }^{150} \mathrm{Gd}$ and ${ }^{154} \mathrm{Dy}$ are not present in the ICRP data but are significant in the equilibrium radiotoxicity of the tungsten target. The ICRP and JAERI data are used together for the remainder of the calculations for the most accuracy. In all cases, the results show that spallation product inventories are more significant than fission products initially, but over the course of 300 years, they decay and no longer have radiotoxicity levels greater than that of natural uranium ore. 


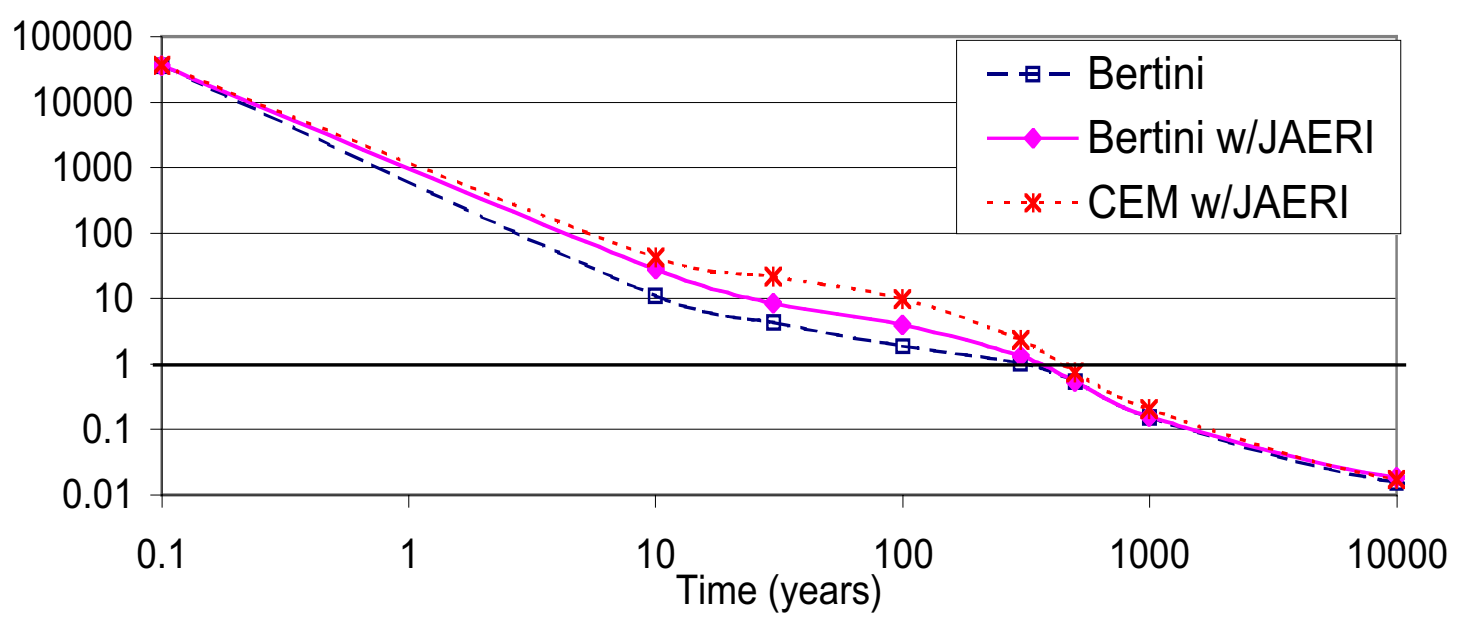

Fig. 5-1. Ingestion Radiotoxicity Relative to Natural U Ore for an LBE Target

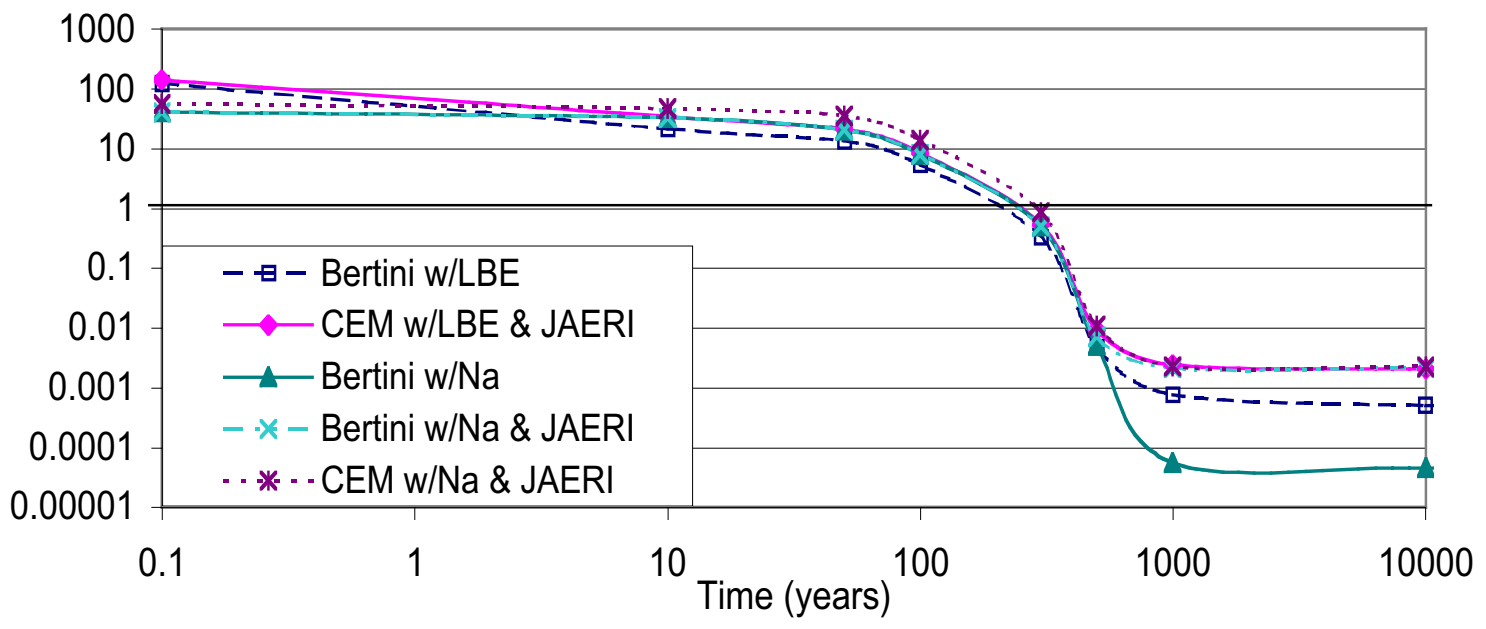

Fig. 5-2. Inhalation Radiotoxicity Relative to Natural U Ore for a Tungsten Target

The results for spallation product radiotoxicity are normalized per metric ton of heavy metal input for the ADS. In other words, the initial inventory of actinides in the sample ADS examined is about 2.2 metric tons, and about $840 \mathrm{~g} /$ day is added in a 840$\mathrm{MW}_{\text {th }}$ system. Over the course of 60 years (the assumed operational period with target replacement as often as necessary), about 20 metric tons of actinides are burned in one such ADS. The radiotoxicity curves show data for one metric ton of actinides from SNF, 


\section{LA-14052-T}

so the results for the spallation product inventories in one ADS are divided by 20 for an appropriate comparison. Figs. 5-3 and 5-4 compare the ingestion and inhalation radiotoxicities respectively using CEM2k for an incoming proton beam energy of $1 \mathrm{GeV}$ for the three different targets to that of SNF and the fission products from both SNF and the transmutation process itself.

The ingestion radiotoxicity of spallation products (especially from LBE) is greater than that of fission products produced during transmutation for the first year, but not thereafter. In particular, the ingestion radiotoxicity of the spallation products decreases to less than ten times that of natural uranium ore within a hundred years and less than that of natural uranium ore within at least five hundred years. Lead and LBE targets pose a bigger inhalation hazard than fission products in the first six months but decay quickly, whereas the inhalation radiotoxicity from tungsten and LBE spallation products is greater than that of fission products for up to a million years (as does the ingestion radiotoxicity for LBE spallation products). The radiotoxicity of fission products decays to less than that of natural uranium ore within three hundred years, so Figs. 5-3 and 5-4 show that the ingestion radiotoxicity of LBE spallation products and the inhalation radiotoxicity of tungsten spallation products is greater than that of fission products between 300 and 500 years. However, after 500 years, even these radiotoxicities fall below that of natural uranium ore, which represents a comparative quantity of material that already exists in the earth today. The radiotoxicity of a material is considered insignificant if it is below that of natural uranium ore. Thus, the results of this research show that spallation products do not pose a significant long-term radiotoxicity hazard but can be important in short-term storage facilities. 


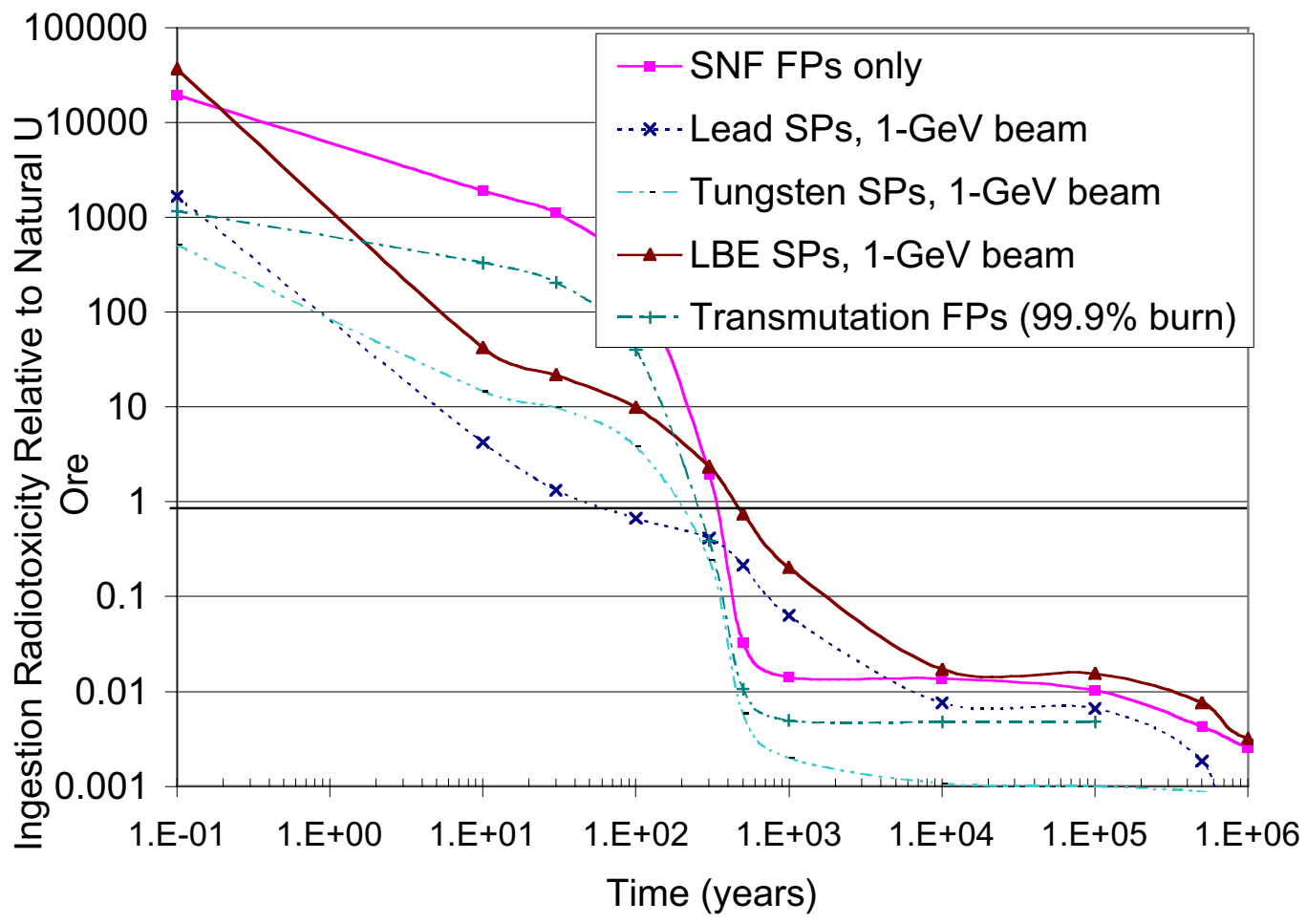

Fig. 5-3. Ingestion Radiotoxicity of Spallation Products Compared to SNF

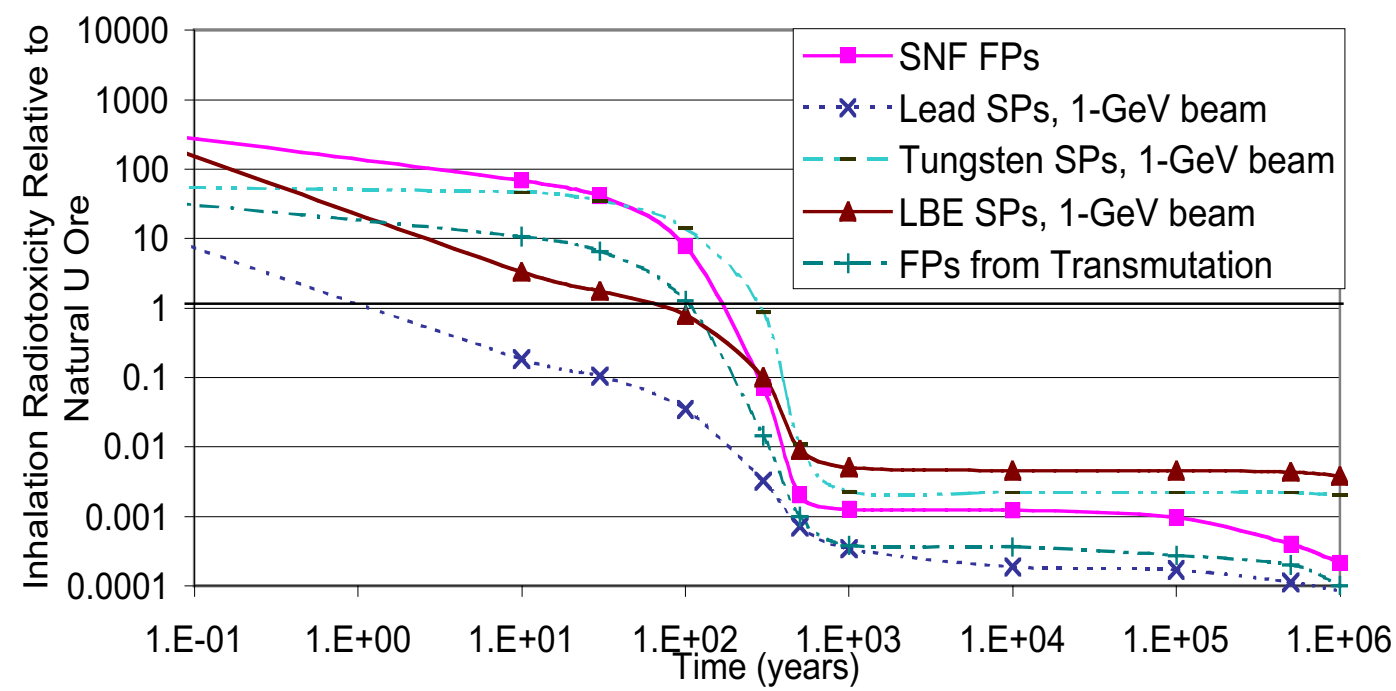

Fig. 5-4. Inhalation Radiotoxicity of Spallation Products Compared to SNF 
The ingestion radiotoxicity from spallation targets increases approximately linearly with proton beam energy with the exception of lead and LBE targets between 100-10,000 years of decay (see Fig. 5-5). The higher the proton beam energy, the more likely protons will interact with the target material and produce spallation products. The exception can be explained by the fact that the higher the energy of the beam, the higher the resulting neutron flux in the material is, which can lead to more absorption of neutrons at lower energies. Although a relatively higher concentration of certain isotopes (e.g., ${ }^{194} \mathrm{Hg}$ ) exists in this case, through neutron capture, more is depleted (e.g., the neutron flux for the $1 \mathrm{GeV}$ case is about $35 \%$ greater than for the $800 \mathrm{MeV}$ case but the yield of ${ }^{194} \mathrm{Hg}$ is only $10 \%$ higher). Thus, using a $1.6 \mathrm{GeV}$ proton beam with a lead or LBE target may be beneficial in producing more neutrons while having a slightly smaller (if not beneficial) impact on the ingestion radiotoxicity. The tungsten target, however, sees no such radiotoxicity benefit, nor is the same effect observed for inhalation radio-

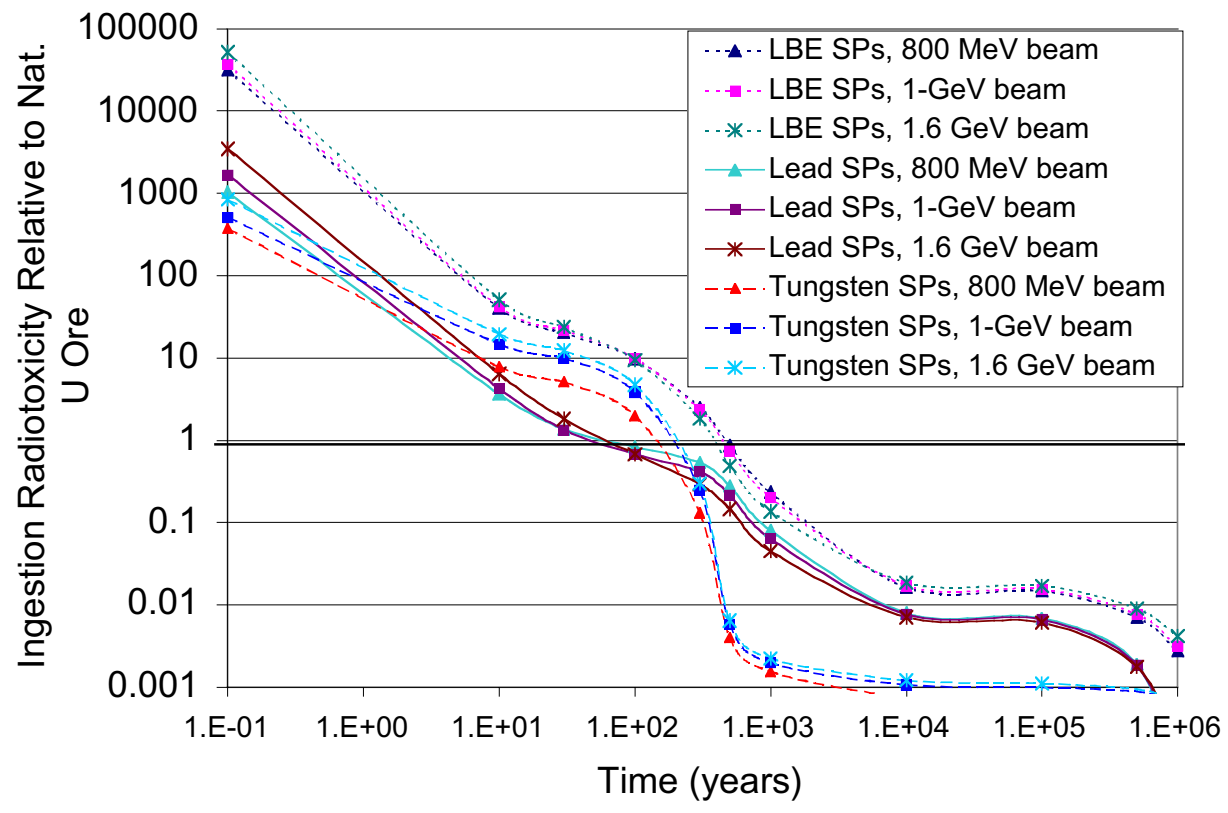

Fig. 5-5. Comparison of Radiotoxicity as a Function of Proton Beam Energy 
toxicity $\left({ }^{194} \mathrm{Hg}\right.$ does not have a significant inhalation radiotoxicity), so neutron generation versus radiotoxicity reduction may indeed be a significant trade-off in those cases.

${ }^{210}$ Po plays the biggest role for ingestion and inhalation radiotoxicity of the lead and LBE targets initially, but since it is short-lived ( $\sim 140$ day half-life), different isotopes are important thereafter. Similarly, for the tungsten target, even though short-lived tungsten and rhenium isotopes contribute the most to ingestion radiotoxicity initially, the ingestion radiotoxicity is dominated by the isotope ${ }^{148} \mathrm{Gd}$ after ten years, and ${ }^{148} \mathrm{Gd}$ also dominates inhalation radiotoxicity for the first 100 years or so. The isotopes making the greatest contributions to each target for both ingestion and inhalation radiotoxicity after 10 years are given in Figs. 5-6 and 5-7 respectively. At this point, LBE is dominated by the isotopes ${ }^{208} \mathrm{Po}$ and ${ }^{209} \mathrm{Po}$, for which ICRP data does not exist. Thus, it is important to remember to include these isotopes in radiotoxicity analyses for LBE spallation products. The lead target does not yield much ${ }^{208} \mathrm{Po}$ or ${ }^{209} \mathrm{Po}$, and its radiotoxicity is instead dominated by ${ }^{204} \mathrm{Tl}$ (ingestion), ${ }^{148} \mathrm{Gd}$ (inhalation), ${ }^{194} \mathrm{Hg}$ (ingestion), ${ }^{90} \mathrm{Sr},{ }^{3} \mathrm{H}$, and ${ }^{22} \mathrm{Na}$; however, its actual radiotoxicity at ten years is an order of magnitude less than that of LBE or tungsten targets.

The large presence of ${ }^{148} \mathrm{Gd}$ in tungsten spallation targets keeps SP inhalation radiotoxicity larger than that seen by most fission products for many years, but their radiotoxicity decays below the radiotoxicity of natural uranium ore within several hundred years nonetheless. The concern of the Japanese is that at equilibrium, the isotopes ${ }^{150} \mathrm{Gd},{ }^{154} \mathrm{Dy}$, and ${ }^{146} \mathrm{Sm}$ play a significant role in the radiotoxicity of tungsten spallation targets (see Sec. 2.3.4.2). In these calculations, it is found that these three isotopes do dominate the inhalation radiotoxicity of spallation targets, but only after 1000 


\section{LA-14052-T}

years of decay when the actual radiotoxicities are two orders of magnitude below that of natural uranium ore! The main isotope driving the inhalation radiotoxicity at equilibrium for $\mathrm{LBE}$ is ${ }^{210 \mathrm{~m}} \mathrm{Bi}$ followed by ${ }^{194} \mathrm{Hg}$, and the radionuclide dominating equilibrium ingestion radiotoxicity for both the lead and LBE targets is ${ }^{194} \mathrm{Hg}$ followed by ${ }^{202} \mathrm{~Pb}$. 


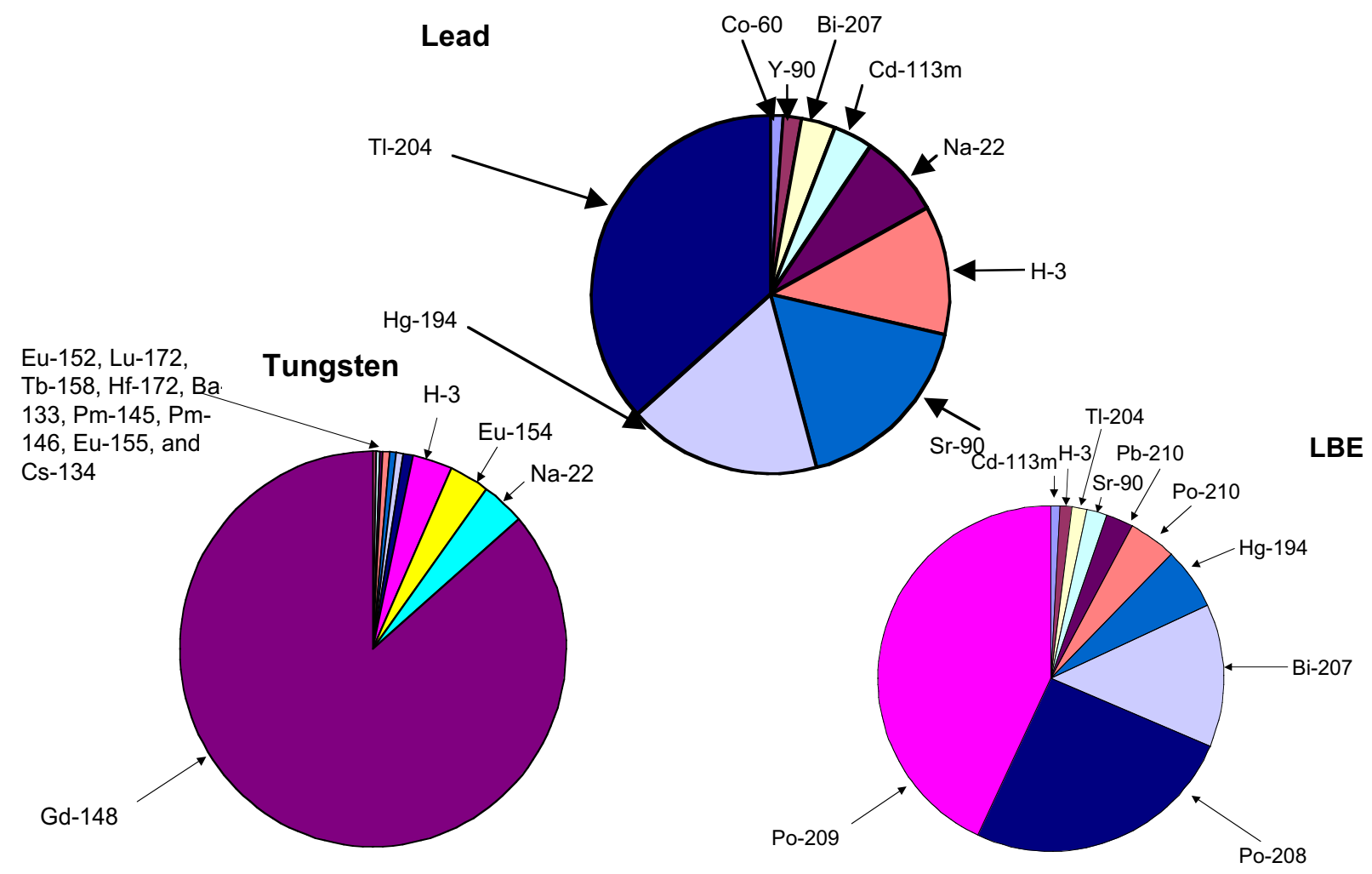

Fig. 5-6. Ingestion Radiotoxicity for Each Target by Isotope

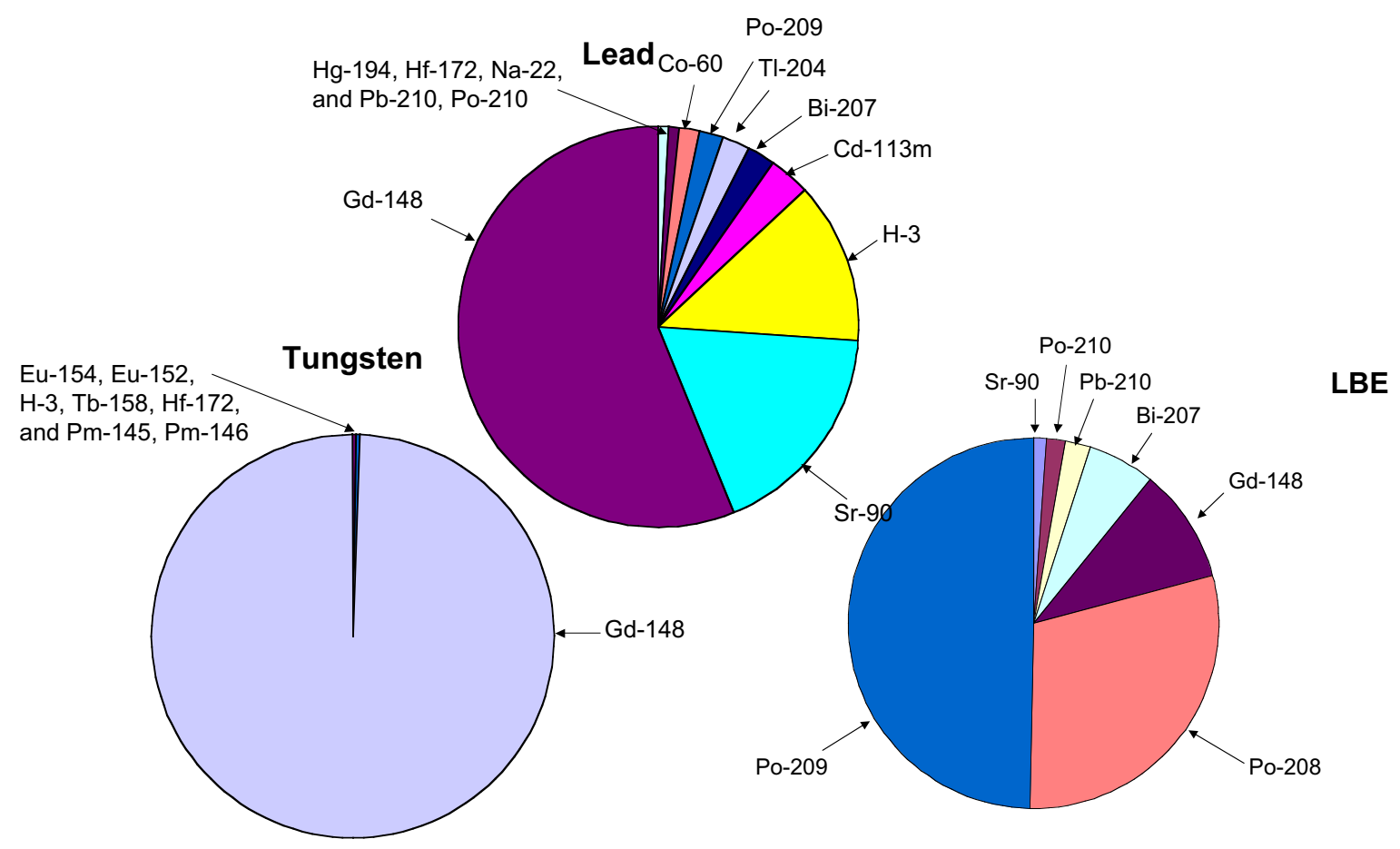

Fig. 5-7. Inhalation Radiotoxicity for Each Target by Isotope 


\subsection{Conclusions and Future Work}

The main goal of this research is to determine how transmutation could be performed more efficiently by finding the best combination of LWR and ADS. In particular, the goal is to improve accelerator performance by reducing the reactivity swing per cycle, which involves decreasing the amount of plutonium in the feed stream through irradiation in the LWR. The first objective is to determine how much plutonium can be burned in a LWR. To complete the mission with a realistic number of LWRs operating today (i.e., less than half) and in the next 50 years, irradiating a full core of MOX and multiple recycling of plutonium is probably required. With two recycles (three passes of plutonium as MOX fuel), the plutonium depletion rate is $\sim 55 \%$, although about a third of that builds up as minor actinides. Additional recycles can burn more plutonium, but the depletion rate decreases cumulatively over time and requires about 13 _ years per pass, which proves that high burnups of plutonium would be time consuming. The second objective of the research is to examine performance of other materials combined with the plutonium in MOX; fission products cause fabrication difficulties and minor actinides decrease the amount of possible depletion significantly.

The third objective of the research is to determine: 1) what the effect of decreasing the amount of plutonium in the feed stream has on reducing the reactivity swing for an equilibrium cycle in the ADS, and 2) at what point is an increase in plutonium destruction in the LWR detrimental to the safety of the ADS at preequilibrium conditions? The answer is that in this research: 1) two or more recycles of plutonium as MOX fuel in an LWR are beneficial in reducing the reactivity swing in the ADS by about half, and 2) more than two recycles of plutonium in an LWR start 
affecting the ability of the ADS to operate subcritically. These conclusions indicate that the best LWR/ADS transmutation combination is one in which the LWR burns plutonium as MOX fuel for three passes (two recycles) and the ADS burns the remaining material. About $37 \%$ of the plutonium is fissioned in this scenario, and the reactivity swing in the ADS is only 0.035 per cycle, which is an increase in the current of the ADS of approximately two during an operation period with a beginning of cycle $\mathrm{k}_{\mathrm{eff}}$ of 0.97 . This scenario requires the use of approximately 41 LWRs burning full cores of MOX fuel for about 40 years and 53 ADSs operating for 60 years to destroy up to $99.75 \%$ of the actinides from SNF.

The fourth objective is to meet neutronic safety conditions in a full core of MOX fuel. The design developed in this research to meet these conditions includes twelve water holes replacing fuel rods, enriched soluble boron (from $\sim 20$ to $25 \%{ }^{10} \mathrm{~B}$ ) in the cooling water, and a change of control rod material from silver-indium-cadmium to enriched $\mathrm{B}_{4} \mathrm{C}$. As the number of recycles increases, the only design change required is increasing the boron enrichment in the control and shutdown rods to $27.5 \%{ }^{10} \mathrm{~B}$.

The fifth and final objective is to make sure that ADSs do not produce more radiotoxic material than is being destroyed (i.e., a comparison of the radiotoxicity of spallation products generated by an ADS with the fission products and actinides produced during transmutation and present in the SNF itself). Spallation product radiotoxicity is shown to decay to levels below that of natural uranium ore within hundreds of years and for the most part, below that of other fission products within decades. Thus, unless shortterm storage of the target is an issue, radiotoxicity should not be a discriminating factor in ADS-based transmutation. 
This work is unique and makes a significant contribution to transmutation/fuel cycle studies in the following respects:

1. Studies involving multi-recycling of plutonium using an enriched uranium support are limited (in other studies, the plutonium fraction relative to uranium is increased, which does not conserve elemental balance in the MOX fuel as a function of recycle), and few studies have been done in combination with assemblies modified to burn full cores of MOX fuel;

2. Only recently has a two-tiered transmutation system combining LWRs and ADSs been proposed in the United States, and some of the work presented and expanded on in this research comes directly from this "original" study; and

3. Research involving the use of spallation targets and spallation product generation in an ADS is relatively new in most countries. Comparing the radiotoxicity of spallation products to that of legacy SNF in the U.S. before irradiation has not been done and is required for ADSs to become feasible.

\subsection{Future Work}

The majority of the work that has to be done to implement the proposed twotiered system is establishing the necessary infrastructure for it to exist. In particular, the following events should occur: 1) separations processes must be developed and be politically approved in the United States; 2) reactors must be re-licensed for full cores of MOX fuel, which would involve additional thermal hydraulic and safety analyses; and 3) ADSs (or a comparable Tier 2 system) must be designed, licensed, and built. 
First, a reprocessing capability, such as PUREX, needs to be established in the U.S., and a large-scale reprocessing plant needs to be built. Changes to nuclear fuel fabrication are also necessary. The fabrication process for MOX is slightly different than for $\mathrm{UO}_{2}$, with the addition of blending (of $\mathrm{UO}_{2}$ and $\mathrm{PuO}_{2}$ powders through the MIMAS process) and dry (instead of wet) grinding of powders, However, the main issues are increased handling and control. ${ }^{81,82}$ For those and other reasons, studies indicate that reprocessing of MOX fuel is more complex than for standard uranium fuel. ${ }^{83}$ There are also issues associated with fabricating recycled spent MOX fuel opposed to weaponsgrade plutonium as examined in the U.S. today. The criticality risk during dissolution is greater, high concentrations of ${ }^{238} \mathrm{Pu}$ and ${ }^{244} \mathrm{Cm}$ increase the effectiveness of the solvent during separations, and ${ }^{238} \mathrm{Pu}$ contaminates the purity of the plutonium. One change implemented in France for fabricating plutonium into MOX from spent MOX fuel requires an extra polishing step because of the change in composition between spent MOX and $\mathrm{UO}_{2}$ fuel (this includes a variance in fission product and actinide isotopes between the two types of SNF). Additionally, during multiple recycling of plutonium, the americium and curium contents must be carefully analyzed to assure that they still meet appropriate fabrication criteria (i.e., to make sure the heatload is not too large). ${ }^{84}$

Second, to expediate the re-licensing of LWRs to burn MOX fuel, more analyses need to be performed on the system, particular thermal hydraulic ones. Variations on the proposed LWR irradiation, such as the use of only one-third cores of MOX fuel and different plutonium versus uranium concentrations in the MOX fuel, are currently being examined. Additionally, not only is the use of plutonium combined with minor actinides being studied for nonproliferation reasons, irradiating plutonium with only the neptunium 
is an option. The ability to meet neutronic safety parameters using a control material other than enriched boron (i.e., erbium, samarium) should also be further examined. The code Monteburns represents an accurate technique to perform these wide range of calculations, but it is fairly slow. Better computing power would make Monteburns a more realistic technique for the sensitivity studies that need to be performed. Linkage to a thermal hydraulic code would also be useful but would require better computers again, man-power, and expertise in both areas.

Finally, the other area of future work for transmutation studies is in ADS or comparable Tier 2 development. ADSs are favored in this research but may be too expensive or unrealistic to implement. Another fast spectrum system, such as a fast reactor or a gas-cooled system (either of which could be designed without the need for a Tier 1), may be more efficient. If an ADS is still desired, then many materials and fuel studies would be required, and neutronics in support of those studies would have to be performed. Particularly, techniques for controlling reactivity in cases where the starting plutonium content is slow may be helpful. This research assumes that when the feed rate has to be decreased as the number of cycles increases, the system is unsafe. However, alternate control measures may be possible to decrease this risk. 
LA-14052-T 


\section{List of Appendices}

Appendix A. Sample MCNP Input File for $1 / 8$ core............................135

Appendix B. Sample Main Monteburns Input File for Reactor

Calculations.......................................................................145

Appendix C. Sample Monteburns Feed File for Reactor Calculations at

Equilibrium.............................................................149

Appendix D. Excerpts from Sample Monteburns Output File for First Pass of MOX

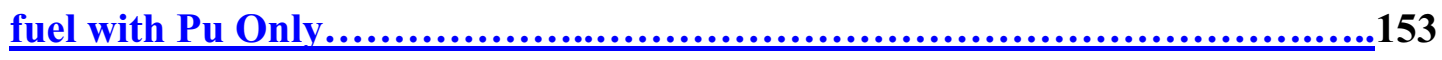

Appendix E. Sample MCNP Input File for ADS..................................159

Appendix F. Sample Main Monteburns Input File for ADS........................181

Appendix G. Sample Monteburns Feed File for ADS $. . . \ldots \ldots \ldots \ldots \ldots \ldots \ldots \ldots \ldots \ldots \ldots . . .187$

Appendix H. Excerpts from Sample Monteburns Output File for an ADS.........193

Appendix I. FORTRAN77 program used to generate MCNP input files for safety calculations.......................................................................197

Appendix J. FORTRAN77 program used to calculate radiotoxicity of spallation products from CINDER90 output..............................................203 
LA-14052-T 


\section{LA-14052-T}

\section{Appendix A. Sample MCNP Input File for 1/8 Core}

\begin{tabular}{|c|c|c|c|c|c|c|c|}
\hline \multirow{2}{*}{1} & \multirow{2}{*}{1} & & \multicolumn{2}{|r|}{-9.95330} & \multirow[b]{2}{*}{$\mathrm{u}=4$} & \multirow{2}{*}{\multicolumn{2}{|c|}{ imp:n=1 \$fuel }} \\
\hline & & & $\begin{array}{lll}-1 & -2 & 3\end{array}$ & & & & \\
\hline 2 & 2 & $-0.781 e-3$ & $\left(\begin{array}{lll}1 & -4 & 3\end{array}\right.$ & $3-5):\left(\begin{array}{lll}-1 & 2 & -5\end{array}\right)$ & $u=4$ & $i m p: n=1$ & \$gap \\
\hline 3 & 3 & -6.44 & $\left(\begin{array}{lll}-6 & 4 & -7\end{array}\right.$ & $-7 \quad 8):\left(\begin{array}{lll}-4 & -3 & 8\end{array}\right):\left(\begin{array}{lll}-4 & 5 & -7\end{array}\right)$ & $u=4$ & imp: $n=1$ & $\$ c l a d$ \\
\hline & 4 & & & -0.71142 & & & \\
\hline & & & 6 & & $\mathrm{u}=4$ & $i m p: n=1$ & \$wat \\
\hline & \multicolumn{2}{|c|}{ Burnable Poison } & \multicolumn{2}{|l|}{ Rod } & & & \\
\hline & 9 & $-0.781 e-3$ & -91 & & $\mathrm{u}=3$ & imp: $n=1$ & \$air \\
\hline 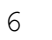 & 8 & -6.44 & -9291 & & $u=3$ & imp: $n=1$ & $\$ S S$ \\
\hline 7 & 9 & $-0.781 e-3$ & -9392 & & $u=3$ & $i m p: n=1$ & \$air \\
\hline & \multicolumn{2}{|l|}{10} & \multicolumn{2}{|r|}{-0.00223} & & & \\
\hline & & & -9493 & & $u=3$ & $i m p: n=1$ & \$borosil \\
\hline \multicolumn{3}{|c|}{ glass } & & & & & \\
\hline 9 & 9 & $-0.781 e-3$ & -9594 & & $u=3$ & $i m p: n=1$ & \$air \\
\hline 10 & 8 & -6.44 & -9695 & & $u=3$ & imp: $n=1$ & \$Zirc. 4 \\
\hline \multirow{2}{*}{11} & \multicolumn{2}{|l|}{15} & \multicolumn{2}{|r|}{-0.71142} & & & \\
\hline & & & 96 & & $u=3$ & $i m p: n=1$ & \$water \\
\hline & \multicolumn{2}{|c|}{ Burnable Poison } & Rod & & & & \\
\hline 54 & 9 & $-0.781 e-3$ & -91 & & $u=8$ & imp: $n=1$ & \$air \\
\hline 55 & 8 & -6.44 & -9291 & & $\mathrm{u}=8$ & imp: $n=1$ & $\$ S S$ \\
\hline 57 & 9 & $-0.781 e-3$ & -9392 & & $\mathrm{u}=8$ & imp: $n=1$ & \$air \\
\hline 58 & 6 & & & -2.29973 & & & \\
\hline & & & -9493 & & $u=8$ & $i m p: n=1$ & \$borosil \\
\hline & ass & & & & & & \\
\hline 59 & 9 & $-0.781 e-3$ & -9594 & & $u=8$ & imp: $n=1$ & \$air \\
\hline 60 & 8 & -6.44 & -9695 & & $u=8$ & imp: $n=1$ & \$zirc. 4 \\
\hline 61 & 4 & & & -0.71142 & & & \\
\hline & & & 96 & & $\mathrm{u}=8$ & $i m p: n=1$ & \$water \\
\hline C & Bur & nable Poison & Rod & & & & \\
\hline 62 & 9 & $-0.781 e-3$ & -91 & & $\mathrm{u}=88$ & imp: $n=1$ & \$air \\
\hline 63 & 8 & -6.44 & -9291 & & $u=88$ & $i m p: n=1$ & $\$ S S$ \\
\hline 64 & 9 & $-0.781 e-3$ & -9392 & & $\mathrm{u}=88$ & imp: $n=1$ & \$air \\
\hline 65 & 17 & & & -0.00230 & & & \\
\hline & & & -9493 & & $\mathrm{u}=88$ & imp: $n=1$ & \$borosil \\
\hline glá & ass & & & & & & \\
\hline 66 & 9 & $-0.781 e-3$ & -9594 & & $\mathrm{u}=88$ & $i m p: n=1$ & \$air \\
\hline 67 & 8 & -6.44 & -9695 & & $\mathrm{u}=88$ & imp: $n=1$ & \$Zirc. 4 \\
\hline 68 & 5 & & & -0.71142 & & & \\
\hline & & & 96 & & $u=88$ & $i m p: n=1$ & \$water \\
\hline $\mathrm{C}$ & Ins & trumentation & $\mathrm{Cell} / \mathrm{Gr}$ & Guide Tubes & & & \\
\hline 12 & 2 & $-0.781 e-3$ & -97 & & $u=39$ & imp: $n=1$ & \$wat \\
\hline 13 & 3 & -6.44 & $97-9 \varepsilon$ & & $u=39$ & $i m p: n=1$ & $\$ c l a d$ \\
\hline 14 & 15 & & & -0.71142 & & & \\
\hline & & & 98 & & $u=39$ & imp: $n=1$ & \$wat \\
\hline $\mathrm{C}$ & Ins & trumentation & $\mathrm{Cell} / \mathrm{G}$ & Guide Tubes & & & \\
\hline 15 & 2 & $-0.781 e-3$ & -97 & & $u=29$ & $i m p: n=1$ & \$wat \\
\hline 16 & 3 & -6.44 & $97-98$ & & $u=29$ & imp: $n=1$ & $\$ c l a d$ \\
\hline 17 & 5 & & & -0.71142 & & & \\
\hline & & & 98 & & $u=29$ & $i m p: n=1$ & \$wat \\
\hline $\mathrm{C}$ & Ins & trumentation & $\mathrm{Cell} / \mathrm{G}$ & Guide Tubes & & & \\
\hline 18 & 2 & $-0.781 e-3$ & -97 & & $u=9$ & imp: $n=1$ & \$wat \\
\hline 19 & 3 & -6.44 & $97-98$ & 8 & $u=9$ & $i m p: n=1$ & $\$ c l a d$ \\
\hline 20 & 4 & & & -0.71142 & & & \\
\hline & & & 98 & & $u=9$ & imp $: n=1$ & \$wat \\
\hline C & $\mathrm{HB}$ & 3 Robinson moc & odel - or & once burned & & & \\
\hline 21 & 11 & & & -9.88647 & & & \\
\hline & & & $\begin{array}{lll}-1 & -2 & 3\end{array}$ & & $u=5$ & imp: $n=1$ & \$fuel \\
\hline 22 & 2 & $-0.781 e-3$ & $\left(\begin{array}{lll}1 & -4 & 3\end{array}\right.$ & $3-5):\left(\begin{array}{lll}-1 & 2 & -5\end{array}\right)$ & $u=5$ & imp: $n=1$ & \$gap \\
\hline 23 & 3 & -6.44 & $\left(\begin{array}{lll}-6 & 4 & -7\end{array}\right.$ & $-7 \quad 8):\left(\begin{array}{lll}-4 & -3 & 8\end{array}\right):\left(\begin{array}{lll}-4 & 5 & -7\end{array}\right)$ & $u=5$ & imp: $n=1$ & \$clad \\
\hline
\end{tabular}




\section{LA-14052-T}

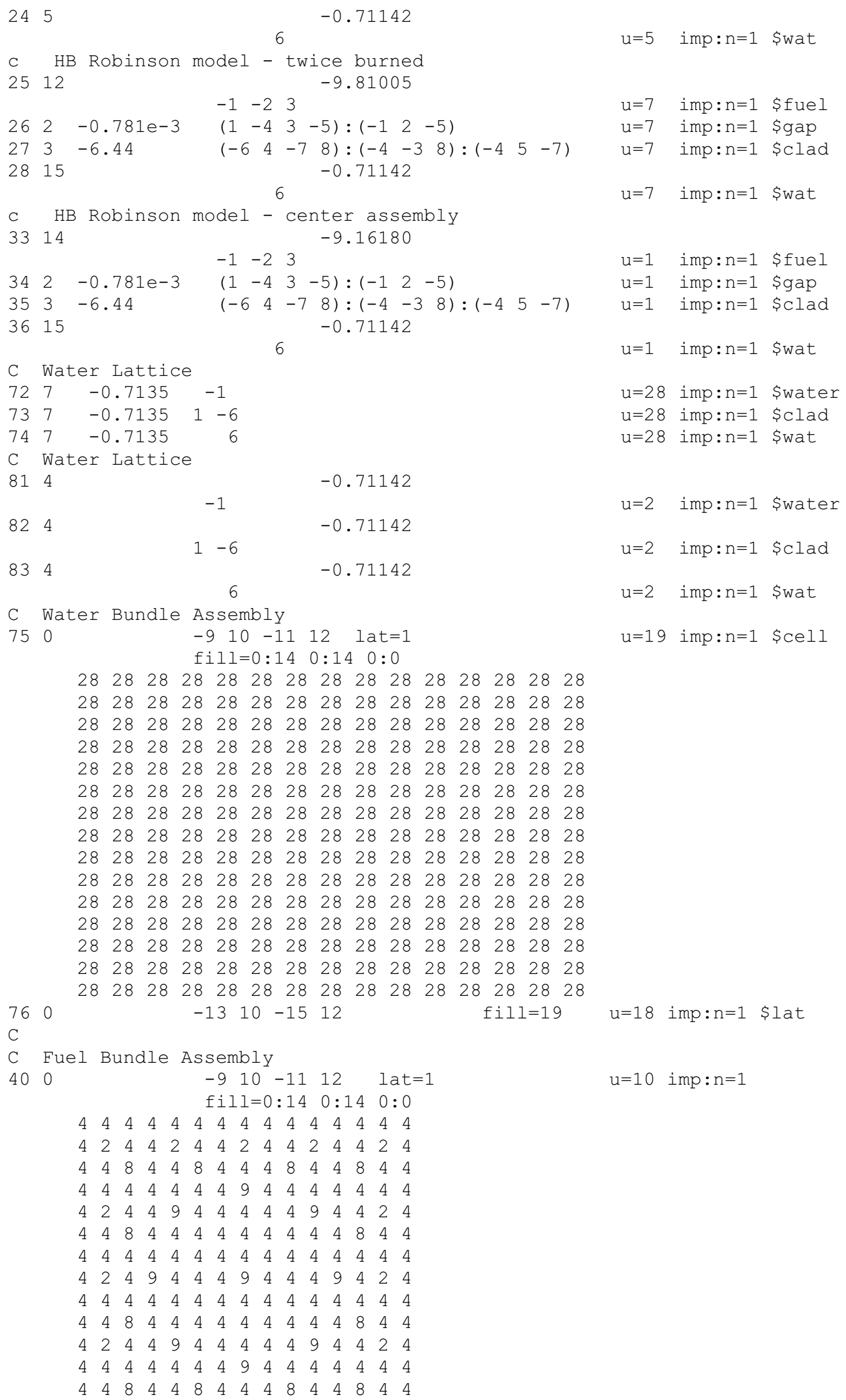




\section{LA-14052-T}

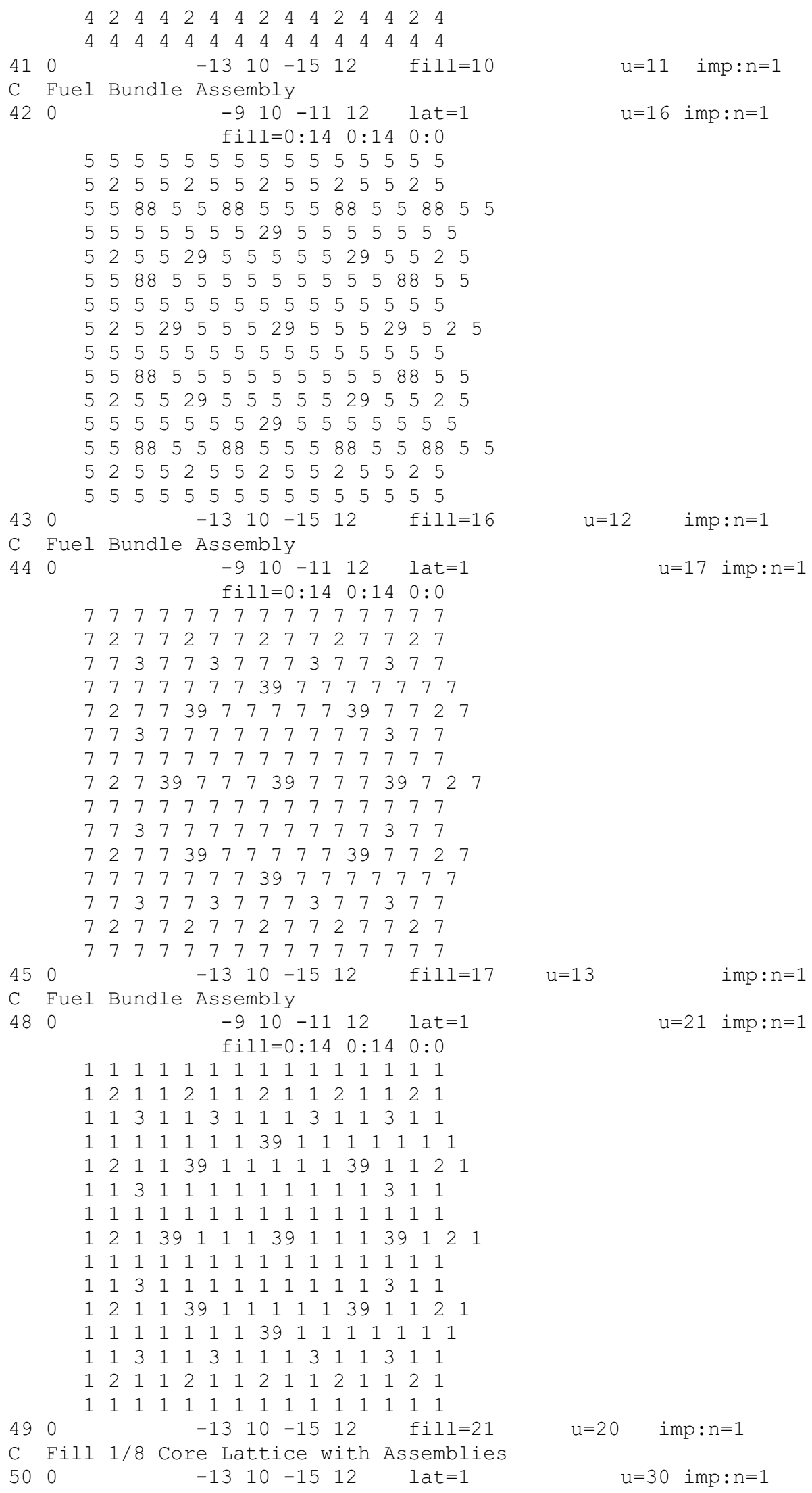




\section{LA-14052-T}

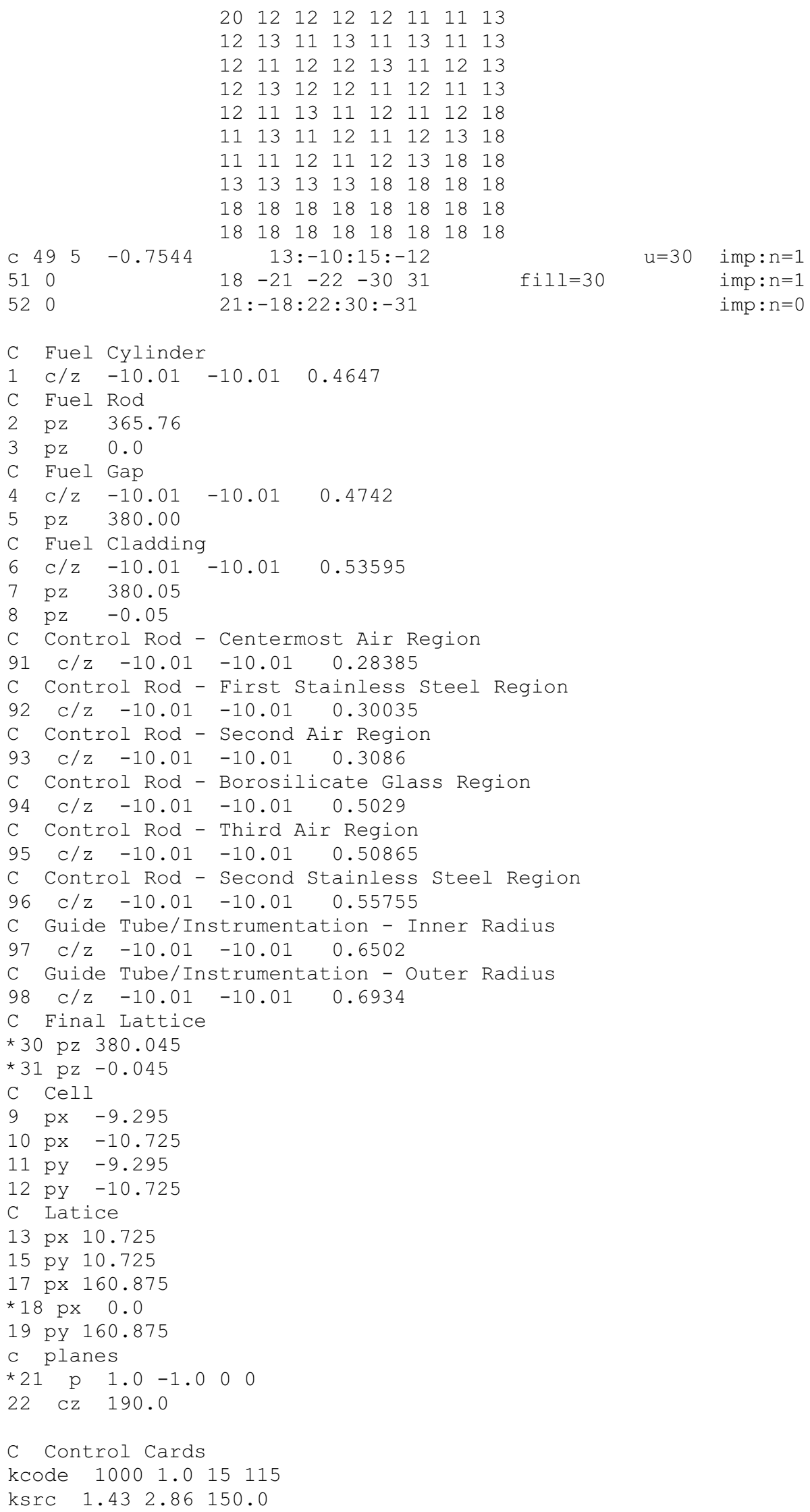




\section{LA-14052-T}

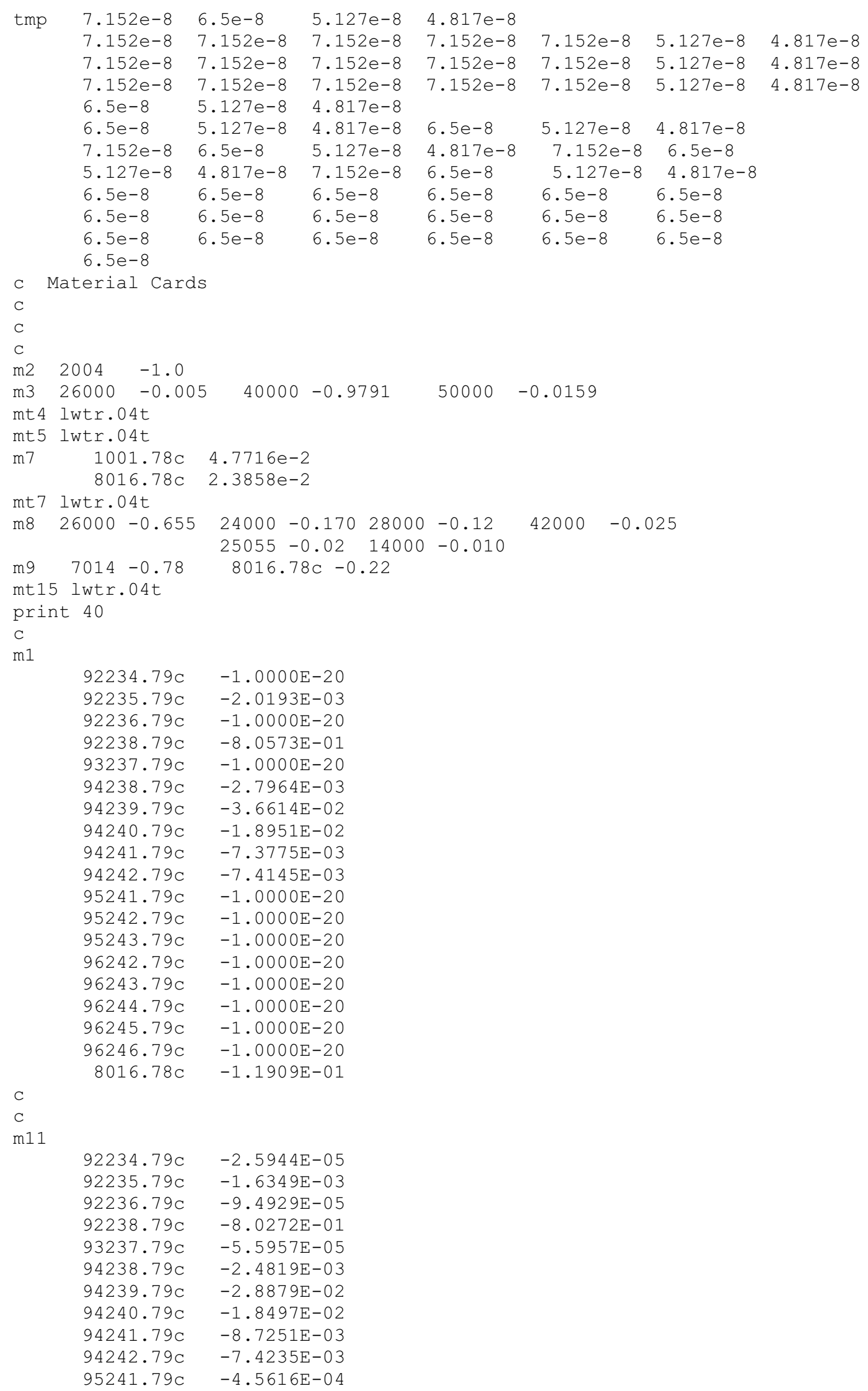




\section{LA-14052-T}

$95242.79 \mathrm{C}$

$95243.79 \mathrm{c}$

$96242.79 \mathrm{c}$

$96243.79 \mathrm{C}$

$96244.79 \mathrm{C}$

$96245.79 c$

$96246.79 \mathrm{C}$

$2004.60 \mathrm{c}$

$6013.35 c$

$8016.78 \mathrm{c}$

$35081.79 c$

$36083.79 \mathrm{c}$

$36084.79 \mathrm{c}$

$37085.79 c$

$36086.79 \mathrm{c}$

$37087.79 \mathrm{c}$

$39089.79 \mathrm{c}$

$40093.50 \mathrm{c}$

$40095.79 \mathrm{C}$

$42095.79 \mathrm{c}$

$43099.79 \mathrm{c}$

$44101.79 \mathrm{c}$

$44103.79 c$

$46105.50 \mathrm{c}$

$46106.79 \mathrm{c}$

$47109.79 \mathrm{c}$

$48113.79 \mathrm{c}$

$53127.79 c$

$53129.79 c$

$54131.79 c$

$54132.79 \mathrm{c}$

$55133.79 \mathrm{c}$

$54134.79 c$

$55134.79 \mathrm{c}$

$55135.79 \mathrm{c}$

$54136.79 c$

$55137.79 c$

$56138.79 \mathrm{C}$

$59141.79 \mathrm{c}$

$60143.79 c$

$60145.79 \mathrm{c}$

$61147.79 \mathrm{c}$

$62147.79 \mathrm{c}$

$60148.79 c$

$62149.79 \mathrm{C}$

$62150.79 \mathrm{c}$

$62151.79 \mathrm{c}$

$63151.79 \mathrm{c}$

$62152.79 \mathrm{c}$

$63153.79 \mathrm{c}$

$63154.79 \mathrm{c}$

$63155.79 \mathrm{c}$

$64155.79 \mathrm{c}$

$64157.79 c$

$64158.79 c$

C

m12
$-5.6795 \mathrm{E}-06$

$-8.2667 \mathrm{E}-04$

$-3.2384 \mathrm{E}-05$

$-5.0264 \mathrm{E}-07$

$-1.8487 \mathrm{E}-04$

$-9.0194 \mathrm{E}-06$

$-1.6613 \mathrm{E}-07$

$-2.9322 \mathrm{E}-06$

$-5.3878 \mathrm{E}-06$

$-1.1989 \mathrm{E}-01$

$-7.3409 \mathrm{E}-06$

$-1.5147 \mathrm{E}-05$

$-2.7223 E-05$

$-2.3685 \mathrm{E}-05$

$-4.3854 E-05$

$-5.4955 \mathrm{E}-05$

$-9.0102 E-05$

$-2.2078 \mathrm{E}-04$

$-2.9480 \mathrm{E}-05$

$-2.2231 \mathrm{E}-04$

$-3.6661 \mathrm{E}-04$

$-3.6944 \mathrm{E}-04$

$-1.8105 E-05$

$-3.2616 \mathrm{E}-04$

$-1.4077 \mathrm{E}-04$

$-9.3127 \mathrm{E}-05$

$-1.1294 \mathrm{E}-06$

$-3.6784 \mathrm{E}-05$

$-1.0724 \mathrm{E}-04$

$-2.6010 \mathrm{E}-04$

$-4.5775 \mathrm{E}-04$

$-5.3350 \mathrm{E}-04$

$-6.2229 \mathrm{E}-04$

$-2.1508 \mathrm{E}-05$

$-3.8234 \mathrm{E}-04$

$-7.9699 \mathrm{E}-04$

$-5.3664 \mathrm{E}-04$

$-5.0745 \mathrm{E}-04$

$-4.4248 E-04$

$-3.8162 \mathrm{E}-04$

$-2.7195 \mathrm{E}-04$

$-1.2724 \mathrm{E}-04$

$-2.6587 \mathrm{E}-05$

$-1.6327 \mathrm{E}-04$

$-1.0160 \mathrm{E}-05$

$-1.2184 \mathrm{E}-04$

$-3.3987 \mathrm{E}-05$

$-1.3686 \mathrm{E}-07$

$-7.5941 \mathrm{E}-05$

$-5.4746 \mathrm{E}-05$

$-8.7705 \mathrm{E}-06$

$-3.4898 \mathrm{E}-06$

$-1.9116 \mathrm{E}-07$

$-5.3077 \mathrm{E}-07$

$-1.4658 \mathrm{E}-05$

$54130.79 \mathrm{c}$

$92234.79 \mathrm{c}$

$92235.79 \mathrm{C}$

$92236.79 \mathrm{C}$

$92238.79 \mathrm{C}$
$-1.0000 \mathrm{E}-20$

$-4.3726 \mathrm{E}-05$

$-1.2526 \mathrm{E}-03$

$-1.7852 \mathrm{E}-04$

$-7.9898 \mathrm{E}-01$ 


\section{LA-14052-T}

\begin{tabular}{|c|c|}
\hline $93237.79 c$ & $-1.1018 \mathrm{E}-0$ \\
\hline $94238.79 c$ & $-2.2707 \mathrm{E}-0$ \\
\hline $4239.79 c$ & $-2.1854 \mathrm{E}-0$ \\
\hline 240.79 & $-1.7376 \mathrm{E}$ \\
\hline $241.79 c$ & $-9.2339 E-0$ \\
\hline 20170 & $-7.6503 E-0$ \\
\hline $241.79 c$ & $-7.2184 \mathrm{E}-0$ \\
\hline & $-1.2602 \mathrm{E}-0$ \\
\hline & $-1.5031 E-0$ \\
\hline & $-9.4645 \mathrm{E}$ \\
\hline & $-2.8869 E-0$ \\
\hline & $-6.8828 E-0$ \\
\hline & $-6.0407 \mathrm{E}-0$ \\
\hline - & $-2.8773 E-0$ \\
\hline (a) & $-8.8091 E-0$ \\
\hline & $-1.1707 \mathrm{E}$ \\
\hline & -1.2 \\
\hline & -1.52 \\
\hline & $-3.0374 E-0$ \\
\hline & $-5.9768 \mathrm{E}$ \\
\hline & $-5.0675 E$ \\
\hline 60 & $-9.3399 \mathrm{E}$ \\
\hline & $-1.1687 \mathrm{E}$ \\
\hline & -1.9 \\
\hline & $-4.6687 \mathrm{E}$ \\
\hline & $-3.3747 \mathrm{E}$ \\
\hline 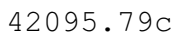 & $-5.1456 \mathrm{E}$ \\
\hline & $-7.5535 \mathrm{E}$ \\
\hline & -7.7 \\
\hline & -2.0 \\
\hline & $-6.8827 \mathrm{E}-$ \\
\hline & $-4.3061 \mathrm{E}-$ \\
\hline 47 & $-1.8198 \mathrm{E}-$ \\
\hline & $-9.5263 E$ \\
\hline & $-7.6672 \mathrm{E}-$ \\
\hline & $-2.2526 \mathrm{E}-$ \\
\hline & $-4.8637 \mathrm{E}-$ \\
\hline 54 & $-1.0477 \mathrm{E}-$ \\
\hline 55. & $-1.0781 \mathrm{E}-$ \\
\hline 54 & $-1.3382 \mathrm{E}$ \\
\hline & $-8.6127 \mathrm{E}-$ \\
\hline & $-7.1056 \mathrm{E}-$ \\
\hline & $-1.8148 \mathrm{E}-$ \\
\hline 5513 & $-1.1334 \mathrm{E}-$ \\
\hline 56138.7 & $-1.0909 \mathrm{E}-$ \\
\hline 5914 & $-9.5363 E-$ \\
\hline & $-7.7229 \mathrm{E}$ \\
\hline & $-5.6096 \mathrm{E}-$ \\
\hline 6114 & $-1.9211 \mathrm{E}-$ \\
\hline & $-7.3929 E-$ \\
\hline 60148.7 & $-3.5010 \mathrm{E}-$ \\
\hline 62149.7 & $-9.4226 \mathrm{E}-$ \\
\hline 6215 & $-2.8568 \mathrm{E}$ \\
\hline 6215 & $-3.8126 \mathrm{E}-$ \\
\hline 6315 & $-1.5434 \mathrm{E}-$ \\
\hline 62152.7 & $-1.4181 \mathrm{E}-$ \\
\hline 63152.79 & $-1.1079 \mathrm{E}-$ \\
\hline 63153.7 & $-1.4576 \mathrm{E}-$ \\
\hline 63154.7 & $-3.8264 E-$ \\
\hline 6415 & $-3.0269 E-c$ \\
\hline 6315 & $-7.2803 E-0$ \\
\hline & $-3.5619 \mathrm{E}-$ \\
\hline & $-5.7719 \mathrm{E}-$ \\
\hline
\end{tabular}




\section{LA-14052-T}

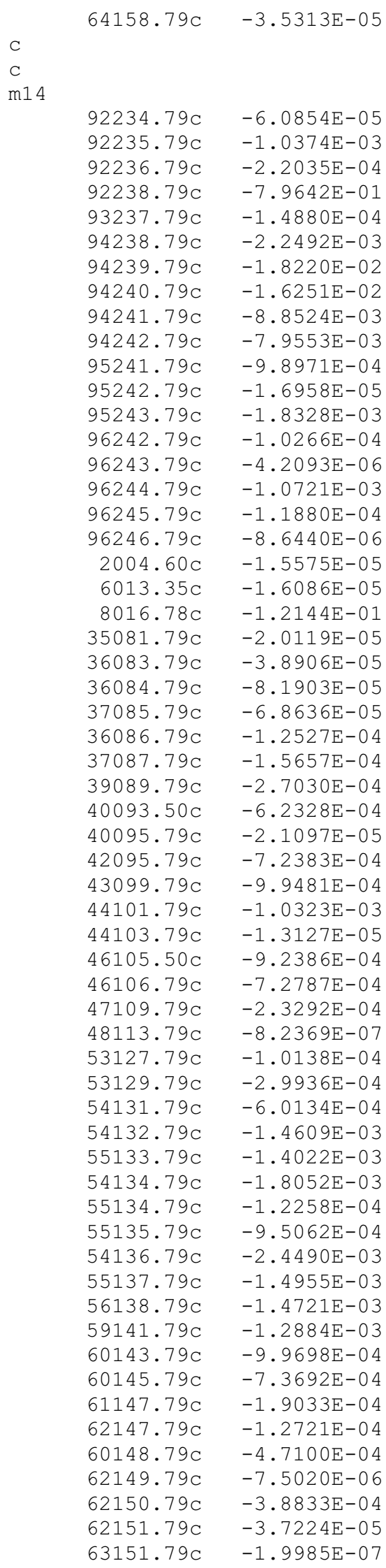




\section{LA-14052-T}

\begin{tabular}{|c|c|c|}
\hline & $62152.79 c$ & $-1.6922 E-04$ \\
\hline & $63152.79 \mathrm{C}$ & $-1.5102 \mathrm{E}-07$ \\
\hline & $63153.79 c$ & $-2.0306 E-04$ \\
\hline & $63154.79 c$ & $-6.0350 \mathrm{E}-05$ \\
\hline & $64154.79 c$ & $-8.6052 E-06$ \\
\hline & $63155.79 c$ & $-1.0606 \mathrm{E}-05$ \\
\hline & $64155.79 c$ & $-6.4672 \mathrm{E}-07$ \\
\hline & $64157.79 c$ & $-5.6372 \mathrm{E}-07$ \\
\hline & $64158.79 c$ & $-5.1057 \mathrm{E}-05$ \\
\hline & & \\
\hline & & \\
\hline m4 & & \\
\hline & $5010.78 c$ & $-2.2994 \mathrm{E}-04$ \\
\hline & $5011.78 \mathrm{C}$ & $-6.8982 \mathrm{E}-04$ \\
\hline & $1001.78 \mathrm{C}$ & $-1.1182 \mathrm{E}-01$ \\
\hline & $8016.78 \mathrm{c}$ & $-8.8726 \mathrm{E}-01$ \\
\hline C & & \\
\hline c & & \\
\hline m5 & & \\
\hline & $5010.78 \mathrm{C}$ & $-2.2994 \mathrm{E}-04$ \\
\hline & $5011.78 \mathrm{C}$ & $-6.8981 E-04$ \\
\hline & $1001.78 \mathrm{C}$ & $-1.1181 \mathrm{E}-01$ \\
\hline & $8016.78 \mathrm{c}$ & $-8.8727 E-01$ \\
\hline C & & \\
\hline C & & \\
\hline m15 & & \\
\hline & $5010.78 \mathrm{C}$ & $-2.2994 \mathrm{E}-04$ \\
\hline & $5011.78 \mathrm{C}$ & $-6.8981 E-04$ \\
\hline & $1001.78 \mathrm{C}$ & $-1.1181 \mathrm{E}-01$ \\
\hline & $8016.78 \mathrm{c}$ & $-8.8727 \mathrm{E}-01$ \\
\hline C & & \\
\hline C & & \\
\hline$m 6$ & & \\
\hline & $5010.78 \mathrm{C}$ & $-7.1988 E-03$ \\
\hline & $5011.78 \mathrm{C}$ & $-3.1867 \mathrm{E}-02$ \\
\hline & $14000.60 \mathrm{c}$ & $-3.7859 \mathrm{E}-01$ \\
\hline & $8016.78 \mathrm{c}$ & $-5.3897 E-01$ \\
\hline & $11023.60 \mathrm{c}$ & $-2.8423 E-02$ \\
\hline & $13027.60 \mathrm{C}$ & $-1.1726 \mathrm{E}-02$ \\
\hline & $19000.60 \mathrm{C}$ & $-3.2226 \mathrm{E}-03$ \\
\hline C & & \\
\hline C & & \\
\hline m17 & & \\
\hline & $5010.78 \mathrm{C}$ & $-2.5163 E-03$ \\
\hline & $5011.78 c$ & $-3.1851 E-02$ \\
\hline & $14000.60 \mathrm{C}$ & $-3.7842 E-01$ \\
\hline & $8016.78 c$ & $-5.3870 E-01$ \\
\hline & $11023.60 \mathrm{c}$ & $-2.8405 E-02$ \\
\hline & $13027.60 \mathrm{c}$ & $-1.1719 \mathrm{E}-02$ \\
\hline & $19000.60 \mathrm{c}$ & $-3.2201 E-03$ \\
\hline & $1001.78 \mathrm{C}$ & $-2.5505 E-07$ \\
\hline & $2004.60 \mathrm{C}$ & $-1.8780 \mathrm{E}-03$ \\
\hline & $3007.60 \mathrm{c}$ & $-3.2749 \mathrm{E}-03$ \\
\hline & $6013.35 \mathrm{c}$ & $-2.0536 \mathrm{E}-05$ \\
\hline $\mathrm{C}$ & & \\
\hline C & & \\
\hline m10 & & \\
\hline & $5010.78 \mathrm{c}$ & $-2.7193 E-04$ \\
\hline & $5011.78 \mathrm{C}$ & $-3.1843 E-02$ \\
\hline & $14000.60 \mathrm{c}$ & $-3.7832 E-01$ \\
\hline & $8016.78 \mathrm{C}$ & $-5.3857 \mathrm{E}-01$ \\
\hline & $11023.60 \mathrm{c}$ & $-2.8387 \mathrm{E}-02$ \\
\hline & $13027.60 \mathrm{C}$ & $-1.1715 \mathrm{E}-02$ \\
\hline
\end{tabular}


LA-14052-T

$\begin{array}{rr}19000.60 \mathrm{C} & -3.2179 \mathrm{E}-03 \\ 1001.78 \mathrm{C} & -5.5278 \mathrm{E}-07 \\ 2004.60 \mathrm{C} & -2.7836 \mathrm{E}-03 \\ 3007.60 \mathrm{C} & -4.8441 \mathrm{E}-03 \\ 6013.35 \mathrm{C} & -4.7503 \mathrm{E}-05\end{array}$




\section{Appendix B. Sample Main Monteburns Input File for Reactor Calculations}

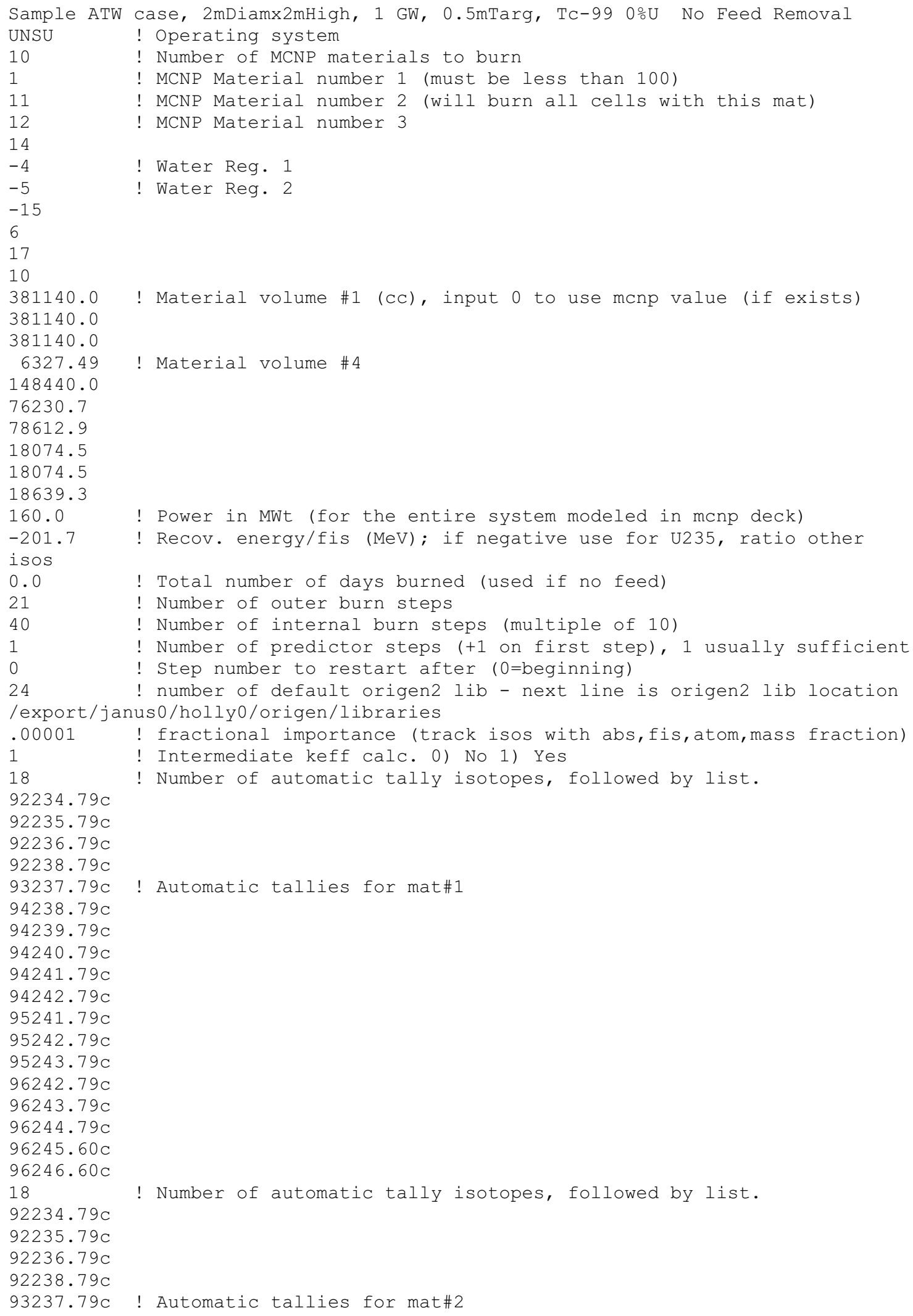




\section{LA-14052-T}

$94238.79 \mathrm{C}$

$94239.79 c$

$94240.79 \mathrm{C}$

$94241.79 \mathrm{C}$

$94242.79 \mathrm{c}$

$95241.79 \mathrm{c}$

$95242.79 \mathrm{c}$

$95243.79 \mathrm{c}$

$96242.79 \mathrm{c}$

$96243.79 \mathrm{c}$

$96244.79 \mathrm{C}$

$96245.60 \mathrm{c}$

$96246.60 \mathrm{c}$

18

$92234.79 \mathrm{C}$

$92235.79 \mathrm{c}$

$92236.79 \mathrm{C}$

$92238.79 \mathrm{c}$

$93237.79 \mathrm{C}$

$94238.79 \mathrm{c}$

$94239.79 \mathrm{c}$

$94240.79 c$

$94241.79 \mathrm{c}$

$94242.79 \mathrm{c}$

$95241.79 \mathrm{c}$

$95242.79 \mathrm{c}$

$95243.79 \mathrm{C}$

$96242.79 \mathrm{c}$

$96243.79 \mathrm{c}$

$96244.79 c$

$96245.60 \mathrm{c}$

$96246.60 \mathrm{c}$

18

$92234.79 \mathrm{C}$

$92235.79 \mathrm{c}$

$92236.79 \mathrm{c}$

$92238.79 \mathrm{c}$

$93237.79 \mathrm{C}$

$94238.79 \mathrm{c}$

$94239.79 \mathrm{c}$

$94240.79 c$

$94241.79 \mathrm{C}$

$94242.79 \mathrm{C}$

$95241.79 c$

$95242.79 \mathrm{c}$

$95243.79 \mathrm{c}$

$96242.79 \mathrm{c}$

$96243.79 \mathrm{C}$

$96244.79 c$

$96245.60 \mathrm{C}$

$96246.60 \mathrm{c}$

2

$5010.78 \mathrm{C}$

$5011.78 \mathrm{c}$

2

$5010.78 c$

$5011.78 \mathrm{C}$

2

$5010.78 \mathrm{c}$

$5011.78 \mathrm{C}$

7

$5010.78 \mathrm{C}$

$5011.78 \mathrm{C}$
! Number of automatic tally isotopes, followed by list.

! Automatic tallies for mat\#3

! Number of automatic tally isotopes, followed by list.

! Automatic tallies for mat\#4 


\section{LA-14052-T}

$14000.60 \mathrm{C}$

$8016.78 \mathrm{c}$

$11023.60 \mathrm{c}$

$13027.60 \mathrm{C}$

$19000.60 \mathrm{c}$

7

$5010.78 \mathrm{C}$

$5011.78 \mathrm{C}$

$14000.60 \mathrm{c}$

$8016.78 \mathrm{c}$

$11023.60 \mathrm{C}$

$13027.60 \mathrm{c}$

$19000.60 \mathrm{c}$

7

$5010.78 \mathrm{C}$

$5011.78 \mathrm{C}$

$14000.60 \mathrm{C}$

$8016.78 \mathrm{C}$

$11023.60 \mathrm{c}$

$13027.60 \mathrm{c}$

$19000.60 \mathrm{c}$ 
LA-14052-T 
Appendix C. Sample Monteburns Feed File for Reactor Calculations at Equilibrium

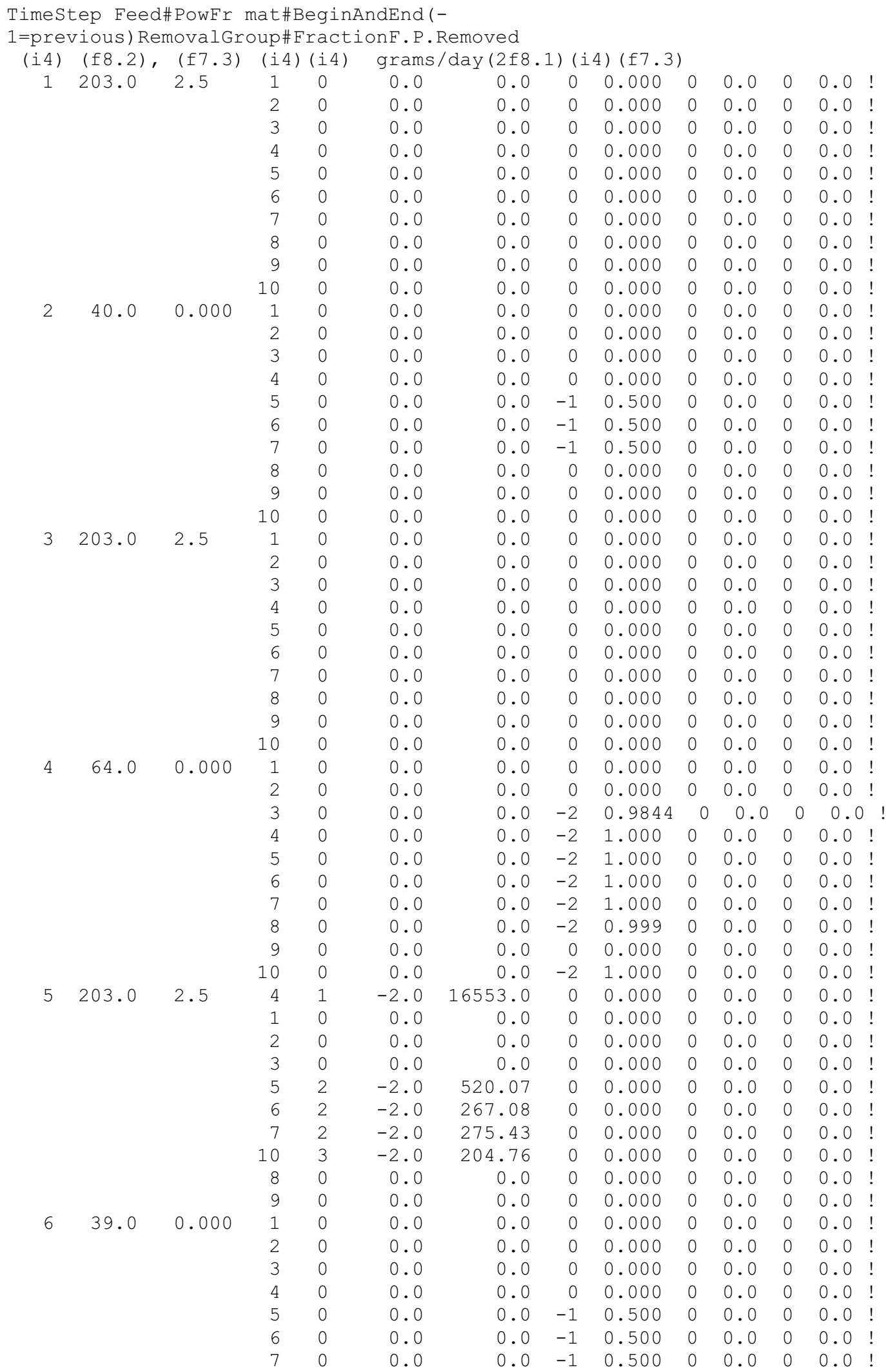




\section{LA-14052-T}

\begin{tabular}{|c|c|c|c|c|c|c|c|c|c|c|c|c|}
\hline & & & 8 & 0 & 0.0 & 0.0 & 0 & 0.000 & 0 & 0.0 & 0 & 0.0 \\
\hline & & & 9 & 0 & 0.0 & 0.0 & 0 & 0.000 & 0 & 0.0 & 0 & 0.0 \\
\hline & & & 10 & 0 & 0.0 & 0.0 & 0 & 0.000 & 0 & 0.0 & 0 & 0.0 \\
\hline \multirow[t]{10}{*}{7} & 203.0 & 2.5 & 1 & 0 & 0.0 & 0.0 & 0 & 0.000 & 0 & 0.0 & 0 & 0.0 \\
\hline & & & 2 & 0 & 0.0 & 0.0 & 0 & 0.000 & 0 & 0.0 & 0 & 0.0 \\
\hline & & & 3 & 0 & 0.0 & 0.0 & 0 & 0.000 & 0 & 0.0 & 0 & 0.0 \\
\hline & & & 4 & 0 & 0.0 & 0.0 & 0 & 0.000 & 0 & 0.0 & 0 & 0.0 \\
\hline & & & 5 & 0 & 0.0 & 0.0 & 0 & 0.000 & 0 & 0.0 & 0 & 0.0 \\
\hline & & & 6 & 0 & 0.0 & 0.0 & 0 & 0.000 & 0 & 0.0 & 0 & 0.0 \\
\hline & & & 7 & 0 & 0.0 & 0.0 & 0 & 0.000 & 0 & 0.0 & 0 & 0.0 \\
\hline & & & 8 & 0 & 0.0 & 0.0 & 0 & 0.000 & 0 & 0.0 & 0 & 0.0 \\
\hline & & & 9 & 0 & 0.0 & 0.0 & 0 & 0.000 & 0 & 0.0 & 0 & 0.0 \\
\hline & & & 10 & 0 & 0.0 & 0.0 & 0 & 0.000 & 0 & 0.0 & 0 & 0.0 \\
\hline \multirow[t]{10}{*}{8} & 64.0 & 0.000 & 1 & 0 & 0.0 & 0.0 & 0 & 0.000 & 0 & 0.0 & 0 & 0.0 \\
\hline & & & 2 & 0 & 0.0 & 0.0 & 0 & 0.000 & 0 & 0.0 & 0 & 0.0 \\
\hline & & & 3 & 0 & 0.0 & 0.0 & -2 & 0.9844 & 0 & 0.0 & 0 & 0.0 \\
\hline & & & 4 & 0 & 0.0 & 0.0 & -2 & 1.000 & 0 & 0.0 & 0 & 0.0 \\
\hline & & & 5 & 0 & 0.0 & 0.0 & -2 & 1.000 & 0 & 0.0 & 0 & 0.0 \\
\hline & & & 6 & 0 & 0.0 & 0.0 & -2 & 1.000 & 0 & 0.0 & 0 & 0.0 \\
\hline & & & 7 & 0 & 0.0 & 0.0 & -2 & 1.000 & 0 & 0.0 & 0 & 0.0 \\
\hline & & & 8 & 0 & 0.0 & 0.0 & -2 & 0.999 & 0 & 0.0 & 0 & 0.0 \\
\hline & & & 9 & 0 & 0.0 & 0.0 & 0 & 0.000 & 0 & 0.0 & 0 & 0.0 \\
\hline & & & 10 & 0 & 0.0 & 0.0 & -2 & 1.000 & 0 & 0.0 & 0 & 0.0 \\
\hline \multirow[t]{10}{*}{9} & 203.0 & 2.5 & 4 & 1 & -2.0 & 16553.0 & 0 & 0.000 & 0 & 0.0 & 0 & 0.0 \\
\hline & & & 1 & 0 & 0.0 & 0.0 & 0 & 0.000 & 0 & 0.0 & 0 & 0.0 \\
\hline & & & 2 & 0 & 0.0 & 0.0 & 0 & 0.000 & 0 & 0.0 & 0 & 0.0 \\
\hline & & & 3 & 0 & 0.0 & 0.0 & 0 & 0.000 & 0 & 0.0 & 0 & 0.0 \\
\hline & & & 5 & 2 & -2.0 & 520.07 & 0 & 0.000 & 0 & 0.0 & 0 & 0.0 \\
\hline & & & 6 & 2 & -2.0 & 267.08 & 0 & 0.000 & 0 & 0.0 & 0 & 0.0 \\
\hline & & & 7 & 2 & -2.0 & 275.43 & 0 & 0.000 & 0 & 0.0 & 0 & 0.0 \\
\hline & & & 10 & 3 & -2.0 & 204.76 & 0 & 0.000 & 0 & 0.0 & 0 & 0.0 \\
\hline & & & 8 & 0 & 0.0 & 0.0 & 0 & 0.000 & 0 & 0.0 & 0 & 0.0 \\
\hline & & & 9 & 0 & 0.0 & 0.0 & 0 & 0.000 & 0 & 0.0 & 0 & 0.0 \\
\hline \multirow[t]{10}{*}{10} & 39.0 & 0.000 & 1 & 0 & 0.0 & 0.0 & 0 & 0.000 & 0 & 0.0 & 0 & 0.0 \\
\hline & & & 2 & 0 & 0.0 & 0.0 & 0 & 0.000 & 0 & 0.0 & 0 & 0.0 \\
\hline & & & 3 & 0 & 0.0 & 0.0 & 0 & 0.000 & 0 & 0.0 & 0 & 0.0 \\
\hline & & & 4 & 0 & 0.0 & 0.0 & 0 & 0.000 & 0 & 0.0 & 0 & 0.0 \\
\hline & & & 5 & 0 & 0.0 & 0.0 & -1 & 0.500 & 0 & 0.0 & 0 & 0.0 \\
\hline & & & 6 & 0 & 0.0 & 0.0 & -1 & 0.500 & 0 & 0.0 & 0 & 0.0 \\
\hline & & & 7 & 0 & 0.0 & 0.0 & -1 & 0.500 & 0 & 0.0 & 0 & 0.0 \\
\hline & & & 8 & 0 & 0.0 & 0.0 & 0 & 0.000 & 0 & 0.0 & 0 & 0.0 \\
\hline & & & 9 & 0 & 0.0 & 0.0 & 0 & 0.000 & 0 & 0.0 & 0 & 0.0 \\
\hline & & & 10 & 0 & 0.0 & 0.0 & 0 & 0.000 & 0 & 0.0 & 0 & 0.0 \\
\hline \multirow[t]{10}{*}{11} & 203.0 & 2.5 & 1 & 0 & 0.0 & 0.0 & 0 & 0.000 & 0 & 0.0 & 0 & 0.0 \\
\hline & & & 2 & 0 & 0.0 & 0.0 & 0 & 0.000 & 0 & 0.0 & 0 & 0.0 \\
\hline & & & 3 & 0 & 0.0 & 0.0 & 0 & 0.000 & 0 & 0.0 & 0 & 0.0 \\
\hline & & & 4 & 0 & 0.0 & 0.0 & 0 & 0.000 & 0 & 0.0 & 0 & 0.0 \\
\hline & & & 5 & 0 & 0.0 & 0.0 & 0 & 0.000 & 0 & 0.0 & 0 & 0.0 \\
\hline & & & 6 & 0 & 0.0 & 0.0 & 0 & 0.000 & 0 & 0.0 & 0 & 0.0 \\
\hline & & & 7 & 0 & 0.0 & 0.0 & 0 & 0.000 & 0 & 0.0 & 0 & 0.0 \\
\hline & & & 8 & 0 & 0.0 & 0.0 & 0 & 0.000 & 0 & 0.0 & 0 & 0.0 \\
\hline & & & 9 & 0 & 0.0 & 0.0 & 0 & 0.000 & 0 & 0.0 & 0 & 0.0 \\
\hline & & & 10 & 0 & 0.0 & 0.0 & 0 & 0.000 & 0 & 0.0 & 0 & 0.0 \\
\hline \multirow[t]{10}{*}{12} & 64.0 & 0.000 & 1 & 0 & 0.0 & 0.0 & 0 & 0.000 & 0 & 0.0 & 0 & 0.0 \\
\hline & & & 2 & 0 & 0.0 & 0.0 & 0 & 0.000 & 0 & 0.0 & 0 & 0.0 \\
\hline & & & 3 & 0 & 0.0 & 0.0 & -2 & 0.9844 & 0 & 0.0 & 0 & 0.0 \\
\hline & & & 4 & 0 & 0.0 & 0.0 & -2 & 1.000 & 0 & 0.0 & 0 & 0.0 \\
\hline & & & 5 & 0 & 0.0 & 0.0 & -2 & 1.000 & 0 & 0.0 & 0 & 0.0 \\
\hline & & & 6 & 0 & 0.0 & 0.0 & -2 & 1.000 & 0 & 0.0 & 0 & 0.0 \\
\hline & & & 7 & 0 & 0.0 & 0.0 & -2 & 1.000 & 0 & 0.0 & 0 & 0.0 \\
\hline & & & 8 & 0 & 0.0 & 0.0 & -2 & 0.999 & 0 & 0.0 & 0 & 0.0 \\
\hline & & & 9 & 0 & 0.0 & 0.0 & 0 & 0.000 & 0 & 0.0 & 0 & 0.0 \\
\hline & & & 10 & 0 & 0.0 & 0.0 & -2 & 1.000 & 0 & 0.0 & 0 & 0.0 \\
\hline
\end{tabular}




\section{LA-14052-T}

\begin{tabular}{|c|c|c|c|c|c|c|c|c|c|c|c|}
\hline \multirow{11}{*}{13} & \multirow[t]{10}{*}{2.5} & 4 & 1 & -2.0 & 6720518.0 & 0 & 0.000 & 0 & 0.0 & 0 & 0.0 \\
\hline & & 1 & 0 & 0.0 & 0.0 & 0 & 0.000 & 0 & 0.0 & 0 & 0.0 \\
\hline & & 2 & 0 & 0.0 & 0.0 & 0 & 0.000 & 0 & 0.0 & 0 & 0.0 \\
\hline & & 3 & 0 & 0.0 & 0.0 & 0 & 0.000 & 0 & 0.0 & 0 & 0.0 \\
\hline & & 5 & 2 & -2.0 & 211148.42 & 0 & 0.000 & 0 & 0.0 & 0 & 0.0 \\
\hline & & 6 & 2 & -2.0 & 108434.48 & 0 & 0.000 & 0 & 0.0 & 0 & 0.0 \\
\hline & & 7 & 2 & -2.0 & 111824.58 & 0 & 0.000 & 0 & 0.0 & 0 & 0.0 \\
\hline & & 10 & 3 & -2.0 & 83132.56 & 0 & 0.000 & 0 & 0.0 & 0 & 0.0 \\
\hline & & 8 & 0 & 0.0 & 0.0 & 0 & 0.000 & 0 & 0.0 & 0 & 0.0 \\
\hline & & 9 & 0 & 0.0 & 0.0 & 0 & 0.000 & 0 & 0.0 & 0 & 0.0 \\
\hline & \multirow[t]{10}{*}{2.5} & 1 & 0 & 0.0 & 0.0 & 0 & 0.000 & 0 & 0.0 & 0 & 0.0 \\
\hline \multirow{9}{*}{202.5} & & 2 & 0 & 0.0 & 0.0 & 0 & 0.000 & 0 & 0.0 & 0 & 0.0 \\
\hline & & 3 & 0 & 0.0 & 0.0 & 0 & 0.000 & 0 & 0.0 & 0 & 0.0 \\
\hline & & 4 & 0 & 0.0 & 0.0 & 0 & 0.000 & 0 & 0.0 & 0 & 0.0 \\
\hline & & 5 & 0 & 0.0 & 0.0 & 0 & 0.000 & 0 & 0.0 & 0 & 0.0 \\
\hline & & 6 & 0 & 0.0 & 0.0 & 0 & 0.000 & 0 & 0.0 & 0 & 0.0 \\
\hline & & 7 & 0 & 0.0 & 0.0 & 0 & 0.000 & 0 & 0.0 & 0 & 0.0 \\
\hline & & 8 & 0 & 0.0 & 0.0 & 0 & 0.000 & 0 & 0.0 & 0 & 0.0 \\
\hline & & 9 & 0 & 0.0 & 0.0 & 0 & 0.000 & 0 & 0.0 & 0 & 0.0 \\
\hline & & 10 & 0 & 0.0 & 0.0 & 0 & 0.000 & 0 & 0.0 & 0 & 0.0 \\
\hline \multirow[t]{10}{*}{39.0} & \multirow[t]{10}{*}{0.000} & 1 & 0 & 0.0 & 0.0 & 0 & 0.000 & 0 & 0.0 & 0 & 0.0 \\
\hline & & 2 & 0 & 0.0 & 0.0 & 0 & 0.000 & 0 & 0.0 & 0 & 0.0 \\
\hline & & 3 & 0 & 0.0 & 0.0 & 0 & 0.000 & 0 & 0.0 & 0 & 0.0 \\
\hline & & 4 & 0 & 0.0 & 0.0 & 0 & 0.000 & 0 & 0.0 & 0 & 0.0 \\
\hline & & 5 & 0 & 0.0 & 0.0 & -1 & 0.500 & 0 & 0.0 & 0 & 0.0 \\
\hline & & 6 & 0 & 0.0 & 0.0 & -1 & 0.500 & 0 & 0.0 & 0 & 0.0 \\
\hline & & 7 & 0 & 0.0 & 0.0 & -1 & 0.500 & 0 & 0.0 & 0 & 0.0 \\
\hline & & 8 & 0 & 0.0 & 0.0 & 0 & 0.000 & 0 & 0.0 & 0 & 0.0 \\
\hline & & 9 & 0 & 0.0 & 0.0 & 0 & 0.000 & 0 & 0.0 & 0 & 0.0 \\
\hline & & 10 & 0 & 0.0 & 0.0 & 0 & 0.000 & 0 & 0.0 & 0 & 0.0 \\
\hline \multirow[t]{10}{*}{203.0} & \multirow[t]{10}{*}{2.5} & 1 & 0 & 0.0 & 0.0 & 0 & 0.000 & 0 & 0.0 & 0 & 0.0 \\
\hline & & 2 & 0 & 0.0 & 0.0 & 0 & 0.000 & 0 & 0.0 & 0 & 0.0 \\
\hline & & 3 & 0 & 0.0 & 0.0 & 0 & 0.000 & 0 & 0.0 & 0 & 0.0 \\
\hline & & 4 & 0 & 0.0 & 0.0 & 0 & 0.000 & 0 & 0.0 & 0 & 0.0 \\
\hline & & 5 & 0 & 0.0 & 0.0 & 0 & 0.000 & 0 & 0.0 & 0 & 0.0 \\
\hline & & 6 & 0 & 0.0 & 0.0 & 0 & 0.000 & 0 & 0.0 & 0 & 0.0 \\
\hline & & 7 & 0 & 0.0 & 0.0 & 0 & 0.000 & 0 & 0.0 & 0 & 0.0 \\
\hline & & 8 & 0 & 0.0 & 0.0 & 0 & 0.000 & 0 & 0.0 & 0 & 0.0 \\
\hline & & 9 & 0 & 0.0 & 0.0 & 0 & 0.000 & 0 & 0.0 & 0 & 0.0 \\
\hline & & 10 & 0 & 0.0 & 0.0 & 0 & 0.000 & 0 & 0.0 & 0 & 0.0 \\
\hline 17365.24 & 0.000 & 1 & 0 & 0.0 & 0.0 & 0 & 0.000 & 0 & 0.0 & 0 & 0.0 \\
\hline & & 2 & 0 & 0.0 & 0.0 & 0 & 0.000 & 0 & 0.0 & 0 & 0.0 \\
\hline & & 3 & 0 & 0.0 & 0.0 & 0 & 0.000 & 0 & 0.0 & 0 & 0.0 \\
\hline & & 4 & 0 & 0.0 & 0.0 & 0 & 0.000 & 0 & 0.0 & 0 & 0.0 \\
\hline & & 5 & 0 & 0.0 & 0.0 & 0 & 0.000 & 0 & 0.0 & 0 & 0.0 \\
\hline & & 6 & 0 & 0.0 & 0.0 & 0 & 0.000 & 0 & 0.0 & 0 & 0.0 \\
\hline & & 7 & 0 & 0.0 & 0.0 & 0 & 0.000 & 0 & 0.0 & 0 & 0.0 \\
\hline & & 8 & 0 & 0.0 & 0.0 & 0 & 0.000 & 0 & 0.0 & 0 & 0.0 \\
\hline & & 9 & 0 & 0.0 & 0.0 & 0 & 0.000 & 0 & 0.0 & 0 & 0.0 \\
\hline & & 10 & 0 & 0.0 & 0.0 & 0 & 0.000 & 0 & 0.0 & 0 & 0.0 \\
\hline 8730.48 & 0.000 & 1 & 0 & 0.0 & 0.0 & 0 & 0.000 & 0 & 0.0 & 0 & 0.0 \\
\hline & & 2 & 0 & 0.0 & 0.0 & 0 & 0.000 & 0 & 0.0 & 0 & 0.0 \\
\hline & & 3 & 0 & 0.0 & 0.0 & 0 & 0.000 & 0 & 0.0 & 0 & 0.0 \\
\hline & & 4 & 0 & 0.0 & 0.0 & 0 & 0.000 & 0 & 0.0 & 0 & 0.0 \\
\hline & & 5 & 0 & 0.0 & 0.0 & 0 & 0.000 & 0 & 0.0 & 0 & 0.0 \\
\hline & & 6 & 0 & 0.0 & 0.0 & 0 & 0.000 & 0 & 0.0 & 0 & 0.0 \\
\hline & & 7 & 0 & 0.0 & 0.0 & 0 & 0.000 & 0 & 0.0 & 0 & 0.0 \\
\hline & & 8 & 0 & 0.0 & 0.0 & 0 & 0.000 & 0 & 0.0 & 0 & 0.0 \\
\hline & & 9 & 0 & 0.0 & 0.0 & 0 & 0.000 & 0 & 0.0 & 0 & 0.0 \\
\hline & & 10 & 0 & 0.0 & 0.0 & 0 & 0.000 & 0 & 0.0 & 0 & 0.0 \\
\hline 9730.48 & 0.000 & 1 & 0 & 0.0 & 0.0 & 0 & 0.000 & 0 & 0.0 & 0 & 0.0 \\
\hline & & 2 & 0 & 0.0 & 0.0 & 0 & 0.000 & 0 & 0.0 & 0 & 0.0 \\
\hline & & 3 & 0 & 0.0 & 0.0 & 0 & 0.000 & 0 & 0.0 & 0 & 0.0 \\
\hline
\end{tabular}




\section{LA-14052-T}

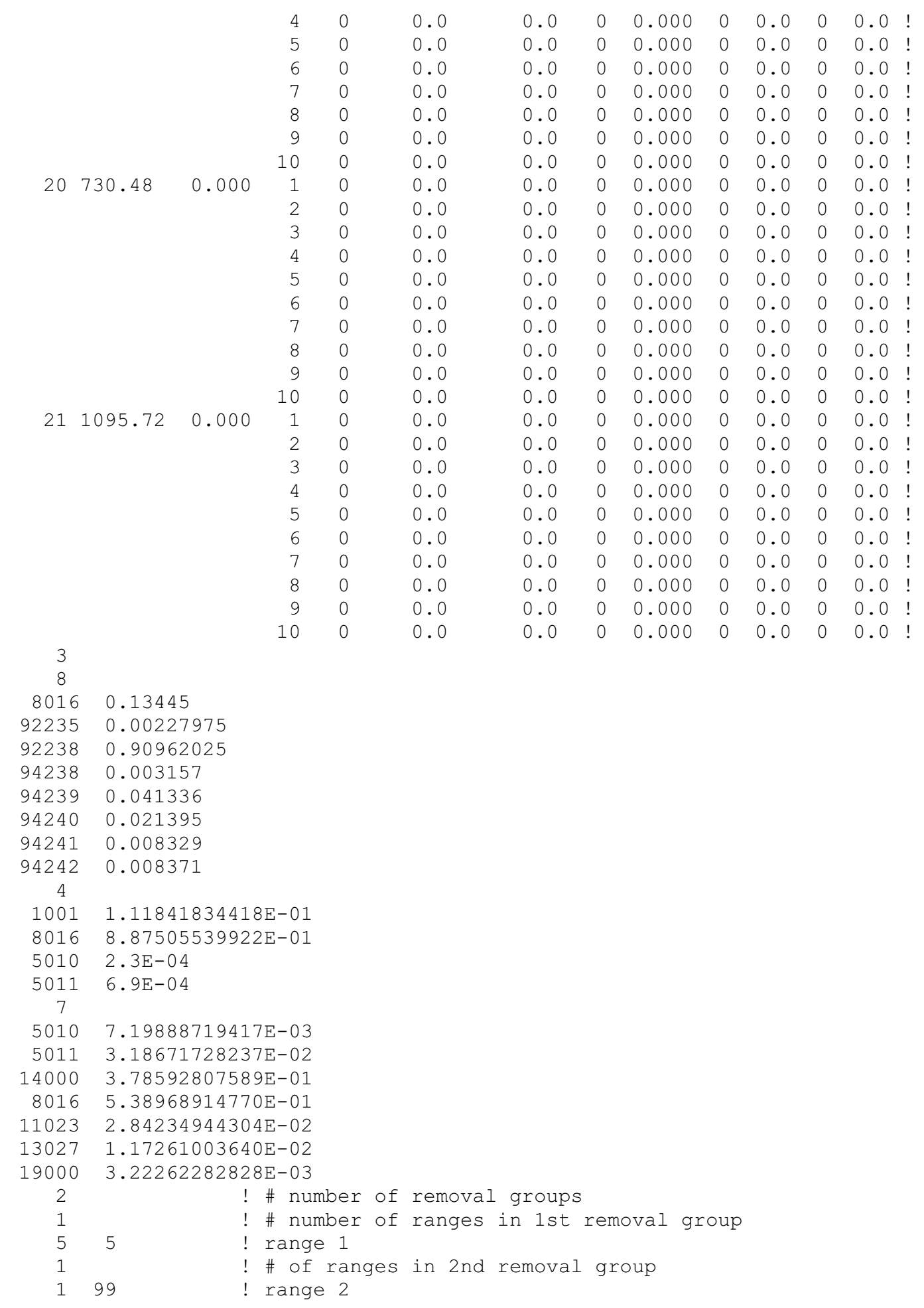




\section{Appendix D. Excerpts from Sample Monteburns Output File for First Pass of MOX}

\section{fuel with Pu Only}

\begin{tabular}{|c|c|c|c|c|c|}
\hline \multicolumn{6}{|c|}{$\begin{array}{l}\text { Total Power }(\mathrm{MW})=1.60 \mathrm{E}+02 \quad \text { Days }=5.63 \mathrm{E}+03 \\
\# \text { outer steps }=21, \# \text { inner steps }=40, \# \text { predictor steps }=1 \\
\text { Importance Fraction }=0.0000\end{array}$} \\
\hline \multicolumn{6}{|c|}{ Monteburns MCNP k-eff Versus Time } \\
\hline $0 \mathrm{~m} \quad 0.00$ & 1.02964 & 0.00216 & 2.867 & 210.075 & 0.804 \\
\hline 1m 101.50 & 0.99950 & 0.00238 & 2.870 & 210.111 & 0.836 \\
\hline 1e 203.00 & 0.98748 & 0.00221 & 2.867 & & \\
\hline 1e 203.00 & 0.98748 & 0.00221 & 2.867 & & \\
\hline $2 \mathrm{e} \quad 243.00$ & 1.00268 & 0.00209 & 2.874 & & \\
\hline $3 m \quad 344.50$ & 1.02761 & 0.00208 & 2.868 & 210.178 & 0.879 \\
\hline 3e 446.00 & 0.99519 & 0.00194 & 2.870 & & \\
\hline 3e 446.00 & 0.99519 & 0.00194 & 2.870 & & \\
\hline 4e 510.00 & 1.00857 & 0.00208 & 2.874 & & \\
\hline $5 b \quad 510.01$ & 1.03331 & 0.00212 & 2.880 & & \\
\hline $5 \mathrm{~m} \quad 611.50$ & 1.03376 & 0.00223 & 2.879 & 210.271 & 0.855 \\
\hline 5e 713.00 & 0.99266 & 0.00192 & 2.882 & & \\
\hline 5e 713.00 & 0.99266 & 0.00192 & 2.882 & & \\
\hline 6e 752.00 & 1.00719 & 0.00227 & 2.879 & & \\
\hline $7 \mathrm{~m} \quad 853.50$ & 1.02972 & 0.00205 & 382 & 210.348 & 0.882 \\
\hline $7 e \quad 955.00$ & 0.99830 & 0.00217 & 2.889 & & \\
\hline 7e 955.00 & 0.99830 & 0.00217 & 2.8 & & \\
\hline $8 \mathrm{e} 1019.00$ & 1.00976 & 0.00249 & 2.8 & & \\
\hline 9b 1019.01 & 1.03656 & 0.00240 & 2.881 & & \\
\hline $9 m \quad 1120.50$ & 1.03929 & 0.00217 & 2.880 & 210.360 & 0.852 \\
\hline 9 e 1222.00 & 1.00125 & 0.00193 & 2.891 & & \\
\hline $9 \mathrm{e} 1222.00$ & 1.00125 & 0.00193 & 2.8 & & \\
\hline $10 \mathrm{e} 1261.00$ & 1.00784 & 0.00246 & 2.8 & & \\
\hline $11 \mathrm{~m} 1362.50$ & 1.03162 & $2 \quad 0.00242$ & 2.891 & 210.436 & 0.883 \\
\hline $11 \mathrm{e} 1464.00$ & 1.00521 & 0.00195 & 2.886 & & \\
\hline $11 \mathrm{e} 1464.00$ & 1.00521 & 0.00195 & 2.886 & & \\
\hline $12 \mathrm{e} 1528.00$ & 1.01266 & 0.00225 & 2.881 & & \\
\hline 13b 1528.01 & 1.03852 & 0.00220 & 2.883 & & \\
\hline $13 m \quad 1528.25$ & 1.03750 & $0 \quad 0.00228$ & 2.888 & 210.368 & 0.864 \\
\hline 13 e 1528.50 & 1.03331 & 0.00213 & 2.887 & & \\
\hline $14 \mathrm{~m} \quad 1629.75$ & $5 \quad 1.01215$ & $5 \quad 0.00205$ & 2.882 & 210.399 & 0.845 \\
\hline $14 \mathrm{e} 1731.00$ & 1.00023 & 0.00224 & 2.887 & & \\
\hline $14 \mathrm{e} 1731.00$ & 1.00023 & 0.00224 & 2.887 & & \\
\hline 15e 1770.00 & 1.01617 & 0.00218 & 2.886 & & \\
\hline $16 \mathrm{~m} \quad 1871.50$ & 1.03454 & $4 \quad 0.00251$ & 2.896 & 210.442 & 0.905 \\
\hline $16 \mathrm{e} 1973.00$ & 0.99776 & 0.00215 & 2.897 & & \\
\hline 16e 1973.00 & 0.99776 & 0.00215 & 2.897 & & \\
\hline 17e 2338.24 & 1.00086 & 0.00203 & 2.883 & & \\
\hline 17e 2338.24 & 1.00086 & 0.00203 & 2.883 & & \\
\hline $18 \mathrm{e} 3068.72$ & 0.98050 & 0.00193 & 2.889 & & \\
\hline $18 \mathrm{e} 3068.72$ & 0.98050 & 0.00193 & 2.889 & & \\
\hline 19 e 3799.20 & 0.96063 & 0.00206 & 2.883 & & \\
\hline 19e 3799.20 & 0.96063 & 0.00206 & 2.883 & & \\
\hline 20 e 4529.68 & 0.94641 & 0.00211 & 2.887 & & \\
\hline 20 e 4529.68 & 0.94641 & 0.00211 & 2.887 & & \\
\hline 21e 5625.40 & 0.92253 & 0.00206 & 2.873 & & \\
\hline
\end{tabular}

Monteburns Transport History for material 2

total material for actinide Qfis Flux SigmaF Power Pow.Den. Burnup n,gamma n,fission fis/cap n2n eta n,gamma $\mathrm{n}$,fission fis/cap $\mathrm{n} 2 \mathrm{n}$ eta (barns)

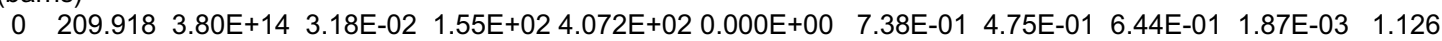
$2.10 \mathrm{E}+00 \quad 1.45 \mathrm{E}+00 \quad 6.93 \mathrm{E}-01 \quad 5.69 \mathrm{E}-03 \quad 1.176$ 


\section{LA-14052-T}

$1 \quad 209.977 \quad 4.06 \mathrm{E}+14 \quad 3.09 \mathrm{E}-02 \quad 1.61 \mathrm{E}+02 \quad 4.215 \mathrm{E}+02 \quad 9.870 \mathrm{E}+00 \quad 7.45 \mathrm{E}-01 \quad 4.60 \mathrm{E}-01 \quad 6.18 \mathrm{E}-01 \quad 2.07 \mathrm{E}-03 \quad 1.099$ 2.07E+00 1.41E+00 6.84E-01 6.30E-03 1.170

$1 \quad 209.977 \quad 4.06 \mathrm{E}+14 \quad 3.09 \mathrm{E}-02 \quad 1.61 \mathrm{E}+02 \quad 4.215 \mathrm{E}+02 \quad 9.870 \mathrm{E}+00 \quad 7.45 \mathrm{E}-01 \quad 4.60 \mathrm{E}-01 \quad 6.18 \mathrm{E}-01 \quad 2.07 \mathrm{E}-03 \quad 1.099$ 2.07E+00 1.41E+00 6.84E-01 6.30E-03 1.170

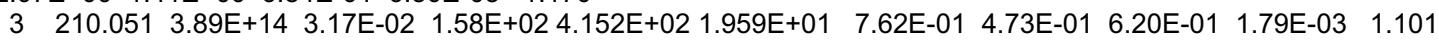
$2.14 \mathrm{E}+00 \quad 1.46 \mathrm{E}+00 \quad 6.82 \mathrm{E}-01 \quad 5.50 \mathrm{E}-03 \quad 1.166$

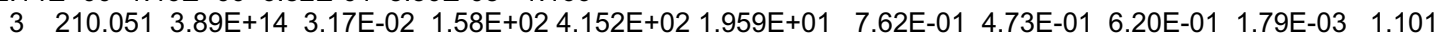
$2.14 \mathrm{E}+00 \quad 1.46 \mathrm{E}+00 \quad 6.82 \mathrm{E}-01 \quad 5.50 \mathrm{E}-03 \quad 1.166$

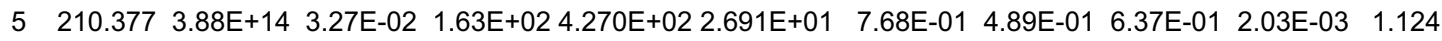
$2.21 \mathrm{E}+00 \quad 1.50 \mathrm{E}+00 \quad 6.79 \mathrm{E}-01 \quad 6.19 \mathrm{E}-03 \quad 1.168$

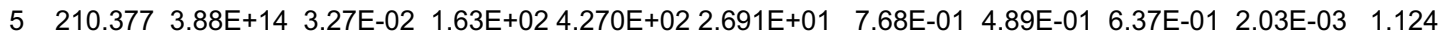
$2.21 \mathrm{E}+00 \quad 1.50 \mathrm{E}+00 \quad 6.79 \mathrm{E}-01 \quad 6.19 \mathrm{E}-03 \quad 1.168$

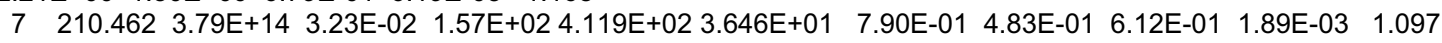
$2.25 \mathrm{E}+00 \quad 1.50 \mathrm{E}+00 \quad 6.65 \mathrm{E}-01 \quad 5.79 \mathrm{E}-03 \quad 1.155$

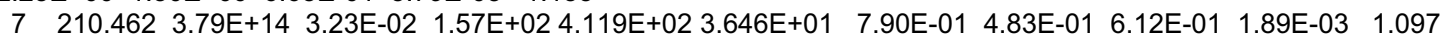
$2.25 \mathrm{E}+00 \quad 1.50 \mathrm{E}+00 \quad 6.65 \mathrm{E}-01 \quad 5.79 \mathrm{E}-03 \quad 1.155$

$9 \quad 210.371 \quad 3.74 \mathrm{E}+14 \quad 3.26 \mathrm{E}-02 \quad 1.57 \mathrm{E}+02 \quad 4.113 \mathrm{E}+02 \quad 4.563 \mathrm{E}+01 \quad 7.64 \mathrm{E}-01 \quad 4.88 \mathrm{E}-01 \quad 6.39 \mathrm{E}-01 \quad 1.90 \mathrm{E}-03 \quad 1.126$ $2.20 \mathrm{E}+00 \quad 1.50 \mathrm{E}+00 \quad 6.81 \mathrm{E}-01 \quad 5.80 \mathrm{E}-03 \quad 1.170$

$9 \quad 210.371 \quad 3.74 \mathrm{E}+14 \quad 3.26 \mathrm{E}-02 \quad 1.57 \mathrm{E}+02 \quad 4.113 \mathrm{E}+02 \quad 4.563 \mathrm{E}+01 \quad 7.64 \mathrm{E}-01 \quad 4.88 \mathrm{E}-01 \quad 6.39 \mathrm{E}-01 \quad 1.90 \mathrm{E}-03 \quad 1.126$ $2.20 \mathrm{E}+00 \quad 1.50 \mathrm{E}+00 \quad 6.81 \mathrm{E}-01 \quad 5.80 \mathrm{E}-03 \quad 1.170$

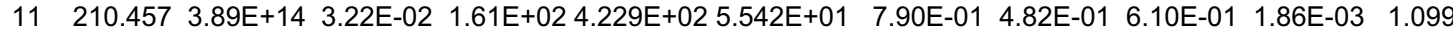
$2.25 \mathrm{E}+00 \quad 1.49 \mathrm{E}+00 \quad 6.63 \mathrm{E}-01 \quad 5.70 \mathrm{E}-03 \quad 1.156$

$11 \quad 210.457 \quad 3.89 \mathrm{E}+14 \quad 3.22 \mathrm{E}-02 \quad 1.61 \mathrm{E}+02$ 4.229E+02 5.542E+01 $\quad 7.90 \mathrm{E}-01 \quad 4.82 \mathrm{E}-01 \quad 6.10 \mathrm{E}-01 \quad 1.86 \mathrm{E}-03 \quad 1.099$ $2.25 \mathrm{E}+00 \quad 1.49 \mathrm{E}+00 \quad 6.63 \mathrm{E}-01 \quad 5.70 \mathrm{E}-03 \quad 1.156$

$13 \quad 210.377 \quad 3.90 \mathrm{E}+14 \quad 3.24 \mathrm{E}-02 \quad 1.62 \mathrm{E}+02 \quad 4.261 \mathrm{E}+02 \quad 2.954 \mathrm{E}+01 \quad 7.65 \mathrm{E}-01 \quad 4.85 \mathrm{E}-01 \quad 6.34 \mathrm{E}-01 \quad 2.00 \mathrm{E}-03 \quad 1.124$ $2.20 \mathrm{E}+00 \quad 1.49 \mathrm{E}+00 \quad 6.75 \mathrm{E}-01 \quad 6.09 \mathrm{E}-03 \quad 1.167$

$14 \quad 210.411 \quad 3.98 \mathrm{E}+14 \quad 3.16 \mathrm{E}-02 \quad 1.61 \mathrm{E}+02$ 4.236E+02 3.932E+01 $\quad 7.77 \mathrm{E}-01 \quad 4.72 \mathrm{E}-01 \quad 6.08 \mathrm{E}-01 \quad 2.05 \mathrm{E}-03 \quad 1.093$ $2.19 \mathrm{E}+00 \quad 1.46 \mathrm{E}+00 \quad 6.64 \mathrm{E}-01 \quad 6.26 \mathrm{E}-03 \quad 1.154$

$14 \quad 210.411 \quad 3.98 \mathrm{E}+14 \quad 3.16 \mathrm{E}-02 \quad 1.61 \mathrm{E}+02$ 4.236E+02 3.932E+01 $\quad 7.77 \mathrm{E}-01 \quad 4.72 \mathrm{E}-01 \quad 6.08 \mathrm{E}-01 \quad 2.05 \mathrm{E}-03 \quad 1.093$ $2.19 \mathrm{E}+00 \quad 1.46 \mathrm{E}+00 \quad 6.64 \mathrm{E}-01 \quad 6.26 \mathrm{E}-03 \quad 1.154$

$16 \quad 210.465 \quad 3.76 \mathrm{E}+14 \quad 3.26 \mathrm{E}-02 \quad 1.57 \mathrm{E}+02 \quad 4.129 \mathrm{E}+02 \quad 4.888 \mathrm{E}+01 \quad 7.86 \mathrm{E}-01 \quad 4.87 \mathrm{E}-01 \quad 6.19 \mathrm{E}-01 \quad 2.02 \mathrm{E}-03 \quad 1.111$ $2.23 \mathrm{E}+00 \quad 1.51 \mathrm{E}+00 \quad 6.75 \mathrm{E}-01 \quad 6.19 \mathrm{E}-03 \quad 1.170$

$16 \quad 210.465 \quad 3.76 \mathrm{E}+14 \quad 3.26 \mathrm{E}-02 \quad 1.57 \mathrm{E}+02 \quad 4.129 \mathrm{E}+02 \quad 4.888 \mathrm{E}+01 \quad 7.86 \mathrm{E}-01 \quad 4.87 \mathrm{E}-01 \quad 6.19 \mathrm{E}-01 \quad 2.02 \mathrm{E}-03 \quad 1.111$ $2.23 \mathrm{E}+00 \quad 1.51 \mathrm{E}+00 \quad 6.75 \mathrm{E}-01 \quad 6.19 \mathrm{E}-03 \quad 1.170$

$16 \quad 210.465 \quad 3.76 \mathrm{E}+14 \quad 3.26 \mathrm{E}-02 \quad 1.57 \mathrm{E}+02 \quad 4.129 \mathrm{E}+02 \quad 4.888 \mathrm{E}+01 \quad 7.86 \mathrm{E}-01 \quad 4.87 \mathrm{E}-01 \quad 6.19 \mathrm{E}-01 \quad 2.02 \mathrm{E}-03 \quad 1.111$ $2.23 \mathrm{E}+00 \quad 1.51 \mathrm{E}+00 \quad 6.75 \mathrm{E}-01 \quad 6.19 \mathrm{E}-03 \quad 1.170$

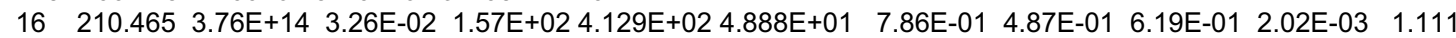
$2.23 \mathrm{E}+00 \quad 1.51 \mathrm{E}+00 \quad 6.75 \mathrm{E}-01 \quad 6.19 \mathrm{E}-03 \quad 1.170$

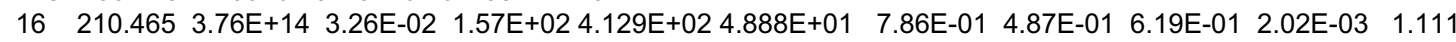
$2.23 \mathrm{E}+00 \quad 1.51 \mathrm{E}+00 \quad 6.75 \mathrm{E}-01 \quad 6.19 \mathrm{E}-03 \quad 1.170$

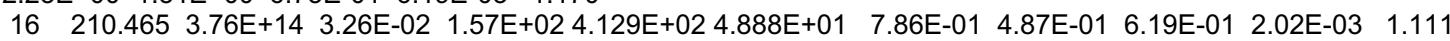
$2.23 \mathrm{E}+00 \quad 1.51 \mathrm{E}+00 \quad 6.75 \mathrm{E}-01 \quad 6.19 \mathrm{E}-03 \quad 1.170$

\begin{tabular}{|c|c|c|c|c|c|c|}
\hline \multicolumn{2}{|c|}{ Monteburns } & \multicolumn{3}{|c|}{ ux Spectrum for } & \multirow[b]{2}{*}{$<1 \mathrm{MeV}$} & \\
\hline & $<.1 \mathrm{eV}$ & $<1 \mathrm{eV}$ & $<100 \mathrm{el}$ & $<100 \mathrm{k}$ & & $<20 \mathrm{MeV}$ \\
\hline 0 & 1.58 & 3.52 & 11.08 & 28.02 & 27.64 & 28.15 \\
\hline 1 & 1.56 & 3.57 & 11.17 & 27.81 & 27.77 & 28.13 \\
\hline 1 & 1.56 & 3.57 & 11.17 & 27.81 & 27.77 & 28.13 \\
\hline 3 & 1.81 & 3.86 & 11.12 & 27.60 & 27.44 & 28.18 \\
\hline 3 & 1.81 & 3.86 & 11.12 & 27.60 & 27.44 & 28.18 \\
\hline 5 & 1.22 & 2.90 & 10.91 & 28.23 & 28.01 & 28.73 \\
\hline 5 & 1.22 & 2.90 & 10.91 & 28.23 & 28.01 & 28.73 \\
\hline 7 & 1.36 & 3.11 & 10.88 & 28.23 & 27.97 & 28.45 \\
\hline 7 & 1.36 & 3.11 & 10.88 & 28.23 & 27.97 & 28.45 \\
\hline 9 & 1.22 & 2.89 & 10.82 & 28.49 & 27.99 & 28.58 \\
\hline 9 & 1.22 & 2.89 & 10.82 & 28.49 & 27.99 & 28.58 \\
\hline 11 & 1.36 & 3.10 & 10.88 & 28.24 & 28.16 & 28.27 \\
\hline 11 & 1.36 & 3.10 & 10.88 & 28.24 & 28.16 & 28.27 \\
\hline 13 & 1.18 & 2.93 & 10.84 & 28.32 & 28.22 & 28.51 \\
\hline 14 & 1.18 & 2.94 & 10.85 & 28.24 & 28.14 & 28.64 \\
\hline 14 & 1.18 & 2.94 & 10.85 & 28.24 & 28.14 & 28.64 \\
\hline 16 & 1.37 & 3.14 & 10.91 & 28.24 & 27.78 & 28.57 \\
\hline 16 & 1.37 & 3.14 & 10.91 & 28.24 & 27.78 & 28.57 \\
\hline 16 & 1.37 & 3.14 & 10.91 & 28.24 & 27.78 & 28.57 \\
\hline 16 & 1.37 & 3.14 & 10.91 & 28.24 & 27.78 & 28.57 \\
\hline 16 & 1.37 & 3.14 & 10.91 & 28.24 & 27.78 & 28.57 \\
\hline 16 & 1.37 & 3.14 & 10.91 & 28.24 & 27.78 & 28.57 \\
\hline
\end{tabular}




\section{LA-14052-T}

Monteburns Grams of Material at End of Steps for material 1

92234.79c 92235.79c 92236.79c 92238.79c 93237.79c 94238.79c 94239.79c 94240.79c 94241.79c 94242.79c 95241.79c 95242.79c 95243.79c 96242.79c 96243.79c 96244.79c 96245.60c 96246.60c actinide

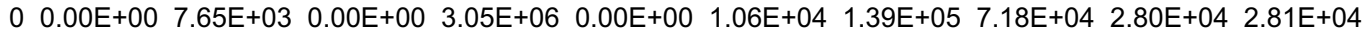

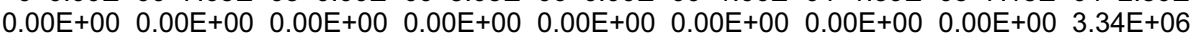

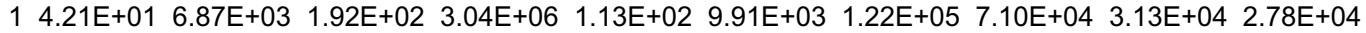

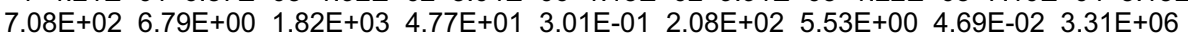

$2 \quad 5.06 \mathrm{E}+01 \quad 6.87 \mathrm{E}+03 \quad 1.93 \mathrm{E}+02 \quad 3.04 \mathrm{E}+06 \quad 1.19 \mathrm{E}+02 \quad 9.91 \mathrm{E}+03 \quad 1.23 \mathrm{E}+05 \quad 7.10 \mathrm{E}+04 \quad 3.12 \mathrm{E}+04 \quad 2.78 \mathrm{E}+04$

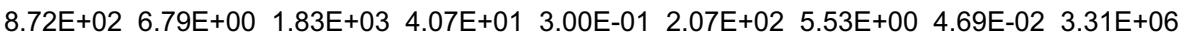

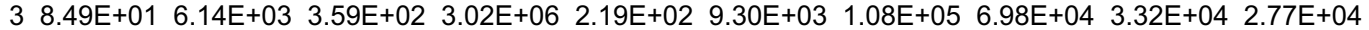

$\begin{array}{lllllllll}1.44 \mathrm{E}+03 & 2.15 \mathrm{E}+01 & 3.37 \mathrm{E}+03 & 1.63 \mathrm{E}+02 & 1.90 \mathrm{E}+00 & 7.31 \mathrm{E}+02 & 3.33 \mathrm{E}+01 & 6.49 \mathrm{E}-01 & 3.28 \mathrm{E}+06\end{array}$

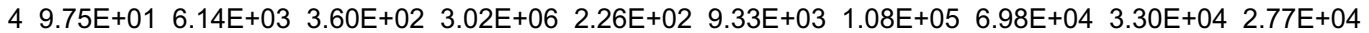

$\begin{array}{llllllll}1.72 \mathrm{E}+03 & 2.14 \mathrm{E}+01 \quad 3.38 \mathrm{E}+03 & 1.25 \mathrm{E}+02 & 1.89 \mathrm{E}+00 & 7.27 \mathrm{E}+02 & 3.33 \mathrm{E}+01 & 6.49 \mathrm{E}-01 & 3.28 \mathrm{E}+06\end{array}$

$5 \quad 4.23 \mathrm{E}+01 \quad 6.89 \mathrm{E}+03 \quad 1.88 \mathrm{E}+02 \quad 3.04 \mathrm{E}+06 \quad 1.05 \mathrm{E}+02 \quad 9.92 \mathrm{E}+03 \quad 1.23 \mathrm{E}+05 \quad 7.16 \mathrm{E}+04 \quad 3.09 \mathrm{E}+04 \quad 2.79 \mathrm{E}+04$

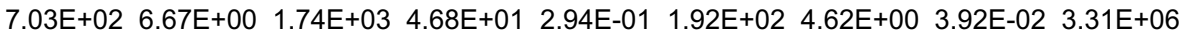

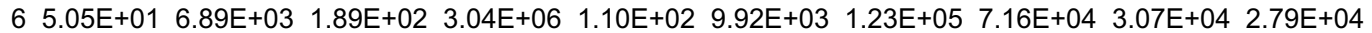

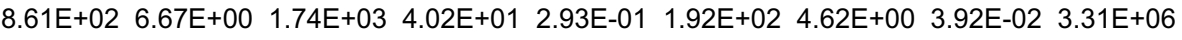

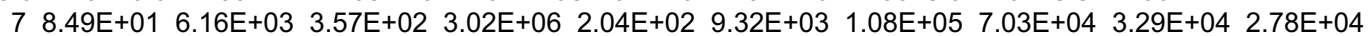
$\begin{array}{lllllllll}1.42 \mathrm{E}+03 & 2.14 \mathrm{E}+01 & 3.25 \mathrm{E}+03 & 1.62 \mathrm{E}+02 & 1.92 \mathrm{E}+00 & 7.21 \mathrm{E}+02 & 3.34 \mathrm{E}+01 & 6.16 \mathrm{E}-01 & 3.29 \mathrm{E}+06\end{array}$

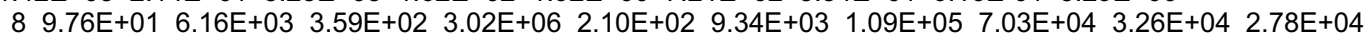

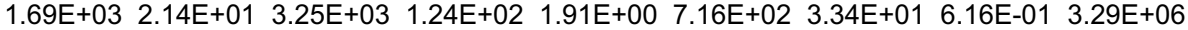

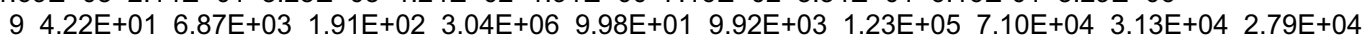

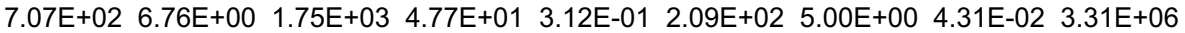

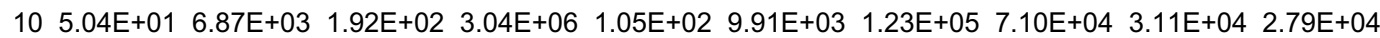

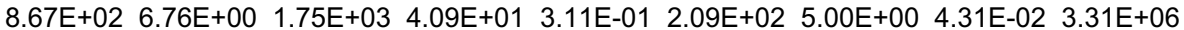

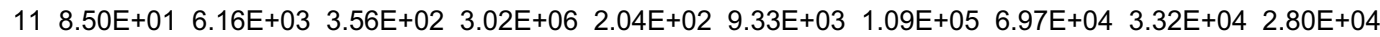

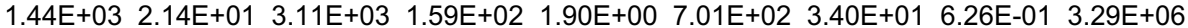

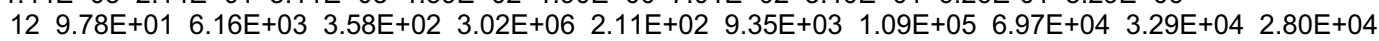
$\begin{array}{lllllllll}1.72 \mathrm{E}+03 & 2.14 \mathrm{E}+01 & 3.12 \mathrm{E}+03 & 1.22 \mathrm{E}+02 & 1.89 \mathrm{E}+00 & 6.97 \mathrm{E}+02 & 3.40 \mathrm{E}+01 & 6.26 \mathrm{E}-01 & 3.29 \mathrm{E}+06\end{array}$

13 1.13E-01 7.66E+03 4.95E-01 3.06E+06 6.23E-03 1.06E+04 1.39E+05 $7.19 \mathrm{E}+04 \quad 2.80 \mathrm{E}+04 \quad 2.81 \mathrm{E}+04$ $1.84 \mathrm{E}+00 \quad 5.78 \mathrm{E}-05 \quad 2.47 \mathrm{E}+00 \quad 5.91 \mathrm{E}-05 \quad 7.13 \mathrm{E}-10 \quad 4.25 \mathrm{E}-04 \quad 2.08 \mathrm{E}-08 \quad 3.36 \mathrm{E}-13 \quad 3.34 \mathrm{E}+06$

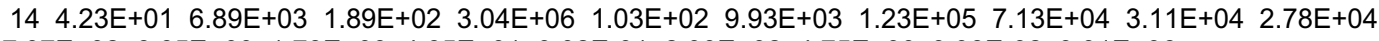

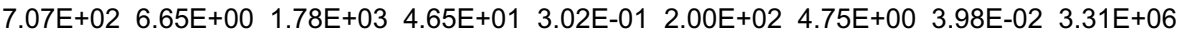

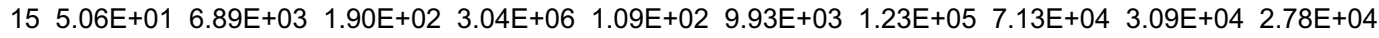

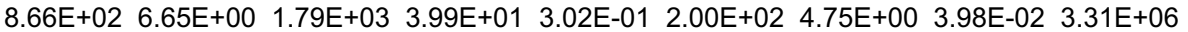

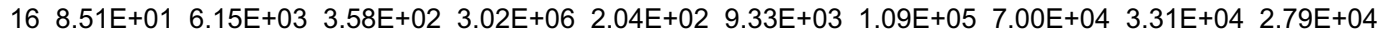

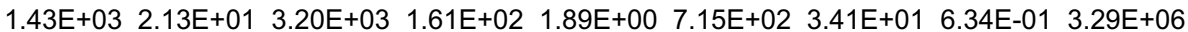

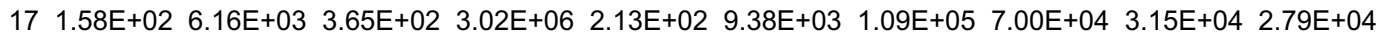
$\begin{array}{llllllllll}2.98 \mathrm{E}+03 & 2.12 \mathrm{E}+01 & 3.20 \mathrm{E}+03 & 3.43 \mathrm{E}+01 & 1.84 \mathrm{E}+00 & 6.89 \mathrm{E}+02 & 3.41 \mathrm{E}+01 & 6.34 \mathrm{E}-01 & 3.29 \mathrm{E}+06\end{array}$

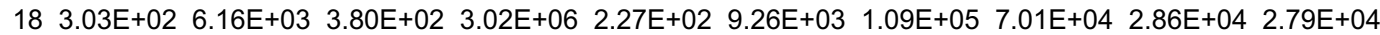

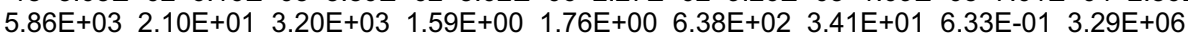

$19 \quad 4.46 \mathrm{E}+02 \quad 6.17 \mathrm{E}+03 \quad 3.95 \mathrm{E}+02 \quad 3.02 \mathrm{E}+06 \quad 2.50 \mathrm{E}+02 \quad 9.12 \mathrm{E}+03 \quad 1.09 \mathrm{E}+05 \quad 7.01 \mathrm{E}+04 \quad 2.60 \mathrm{E}+04 \quad 2.79 \mathrm{E}+04$

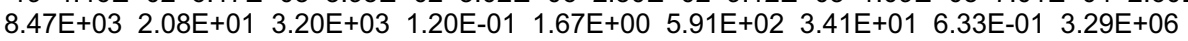
$20 \quad 5.86 \mathrm{E}+02 \quad 6.17 \mathrm{E}+03 \quad 4.09 \mathrm{E}+02 \quad 3.02 \mathrm{E}+06 \quad 2.81 \mathrm{E}+02 \quad 8.98 \mathrm{E}+03 \quad 1.09 \mathrm{E}+05 \quad 7.01 \mathrm{E}+04 \quad 2.36 \mathrm{E}+04 \quad 2.79 \mathrm{E}+04$

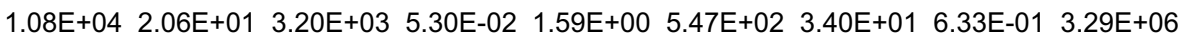
$21 \quad 7.93 \mathrm{E}+02 \quad 6.18 \mathrm{E}+03 \quad 4.31 \mathrm{E}+02 \quad 3.02 \mathrm{E}+06 \quad 3.40 \mathrm{E}+02 \quad 8.77 \mathrm{E}+03 \quad 1.09 \mathrm{E}+05 \quad 7.02 \mathrm{E}+04 \quad 2.04 \mathrm{E}+04 \quad 2.79 \mathrm{E}+04$

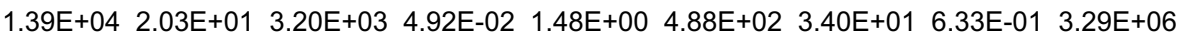

Monteburns Grams of Material at End of Steps for material 2

92234.79c 92235.79c 92236.79c 92238.79c 93237.79c 94238.79c 94239.79c 94240.79c 94241.79c 94242.79c 95241.79c 95242.79c 95243.79c 96242.79c 96243.79c 96244.79c 96245.60c 96246.60c actinide

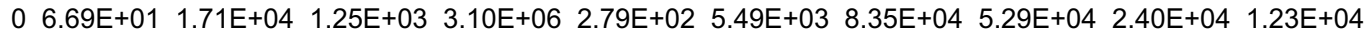

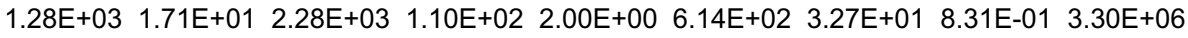

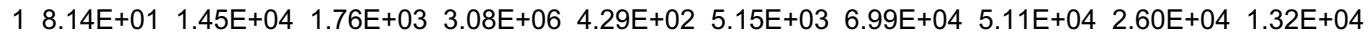

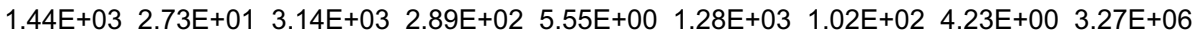

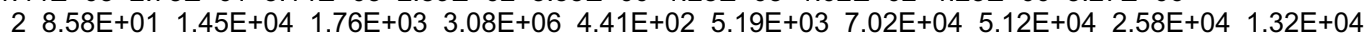

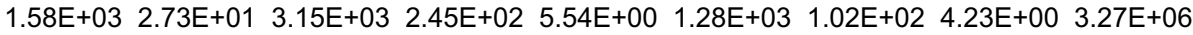

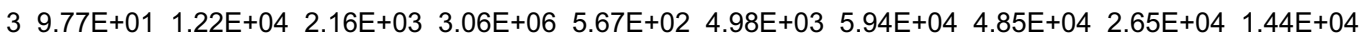

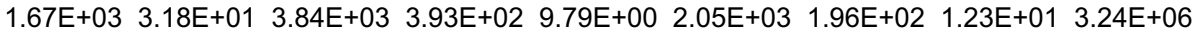

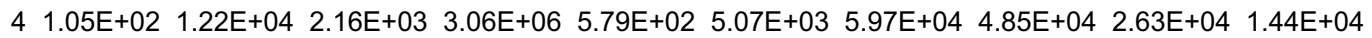

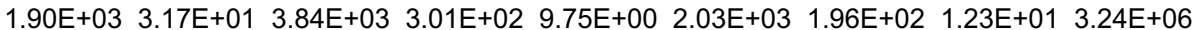

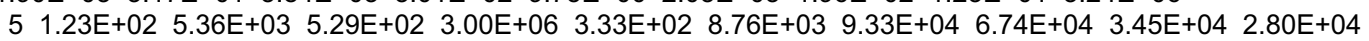
$2.05 \mathrm{E}+03 \quad 3.74 \mathrm{E}+01 \quad 4.75 \mathrm{E}+03 \quad 3.26 \mathrm{E}+02 \quad 5.74 \mathrm{E}+00 \quad 1.60 \mathrm{E}+03 \quad 1.15 \mathrm{E}+02 \quad 3.66 \mathrm{E}+00 \quad 3.25 \mathrm{E}+06$

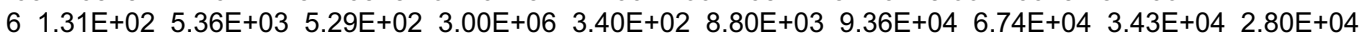

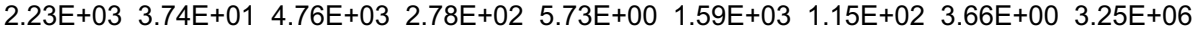

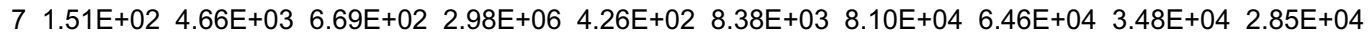
$2.43 \mathrm{E}+03 \quad 4.76 \mathrm{E}+01 \quad 5.80 \mathrm{E}+03 \quad 4.61 \mathrm{E}+02 \quad 1.11 \mathrm{E}+01 \quad 2.63 \mathrm{E}+03 \quad 2.39 \mathrm{E}+02 \quad 1.14 \mathrm{E}+01 \quad 3.22 \mathrm{E}+06$

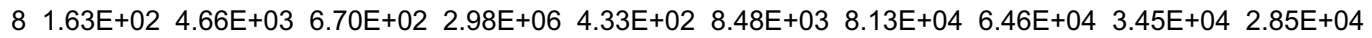
$2.72 \mathrm{E}+03 \quad 4.75 \mathrm{E}+01 \quad 5.80 \mathrm{E}+03 \quad 3.54 \mathrm{E}+02 \quad 1.10 \mathrm{E}+01 \quad 2.61 \mathrm{E}+03 \quad 2.39 \mathrm{E}+02 \quad 1.14 \mathrm{E}+01 \quad 3.22 \mathrm{E}+06$ 


\section{LA-14052-T}

$9 \quad 1.24 \mathrm{E}+02 \quad 5.40 \mathrm{E}+03 \quad 5.21 \mathrm{E}+02 \quad 3.01 \mathrm{E}+06 \quad 3.08 \mathrm{E}+02 \quad 8.80 \mathrm{E}+03 \quad 9.42 \mathrm{E}+04 \quad 6.81 \mathrm{E}+04 \quad 3.42 \mathrm{E}+04 \quad 2.80 \mathrm{E}+04$ $\begin{array}{lllllllll}2.04 \mathrm{E}+03 & 3.74 \mathrm{E}+01 & 4.54 \mathrm{E}+03 & 3.15 \mathrm{E}+02 & 5.50 \mathrm{E}+00 & 1.55 \mathrm{E}+03 & 1.06 \mathrm{E}+02 & 3.34 \mathrm{E}+00 & 3.25 \mathrm{E}+06\end{array}$

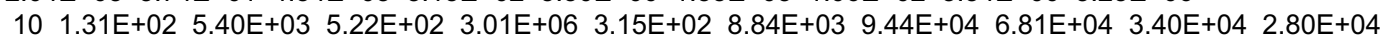

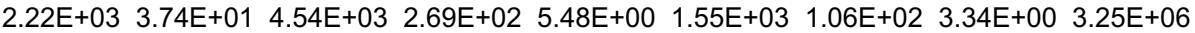

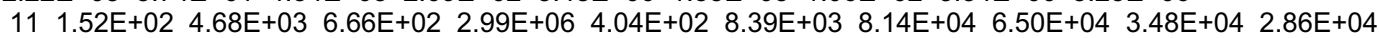
$\begin{array}{llllllllll}2.41 \mathrm{E}+03 & 4.72 \mathrm{E}+01 & 5.62 \mathrm{E}+03 & 4.62 \mathrm{E}+02 & 1.08 \mathrm{E}+01 & 2.59 \mathrm{E}+03 & 2.26 \mathrm{E}+02 & 1.08 \mathrm{E}+01 & 3.22 \mathrm{E}+06\end{array}$

$\begin{array}{lllllllllll}12 & 1.63 \mathrm{E}+02 & 4.68 \mathrm{E}+03 & 6.68 \mathrm{E}+02 & 2.99 \mathrm{E}+06 & 4.12 \mathrm{E}+02 & 8.49 \mathrm{E}+03 & 8.17 \mathrm{E}+04 & 6.50 \mathrm{E}+04 & 3.45 \mathrm{E}+04 & 2.86 \mathrm{E}+04\end{array}$ $\begin{array}{lllllllll}2.70 \mathrm{E}+03 & 4.71 \mathrm{E}+01 & 5.62 \mathrm{E}+03 & 3.54 \mathrm{E}+02 & 1.08 \mathrm{E}+01 & 2.57 \mathrm{E}+03 & 2.26 \mathrm{E}+02 & 1.08 \mathrm{E}+01 & 3.22 \mathrm{E}+06\end{array}$

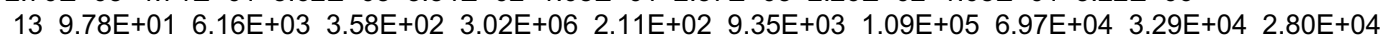
$\begin{array}{lllllllll}1.72 \mathrm{E}+03 & 2.15 \mathrm{E}+01 & 3.12 \mathrm{E}+03 & 1.22 \mathrm{E}+02 & 1.90 \mathrm{E}+00 & 6.98 \mathrm{E}+02 & 3.41 \mathrm{E}+01 & 6.30 \mathrm{E}-01 & 3.29 \mathrm{E}+06\end{array}$

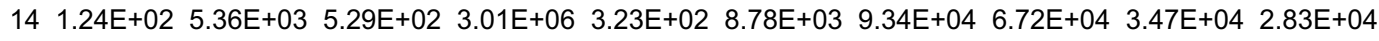

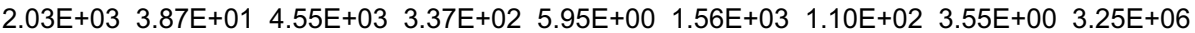

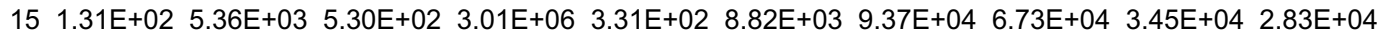

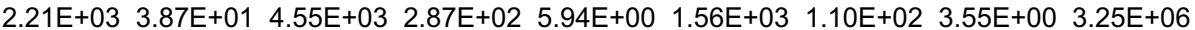

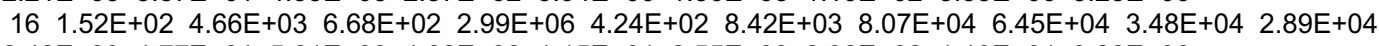

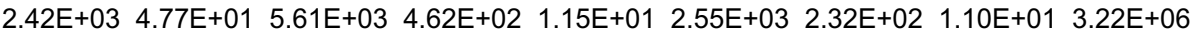

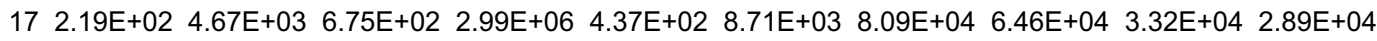

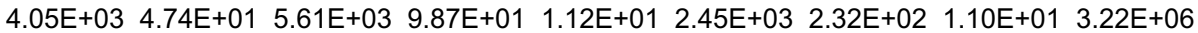

$18 \quad 3.55 \mathrm{E}+02 \quad 4.67 \mathrm{E}+03 \quad 6.88 \mathrm{E}+02 \quad 2.99 \mathrm{E}+06 \quad 4.55 \mathrm{E}+02 \quad 8.67 \mathrm{E}+03 \quad 8.09 \mathrm{E}+04 \quad 6.48 \mathrm{E}+04 \quad 3.02 \mathrm{E}+04 \quad 2.89 \mathrm{E}+04$

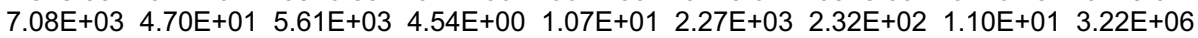

$19 \quad 4.88 \mathrm{E}+02 \quad 4.68 \mathrm{E}+03 \quad 7.02 \mathrm{E}+02 \quad 2.99 \mathrm{E}+06 \quad 4.82 \mathrm{E}+02 \quad 8.53 \mathrm{E}+03 \quad 8.09 \mathrm{E}+04 \quad 6.49 \mathrm{E}+04 \quad 2.74 \mathrm{E}+04 \quad 2.89 \mathrm{E}+04$

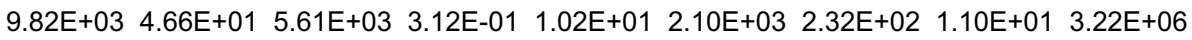

$20 \quad 6.20 \mathrm{E}+02 \quad 4.68 \mathrm{E}+03 \quad 7.15 \mathrm{E}+02 \quad 2.99 \mathrm{E}+06 \quad 5.17 \mathrm{E}+02 \quad 8.40 \mathrm{E}+03 \quad 8.09 \mathrm{E}+04 \quad 6.50 \mathrm{E}+04 \quad 2.49 \mathrm{E}+04 \quad 2.89 \mathrm{E}+04$

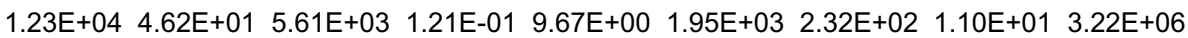

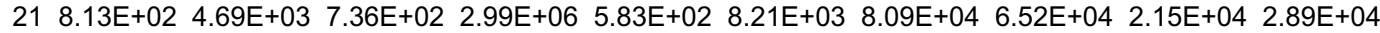

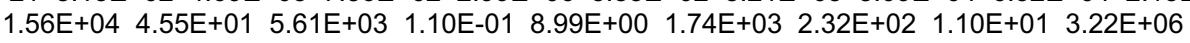

Monteburns Grams of Material at End of Steps for material 3

92234.79c 92235.79c 92236.79c 92238.79c 93237.79c 94238.79c 94239.79c 94240.79c 94241.79c 94242.79c 95241.79c 95242.79c 95243.79c 96242.79c 96243.79c 96244.79c 96245.60c 96246.60c actinide

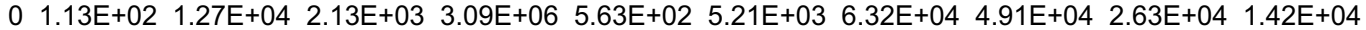

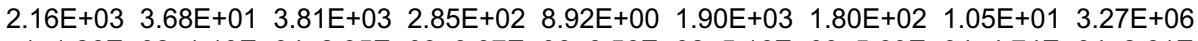

$1 \quad 1.26 \mathrm{E}+02 \quad 1.13 \mathrm{E}+04 \quad 2.35 \mathrm{E}+03 \quad 3.07 \mathrm{E}+06 \quad 6.56 \mathrm{E}+02 \quad 5.16 \mathrm{E}+03 \quad 5.69 \mathrm{E}+04 \quad 4.74 \mathrm{E}+04 \quad 2.61 \mathrm{E}+04 \quad 1.50 \mathrm{E}+04$ $\begin{array}{lllllllll}2.29 \mathrm{E}+03 & 4.25 \mathrm{E}+01 & 4.28 \mathrm{E}+03 & 3.92 \mathrm{E}+02 & 1.13 \mathrm{E}+01 & 2.44 \mathrm{E}+03 & 2.47 \mathrm{E}+02 & 1.84 \mathrm{E}+01 & 3.25 \mathrm{E}+06\end{array}$

$2 \quad 1.31 \mathrm{E}+02 \quad 1.13 \mathrm{E}+04 \quad 2.35 \mathrm{E}+03 \quad 3.07 \mathrm{E}+06 \quad 6.64 \mathrm{E}+02 \quad 5.22 \mathrm{E}+03 \quad 5.71 \mathrm{E}+04 \quad 4.74 \mathrm{E}+04 \quad 2.59 \mathrm{E}+04 \quad 1.50 \mathrm{E}+04$ $\begin{array}{llllllllll}2.43 \mathrm{E}+03 & 4.25 \mathrm{E}+01 & 4.28 \mathrm{E}+03 & 3.32 \mathrm{E}+02 & 1.13 \mathrm{E}+01 & 2.43 \mathrm{E}+03 & 2.47 \mathrm{E}+02 & 1.84 \mathrm{E}+01 & 3.25 \mathrm{E}+06\end{array}$

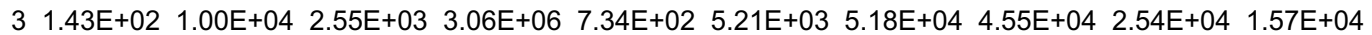
$2.50 \mathrm{E}+03 \quad 4.57 \mathrm{E}+01 \quad 4.68 \mathrm{E}+03 \quad 4.37 \mathrm{E}+02 \quad 1.34 \mathrm{E}+01 \quad 2.97 \mathrm{E}+03 \quad 3.17 \mathrm{E}+02 \quad 2.92 \mathrm{E}+01 \quad 3.23 \mathrm{E}+06$

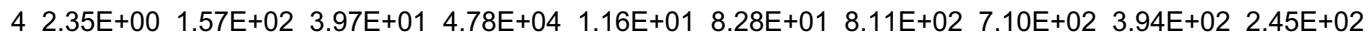

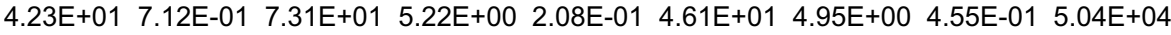

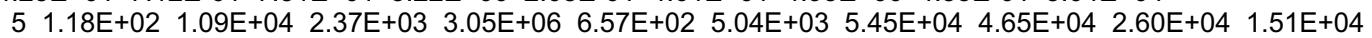

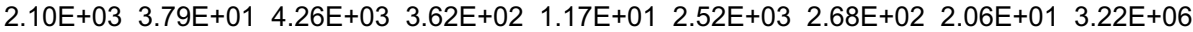

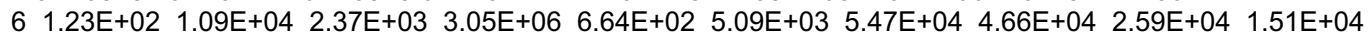
$\begin{array}{lllllllll}2.24 \mathrm{E}+03 & 3.79 \mathrm{E}+01 & 4.27 \mathrm{E}+03 & 3.08 \mathrm{E}+02 & 1.17 \mathrm{E}+01 & 2.51 \mathrm{E}+03 & 2.68 \mathrm{E}+02 & 2.06 \mathrm{E}+01 & 3.22 \mathrm{E}+06\end{array}$

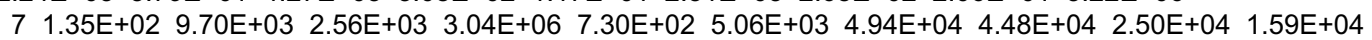
$2.32 \mathrm{E}+03 \quad 4.16 \mathrm{E}+01 \quad 4.67 \mathrm{E}+03 \quad 4.15 \mathrm{E}+02 \quad 1.37 \mathrm{E}+01 \quad 3.05 \mathrm{E}+03 \quad 3.43 \mathrm{E}+02 \quad 3.28 \mathrm{E}+01 \quad 3.20 \mathrm{E}+06$

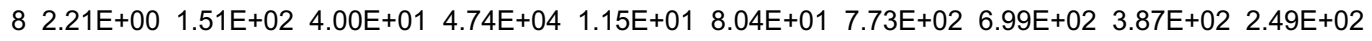
3.95E+01 6.49E-01 7.29E+01 4.96E+00 2.13E-01 4.73E+01 5.35E+00 5.12E-01 4.99E+04

$\begin{aligned} & 9 \\ & 1.87 \mathrm{E}+02\end{aligned} \quad 4.25 \mathrm{E}+03 \quad 7.48 \mathrm{E}+02 \quad 2.97 \mathrm{E}+06 \quad 4.87 \mathrm{E}+02 \quad 8.33 \mathrm{E}+03 \quad 7.42 \mathrm{E}+04 \quad 6.26 \mathrm{E}+04 \quad 3.40 \mathrm{E}+04 \quad 2.90 \mathrm{E}+04$

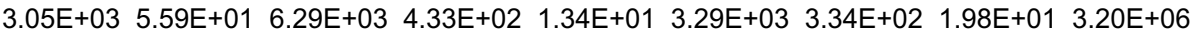

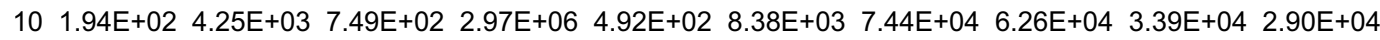

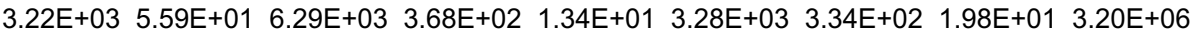

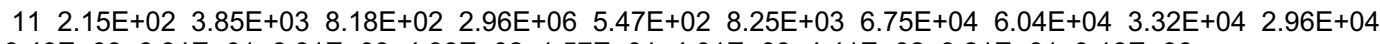

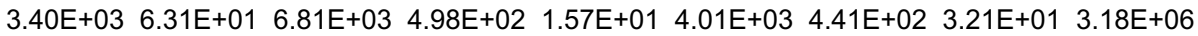

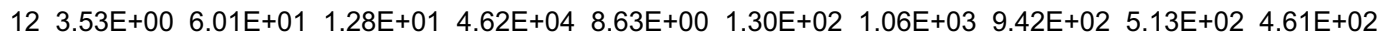

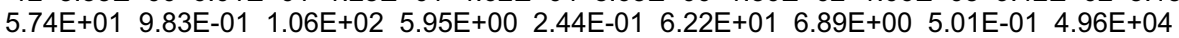

$13 \quad 1.64 \mathrm{E}+02 \quad 4.68 \mathrm{E}+03 \quad 6.68 \mathrm{E}+02 \quad 2.99 \mathrm{E}+06 \quad 4.12 \mathrm{E}+02 \quad 8.49 \mathrm{E}+03 \quad 8.17 \mathrm{E}+04 \quad 6.50 \mathrm{E}+04 \quad 3.45 \mathrm{E}+04 \quad 2.86 \mathrm{E}+04$ $\begin{array}{lllllllll}2.70 \mathrm{E}+03 & 4.71 \mathrm{E}+01 & 5.62 \mathrm{E}+03 & 3.53 \mathrm{E}+02 & 1.08 \mathrm{E}+01 & 2.57 \mathrm{E}+03 & 2.26 \mathrm{E}+02 & 1.08 \mathrm{E}+01 & 3.22 \mathrm{E}+06\end{array}$

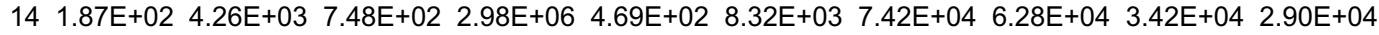

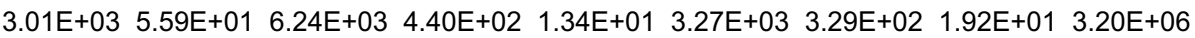

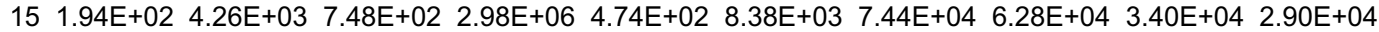
$\begin{array}{lllllllll}3.19 \mathrm{E}+03 & 5.58 \mathrm{E}+01 & 6.25 \mathrm{E}+03 & 3.75 \mathrm{E}+02 & 1.34 \mathrm{E}+01 & 3.26 \mathrm{E}+03 & 3.29 \mathrm{E}+02 & 1.92 \mathrm{E}+01 & 3.20 \mathrm{E}+06\end{array}$

$16 \quad 2.15 \mathrm{E}+02 \quad 3.86 \mathrm{E}+03 \quad 8.20 \mathrm{E}+02 \quad 2.96 \mathrm{E}+06 \quad 5.17 \mathrm{E}+02 \quad 8.24 \mathrm{E}+03 \quad 6.75 \mathrm{E}+04 \quad 6.06 \mathrm{E}+04 \quad 3.32 \mathrm{E}+04 \quad 2.95 \mathrm{E}+04$

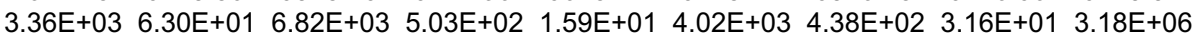

$17 \quad 2.81 \mathrm{E}+02 \quad 3.86 \mathrm{E}+03 \quad 8.26 \mathrm{E}+02 \quad 2.96 \mathrm{E}+06 \quad 5.28 \mathrm{E}+02 \quad 8.56 \mathrm{E}+03 \quad 6.77 \mathrm{E}+04 \quad 6.08 \mathrm{E}+04 \quad 3.17 \mathrm{E}+04 \quad 2.95 \mathrm{E}+04$

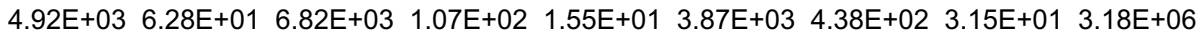

$18 \quad 4.14 \mathrm{E}+02 \quad 3.87 \mathrm{E}+03 \quad 8.39 \mathrm{E}+02 \quad 2.96 \mathrm{E}+06 \quad 5.48 \mathrm{E}+02 \quad 8.53 \mathrm{E}+03 \quad 6.77 \mathrm{E}+04 \quad 6.10 \mathrm{E}+04 \quad 2.88 \mathrm{E}+04 \quad 2.95 \mathrm{E}+04$ $\begin{array}{llllllllll}7.80 \mathrm{E}+03 & 6.22 \mathrm{E}+01 & 6.82 \mathrm{E}+03 & 4.96 \mathrm{E}+00 & 1.48 \mathrm{E}+01 & 3.58 \mathrm{E}+03 & 4.38 \mathrm{E}+02 & 3.15 \mathrm{E}+01 & 3.18 \mathrm{E}+06\end{array}$

$19 \quad 5.46 \mathrm{E}+02 \quad 3.87 \mathrm{E}+03 \quad 8.52 \mathrm{E}+02 \quad 2.96 \mathrm{E}+06 \quad 5.77 \mathrm{E}+02 \quad 8.40 \mathrm{E}+03 \quad 6.77 \mathrm{E}+04 \quad 6.13 \mathrm{E}+04 \quad 2.61 \mathrm{E}+04 \quad 2.95 \mathrm{E}+04$

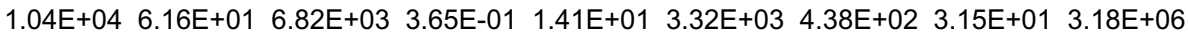




\section{LA-14052-T}

$20 \quad 6.75 \mathrm{E}+02 \quad 3.87 \mathrm{E}+03 \quad 8.65 \mathrm{E}+02 \quad 2.96 \mathrm{E}+06 \quad 6.14 \mathrm{E}+02 \quad 8.27 \mathrm{E}+03 \quad 6.77 \mathrm{E}+04 \quad 6.15 \mathrm{E}+04 \quad 2.37 \mathrm{E}+04 \quad 2.95 \mathrm{E}+04$

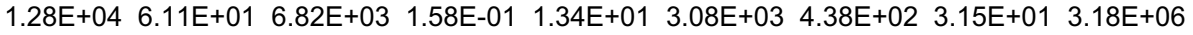

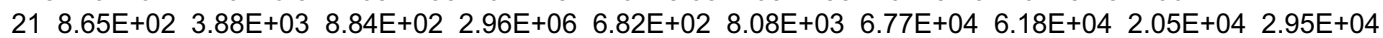

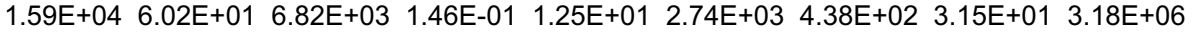


LA-14052-T 


\section{LA-14052-T}

\section{Appendix E. Sample MCNP Input File for ADS}

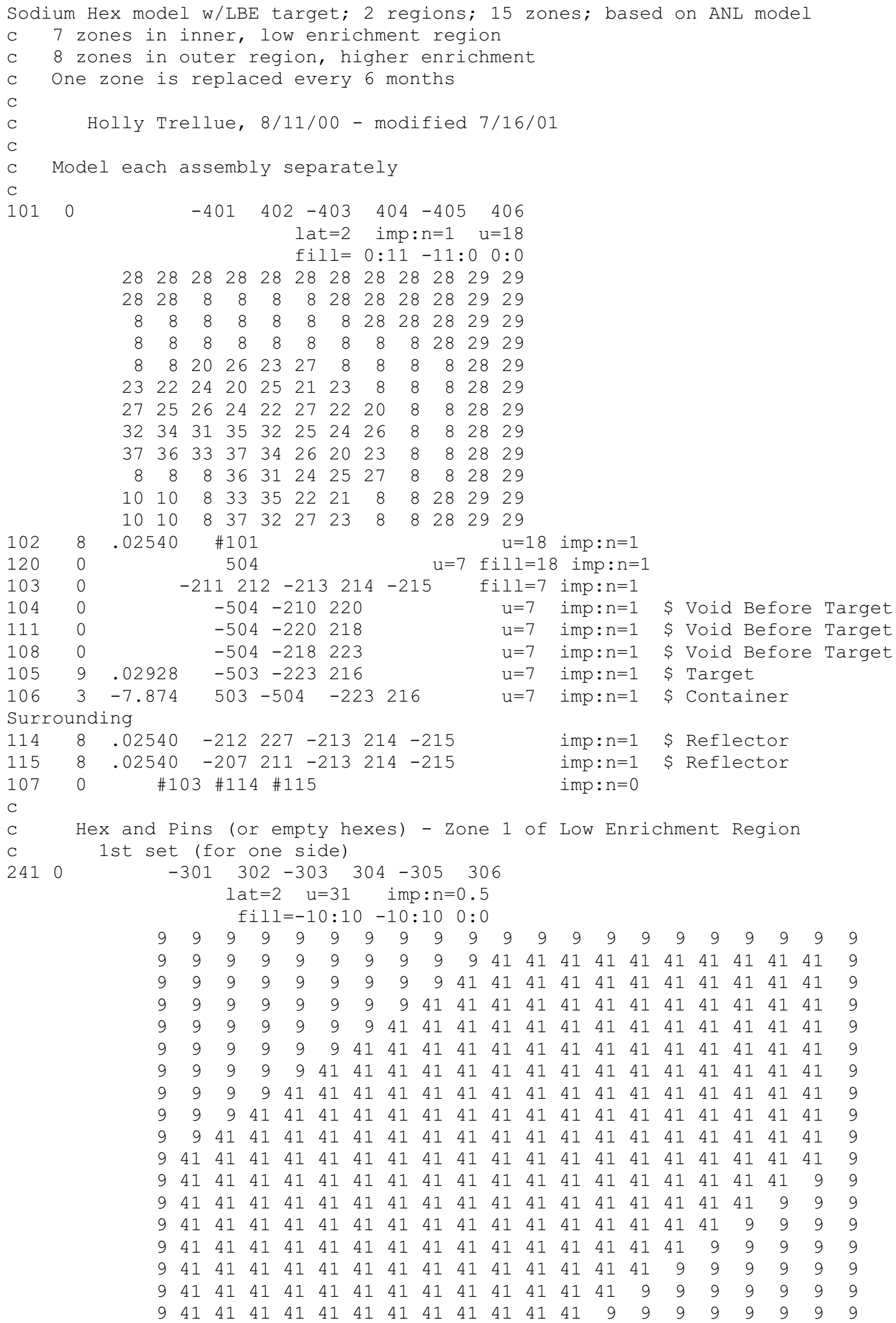




\section{LA-14052-T}

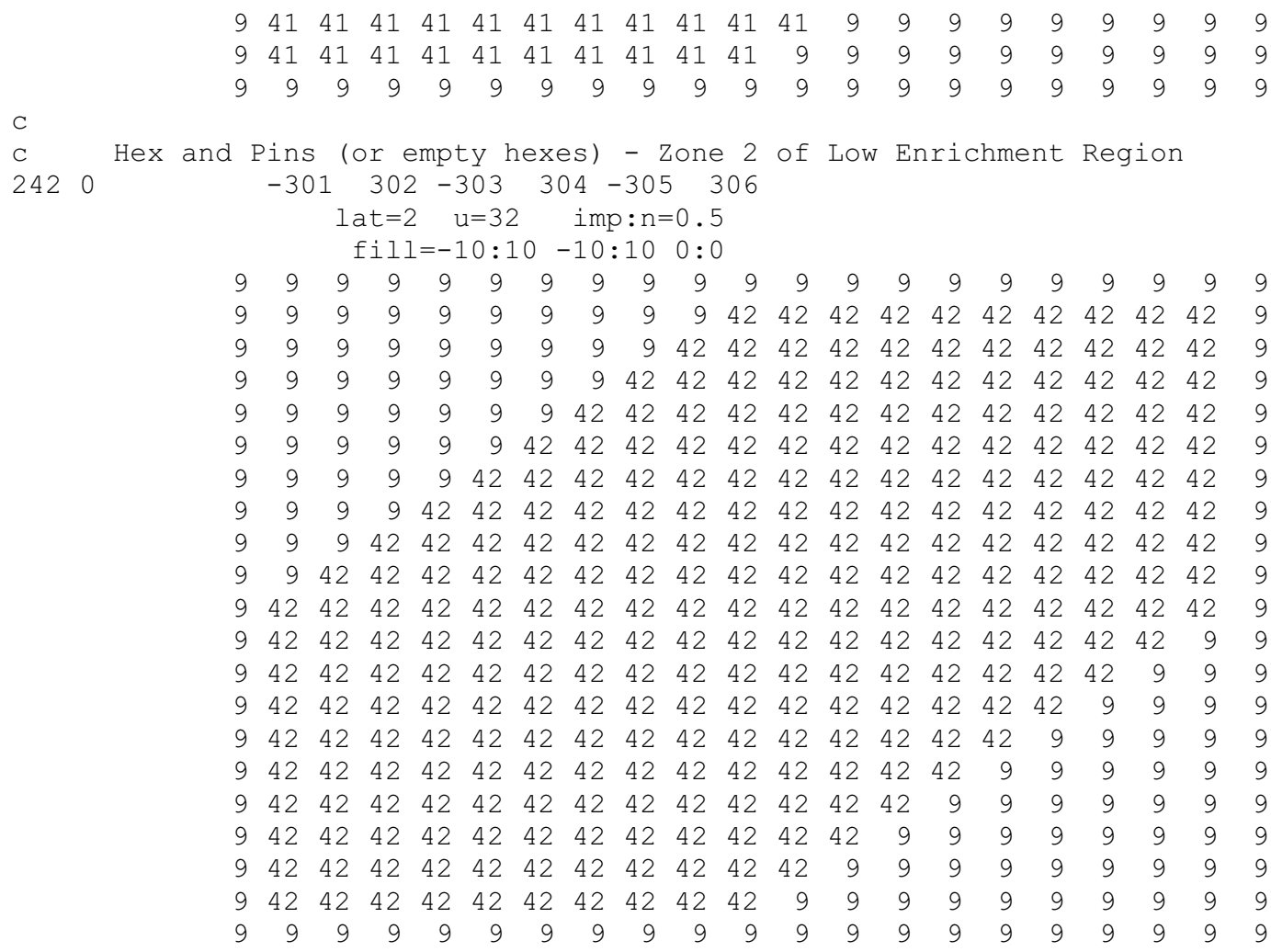

c

C Hex and Pins (or empty hexes) - Zone 3 of Low Enrichment Region

$2430 \quad-301 \quad 302-303 \quad 304-305 \quad 306$

lat $=2 \quad u=33 \quad$ imp $: n=0.5$

fill $=-10: 10-10: 10 \quad 0: 0$

$\begin{array}{lllllllllllllllllllll}9 & 9 & 9 & 9 & 9 & 9 & 9 & 9 & 9 & 9 & 9 & 9 & 9 & 9 & 9 & 9 & 9 & 9 & 9 & 9 & 9\end{array}$

$\begin{array}{lllllllllllllllllllll}9 & 9 & 9 & 9 & 9 & 9 & 9 & 9 & 9 & 9 & 43 & 43 & 43 & 43 & 43 & 43 & 43 & 43 & 43 & 43 & 9\end{array}$

$\begin{array}{lllllllllllllllllllll}9 & 9 & 9 & 9 & 9 & 9 & 9 & 9 & 9 & 43 & 43 & 43 & 43 & 43 & 43 & 43 & 43 & 43 & 43 & 43 & 9\end{array}$

$\begin{array}{lllllllllllllllllllll}9 & 9 & 9 & 9 & 9 & 9 & 9 & 9 & 43 & 43 & 43 & 43 & 43 & 43 & 43 & 43 & 43 & 43 & 43 & 43 & 9\end{array}$

$\begin{array}{llllllllllllllllllllll}9 & 9 & 9 & 9 & 9 & 9 & 9 & 43 & 43 & 43 & 43 & 43 & 43 & 43 & 43 & 43 & 43 & 43 & 43 & 43 & 9\end{array}$

$\begin{array}{lllllllllllllllllllll}9 & 9 & 9 & 9 & 9 & 9 & 43 & 43 & 43 & 43 & 43 & 43 & 43 & 43 & 43 & 43 & 43 & 43 & 43 & 43 & 9\end{array}$

$\begin{array}{lllllllllllllllllllll}9 & 9 & 9 & 9 & 9 & 43 & 43 & 43 & 43 & 43 & 43 & 43 & 43 & 43 & 43 & 43 & 43 & 43 & 43 & 43 & 9\end{array}$

$\begin{array}{lllllllllllllllllllll}9 & 9 & 9 & 9 & 43 & 43 & 43 & 43 & 43 & 43 & 43 & 43 & 43 & 43 & 43 & 43 & 43 & 43 & 43 & 43 & 9\end{array}$

$\begin{array}{lllllllllllllllllllll}9 & 9 & 9 & 43 & 43 & 43 & 43 & 43 & 43 & 43 & 43 & 43 & 43 & 43 & 43 & 43 & 43 & 43 & 43 & 43 & 9\end{array}$

$\begin{array}{lllllllllllllllllllll}9 & 9 & 43 & 43 & 43 & 43 & 43 & 43 & 43 & 43 & 43 & 43 & 43 & 43 & 43 & 43 & 43 & 43 & 43 & 43 & 9\end{array}$

$\begin{array}{lllllllllllllllllllll}9 & 43 & 43 & 43 & 43 & 43 & 43 & 43 & 43 & 43 & 43 & 43 & 43 & 43 & 43 & 43 & 43 & 43 & 43 & 43 & 9\end{array}$

$\begin{array}{lllllllllllllllllllll}9 & 43 & 43 & 43 & 43 & 43 & 43 & 43 & 43 & 43 & 43 & 43 & 43 & 43 & 43 & 43 & 43 & 43 & 43 & 9 & 9\end{array}$

$\begin{array}{lllllllllllllllllllll}9 & 43 & 43 & 43 & 43 & 43 & 43 & 43 & 43 & 43 & 43 & 43 & 43 & 43 & 43 & 43 & 43 & 43 & 9 & 9 & 9\end{array}$

$\begin{array}{lllllllllllllllllllll}9 & 43 & 43 & 43 & 43 & 43 & 43 & 43 & 43 & 43 & 43 & 43 & 43 & 43 & 43 & 43 & 43 & 9 & 9 & 9 & 9\end{array}$

$\begin{array}{lllllllllllllllllllll}9 & 43 & 43 & 43 & 43 & 43 & 43 & 43 & 43 & 43 & 43 & 43 & 43 & 43 & 43 & 43 & 9 & 9 & 9 & 9 & 9\end{array}$

$\begin{array}{llllllllllllllllllllll}9 & 43 & 43 & 43 & 43 & 43 & 43 & 43 & 43 & 43 & 43 & 43 & 43 & 43 & 43 & 9 & 9 & 9 & 9 & 9 & 9\end{array}$

$\begin{array}{lllllllllllllllllllll}9 & 43 & 43 & 43 & 43 & 43 & 43 & 43 & 43 & 43 & 43 & 43 & 43 & 43 & 9 & 9 & 9 & 9 & 9 & 9 & 9\end{array}$

$\begin{array}{lllllllllllllllllllll}9 & 43 & 43 & 43 & 43 & 43 & 43 & 43 & 43 & 43 & 43 & 43 & 43 & 9 & 9 & 9 & 9 & 9 & 9 & 9 & 9\end{array}$

$\begin{array}{llllllllllllllllllllll}9 & 43 & 43 & 43 & 43 & 43 & 43 & 43 & 43 & 43 & 43 & 43 & 9 & 9 & 9 & 9 & 9 & 9 & 9 & 9 & 9\end{array}$

$\begin{array}{lllllllllllllllllllll}9 & 43 & 43 & 43 & 43 & 43 & 43 & 43 & 43 & 43 & 43 & 9 & 9 & 9 & 9 & 9 & 9 & 9 & 9 & 9 & 9\end{array}$

c

c Hex and Pins (or empty hexes) - Zone 4 of Low Enrichment Region

$2440 \quad-301 \quad 302-303 \quad 304-305 \quad 306$

lat $=2 \quad u=34 \quad$ imp $: n=0.5$

fill=-10:10 -10:10 $0: 0$

$\begin{array}{lllllllllllllllllllll}9 & 9 & 9 & 9 & 9 & 9 & 9 & 9 & 9 & 9 & 9 & 9 & 9 & 9 & 9 & 9 & 9 & 9 & 9 & 9 & 9\end{array}$

$\begin{array}{llllllllllllllllllllll}9 & 9 & 9 & 9 & 9 & 9 & 9 & 9 & 9 & 9 & 44 & 44 & 44 & 44 & 44 & 44 & 44 & 44 & 44 & 44 & 9 \\ 9 & 9 & 9 & 9 & 9 & 9 & 9 & 9 & 9 & 44 & 44 & 44 & 44 & 44 & 44 & 44 & 44 & 44 & 44 & 44 & 9\end{array}$ 


\section{LA-14052-T}

$\begin{array}{rrrrrrrrrrrrrrrrrrrrrrrrrrrrrrrrr}9 & 9 & 9 & 9 & 9 & 9 & 9 & 9 & 44 & 44 & 44 & 44 & 44 & 44 & 44 & 44 & 44 & 44 & 44 & 44 & 9 \\ 9 & 9 & 9 & 9 & 9 & 9 & 9 & 44 & 44 & 44 & 44 & 44 & 44 & 44 & 44 & 44 & 44 & 44 & 44 & 44 & 9 \\ 9 & 9 & 9 & 9 & 9 & 9 & 44 & 44 & 44 & 44 & 44 & 44 & 44 & 44 & 44 & 44 & 44 & 44 & 44 & 44 & 9 \\ 9 & 9 & 9 & 9 & 9 & 44 & 44 & 44 & 44 & 44 & 44 & 44 & 44 & 44 & 44 & 44 & 44 & 44 & 44 & 44 & 9 \\ 9 & 9 & 9 & 9 & 44 & 44 & 44 & 44 & 44 & 44 & 44 & 44 & 44 & 44 & 44 & 44 & 44 & 44 & 44 & 44 & 9 \\ 9 & 9 & 9 & 44 & 44 & 44 & 44 & 44 & 44 & 44 & 44 & 44 & 44 & 44 & 44 & 44 & 44 & 44 & 44 & 44 & 9 \\ 9 & 9 & 44 & 44 & 44 & 44 & 44 & 44 & 44 & 44 & 44 & 44 & 44 & 44 & 44 & 44 & 44 & 44 & 44 & 44 & 9 \\ 9 & 44 & 44 & 44 & 44 & 44 & 44 & 44 & 44 & 44 & 44 & 44 & 44 & 44 & 44 & 44 & 44 & 44 & 44 & 44 & 9 \\ 9 & 44 & 44 & 44 & 44 & 44 & 44 & 44 & 44 & 44 & 44 & 44 & 44 & 44 & 44 & 44 & 44 & 44 & 44 & 9 & 9 \\ 9 & 44 & 44 & 44 & 44 & 44 & 44 & 44 & 44 & 44 & 44 & 44 & 44 & 44 & 44 & 44 & 44 & 44 & 9 & 9 & 9 \\ 9 & 44 & 44 & 44 & 44 & 44 & 44 & 44 & 44 & 44 & 44 & 44 & 44 & 44 & 44 & 44 & 44 & 9 & 9 & 9 & 9 \\ 9 & 44 & 44 & 44 & 44 & 44 & 44 & 44 & 44 & 44 & 44 & 44 & 44 & 44 & 44 & 44 & 9 & 9 & 9 & 9 & 9 \\ 9 & 44 & 44 & 44 & 44 & 44 & 44 & 44 & 44 & 44 & 44 & 44 & 44 & 44 & 44 & 9 & 9 & 9 & 9 & 9 & 9 \\ 9 & 44 & 44 & 44 & 44 & 44 & 44 & 44 & 44 & 44 & 44 & 44 & 44 & 44 & 9 & 9 & 9 & 9 & 9 & 9 & 9 \\ 9 & 44 & 44 & 44 & 44 & 44 & 44 & 44 & 44 & 44 & 44 & 44 & 44 & 9 & 9 & 9 & 9 & 9 & 9 & 9 & 9 \\ 9 & 44 & 44 & 44 & 44 & 44 & 44 & 44 & 44 & 44 & 44 & 44 & 9 & 9 & 9 & 9 & 9 & 9 & 9 & 9 & 9 \\ 9 & 44 & 44 & 44 & 44 & 44 & 44 & 44 & 44 & 44 & 44 & 9 & 9 & 9 & 9 & 9 & 9 & 9 & 9 & 9 & 9 \\ 9 & 9 & 9 & 9 & 9 & 9 & 9 & 9 & 9 & 9 & 9 & 9 & 9 & 9 & 9 & 9 & 9 & 9 & 9 & 9 & 9\end{array}$

C Hex and Pins (or empty hexes) - Zone 5 of Low Enrichment Region $2450 \quad-301 \quad 302-303 \quad 304-305 \quad 306$ lat $=2 \quad u=35 \quad$ imp: $n=0.5$ fill=-10:10 $-10: 10 \quad 0: 0$

$\begin{array}{lllllllllllllllllllll}9 & 9 & 9 & 9 & 9 & 9 & 9 & 9 & 9 & 9 & 9 & 9 & 9 & 9 & 9 & 9 & 9 & 9 & 9 & 9 & 9\end{array}$ $\begin{array}{lllllllllllllllllllll}9 & 9 & 9 & 9 & 9 & 9 & 9 & 9 & 9 & 9 & 45 & 45 & 45 & 45 & 45 & 45 & 45 & 45 & 45 & 45 & 9\end{array}$ $\begin{array}{lllllllllllllllllllll}9 & 9 & 9 & 9 & 9 & 9 & 9 & 9 & 9 & 45 & 45 & 45 & 45 & 45 & 45 & 45 & 45 & 45 & 45 & 45 & 9\end{array}$ $\begin{array}{lllllllllllllllllllll}9 & 9 & 9 & 9 & 9 & 9 & 9 & 9 & 45 & 45 & 45 & 45 & 45 & 45 & 45 & 45 & 45 & 45 & 45 & 45 & 9\end{array}$ $\begin{array}{lllllllllllllllllllll}9 & 9 & 9 & 9 & 9 & 9 & 9 & 45 & 45 & 45 & 45 & 45 & 45 & 45 & 45 & 45 & 45 & 45 & 45 & 45 & 9\end{array}$ $\begin{array}{lllllllllllllllllllll}9 & 9 & 9 & 9 & 9 & 9 & 45 & 45 & 45 & 45 & 45 & 45 & 45 & 45 & 45 & 45 & 45 & 45 & 45 & 45 & 9\end{array}$ $\begin{array}{lllllllllllllllllllll}9 & 9 & 9 & 9 & 9 & 45 & 45 & 45 & 45 & 45 & 45 & 45 & 45 & 45 & 45 & 45 & 45 & 45 & 45 & 45 & 9\end{array}$ $\begin{array}{llllllllllllllllllllll}9 & 9 & 9 & 9 & 45 & 45 & 45 & 45 & 45 & 45 & 45 & 45 & 45 & 45 & 45 & 45 & 45 & 45 & 45 & 45 & 9\end{array}$ $\begin{array}{lllllllllllllllllllll}9 & 9 & 9 & 45 & 45 & 45 & 45 & 45 & 45 & 45 & 45 & 45 & 45 & 45 & 45 & 45 & 45 & 45 & 45 & 45 & 9\end{array}$ $\begin{array}{lllllllllllllllllllll}9 & 9 & 45 & 45 & 45 & 45 & 45 & 45 & 45 & 45 & 45 & 45 & 45 & 45 & 45 & 45 & 45 & 45 & 45 & 45 & 9\end{array}$ $\begin{array}{lllllllllllllllllllll}9 & 45 & 45 & 45 & 45 & 45 & 45 & 45 & 45 & 45 & 45 & 45 & 45 & 45 & 45 & 45 & 45 & 45 & 45 & 45 & 9\end{array}$ $\begin{array}{lllllllllllllllllllll}9 & 45 & 45 & 45 & 45 & 45 & 45 & 45 & 45 & 45 & 45 & 45 & 45 & 45 & 45 & 45 & 45 & 45 & 45 & 9 & 9\end{array}$ $\begin{array}{lllllllllllllllllllll}9 & 45 & 45 & 45 & 45 & 45 & 45 & 45 & 45 & 45 & 45 & 45 & 45 & 45 & 45 & 45 & 45 & 45 & 9 & 9 & 9\end{array}$ $\begin{array}{llllllllllllllllllllll}9 & 45 & 45 & 45 & 45 & 45 & 45 & 45 & 45 & 45 & 45 & 45 & 45 & 45 & 45 & 45 & 45 & 9 & 9 & 9 & 9\end{array}$ $\begin{array}{lllllllllllllllllllll}9 & 45 & 45 & 45 & 45 & 45 & 45 & 45 & 45 & 45 & 45 & 45 & 45 & 45 & 45 & 45 & 9 & 9 & 9 & 9 & 9\end{array}$ $\begin{array}{llllllllllllllllllllll}9 & 45 & 45 & 45 & 45 & 45 & 45 & 45 & 45 & 45 & 45 & 45 & 45 & 45 & 45 & 9 & 9 & 9 & 9 & 9 & 9\end{array}$ $\begin{array}{lllllllllllllllllllll}9 & 45 & 45 & 45 & 45 & 45 & 45 & 45 & 45 & 45 & 45 & 45 & 45 & 45 & 9 & 9 & 9 & 9 & 9 & 9 & 9\end{array}$ $\begin{array}{lllllllllllllllllllll}9 & 45 & 45 & 45 & 45 & 45 & 45 & 45 & 45 & 45 & 45 & 45 & 45 & 9 & 9 & 9 & 9 & 9 & 9 & 9 & 9\end{array}$

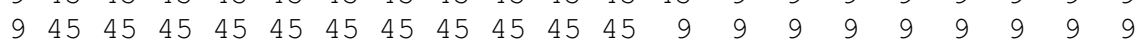
$\begin{array}{lllllllllllllllllllll}9 & 45 & 45 & 45 & 45 & 45 & 45 & 45 & 45 & 45 & 45 & 9 & 9 & 9 & 9 & 9 & 9 & 9 & 9 & 9 & 9\end{array}$

c $\begin{array}{lllllllllllllllllllll}9 & 9 & 9 & 9 & 9 & 9 & 9 & 9 & 9 & 9 & 9 & 9 & 9 & 9 & 9 & 9 & 9 & 9 & 9 & 9 & 9\end{array}$

c Hex and Pins (or empty hexes) - Zone 6 of Low Enrichment Region $246 \quad 0 \quad-301 \quad 302-303 \quad 304-305 \quad 306$ lat $=2 \quad u=36 \quad$ imp $: n=0.5$ fill=-10:10 $-10: 10 \quad 0: 0$

$\begin{array}{lllllllllllllllllllll}9 & 9 & 9 & 9 & 9 & 9 & 9 & 9 & 9 & 9 & 9 & 9 & 9 & 9 & 9 & 9 & 9 & 9 & 9 & 9 & 9\end{array}$ $\begin{array}{lllllllllllllllllllll}9 & 9 & 9 & 9 & 9 & 9 & 9 & 9 & 9 & 9 & 46 & 46 & 46 & 46 & 46 & 46 & 46 & 46 & 46 & 46 & 9\end{array}$ $\begin{array}{lllllllllllllllllllll}9 & 9 & 9 & 9 & 9 & 9 & 9 & 9 & 9 & 46 & 46 & 46 & 46 & 46 & 46 & 46 & 46 & 46 & 46 & 46 & 9\end{array}$ $\begin{array}{lllllllllllllllllllll}9 & 9 & 9 & 9 & 9 & 9 & 9 & 9 & 46 & 46 & 46 & 46 & 46 & 46 & 46 & 46 & 46 & 46 & 46 & 46 & 9\end{array}$ $\begin{array}{lllllllllllllllllllll}9 & 9 & 9 & 9 & 9 & 9 & 9 & 46 & 46 & 46 & 46 & 46 & 46 & 46 & 46 & 46 & 46 & 46 & 46 & 46 & 9\end{array}$ $\begin{array}{lllllllllllllllllllll}9 & 9 & 9 & 9 & 9 & 9 & 46 & 46 & 46 & 46 & 46 & 46 & 46 & 46 & 46 & 46 & 46 & 46 & 46 & 46 & 9\end{array}$ $\begin{array}{lllllllllllllllllllll}9 & 9 & 9 & 9 & 9 & 46 & 46 & 46 & 46 & 46 & 46 & 46 & 46 & 46 & 46 & 46 & 46 & 46 & 46 & 46 & 9\end{array}$

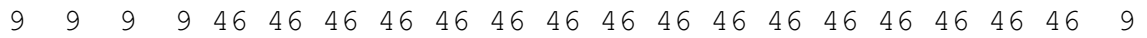
$9999446 \quad 46 \quad 46 \quad 46 \quad 46 \quad 46 \quad 46 \quad 46 \quad 46 \quad 46 \quad 46 \quad 46 \quad 46 \quad 46 \quad 46 \quad 46 \quad 46 \quad 9$

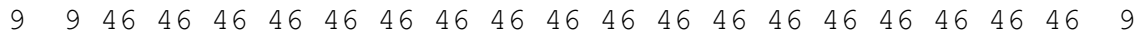

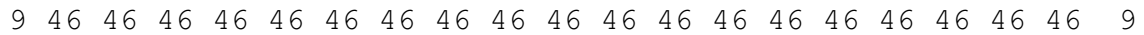

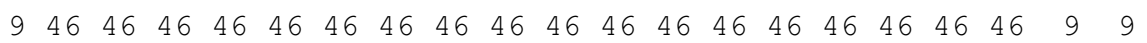

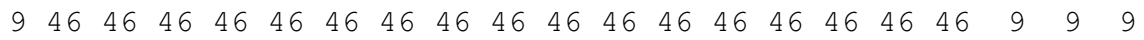

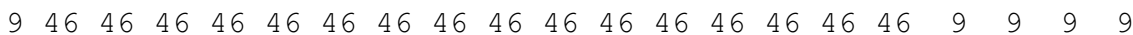




\section{LA-14052-T}

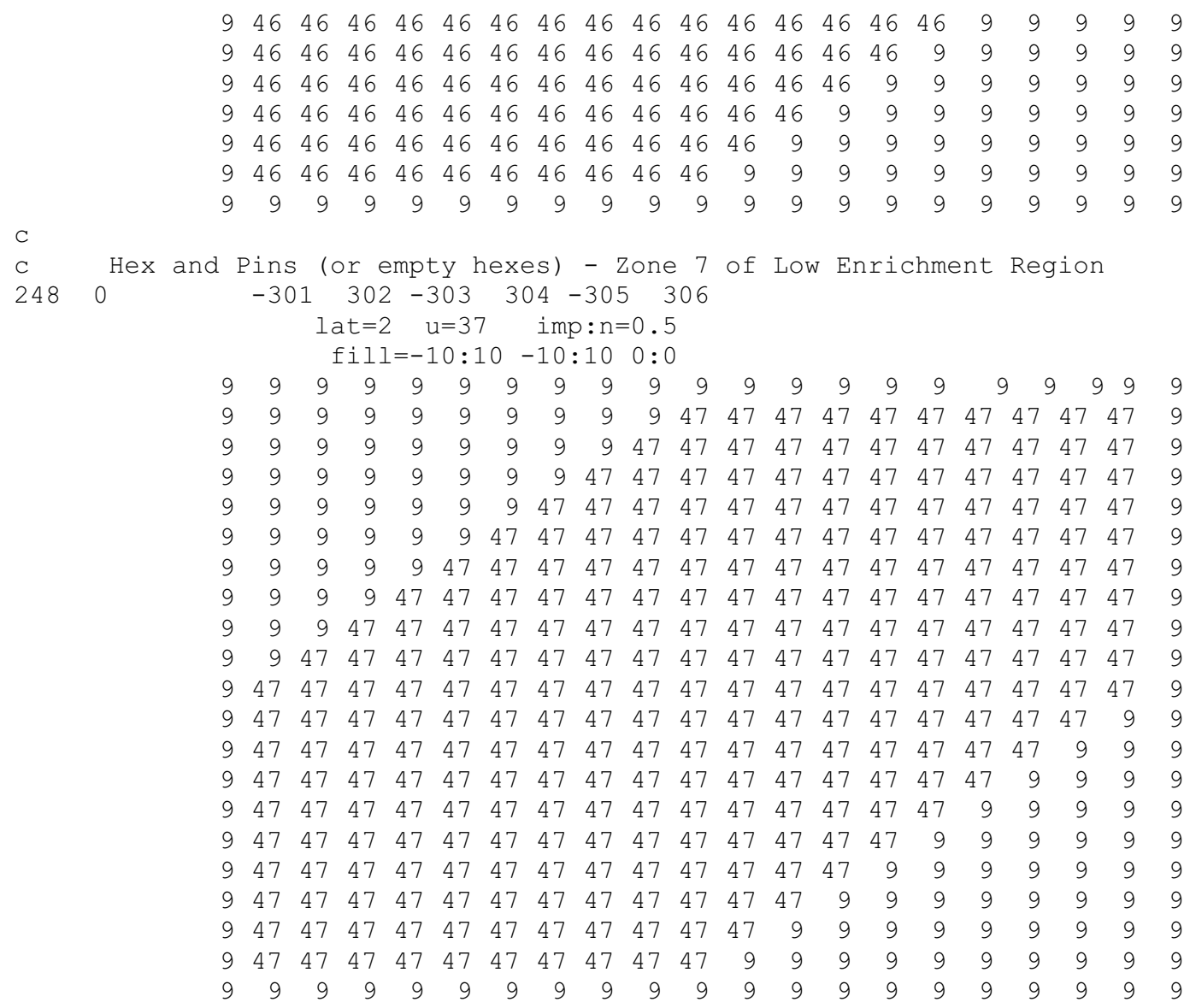

c

c Hex and Pins (or empty hexes) - Zone 1 of Medium Enrichment Region

$2510 \quad-301 \quad 302-303 \quad 304-305 \quad 306$

lat $=2 \quad u=21 \quad$ imp: $n=0.25$

fill $=-10: 10-10: 10 \quad 0: 0$

$\begin{array}{lllllllllllllllllllll}9 & 9 & 9 & 9 & 9 & 9 & 9 & 9 & 9 & 9 & 9 & 9 & 9 & 9 & 9 & 9 & 9 & 9 & 9 & 9 & 9\end{array}$ $\begin{array}{lllllllllllllllllllll}9 & 9 & 9 & 9 & 9 & 9 & 9 & 9 & 9 & 9 & 51 & 51 & 51 & 51 & 51 & 51 & 51 & 51 & 51 & 51 & 9\end{array}$

$\begin{array}{lllllllllllllllllllll}9 & 9 & 9 & 9 & 9 & 9 & 9 & 9 & 9 & 51 & 51 & 51 & 51 & 51 & 51 & 51 & 51 & 51 & 51 & 51 & 9\end{array}$

$\begin{array}{lllllllllllllllllllll}9 & 9 & 9 & 9 & 9 & 9 & 9 & 9 & 51 & 51 & 51 & 51 & 51 & 51 & 51 & 51 & 51 & 51 & 51 & 51 & 9\end{array}$

$\begin{array}{lllllllllllllllllllll}9 & 9 & 9 & 9 & 9 & 9 & 9 & 51 & 51 & 51 & 51 & 51 & 51 & 51 & 51 & 51 & 51 & 51 & 51 & 51 & 9\end{array}$

$\begin{array}{lllllllllllllllllllll}9 & 9 & 9 & 9 & 9 & 9 & 51 & 51 & 51 & 51 & 51 & 51 & 51 & 51 & 51 & 51 & 51 & 51 & 51 & 51 & 9\end{array}$

$\begin{array}{lllllllllllllllllllll}9 & 9 & 9 & 9 & 9 & 51 & 51 & 51 & 51 & 51 & 51 & 51 & 51 & 51 & 51 & 51 & 51 & 51 & 51 & 51 & 9\end{array}$

$\begin{array}{lllllllllllllllllllll}9 & 9 & 9 & 9 & 51 & 51 & 51 & 51 & 51 & 51 & 51 & 51 & 51 & 51 & 51 & 51 & 51 & 51 & 51 & 51 & 9\end{array}$

$\begin{array}{lllllllllllllllllllll}9 & 9 & 9 & 51 & 51 & 51 & 51 & 51 & 51 & 51 & 51 & 51 & 51 & 51 & 51 & 51 & 51 & 51 & 51 & 51 & 9\end{array}$

$\begin{array}{lllllllllllllllllllll}9 & 9 & 51 & 51 & 51 & 51 & 51 & 51 & 51 & 51 & 51 & 51 & 51 & 51 & 51 & 51 & 51 & 51 & 51 & 51 & 9\end{array}$

$\begin{array}{lllllllllllllllllllll}9 & 51 & 51 & 51 & 51 & 51 & 51 & 51 & 51 & 51 & 51 & 51 & 51 & 51 & 51 & 51 & 51 & 51 & 51 & 51 & 9\end{array}$

$\begin{array}{lllllllllllllllllllll}9 & 51 & 51 & 51 & 51 & 51 & 51 & 51 & 51 & 51 & 51 & 51 & 51 & 51 & 51 & 51 & 51 & 51 & 51 & 9 & 9\end{array}$

$\begin{array}{lllllllllllllllllllll}9 & 51 & 51 & 51 & 51 & 51 & 51 & 51 & 51 & 51 & 51 & 51 & 51 & 51 & 51 & 51 & 51 & 51 & 9 & 9 & 9\end{array}$

$\begin{array}{lllllllllllllllllllll}9 & 51 & 51 & 51 & 51 & 51 & 51 & 51 & 51 & 51 & 51 & 51 & 51 & 51 & 51 & 51 & 51 & 9 & 9 & 9 & 9\end{array}$

$\begin{array}{lllllllllllllllllllll}9 & 51 & 51 & 51 & 51 & 51 & 51 & 51 & 51 & 51 & 51 & 51 & 51 & 51 & 51 & 51 & 9 & 9 & 9 & 9 & 9\end{array}$

$\begin{array}{lllllllllllllllllllll}9 & 51 & 51 & 51 & 51 & 51 & 51 & 51 & 51 & 51 & 51 & 51 & 51 & 51 & 51 & 9 & 9 & 9 & 9 & 9 & 9\end{array}$

$\begin{array}{lllllllllllllllllllll}9 & 51 & 51 & 51 & 51 & 51 & 51 & 51 & 51 & 51 & 51 & 51 & 51 & 51 & 9 & 9 & 9 & 9 & 9 & 9 & 9\end{array}$

$\begin{array}{lllllllllllllllllllll}9 & 51 & 51 & 51 & 51 & 51 & 51 & 51 & 51 & 51 & 51 & 51 & 51 & 9 & 9 & 9 & 9 & 9 & 9 & 9 & 9\end{array}$

$\begin{array}{lllllllllllllllllllll}9 & 51 & 51 & 51 & 51 & 51 & 51 & 51 & 51 & 51 & 51 & 51 & 9 & 9 & 9 & 9 & 9 & 9 & 9 & 9 & 9\end{array}$

$\begin{array}{lllllllllllllllllllll}9 & 51 & 51 & 51 & 51 & 51 & 51 & 51 & 51 & 51 & 51 & 9 & 9 & 9 & 9 & 9 & 9 & 9 & 9 & 9 & 9\end{array}$

$\mathrm{C}$ $\begin{array}{lllllllllllllllllllll}9 & 9 & 9 & 9 & 9 & 9 & 9 & 9 & 9 & 9 & 9 & 9 & 9 & 9 & 9 & 9 & 9 & 9 & 9 & 9 & 9\end{array}$

C Hex and Pins (or empty hexes) - Zone 2 of Medium Enrichment Region $\begin{array}{llllllll}252 & 0 & -301 & 302 & -303 & 304 & -305 & 306\end{array}$

lat $=2 \quad u=22 \quad$ imp $: n=0.25$ 


\section{LA-14052-T}

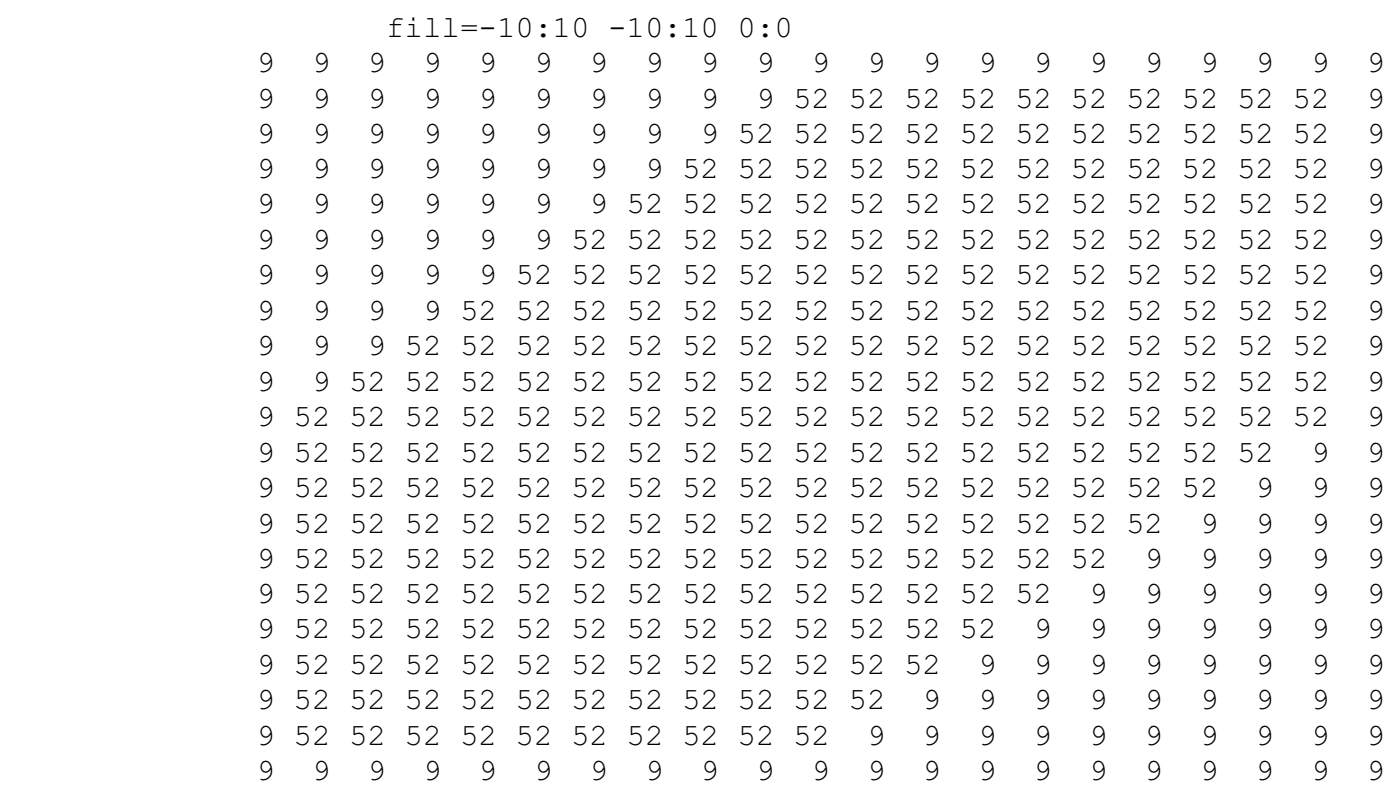

C Hex and Pins (or empty hexes) - Zone 3 of Medium Enrichment Region

$2530 \quad-301 \quad 302-303 \quad 304-305 \quad 306$ lat $=2 \quad u=23 \quad$ imp $: n=0.25$ fill $=-10: 10-10: 10 \quad 0: 0$

$\begin{array}{lllllllllllllllllllll}9 & 9 & 9 & 9 & 9 & 9 & 9 & 9 & 9 & 9 & 9 & 9 & 9 & 9 & 9 & 9 & 9 & 9 & 9 & 9 & 9\end{array}$ $\begin{array}{lllllllllllllllllllll}9 & 9 & 9 & 9 & 9 & 9 & 9 & 9 & 9 & 9 & 53 & 53 & 53 & 53 & 53 & 53 & 53 & 53 & 53 & 53 & 9\end{array}$ $\begin{array}{lllllllllllllllllllll}9 & 9 & 9 & 9 & 9 & 9 & 9 & 9 & 9 & 53 & 53 & 53 & 53 & 53 & 53 & 53 & 53 & 53 & 53 & 53 & 9\end{array}$ $\begin{array}{lllllllllllllllllllllll}9 & 9 & 9 & 9 & 9 & 9 & 9 & 9 & 53 & 53 & 53 & 53 & 53 & 53 & 53 & 53 & 53 & 53 & 53 & 53 & 9\end{array}$ $\begin{array}{lllllllllllllllllllll}9 & 9 & 9 & 9 & 9 & 9 & 9 & 53 & 53 & 53 & 53 & 53 & 53 & 53 & 53 & 53 & 53 & 53 & 53 & 53 & 9\end{array}$ $\begin{array}{lllllllllllllllllllll}9 & 9 & 9 & 9 & 9 & 9 & 53 & 53 & 53 & 53 & 53 & 53 & 53 & 53 & 53 & 53 & 53 & 53 & 53 & 53 & 9\end{array}$ $\begin{array}{lllllllllllllllllllll}9 & 9 & 9 & 9 & 9 & 53 & 53 & 53 & 53 & 53 & 53 & 53 & 53 & 53 & 53 & 53 & 53 & 53 & 53 & 53 & 9\end{array}$ $\begin{array}{lllllllllllllllllllll}9 & 9 & 9 & 9 & 53 & 53 & 53 & 53 & 53 & 53 & 53 & 53 & 53 & 53 & 53 & 53 & 53 & 53 & 53 & 53 & 9\end{array}$ $\begin{array}{lllllllllllllllllllll}9 & 9 & 9 & 53 & 53 & 53 & 53 & 53 & 53 & 53 & 53 & 53 & 53 & 53 & 53 & 53 & 53 & 53 & 53 & 53 & 9\end{array}$ $\begin{array}{lllllllllllllllllllll}9 & 9 & 53 & 53 & 53 & 53 & 53 & 53 & 53 & 53 & 53 & 53 & 53 & 53 & 53 & 53 & 53 & 53 & 53 & 53 & 9\end{array}$ $\begin{array}{lllllllllllllllllllll}9 & 53 & 53 & 53 & 53 & 53 & 53 & 53 & 53 & 53 & 53 & 53 & 53 & 53 & 53 & 53 & 53 & 53 & 53 & 53 & 9\end{array}$ $\begin{array}{lllllllllllllllllllll}9 & 53 & 53 & 53 & 53 & 53 & 53 & 53 & 53 & 53 & 53 & 53 & 53 & 53 & 53 & 53 & 53 & 53 & 53 & 9 & 9\end{array}$ $\begin{array}{lllllllllllllllllllll}9 & 53 & 53 & 53 & 53 & 53 & 53 & 53 & 53 & 53 & 53 & 53 & 53 & 53 & 53 & 53 & 53 & 53 & 9 & 9 & 9\end{array}$ $\begin{array}{lllllllllllllllllllll}9 & 53 & 53 & 53 & 53 & 53 & 53 & 53 & 53 & 53 & 53 & 53 & 53 & 53 & 53 & 53 & 53 & 9 & 9 & 9 & 9\end{array}$ $\begin{array}{lllllllllllllllllllll}9 & 53 & 53 & 53 & 53 & 53 & 53 & 53 & 53 & 53 & 53 & 53 & 53 & 53 & 53 & 53 & 9 & 9 & 9 & 9 & 9\end{array}$ $\begin{array}{lllllllllllllllllllll}9 & 53 & 53 & 53 & 53 & 53 & 53 & 53 & 53 & 53 & 53 & 53 & 53 & 53 & 53 & 9 & 9 & 9 & 9 & 9 & 9\end{array}$ $\begin{array}{lllllllllllllllllllll}9 & 53 & 53 & 53 & 53 & 53 & 53 & 53 & 53 & 53 & 53 & 53 & 53 & 53 & 9 & 9 & 9 & 9 & 9 & 9 & 9\end{array}$

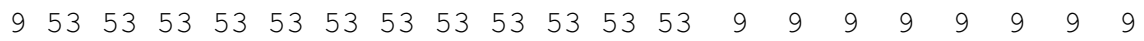
$\begin{array}{lllllllllllllllllllll}9 & 53 & 53 & 53 & 53 & 53 & 53 & 53 & 53 & 53 & 53 & 53 & 9 & 9 & 9 & 9 & 9 & 9 & 9 & 9 & 9\end{array}$ $\begin{array}{lllllllllllllllllllll}9 & 53 & 53 & 53 & 53 & 53 & 53 & 53 & 53 & 53 & 53 & 9 & 9 & 9 & 9 & 9 & 9 & 9 & 9 & 9 & 9\end{array}$

$\mathrm{C}$

C Hex and Pins (or empty hexes) - Zone 4 of Medium Enrichment Region $2540 \quad-301 \quad 302-303 \quad 304-305 \quad 306$ lat $=2 \quad u=24 \quad$ imp $: n=0.25$ fill $=-10: 10-10: 10 \quad 0: 0$

$\begin{array}{rrrrrrrrrrrrrrrrrrrr}9 & 9 & 9 & 9 & 9 & 9 & 9 & 9 & 9 & 9 & 9 & 9 & 9 & 9 & 9 & 9 & 9 & 9 & 9 & 9 \\ 9 & 9 & 9 & 9 & 9 & 9 & 9 & 9 & 9 & 54 & 54 & 54 & 54 & 54 & 54 & 54 & 54 & 54 & 54 & 9 \\ 9 & 9 & 9 & 9 & 9 & 9 & 9 & 9 & 54 & 54 & 54 & 54 & 54 & 54 & 54 & 54 & 54 & 54 & 54 & 9 \\ 9 & 9 & 9 & 9 & 9 & 9 & 9 & 54 & 54 & 54 & 54 & 54 & 54 & 54 & 54 & 54 & 54 & 54 & 54 & 9 \\ 9 & 9 & 9 & 9 & 9 & 9 & 54 & 54 & 54 & 54 & 54 & 54 & 54 & 54 & 54 & 54 & 54 & 54 & 54 & 9 \\ 9 & 9 & 9 & 9 & 9 & 54 & 54 & 54 & 54 & 54 & 54 & 54 & 54 & 54 & 54 & 54 & 54 & 54 & 54 & 9 \\ 9 & 9 & 9 & 9 & 54 & 54 & 54 & 54 & 54 & 54 & 54 & 54 & 54 & 54 & 54 & 54 & 54 & 54 & 54 & 9 \\ 9 & 9 & 9 & 54 & 54 & 54 & 54 & 54 & 54 & 54 & 54 & 54 & 54 & 54 & 54 & 54 & 54 & 54 & 54 & 9 \\ 9 & 9 & 54 & 54 & 54 & 54 & 54 & 54 & 54 & 54 & 54 & 54 & 54 & 54 & 54 & 54 & 54 & 54 & 54 & 9 \\ 9 & 54 & 54 & 54 & 54 & 54 & 54 & 54 & 54 & 54 & 54 & 54 & 54 & 54 & 54 & 54 & 54 & 54 & 54 & 9\end{array}$




\section{LA-14052-T}

$9 \begin{array}{llllllllllllllllllll}54 & 54 & 54 & 54 & 54 & 54 & 54 & 54 & 54 & 54 & 54 & 54 & 54 & 54 & 54 & 54 & 54 & 54 & 54 & 9\end{array}$

$\begin{array}{lllllllllllllllllllll}9 & 54 & 54 & 54 & 54 & 54 & 54 & 54 & 54 & 54 & 54 & 54 & 54 & 54 & 54 & 54 & 54 & 54 & 54 & 9 & 9\end{array}$

$\begin{array}{lllllllllllllllllllll}9 & 54 & 54 & 54 & 54 & 54 & 54 & 54 & 54 & 54 & 54 & 54 & 54 & 54 & 54 & 54 & 54 & 54 & 9 & 9 & 9\end{array}$

$\begin{array}{lllllllllllllllllllll}9 & 54 & 54 & 54 & 54 & 54 & 54 & 54 & 54 & 54 & 54 & 54 & 54 & 54 & 54 & 54 & 54 & 9 & 9 & 9 & 9\end{array}$

$\begin{array}{lllllllllllllllllllll}9 & 54 & 54 & 54 & 54 & 54 & 54 & 54 & 54 & 54 & 54 & 54 & 54 & 54 & 54 & 54 & 9 & 9 & 9 & 9 & 9\end{array}$

$\begin{array}{lllllllllllllllllllll}9 & 54 & 54 & 54 & 54 & 54 & 54 & 54 & 54 & 54 & 54 & 54 & 54 & 54 & 54 & 9 & 9 & 9 & 9 & 9 & 9\end{array}$

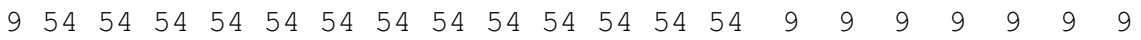

$\begin{array}{lllllllllllllllllllll}9 & 54 & 54 & 54 & 54 & 54 & 54 & 54 & 54 & 54 & 54 & 54 & 54 & 9 & 9 & 9 & 9 & 9 & 9 & 9 & 9\end{array}$

$\begin{array}{lllllllllllllllllllll}9 & 54 & 54 & 54 & 54 & 54 & 54 & 54 & 54 & 54 & 54 & 54 & 9 & 9 & 9 & 9 & 9 & 9 & 9 & 9 & 9\end{array}$

$\begin{array}{lllllllllllllllllllll}9 & 54 & 54 & 54 & 54 & 54 & 54 & 54 & 54 & 54 & 54 & 9 & 9 & 9 & 9 & 9 & 9 & 9 & 9 & 9 & 9\end{array}$

$\begin{array}{lllllllllllllllllllll}9 & 9 & 9 & 9 & 9 & 9 & 9 & 9 & 9 & 9 & 9 & 9 & 9 & 9 & 9 & 9 & 9 & 9 & 9 & 9 & 9\end{array}$

c Hex and Pins (or empty hexes) - Zone 5 of Medium Enrichment Region

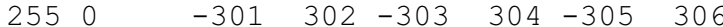

lat $=2 \quad u=25 \quad$ imp $: \mathrm{n}=0.25$

fill=-10:10 -10:10 $0: 0$

$\begin{array}{lllllllllllllllllllll}9 & 9 & 9 & 9 & 9 & 9 & 9 & 9 & 9 & 9 & 9 & 9 & 9 & 9 & 9 & 9 & 9 & 9 & 9 & 9 & 9\end{array}$

$\begin{array}{lllllllllllllllllllll}9 & 9 & 9 & 9 & 9 & 9 & 9 & 9 & 9 & 9 & 55 & 55 & 55 & 55 & 55 & 55 & 55 & 55 & 55 & 55 & 9\end{array}$

$\begin{array}{llllllllllllllllllllll}9 & 9 & 9 & 9 & 9 & 9 & 9 & 9 & 9 & 55 & 55 & 55 & 55 & 55 & 55 & 55 & 55 & 55 & 55 & 55 & 9\end{array}$

$\begin{array}{lllllllllllllllllllll}9 & 9 & 9 & 9 & 9 & 9 & 9 & 9 & 55 & 55 & 55 & 55 & 55 & 55 & 55 & 55 & 55 & 55 & 55 & 55 & 9\end{array}$

$\begin{array}{lllllllllllllllllllll}9 & 9 & 9 & 9 & 9 & 9 & 9 & 55 & 55 & 55 & 55 & 55 & 55 & 55 & 55 & 55 & 55 & 55 & 55 & 55 & 9\end{array}$

$\begin{array}{lllllllllllllllllllll}9 & 9 & 9 & 9 & 9 & 9 & 55 & 55 & 55 & 55 & 55 & 55 & 55 & 55 & 55 & 55 & 55 & 55 & 55 & 55 & 9\end{array}$

$\begin{array}{lllllllllllllllllllll}9 & 9 & 9 & 9 & 9 & 55 & 55 & 55 & 55 & 55 & 55 & 55 & 55 & 55 & 55 & 55 & 55 & 55 & 55 & 55 & 9\end{array}$

$99 \begin{array}{llllllllllllllllllll}9 & 9 & 9 & 55 & 55 & 55 & 55 & 55 & 55 & 55 & 55 & 55 & 55 & 55 & 55 & 55 & 55 & 55 & 55 & 9\end{array}$

$9999 \begin{array}{lllllllllllllllllll}95 & 55 & 55 & 55 & 55 & 55 & 55 & 55 & 55 & 55 & 55 & 55 & 55 & 55 & 55 & 55 & 55 & 9\end{array}$

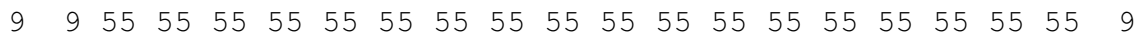

$9 \begin{array}{llllllllllllllllllll}95 & 55 & 55 & 55 & 55 & 55 & 55 & 55 & 55 & 55 & 55 & 55 & 55 & 55 & 55 & 55 & 55 & 55 & 55 & 9\end{array}$

$\begin{array}{lllllllllllllllllllll}9 & 55 & 55 & 55 & 55 & 55 & 55 & 55 & 55 & 55 & 55 & 55 & 55 & 55 & 55 & 55 & 55 & 55 & 55 & 9 & 9\end{array}$

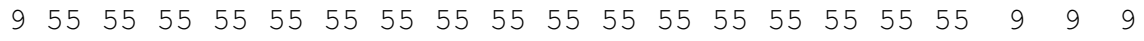

$\begin{array}{lllllllllllllllllllll}9 & 55 & 55 & 55 & 55 & 55 & 55 & 55 & 55 & 55 & 55 & 55 & 55 & 55 & 55 & 55 & 55 & 9 & 9 & 9 & 9\end{array}$

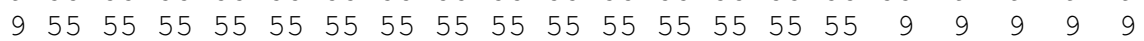

$\begin{array}{lllllllllllllllllllll}9 & 55 & 55 & 55 & 55 & 55 & 55 & 55 & 55 & 55 & 55 & 55 & 55 & 55 & 55 & 9 & 9 & 9 & 9 & 9 & 9\end{array}$

$\begin{array}{lllllllllllllllllllll}9 & 55 & 55 & 55 & 55 & 55 & 55 & 55 & 55 & 55 & 55 & 55 & 55 & 55 & 9 & 9 & 9 & 9 & 9 & 9 & 9\end{array}$

$\begin{array}{lllllllllllllllllllll}9 & 55 & 55 & 55 & 55 & 55 & 55 & 55 & 55 & 55 & 55 & 55 & 55 & 9 & 9 & 9 & 9 & 9 & 9 & 9 & 9\end{array}$

$\begin{array}{lllllllllllllllllllll}9 & 55 & 55 & 55 & 55 & 55 & 55 & 55 & 55 & 55 & 55 & 55 & 9 & 9 & 9 & 9 & 9 & 9 & 9 & 9 & 9\end{array}$

$\begin{array}{lllllllllllllllllllll}9 & 55 & 55 & 55 & 55 & 55 & 55 & 55 & 55 & 55 & 55 & 9 & 9 & 9 & 9 & 9 & 9 & 9 & 9 & 9 & 9\end{array}$

C

$\begin{array}{lllllllllllllllllllll}9 & 9 & 9 & 9 & 9 & 9 & 9 & 9 & 9 & 9 & 9 & 9 & 9 & 9 & 9 & 9 & 9 & 9 & 9 & 9 & 9\end{array}$

C Hex and Pins (or empty hexes) - Zone 6 of Medium Enrichment Region

$2560 \quad-301 \quad 302-303 \quad 304-305 \quad 306$

lat $=2 \quad u=26 \quad$ imp $: n=0.25$

fill $=-10: 10-10: 10 \quad 0: 0$

$\begin{array}{lllllllllllllllllllll}9 & 9 & 9 & 9 & 9 & 9 & 9 & 9 & 9 & 9 & 9 & 9 & 9 & 9 & 9 & 9 & 9 & 9 & 9 & 9 & 9\end{array}$

$\begin{array}{lllllllllllllllllllll}9 & 9 & 9 & 9 & 9 & 9 & 9 & 9 & 9 & 9 & 56 & 56 & 56 & 56 & 56 & 56 & 56 & 56 & 56 & 56 & 9\end{array}$

$\begin{array}{lllllllllllllllllllll}9 & 9 & 9 & 9 & 9 & 9 & 9 & 9 & 9 & 56 & 56 & 56 & 56 & 56 & 56 & 56 & 56 & 56 & 56 & 56 & 9\end{array}$

$\begin{array}{lllllllllllllllllllll}9 & 9 & 9 & 9 & 9 & 9 & 9 & 9 & 56 & 56 & 56 & 56 & 56 & 56 & 56 & 56 & 56 & 56 & 56 & 56 & 9\end{array}$

$\begin{array}{lllllllllllllllllllll}9 & 9 & 9 & 9 & 9 & 9 & 9 & 56 & 56 & 56 & 56 & 56 & 56 & 56 & 56 & 56 & 56 & 56 & 56 & 56 & 9\end{array}$

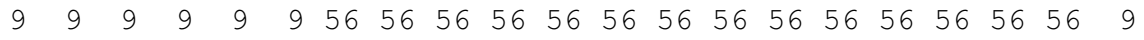

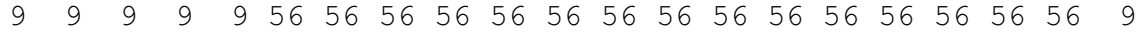

$9999095656 \quad 56 \quad 56 \quad 56 \quad 56 \quad 56 \quad 56 \quad 56 \quad 56 \quad 56 \quad 56 \quad 56 \quad 56 \quad 56 \quad 56 \quad 9$

$999 \quad 956 \quad 56 \quad 56 \quad 56 \quad 56 \quad 56 \quad 56 \quad 56 \quad 56 \quad 56 \quad 56 \quad 56 \quad 56 \quad 56 \quad 56 \quad 56 \quad 56 \quad 9$

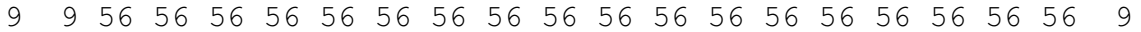

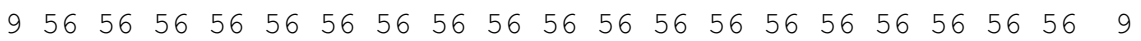

$956 \quad 56 \quad 56 \quad 56 \quad 56 \quad 56 \quad 56 \quad 56 \quad 56 \quad 56 \quad 56 \quad 56 \quad 56 \quad 56 \quad 56 \quad 56 \quad 56 \quad 56 \quad 9 \quad 9$

$9 \begin{array}{llllllllllllllllllll}96 & 56 & 56 & 56 & 56 & 56 & 56 & 56 & 56 & 56 & 56 & 56 & 56 & 56 & 56 & 56 & 56 & 9 & 9 & 9\end{array}$

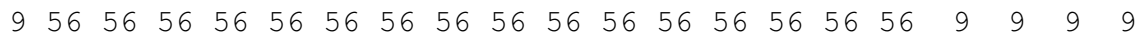

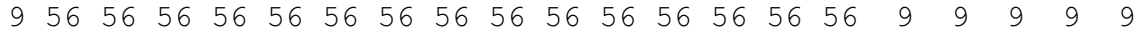

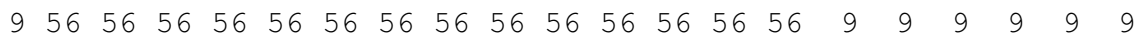

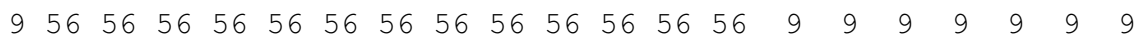

$\begin{array}{lllllllllllllllllllll}9 & 56 & 56 & 56 & 56 & 56 & 56 & 56 & 56 & 56 & 56 & 56 & 56 & 9 & 9 & 9 & 9 & 9 & 9 & 9 & 9\end{array}$

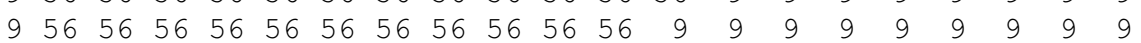

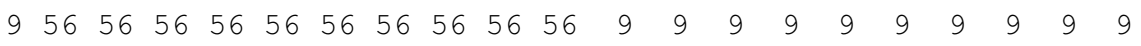

$\begin{array}{lllllllllllllllllllll}9 & 9 & 9 & 9 & 9 & 9 & 9 & 9 & 9 & 9 & 9 & 9 & 9 & 9 & 9 & 9 & 9 & 9 & 9 & 9 & 9\end{array}$ 


\section{LA-14052-T}

C Hex and Pins (or empty hexes) - Zone 7 of Medium Enrichment Region c $\quad$ st set

$2570 \quad-301 \quad 302-303 \quad 304-305 \quad 306$

lat $=2 \quad u=27 \quad$ imp $: n=0.25$

fill $=-10: 10-10: 10 \quad 0: 0$

$\begin{array}{lllllllllllllllllllll}9 & 9 & 9 & 9 & 9 & 9 & 9 & 9 & 9 & 9 & 9 & 9 & 9 & 9 & 9 & 9 & 9 & 9 & 9 & 9 & 9\end{array}$

$\begin{array}{lllllllllllllllllllll}9 & 9 & 9 & 9 & 9 & 9 & 9 & 9 & 9 & 9 & 57 & 57 & 57 & 57 & 57 & 57 & 57 & 57 & 57 & 57 & 9\end{array}$

$\begin{array}{lllllllllllllllllllll}9 & 9 & 9 & 9 & 9 & 9 & 9 & 9 & 9 & 57 & 57 & 57 & 57 & 57 & 57 & 57 & 57 & 57 & 57 & 57 & 9\end{array}$

$\begin{array}{lllllllllllllllllllll}9 & 9 & 9 & 9 & 9 & 9 & 9 & 9 & 57 & 57 & 57 & 57 & 57 & 57 & 57 & 57 & 57 & 57 & 57 & 57 & 9\end{array}$

$\begin{array}{lllllllllllllllllllll}9 & 9 & 9 & 9 & 9 & 9 & 9 & 57 & 57 & 57 & 57 & 57 & 57 & 57 & 57 & 57 & 57 & 57 & 57 & 57 & 9\end{array}$

$\begin{array}{lllllllllllllllllllll}9 & 9 & 9 & 9 & 9 & 9 & 57 & 57 & 57 & 57 & 57 & 57 & 57 & 57 & 57 & 57 & 57 & 57 & 57 & 57 & 9\end{array}$

$\begin{array}{lllllllllllllllllllll}9 & 9 & 9 & 9 & 9 & 57 & 57 & 57 & 57 & 57 & 57 & 57 & 57 & 57 & 57 & 57 & 57 & 57 & 57 & 57 & 9\end{array}$

$\begin{array}{lllllllllllllllllllll}9 & 9 & 9 & 9 & 57 & 57 & 57 & 57 & 57 & 57 & 57 & 57 & 57 & 57 & 57 & 57 & 57 & 57 & 57 & 57 & 9\end{array}$

$\begin{array}{lllllllllllllllllllll}9 & 9 & 9 & 57 & 57 & 57 & 57 & 57 & 57 & 57 & 57 & 57 & 57 & 57 & 57 & 57 & 57 & 57 & 57 & 57 & 9\end{array}$

$\begin{array}{lllllllllllllllllllll}9 & 9 & 57 & 57 & 57 & 57 & 57 & 57 & 57 & 57 & 57 & 57 & 57 & 57 & 57 & 57 & 57 & 57 & 57 & 57 & 9\end{array}$

$\begin{array}{lllllllllllllllllllll}9 & 57 & 57 & 57 & 57 & 57 & 57 & 57 & 57 & 57 & 57 & 57 & 57 & 57 & 57 & 57 & 57 & 57 & 57 & 57 & 9\end{array}$

$\begin{array}{lllllllllllllllllllll}9 & 57 & 57 & 57 & 57 & 57 & 57 & 57 & 57 & 57 & 57 & 57 & 57 & 57 & 57 & 57 & 57 & 57 & 57 & 9 & 9\end{array}$

$\begin{array}{lllllllllllllllllllll}9 & 57 & 57 & 57 & 57 & 57 & 57 & 57 & 57 & 57 & 57 & 57 & 57 & 57 & 57 & 57 & 57 & 57 & 9 & 9 & 9\end{array}$

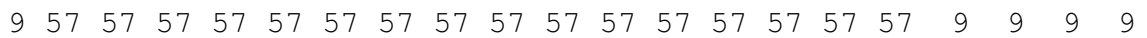

$\begin{array}{lllllllllllllllllllll}9 & 57 & 57 & 57 & 57 & 57 & 57 & 57 & 57 & 57 & 57 & 57 & 57 & 57 & 57 & 57 & 9 & 9 & 9 & 9 & 9\end{array}$

$\begin{array}{lllllllllllllllllllll}9 & 57 & 57 & 57 & 57 & 57 & 57 & 57 & 57 & 57 & 57 & 57 & 57 & 57 & 57 & 9 & 9 & 9 & 9 & 9 & 9\end{array}$

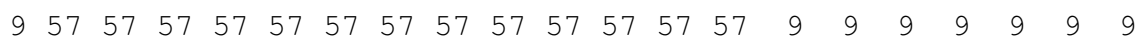

$\begin{array}{lllllllllllllllllllll}9 & 57 & 57 & 57 & 57 & 57 & 57 & 57 & 57 & 57 & 57 & 57 & 57 & 9 & 9 & 9 & 9 & 9 & 9 & 9 & 9\end{array}$

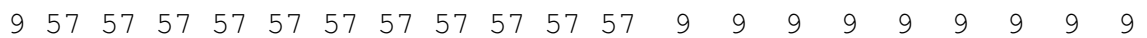

$\begin{array}{lllllllllllllllllllll}9 & 57 & 57 & 57 & 57 & 57 & 57 & 57 & 57 & 57 & 57 & 9 & 9 & 9 & 9 & 9 & 9 & 9 & 9 & 9 & 9\end{array}$

C Hex and Pins (or empty hexes) - Zone 8 of Medium Enrichment Region c 2nd set

$2580 \quad-301 \quad 302-303 \quad 304-305 \quad 306$

lat $=2 \quad u=20 \quad$ imp $: n=0.25$

fill=-10:10 -10:10 $0: 0$

$\begin{array}{lllllllllllllllllllll}9 & 9 & 9 & 9 & 9 & 9 & 9 & 9 & 9 & 9 & 9 & 9 & 9 & 9 & 9 & 9 & 9 & 9 & 9 & 9 & 9\end{array}$

$\begin{array}{lllllllllllllllllllll}9 & 9 & 9 & 9 & 9 & 9 & 9 & 9 & 9 & 9 & 58 & 58 & 58 & 58 & 58 & 58 & 58 & 58 & 58 & 58 & 9\end{array}$

$\begin{array}{lllllllllllllllllllll}9 & 9 & 9 & 9 & 9 & 9 & 9 & 9 & 9 & 58 & 58 & 58 & 58 & 58 & 58 & 58 & 58 & 58 & 58 & 58 & 9\end{array}$

$\begin{array}{lllllllllllllllllllll}9 & 9 & 9 & 9 & 9 & 9 & 9 & 9 & 58 & 58 & 58 & 58 & 58 & 58 & 58 & 58 & 58 & 58 & 58 & 58 & 9\end{array}$

$\begin{array}{lllllllllllllllllllll}9 & 9 & 9 & 9 & 9 & 9 & 9 & 58 & 58 & 58 & 58 & 58 & 58 & 58 & 58 & 58 & 58 & 58 & 58 & 58 & 9\end{array}$

$\begin{array}{lllllllllllllllllllll}9 & 9 & 9 & 9 & 9 & 9 & 58 & 58 & 58 & 58 & 58 & 58 & 58 & 58 & 58 & 58 & 58 & 58 & 58 & 58 & 9\end{array}$

$\begin{array}{lllllllllllllllllllll}9 & 9 & 9 & 9 & 9 & 58 & 58 & 58 & 58 & 58 & 58 & 58 & 58 & 58 & 58 & 58 & 58 & 58 & 58 & 58 & 9\end{array}$

$\begin{array}{lllllllllllllllllllll}9 & 9 & 9 & 9 & 58 & 58 & 58 & 58 & 58 & 58 & 58 & 58 & 58 & 58 & 58 & 58 & 58 & 58 & 58 & 58 & 9\end{array}$

$\begin{array}{lllllllllllllllllllll}9 & 9 & 9 & 58 & 58 & 58 & 58 & 58 & 58 & 58 & 58 & 58 & 58 & 58 & 58 & 58 & 58 & 58 & 58 & 58 & 9\end{array}$

$\begin{array}{lllllllllllllllllllll}9 & 9 & 58 & 58 & 58 & 58 & 58 & 58 & 58 & 58 & 58 & 58 & 58 & 58 & 58 & 58 & 58 & 58 & 58 & 58 & 9\end{array}$

$9 \begin{array}{lllllllllllllllllllll}58 & 58 & 58 & 58 & 58 & 58 & 58 & 58 & 58 & 58 & 58 & 58 & 58 & 58 & 58 & 58 & 58 & 58 & 58 & 9\end{array}$

$\begin{array}{lllllllllllllllllllll}9 & 58 & 58 & 58 & 58 & 58 & 58 & 58 & 58 & 58 & 58 & 58 & 58 & 58 & 58 & 58 & 58 & 58 & 58 & 9 & 9\end{array}$

$\begin{array}{lllllllllllllllllllll}9 & 58 & 58 & 58 & 58 & 58 & 58 & 58 & 58 & 58 & 58 & 58 & 58 & 58 & 58 & 58 & 58 & 58 & 9 & 9 & 9\end{array}$

$\begin{array}{lllllllllllllllllllll}9 & 58 & 58 & 58 & 58 & 58 & 58 & 58 & 58 & 58 & 58 & 58 & 58 & 58 & 58 & 58 & 58 & 9 & 9 & 9 & 9\end{array}$

$\begin{array}{lllllllllllllllllllll}9 & 58 & 58 & 58 & 58 & 58 & 58 & 58 & 58 & 58 & 58 & 58 & 58 & 58 & 58 & 58 & 9 & 9 & 9 & 9 & 9\end{array}$

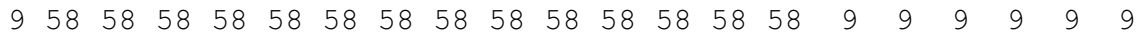

$\begin{array}{lllllllllllllllllllll}9 & 58 & 58 & 58 & 58 & 58 & 58 & 58 & 58 & 58 & 58 & 58 & 58 & 58 & 9 & 9 & 9 & 9 & 9 & 9 & 9\end{array}$

$\begin{array}{lllllllllllllllllllll}9 & 58 & 58 & 58 & 58 & 58 & 58 & 58 & 58 & 58 & 58 & 58 & 58 & 9 & 9 & 9 & 9 & 9 & 9 & 9 & 9\end{array}$

$\begin{array}{lllllllllllllllllllll}9 & 58 & 58 & 58 & 58 & 58 & 58 & 58 & 58 & 58 & 58 & 58 & 9 & 9 & 9 & 9 & 9 & 9 & 9 & 9 & 9\end{array}$

$\begin{array}{lllllllllllllllllllll}9 & 58 & 58 & 58 & 58 & 58 & 58 & 58 & 58 & 58 & 58 & 9 & 9 & 9 & 9 & 9 & 9 & 9 & 9 & 9 & 9\end{array}$

C

$\begin{array}{lllllllllllllllllllll}9 & 9 & 9 & 9 & 9 & 9 & 9 & 9 & 9 & 9 & 9 & 9 & 9 & 9 & 9 & 9 & 9 & 9 & 9 & 9 & 9\end{array}$

c Sodium filled hex (reflector)

c Hex and Pins (or empty hexes)

$2080 \quad-301 \quad 302-303 \quad 304-305 \quad 306$

lat $=2 \quad u=8 \quad$ imp $: n=0.50$

fill=-10:10 $-10: 10 \quad 0: 0$

$\begin{array}{lllllllllllllllllllll}9 & 9 & 9 & 9 & 9 & 9 & 9 & 9 & 9 & 9 & 9 & 9 & 9 & 9 & 9 & 9 & 9 & 9 & 9 & 9 & 9\end{array}$

$\begin{array}{lllllllllllllllllllll}9 & 9 & 9 & 9 & 9 & 9 & 9 & 9 & 9 & 9 & 9 & 9 & 9 & 9 & 9 & 9 & 9 & 9 & 9 & 9 & 9\end{array}$

$\begin{array}{lllllllllllllllllllll}9 & 9 & 9 & 9 & 9 & 9 & 9 & 9 & 9 & 9 & 9 & 9 & 9 & 9 & 9 & 9 & 9 & 9 & 9 & 9 & 9\end{array}$ 


\title{
LA-14052-T
}

\author{
$\begin{array}{lllllllllllllllllllll}9 & 9 & 9 & 9 & 9 & 9 & 9 & 9 & 9 & 9 & 9 & 9 & 9 & 9 & 9 & 9 & 9 & 9 & 9 & 9 & 9\end{array}$ \\ $\begin{array}{lllllllllllllllllllll}9 & 9 & 9 & 9 & 9 & 9 & 9 & 9 & 9 & 9 & 9 & 9 & 9 & 9 & 9 & 9 & 9 & 9 & 9 & 9 & 9\end{array}$ \\ $\begin{array}{lllllllllllllllllllll}9 & 9 & 9 & 9 & 9 & 9 & 9 & 9 & 9 & 9 & 9 & 9 & 9 & 9 & 9 & 9 & 9 & 9 & 9 & 9 & 9\end{array}$ \\ $\begin{array}{lllllllllllllllllllll}9 & 9 & 9 & 9 & 9 & 9 & 9 & 9 & 9 & 9 & 9 & 9 & 9 & 9 & 9 & 9 & 9 & 9 & 9 & 9 & 9\end{array}$ \\ $\begin{array}{lllllllllllllllllllll}9 & 9 & 9 & 9 & 9 & 9 & 9 & 9 & 9 & 9 & 9 & 9 & 9 & 9 & 9 & 9 & 9 & 9 & 9 & 9 & 9\end{array}$ \\ $\begin{array}{lllllllllllllllllllll}9 & 9 & 9 & 9 & 9 & 9 & 9 & 9 & 9 & 9 & 9 & 9 & 9 & 9 & 9 & 9 & 9 & 9 & 9 & 9 & 9\end{array}$ \\ $\begin{array}{lllllllllllllllllllll}9 & 9 & 9 & 9 & 9 & 9 & 9 & 9 & 9 & 9 & 9 & 9 & 9 & 9 & 9 & 9 & 9 & 9 & 9 & 9 & 9\end{array}$ \\ $\begin{array}{lllllllllllllllllllll}9 & 9 & 9 & 9 & 9 & 9 & 9 & 9 & 9 & 9 & 9 & 9 & 9 & 9 & 9 & 9 & 9 & 9 & 9 & 9 & 9\end{array}$ \\ $\begin{array}{lllllllllllllllllllll}9 & 9 & 9 & 9 & 9 & 9 & 9 & 9 & 9 & 9 & 9 & 9 & 9 & 9 & 9 & 9 & 9 & 9 & 9 & 9 & 9\end{array}$ \\ $\begin{array}{lllllllllllllllllllll}9 & 9 & 9 & 9 & 9 & 9 & 9 & 9 & 9 & 9 & 9 & 9 & 9 & 9 & 9 & 9 & 9 & 9 & 9 & 9 & 9\end{array}$ \\ $\begin{array}{lllllllllllllllllllll}9 & 9 & 9 & 9 & 9 & 9 & 9 & 9 & 9 & 9 & 9 & 9 & 9 & 9 & 9 & 9 & 9 & 9 & 9 & 9 & 9\end{array}$ \\ $\begin{array}{lllllllllllllllllllll}9 & 9 & 9 & 9 & 9 & 9 & 9 & 9 & 9 & 9 & 9 & 9 & 9 & 9 & 9 & 9 & 9 & 9 & 9 & 9 & 9\end{array}$ \\ $\begin{array}{lllllllllllllllllllll}9 & 9 & 9 & 9 & 9 & 9 & 9 & 9 & 9 & 9 & 9 & 9 & 9 & 9 & 9 & 9 & 9 & 9 & 9 & 9 & 9\end{array}$ \\ $\begin{array}{lllllllllllllllllllll}9 & 9 & 9 & 9 & 9 & 9 & 9 & 9 & 9 & 9 & 9 & 9 & 9 & 9 & 9 & 9 & 9 & 9 & 9 & 9 & 9\end{array}$ \\ $\begin{array}{lllllllllllllllllllll}9 & 9 & 9 & 9 & 9 & 9 & 9 & 9 & 9 & 9 & 9 & 9 & 9 & 9 & 9 & 9 & 9 & 9 & 9 & 9 & 9\end{array}$ \\ $\begin{array}{lllllllllllllllllllll}9 & 9 & 9 & 9 & 9 & 9 & 9 & 9 & 9 & 9 & 9 & 9 & 9 & 9 & 9 & 9 & 9 & 9 & 9 & 9 & 9\end{array}$ \\ $\begin{array}{lllllllllllllllllllll}9 & 9 & 9 & 9 & 9 & 9 & 9 & 9 & 9 & 9 & 9 & 9 & 9 & 9 & 9 & 9 & 9 & 9 & 9 & 9 & 9\end{array}$ \\ $\begin{array}{lllllllllllllllllllll}9 & 9 & 9 & 9 & 9 & 9 & 9 & 9 & 9 & 9 & 9 & 9 & 9 & 9 & 9 & 9 & 9 & 9 & 9 & 9 & 9\end{array}$ \\ C \\ C Void hex (around target) \\ c Hex and Pins (or empty hexes) \\ $2090 \quad-301 \quad 302-303 \quad 304-305 \quad 306$ \\ lat $=2 \quad u=10 \quad$ imp $: n=1$ \\ fill=-10:10 $-10: 10 \quad 0: 0$ \\ $\begin{array}{lllllllllllllllllllll}19 & 19 & 19 & 19 & 19 & 19 & 19 & 19 & 19 & 19 & 19 & 19 & 19 & 19 & 19 & 19 & 19 & 19 & 19 & 19 & 19\end{array}$ \\ $\begin{array}{lllllllllllllllllllll}19 & 19 & 19 & 19 & 19 & 19 & 19 & 19 & 19 & 19 & 19 & 19 & 19 & 19 & 19 & 19 & 19 & 19 & 19 & 19 & 19\end{array}$ \\ $\begin{array}{lllllllllllllllllllll}19 & 19 & 19 & 19 & 19 & 19 & 19 & 19 & 19 & 19 & 19 & 19 & 19 & 19 & 19 & 19 & 19 & 19 & 19 & 19 & 19\end{array}$ \\ $\begin{array}{lllllllllllllllllllll}19 & 19 & 19 & 19 & 19 & 19 & 19 & 19 & 19 & 19 & 19 & 19 & 19 & 19 & 19 & 19 & 19 & 19 & 19 & 19 & 19\end{array}$ \\ $\begin{array}{lllllllllllllllllllll}19 & 19 & 19 & 19 & 19 & 19 & 19 & 19 & 19 & 19 & 19 & 19 & 19 & 19 & 19 & 19 & 19 & 19 & 19 & 19 & 19\end{array}$ \\ $\begin{array}{lllllllllllllllllllll}19 & 19 & 19 & 19 & 19 & 19 & 19 & 19 & 19 & 19 & 19 & 19 & 19 & 19 & 19 & 19 & 19 & 19 & 19 & 19 & 19\end{array}$ \\ $\begin{array}{llllllllllllllllllllll}19 & 19 & 19 & 19 & 19 & 19 & 19 & 19 & 19 & 19 & 19 & 19 & 19 & 19 & 19 & 19 & 19 & 19 & 19 & 19 & 19\end{array}$ \\ $\begin{array}{lllllllllllllllllllll}19 & 19 & 19 & 19 & 19 & 19 & 19 & 19 & 19 & 19 & 19 & 19 & 19 & 19 & 19 & 19 & 19 & 19 & 19 & 19 & 19\end{array}$ \\ $\begin{array}{lllllllllllllllllllll}19 & 19 & 19 & 19 & 19 & 19 & 19 & 19 & 19 & 19 & 19 & 19 & 19 & 19 & 19 & 19 & 19 & 19 & 19 & 19 & 19\end{array}$ \\ $\begin{array}{lllllllllllllllllllll}19 & 19 & 19 & 19 & 19 & 19 & 19 & 19 & 19 & 19 & 19 & 19 & 19 & 19 & 19 & 19 & 19 & 19 & 19 & 19 & 19\end{array}$ \\ $\begin{array}{lllllllllllllllllllll}19 & 19 & 19 & 19 & 19 & 19 & 19 & 19 & 19 & 19 & 19 & 19 & 19 & 19 & 19 & 19 & 19 & 19 & 19 & 19 & 19\end{array}$ \\ $\begin{array}{lllllllllllllllllllll}19 & 19 & 19 & 19 & 19 & 19 & 19 & 19 & 19 & 19 & 19 & 19 & 19 & 19 & 19 & 19 & 19 & 19 & 19 & 19 & 19\end{array}$ \\ $\begin{array}{lllllllllllllllllllll}19 & 19 & 19 & 19 & 19 & 19 & 19 & 19 & 19 & 19 & 19 & 19 & 19 & 19 & 19 & 19 & 19 & 19 & 19 & 19 & 19\end{array}$ \\ $\begin{array}{lllllllllllllllllllll}19 & 19 & 19 & 19 & 19 & 19 & 19 & 19 & 19 & 19 & 19 & 19 & 19 & 19 & 19 & 19 & 19 & 19 & 19 & 19 & 19\end{array}$ \\ $\begin{array}{lllllllllllllllllllll}19 & 19 & 19 & 19 & 19 & 19 & 19 & 19 & 19 & 19 & 19 & 19 & 19 & 19 & 19 & 19 & 19 & 19 & 19 & 19 & 19\end{array}$ \\ $\begin{array}{lllllllllllllllllllll}19 & 19 & 19 & 19 & 19 & 19 & 19 & 19 & 19 & 19 & 19 & 19 & 19 & 19 & 19 & 19 & 19 & 19 & 19 & 19 & 19\end{array}$ \\ $\begin{array}{lllllllllllllllllllll}19 & 19 & 19 & 19 & 19 & 19 & 19 & 19 & 19 & 19 & 19 & 19 & 19 & 19 & 19 & 19 & 19 & 19 & 19 & 19 & 19\end{array}$ \\ $\begin{array}{lllllllllllllllllllll}19 & 19 & 19 & 19 & 19 & 19 & 19 & 19 & 19 & 19 & 19 & 19 & 19 & 19 & 19 & 19 & 19 & 19 & 19 & 19 & 19\end{array}$ \\ $\begin{array}{lllllllllllllllllllll}19 & 19 & 19 & 19 & 19 & 19 & 19 & 19 & 19 & 19 & 19 & 19 & 19 & 19 & 19 & 19 & 19 & 19 & 19 & 19 & 19\end{array}$ \\ $\begin{array}{lllllllllllllllllllll}19 & 19 & 19 & 19 & 19 & 19 & 19 & 19 & 19 & 19 & 19 & 19 & 19 & 19 & 19 & 19 & 19 & 19 & 19 & 19 & 19\end{array}$ \\ $\begin{array}{lllllllllllllllllllll}19 & 19 & 19 & 19 & 19 & 19 & 19 & 19 & 19 & 19 & 19 & 19 & 19 & 19 & 19 & 19 & 19 & 19 & 19 & 19 & 19\end{array}$ \\ c \\ C Fuel Pin - Zone 1 of Med Enrichment region \\ $54021 \quad-10.02037$

$\begin{array}{llllll} & & -501 & u=51 \text { imp }: n=1 & \$ \text { Fuel Pellet } \\ 541 & 2 & -7.92 & 501-502 & u=51 \text { imp }: n=1 & \$ \text { Clad } \\ 542 & 8 & .02540 & 502 & u=51 \text { imp }: n=1 & \text { \$ Coolant }\end{array}$ \\ C Fuel Pin - Zone 2 of Med Enrichment region \\ $54322 \quad-8.08890$

$\begin{array}{ccccc}544 & 2 & -7.92 & 501-502 & u=52 \text { imp }: n=1 \\ 545 & 8 & .02540 & 502 & u=52 \text { imp: } n=1 \\ & & & u=52 \text { imp }: n=1\end{array}$ \\ \$ Fuel Pellet \\ $\$$ Clad \\ \$Coolant \\ c Fuel Pin - Zone 3 of Med Enrichment region \\ 54623 \\ $-8.66783$ \\ $547-7.92 \quad 501-502 \quad u=53$ imp $: n=1$ \\ $548.02540 \quad 502 \quad u=53$ imp: $n=1$ \\ \$ Fuel Pellet \\ $\$$ Clad \\ \$ Coolant
}




\section{LA-14052-T}

c Fuel Pin - Zone 4 of Med Enrichment region

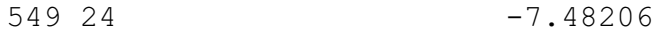




\section{LA-14052-T}

\begin{tabular}{|c|c|c|c|c|c|c|}
\hline & & & -501 & $\mathrm{u}=46$ imp $: \mathrm{n}=1$ & $\$$ & Fuel Pellet \\
\hline 576 & -7.92 & 501 & -502 & $\mathrm{u}=46$ imp $: \mathrm{n}=1$ & $\$$ & Clad \\
\hline 577 & .02540 & 50 & 02 & $\mathrm{u}=46$ imp: $\mathrm{n}=1$ & $\$$ & Coolant \\
\hline C & & & & & & \\
\hline C & Fuel Pin - & - Zone 7 & 7 of Low Enric & chment region & & \\
\hline 6913 & 37 & & -7.66301 & & & \\
\hline & & & -501 & $u=47$ imp: $n=1$ & $\$$ & Fuel Pellet \\
\hline 692 & -7.92 & 501 & -502 & $u=47$ imp: $n=1$ & $\$$ & Clad \\
\hline 693 & .02540 & 50 & & $\mathrm{u}=47$ imp: $\mathrm{n}=1$ & $\$$ & Coolant \\
\hline C & & & & & & \\
\hline c & $\mathrm{Na}$ Hex & & & & & \\
\hline 528 & 8.02540 & -50 & & $\mathrm{u}=9$ imp: $\mathrm{n}=1$ & $\$$ & $\mathrm{Na}$ \\
\hline 529 & .02540 & 501 & -502 & $u=9$ imp: $n=1$ & $\$$ & $\mathrm{Na}$ \\
\hline 530 & .02540 & 50 & & $u=9$ imp: $n=1$ & $\$$ & $\mathrm{Na}$ \\
\hline C & & & & & & \\
\hline C & Void Surror & Dunding & Target & & & \\
\hline 531 & 0 & -50 & & $u=19$ imp $: n=1$ & $\$$ & Vacuum \\
\hline 532 & 0 & 501 & -502 & $u=19$ imp: $n=1$ & $\$$ & Vacuum \\
\hline 533 & 0 & 50 & & $u=19$ imp $: n=1$ & $\$$ & Vacuum \\
\hline C & & & & & & \\
\hline C & B4C shield & & & & & \\
\hline 5351 & $19-2.3$ & -50 & & $\mathrm{u}=28$ imp $: \mathrm{n}=1$ & $\$ \$$ & Shield \\
\hline 5361 & $19-2.3$ & 50 & & $u=28$ imp $: n=1$ & $\$ \$$ & Shield \\
\hline C & Outside col & re & & & & \\
\hline 5730 & 0 & -50 & & $\mathrm{u}=29$ imp $: \mathrm{n}=1$ & $\$ \$$ & Shield \\
\hline 5740 & 0 & 50 & & $u=29$ imp: $n=1$ & $\$$ & Shield \\
\hline C & Cookie-cut & ter cel & 11 for source & definition & & \\
\hline C 900 & $\begin{array}{lll}0 & 0 & -21\end{array}$ & 13214 & -505 & imp $: n=1$ & & \\
\hline C & & & & & & \\
\hline C Su & urface Cards & & & & & \\
\hline 207 & $\mathrm{pz} 150.0$ & & & & & \\
\hline 210 & pz 54.0 & & & & & \\
\hline 211 & $\mathrm{pz} 53.5$ & & & & & \\
\hline 217 & $\mathrm{pz} \quad 6.0$ & & & & & \\
\hline 220 & $\mathrm{pz} \quad 5.0$ & & & & & \\
\hline 218 & $\mathrm{pz} \quad 4.5$ & & & & & \\
\hline 223 & $\mathrm{pz} \quad 4.0$ & & & & & \\
\hline 221 & $\mathrm{pz} \quad 3.0$ & & & & & \\
\hline 225 & $p z-6.0$ & & & & & \\
\hline 212 & $\mathrm{pz} \quad-53.5$ & & & & & \\
\hline 216 & $\mathrm{pz} \quad-54.0$ & & & & & \\
\hline 227 & $\mathrm{pz} \quad-150.0$ & & & & & \\
\hline C & & & & & & \\
\hline$\star 213$ & $p-0.5774$ & $\begin{array}{lll}-1 & 0 & 0\end{array}$ & & & & \\
\hline$\star 214$ & p 0.5774 & $\begin{array}{lll}-1 & 0 & 0\end{array}$ & & & & \\
\hline 215 & Cz 140.0 & & & & & \\
\hline C & & & & & & \\
\hline c & Fuel pin he & lex & & & & \\
\hline 301 & px 0.44528 & & & \$ Flat to center & & \\
\hline 302 & $p x-0.44528$ & & & & & \\
\hline 303 & $\mathrm{p} \quad .57735$ & 1 & 0.51412 & & & \\
\hline 304 & .57735 & 1 & -0.51412 & & & \\
\hline 305 & -.57735 & 1 & 0.51412 & & & \\
\hline 306 & -.57735 & 1 & -0.51412 & & & \\
\hline c & & & & & & \\
\hline C & Moly inner & planes & & & & \\
\hline 403 & py $\quad 7.355$ & & & & & \\
\hline 404 & py $\quad-7.355$ & & & & & \\
\hline 401 & $\mathrm{p} \quad 1.73205$ & 1 & 14.71 & & & \\
\hline 402 & $\mathrm{p} \quad 1.73205$ & 1 & -14.71 & & & \\
\hline 405 & $p-1.73205$ & 1 & 14.71 & & & \\
\hline 406 & $p-1.73205$ & 1 & -14.71 & & & \\
\hline
\end{tabular}




\section{LA-14052-T}

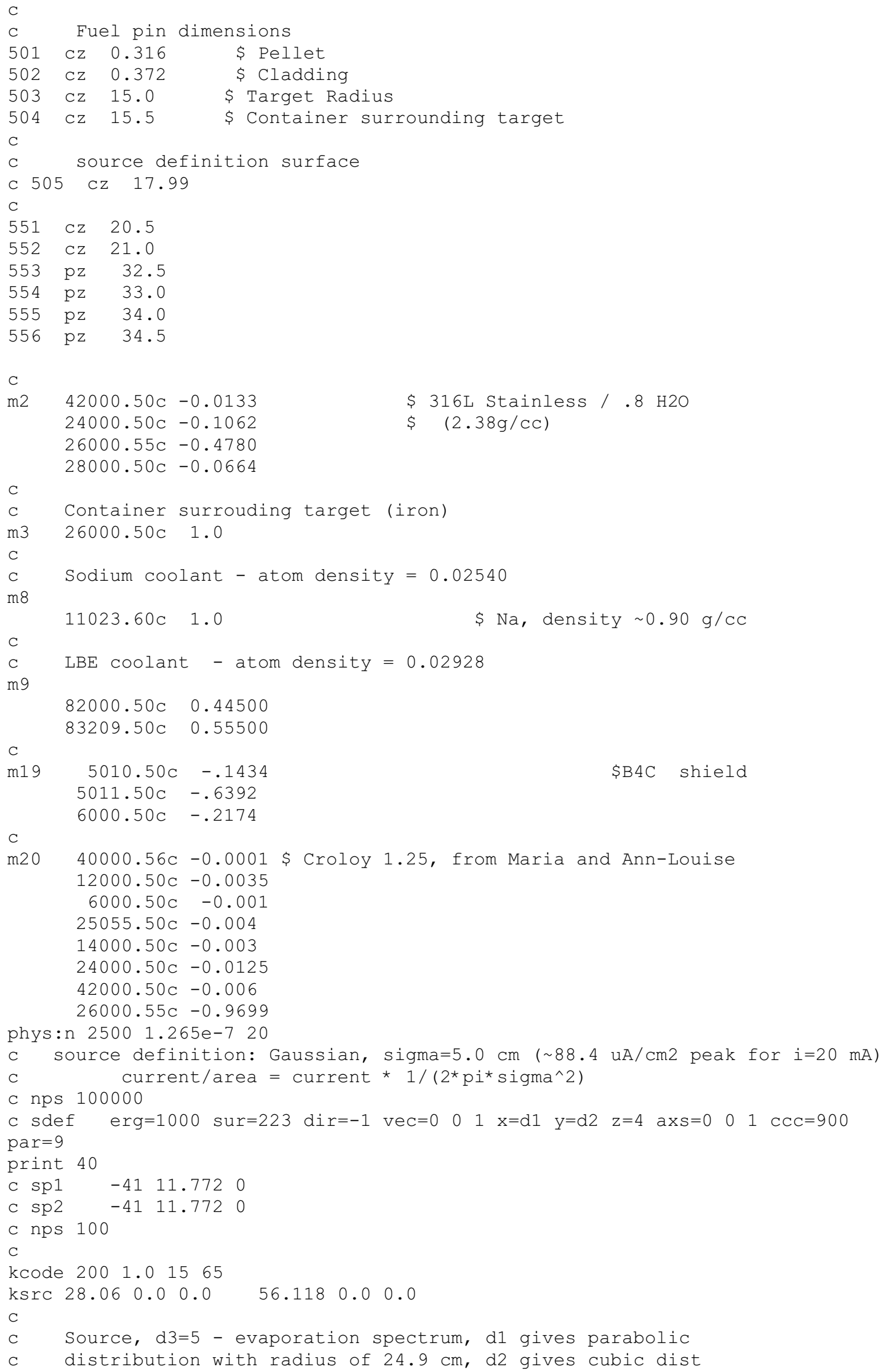




\section{LA-14052-T}

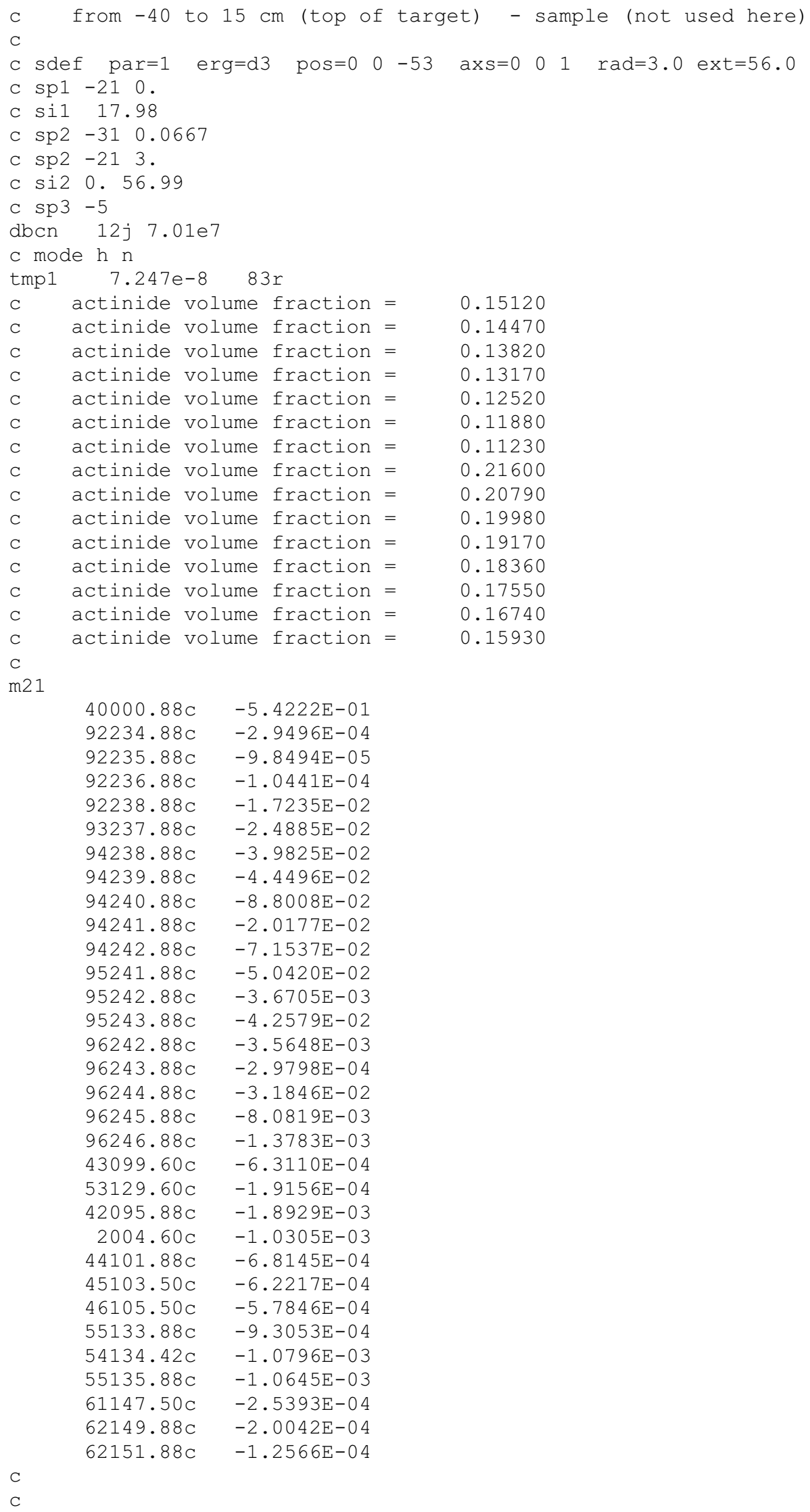




\section{LA-14052-T}

m22

$40000.88 \mathrm{C}$

$92234.88 \mathrm{c}$

$92235.88 \mathrm{c}$

$92236.88 \mathrm{C}$

$92238.88 \mathrm{c}$

$93237.88 \mathrm{c}$

$94238.88 \mathrm{c}$

$94239.88 \mathrm{c}$

$94240.88 \mathrm{c}$

$94241.88 \mathrm{c}$

$94242.88 \mathrm{C}$

$95241.88 \mathrm{c}$

$95242.88 \mathrm{c}$

$95243.88 \mathrm{c}$

$96242.88 \mathrm{c}$

$96243.88 \mathrm{c}$

$96244.88 \mathrm{c}$

$96245.88 \mathrm{c}$

$96246.88 \mathrm{C}$

$43099.60 \mathrm{c}$

$53129.60 \mathrm{c}$

$42095.88 \mathrm{c}$

$2004.60 \mathrm{c}$

$44101.88 \mathrm{C}$

$45103.50 \mathrm{c}$

$46105.50 \mathrm{C}$

$55133.88 \mathrm{c}$

$62149.88 \mathrm{c}$

C

m23

$40000.88 \mathrm{c}$

$92234.88 \mathrm{C}$

$92235.88 \mathrm{C}$

$92236.88 \mathrm{c}$

$92238.88 \mathrm{c}$

$93237.88 \mathrm{c}$

$94238.88 \mathrm{c}$

$94239.88 \mathrm{c}$

$94240.88 \mathrm{c}$

$94241.88 \mathrm{c}$

$94242.88 \mathrm{c}$

$95241.88 \mathrm{c}$

$95242.88 \mathrm{c}$

$95243.88 \mathrm{c}$

$96242.88 \mathrm{c}$

$96243.88 \mathrm{c}$

$96244.88 \mathrm{c}$

$96245.88 \mathrm{c}$

$96246.88 \mathrm{c}$

$43099.60 \mathrm{c}$

$53129.60 \mathrm{c}$

$42095.88 \mathrm{c}$

$2004.60 \mathrm{c}$

C

$\mathrm{C}$

m24

$40000.88 \mathrm{c}$

$92234.88 \mathrm{c}$

$92235.88 \mathrm{C}$

$92236.88 \mathrm{C}$

$92238.88 \mathrm{c}$
$-6.6487 \mathrm{E}-01$

$-1.1603 \mathrm{E}-04$

$-6.4743 E-05$

$-6.2776 \mathrm{E}-05$

$-1.0864 \mathrm{E}-02$

$-1.6429 \mathrm{E}-02$

$-3.0332 \mathrm{E}-02$

$-3.1802 \mathrm{E}-02$

$-6.6022 \mathrm{E}-02$

$-1.5411 \mathrm{E}-02$

$-5.4653 \mathrm{E}-02$

$-3.3381 \mathrm{E}-02$

$-2.3704 \mathrm{E}-03$

$-3.1360 \mathrm{E}-02$

$-2.6133 \mathrm{E}-03$

$-2.5493 \mathrm{E}-04$

$-2.6399 \mathrm{E}-02$

$-7.0514 \mathrm{E}-03$

$-1.4281 \mathrm{E}-03$

$-2.3966 \mathrm{E}-04$

$-7.1405 \mathrm{E}-05$

$-2.1702 \mathrm{E}-03$

$-9.3026 \mathrm{E}-04$

$-2.6139 \mathrm{E}-04$

$-1.9595 \mathrm{E}-04$

$-2.2165 \mathrm{E}-04$

$-3.4628 \mathrm{E}-04$

$-7.7806 \mathrm{E}-05$

$-6.1541 \mathrm{E}-01$

$-8.6854 \mathrm{E}-07$

$-6.8905 \mathrm{E}-05$

$-5.5974 \mathrm{E}-05$

$-1.0508 \mathrm{E}-02$

$-2.1830 \mathrm{E}-02$

$-3.5216 \mathrm{E}-02$

$-4.0999 \mathrm{E}-02$

$-7.5711 \mathrm{E}-02$

$-1.8378 \mathrm{E}-02$

$-5.9635 \mathrm{E}-02$

$-4.5575 \mathrm{E}-02$

$-2.9533 E-03$

$-3.5516 \mathrm{E}-02$

$-2.0082 \mathrm{E}-03$

$-2.5703 \mathrm{E}-04$

$-2.6301 \mathrm{E}-02$

$-6.4455 \mathrm{E}-03$

$-1.0180 \mathrm{E}-03$

$-1.1488 \mathrm{E}-07$

$-1.0000 \mathrm{E}-20$

$-1.3334 \mathrm{E}-03$

$-7.8476 \mathrm{E}-04$

$-7.0458 \mathrm{E}-01$

$-6.8432 \mathrm{E}-04$

$-9.8358 \mathrm{E}-05$

$-8.4222 \mathrm{E}-05$

$-1.0116 \mathrm{E}-02$ 


\section{LA-14052-T}

\begin{tabular}{|c|c|c|}
\hline & & \\
\hline & $93237.88 \mathrm{C}$ & $-9.9262 E-03$ \\
\hline & $94238.88 \mathrm{C}$ & $-2.8696 \mathrm{E}-02$ \\
\hline & $94239.88 c$ & $-2.0096 \mathrm{E}-02$ \\
\hline & $94240.88 c$ & $-5.4075 E-02$ \\
\hline & $94241.88 \mathrm{C}$ & $-1.1004 \mathrm{E}-02$ \\
\hline & $94242.88 \mathrm{C}$ & $-4.6671 E-02$ \\
\hline & $95241.88 \mathrm{C}$ & $-1.9447 \mathrm{E}-02$ \\
\hline & $95242.88 \mathrm{C}$ & $-2.1519 \mathrm{E}-03$ \\
\hline & $95243.88 c$ & $-2.5050 \mathrm{E}-02$ \\
\hline & $96242.88 c$ & $-2.1593 E-03$ \\
\hline & $96243.88 \mathrm{C}$ & $-2.6709 \mathrm{E}-04$ \\
\hline & $96244.88 \mathrm{C}$ & $-2.4245 E-02$ \\
\hline & $96245.88 \mathrm{C}$ & $-7.0506 E-03$ \\
\hline & $96246.88 \mathrm{C}$ & $-1.5362 \mathrm{E}-03$ \\
\hline & $43099.60 \mathrm{C}$ & $-1.4678 E-03$ \\
\hline & $53129.60 \mathrm{C}$ & $-4.6296 \mathrm{E}-04$ \\
\hline & $42095.88 \mathrm{C}$ & $-3.3985 E-03$ \\
\hline & $2004.60 \mathrm{c}$ & $-9.8980 E-04$ \\
\hline & $44101.88 \mathrm{C}$ & $-1.5324 \mathrm{E}-03$ \\
\hline & $45103.50 \mathrm{C}$ & $-1.5814 \mathrm{E}-03$ \\
\hline & $46105.50 \mathrm{C}$ & $-1.3086 E-03$ \\
\hline & $46108.50 \mathrm{C}$ & $-8.7873 E-04$ \\
\hline & $47109.88 \mathrm{C}$ & $-5.4005 \mathrm{E}-04$ \\
\hline & $54131.50 \mathrm{C}$ & $-1.2998 \mathrm{E}-03$ \\
\hline & $55133.88 \mathrm{C}$ & $-2.1772 \mathrm{E}-03$ \\
\hline & $54134.42 \mathrm{C}$ & $-2.6899 \mathrm{E}-03$ \\
\hline & $55135.88 c$ & $-2.6949 \mathrm{E}-03$ \\
\hline & $55137.60 \mathrm{C}$ & $-2.2838 E-03$ \\
\hline & $56138.60 \mathrm{c}$ & $-2.3772 E-03$ \\
\hline & $59141.50 \mathrm{C}$ & $-1.9803 E-03$ \\
\hline & $60143.88 \mathrm{C}$ & $-1.5837 \mathrm{E}-03$ \\
\hline & $60145.88 \mathrm{C}$ & $-1.1282 \mathrm{E}-03$ \\
\hline & $61147.50 \mathrm{C}$ & $-3.4417 \mathrm{E}-04$ \\
\hline & $62147.88 \mathrm{C}$ & $-1.8898 \mathrm{E}-04$ \\
\hline & $62149.88 \mathrm{C}$ & $-3.8329 E-04$ \\
\hline & $62151.88 \mathrm{C}$ & $-2.3066 E-04$ \\
\hline & $62152.88 c$ & $-3.9265 E-04$ \\
\hline & $63153.88 c$ & $-1.4341 \mathrm{E}-04$ \\
\hline & & \\
\hline & & \\
\hline & & \\
\hline & $40000.88 \mathrm{c}$ & $-6.9544 \mathrm{E}-01$ \\
\hline & $92234.88 c$ & $-6.1194 \mathrm{E}-04$ \\
\hline & $92235.88 \mathrm{C}$ & $-8.5087 \mathrm{E}-05$ \\
\hline & $92236.88 \mathrm{C}$ & $-8.0872 E-05$ \\
\hline & $92238.88 \mathrm{C}$ & $-1.0457 \mathrm{E}-02$ \\
\hline & $93237.88 \mathrm{C}$ & $-1.1294 \mathrm{E}-02$ \\
\hline & $94238.88 \mathrm{C}$ & $-2.9350 \mathrm{E}-02$ \\
\hline & $94239.88 \mathrm{C}$ & $-2.2007 \mathrm{E}-02$ \\
\hline & $94240.88 \mathrm{C}$ & $-5.6442 E-02$ \\
\hline & $94241.88 \mathrm{C}$ & $-1.1690 \mathrm{E}-02$ \\
\hline & $94242.88 \mathrm{C}$ & $-4.8353 E-02$ \\
\hline & $95241.88 \mathrm{C}$ & $-2.2211 \mathrm{E}-02$ \\
\hline & $95242.88 \mathrm{C}$ & $-2.3260 \mathrm{E}-03$ \\
\hline & $95243.88 \mathrm{C}$ & $-2.6236 \mathrm{E}-02$ \\
\hline & $96242.88 \mathrm{C}$ & $-2.2551 \mathrm{E}-03$ \\
\hline & $96243.88 \mathrm{C}$ & $-2.5657 \mathrm{E}-04$ \\
\hline & $96244.88 \mathrm{C}$ & $-2.4475 E-02$ \\
\hline & $96245.88 \mathrm{C}$ & $-7.0440 \mathrm{E}-03$ \\
\hline & $96246.88 \mathrm{C}$ & $-1.4742 E-03$ \\
\hline & $43099.60 \mathrm{C}$ & $-1.2747 \mathrm{E}-03$ \\
\hline & $53129.60 \mathrm{C}$ & $-3.9740 \mathrm{E}-04$ \\
\hline & 42095.88 & $-3.1589 \mathrm{E}-03$ \\
\hline
\end{tabular}




\section{LA-14052-T}

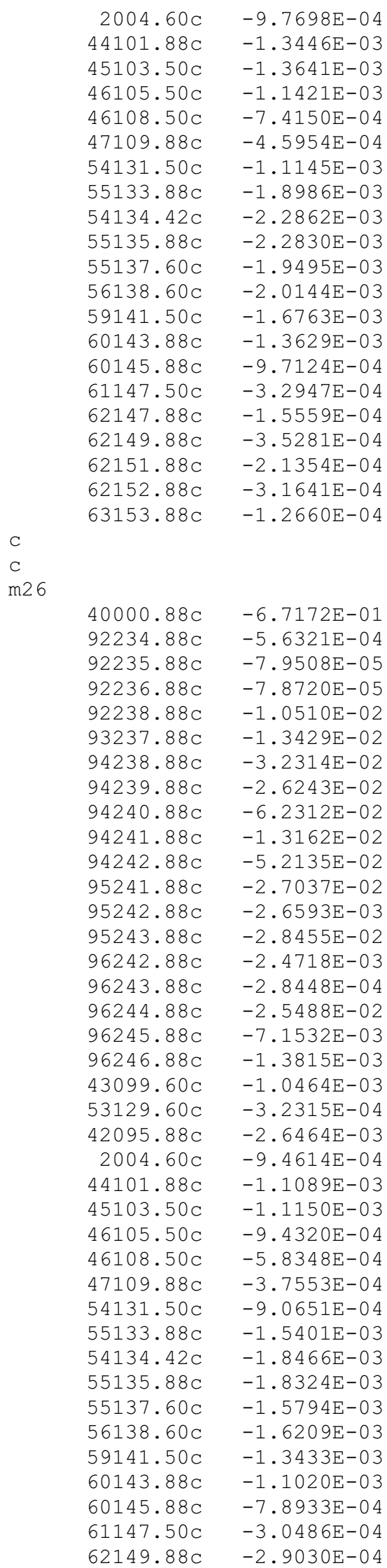




\section{LA-14052-T}

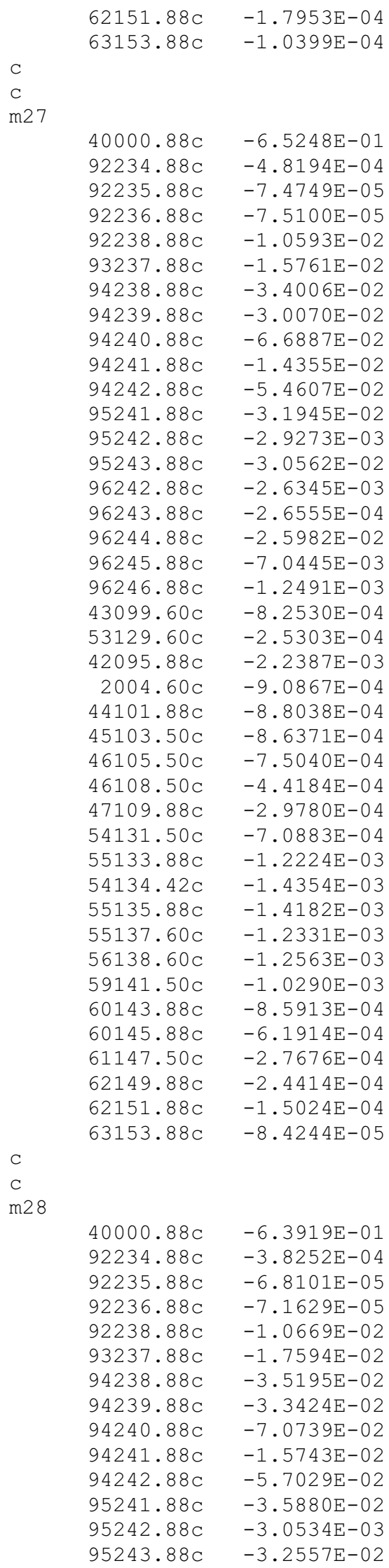




\section{LA-14052-T}

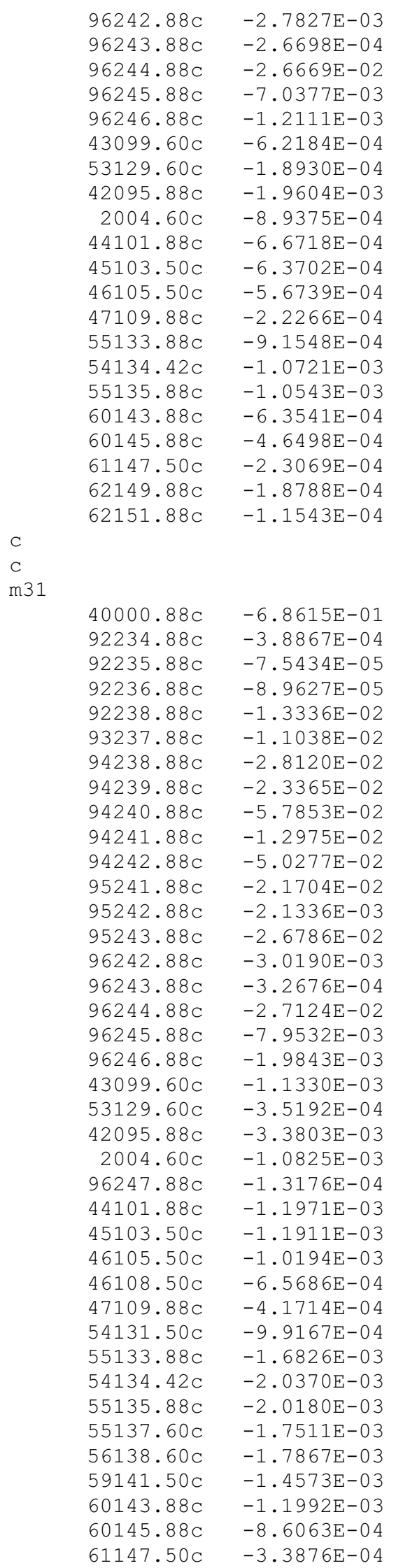




\section{LA-14052-T}

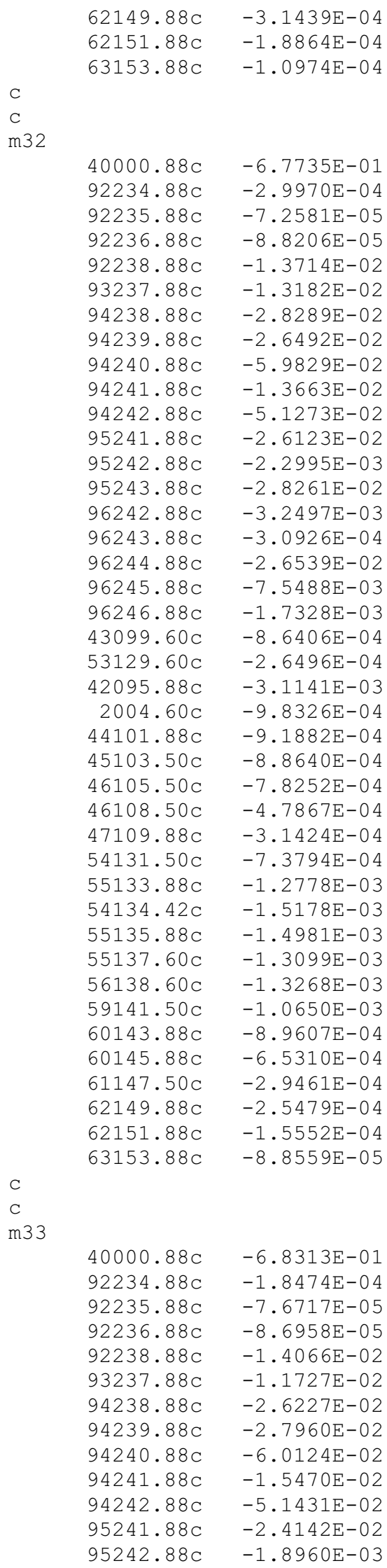




\section{LA-14052-T}

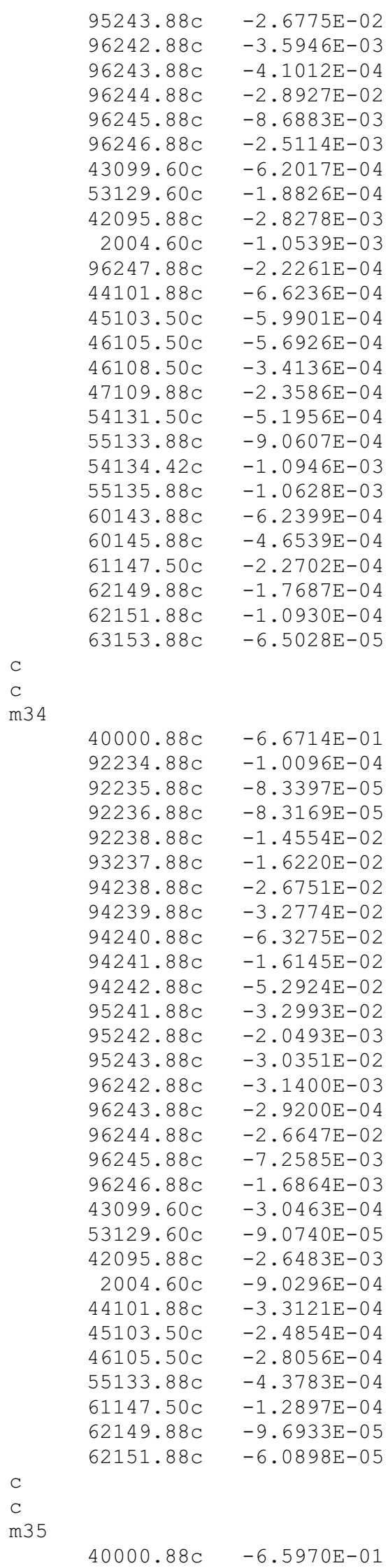




\section{LA-14052-T}

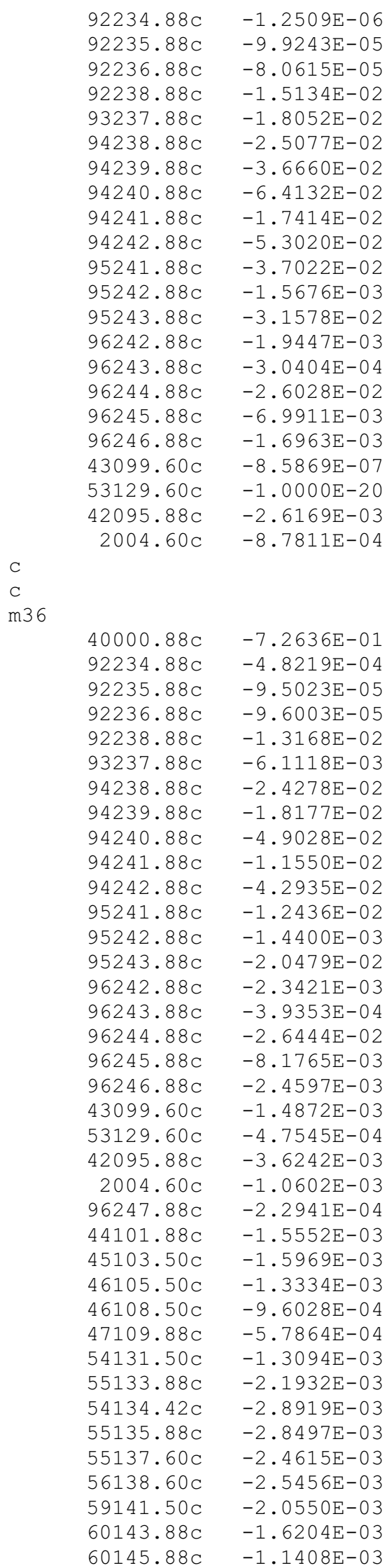




\section{LA-14052-T}

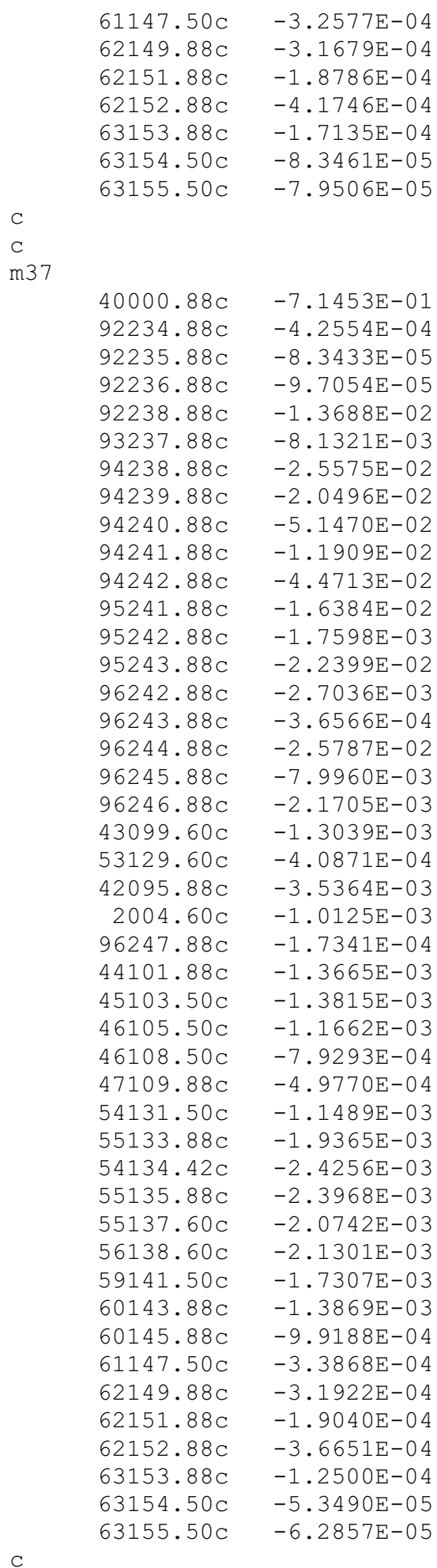


LA-14052-T 


\section{LA-14052-T}

\section{Appendix F. Sample Main Monteburns Input File for ADS}

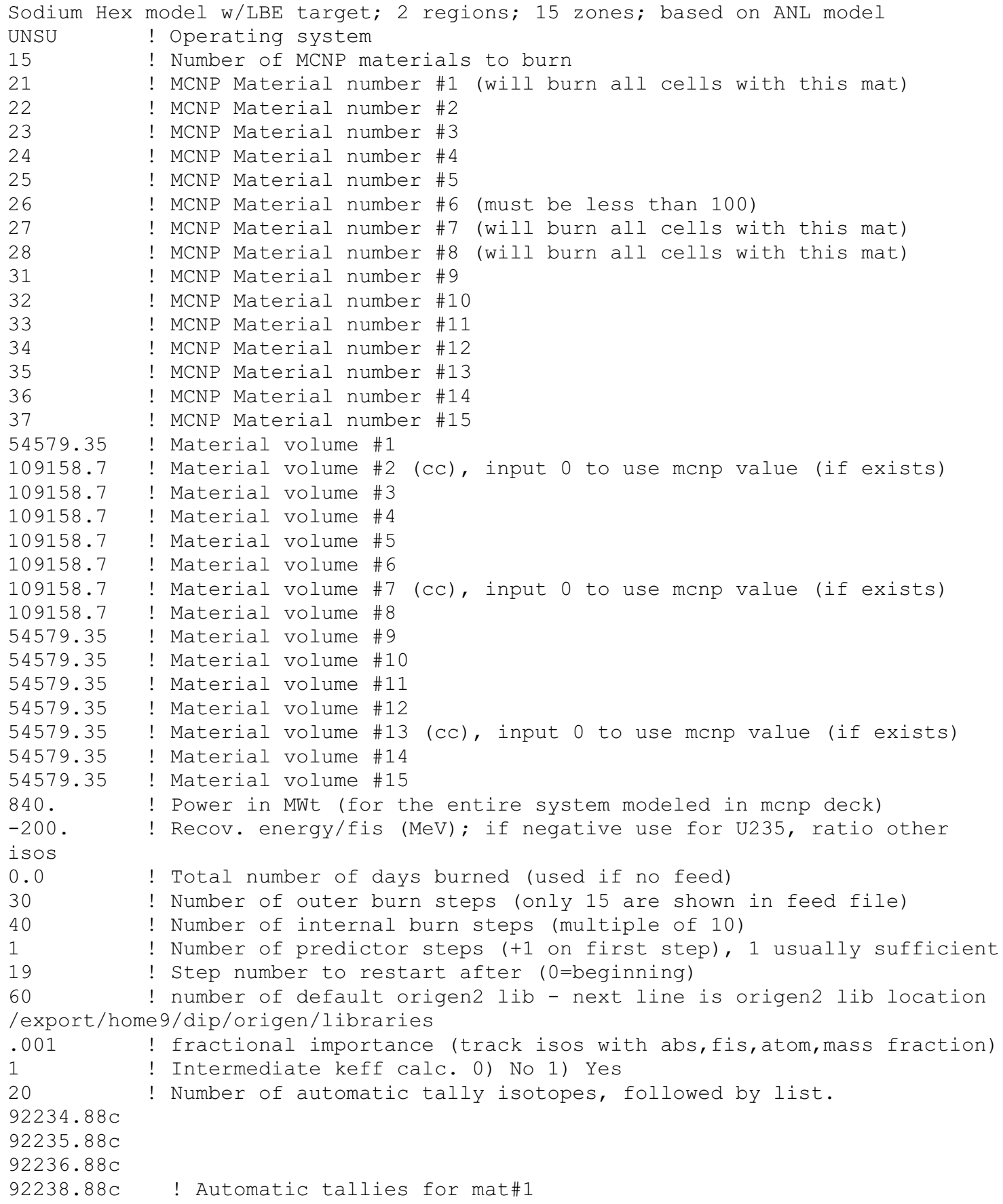




\section{LA-14052-T}

$96243.88 \mathrm{C}$

$96244.88 \mathrm{c}$

$96245.88 \mathrm{c}$

$96246.88 \mathrm{C}$

$43099.60 \mathrm{c}$

$53129.60 \mathrm{C}$

20

$92234.88 \mathrm{c}$

$92235.88 \mathrm{C}$

$92236.88 \mathrm{c}$

$92238.88 \mathrm{c}$

$93237.88 \mathrm{C}$

$94238.88 \mathrm{c}$

$94239.88 \mathrm{c}$

$94240.88 \mathrm{C}$

$94241.88 \mathrm{C}$

$94242.88 \mathrm{c}$

$95241.88 \mathrm{c}$

$95242.88 \mathrm{C}$

$95243.88 \mathrm{C}$

$96242.88 \mathrm{c}$

$96243.88 \mathrm{C}$

$96244.88 \mathrm{c}$

$96245.88 \mathrm{c}$

$96246.88 \mathrm{c}$

$43099.60 \mathrm{c}$

$53129.60 \mathrm{C}$

20

$92234.88 \mathrm{C}$

$92235.88 \mathrm{C}$

$92236.88 \mathrm{C}$

$92238.88 \mathrm{c}$

$93237.88 \mathrm{C}$

$94238.88 \mathrm{c}$

$94239.88 \mathrm{C}$

$94240.88 \mathrm{C}$

$94241.88 \mathrm{c}$

$94242.88 \mathrm{c}$

$95241.88 \mathrm{c}$

$95242.88 \mathrm{C}$

$95243.88 \mathrm{C}$

$96242.88 \mathrm{c}$

$96243.88 \mathrm{C}$

$96244.88 \mathrm{c}$

$96245.88 \mathrm{c}$

$96246.88 \mathrm{C}$

$43099.60 \mathrm{c}$

$53129.60 \mathrm{c}$

20

$92234.88 \mathrm{C}$

$92235.88 \mathrm{c}$

$92236.88 \mathrm{C}$

$92238.88 \mathrm{c}$

$93237.88 \mathrm{C}$

$94238.88 \mathrm{c}$

$94239.88 \mathrm{c}$

$94240.88 \mathrm{C}$

$94241.88 \mathrm{C}$

$94242.88 \mathrm{c}$

$95241.88 \mathrm{C}$

$95242.88 \mathrm{C}$

$95243.88 \mathrm{C}$

$96242.88 \mathrm{C}$
! Automatic tallies for mat\#2

! Automatic tallies for mat\#3 


\section{LA-14052-T}

$96243.88 \mathrm{C}$

$96244.88 \mathrm{c}$

$96245.88 \mathrm{c}$

$96246.88 \mathrm{C}$

$43099.60 \mathrm{c}$

$53129.60 \mathrm{C}$

20

$92234.88 \mathrm{c}$

$92235.88 \mathrm{C}$

$92236.88 \mathrm{c}$

$92238.88 \mathrm{c}$

$93237.88 \mathrm{C}$

$94238.88 \mathrm{c}$

$94239.88 \mathrm{c}$

$94240.88 \mathrm{C}$

$94241.88 \mathrm{C}$

$94242.88 \mathrm{c}$

$95241.88 \mathrm{c}$

$95242.88 \mathrm{C}$

$95243.88 \mathrm{c}$

$96242.88 \mathrm{c}$

$96243.88 \mathrm{c}$

$96244.88 \mathrm{c}$

$96245.88 \mathrm{c}$

$96246.88 \mathrm{c}$

$43099.60 \mathrm{c}$

$53129.60 \mathrm{c}$

20

$92234.88 \mathrm{C}$

$92235.88 \mathrm{C}$

$92236.88 \mathrm{C}$

$92238.88 \mathrm{c}$

$93237.88 \mathrm{c}$

$94238.88 \mathrm{c}$

$94239.88 \mathrm{c}$

$94240.88 \mathrm{C}$

$94241.88 \mathrm{c}$

$94242.88 \mathrm{C}$

$95241.88 \mathrm{c}$

$95242.88 \mathrm{c}$

$95243.88 \mathrm{c}$

$96242.88 \mathrm{C}$

$96243.88 \mathrm{C}$

$96244.88 \mathrm{c}$

$96245.88 \mathrm{c}$

$96246.88 \mathrm{C}$

$43099.60 \mathrm{c}$

$53129.60 \mathrm{c}$

20

$92234.88 \mathrm{C}$

$92235.88 \mathrm{c}$

$92236.88 \mathrm{C}$

$92238.88 \mathrm{c}$

$93237.88 \mathrm{C}$

$94238.88 \mathrm{C}$

$94239.88 \mathrm{c}$

$94240.88 \mathrm{C}$

$94241.88 \mathrm{C}$

$94242.88 \mathrm{c}$

$95241.88 \mathrm{C}$

$95242.88 \mathrm{C}$

$95243.88 \mathrm{C}$

$96242.88 \mathrm{C}$
! Automatic tallies for mat\#5

! Automatic tallies for mat\#6 


\section{LA-14052-T}

$96243.88 \mathrm{C}$

$96244.88 \mathrm{c}$

$96245.88 \mathrm{c}$

$96246.88 \mathrm{C}$

$43099.60 \mathrm{c}$

$53129.60 \mathrm{C}$

20

$92234.88 \mathrm{c}$

$92235.88 \mathrm{C}$

$92236.88 \mathrm{c}$

$92238.88 \mathrm{c}$

$93237.88 \mathrm{C}$

$94238.88 \mathrm{c}$

$94239.88 \mathrm{C}$

$94240.88 \mathrm{C}$

$94241.88 \mathrm{C}$

$94242.88 \mathrm{c}$

$95241.88 \mathrm{c}$

$95242.88 \mathrm{C}$

$95243.88 \mathrm{c}$

$96242.88 \mathrm{c}$

$96243.88 \mathrm{c}$

$96244.88 \mathrm{c}$

$96245.88 \mathrm{c}$

$96246.88 \mathrm{c}$

$43099.60 \mathrm{c}$

$53129.60 \mathrm{c}$

20

$92234.88 \mathrm{C}$

$92235.88 \mathrm{C}$

$92236.88 \mathrm{C}$

$92238.88 \mathrm{c}$

$93237.88 \mathrm{c}$

$94238.88 \mathrm{c}$

$94239.88 \mathrm{c}$

$94240.88 \mathrm{C}$

$94241.88 \mathrm{c}$

$94242.88 \mathrm{C}$

$95241.88 \mathrm{C}$

$95242.88 \mathrm{c}$

$95243.88 \mathrm{c}$

$96242.88 \mathrm{c}$

$96243.88 \mathrm{C}$

$96244.88 \mathrm{c}$

$96245.88 \mathrm{c}$

$96246.88 \mathrm{C}$

$43099.60 \mathrm{c}$

$53129.60 \mathrm{c}$

20

$92234.88 \mathrm{C}$

$92235.88 \mathrm{c}$

$92236.88 \mathrm{C}$

$92238.88 \mathrm{c}$

$93237.88 \mathrm{C}$

$94238.88 \mathrm{C}$

$94239.88 \mathrm{c}$

$94240.88 \mathrm{C}$

$94241.88 \mathrm{C}$

$94242.88 \mathrm{c}$

$95241.88 \mathrm{C}$

$95242.88 \mathrm{C}$

$95243.88 \mathrm{C}$

$96242.88 \mathrm{C}$
! Automatic tallies for mat\#8

! Automatic tallies for mat\#9 


\section{LA-14052-T}

$96243.88 \mathrm{C}$

$96244.88 \mathrm{c}$

$96245.88 \mathrm{c}$

$96246.88 \mathrm{C}$

$43099.60 \mathrm{c}$

$53129.60 \mathrm{C}$

20

$92234.88 \mathrm{c}$

$92235.88 \mathrm{C}$

$92236.88 \mathrm{c}$

$92238.88 \mathrm{c}$

$93237.88 \mathrm{c}$

$94238.88 \mathrm{c}$

$94239.88 \mathrm{c}$

$94240.88 \mathrm{C}$

$94241.88 \mathrm{C}$

$94242.88 \mathrm{c}$

$95241.88 \mathrm{c}$

$95242.88 \mathrm{C}$

$95243.88 \mathrm{C}$

$96242.88 \mathrm{c}$

$96243.88 \mathrm{C}$

$96244.88 \mathrm{c}$

$96245.88 \mathrm{c}$

$96246.88 \mathrm{c}$

$43099.60 \mathrm{c}$

$53129.60 \mathrm{C}$

20

$92234.88 \mathrm{C}$

$92235.88 \mathrm{C}$

$92236.88 \mathrm{C}$

$92238.88 \mathrm{c}$

$93237.88 \mathrm{c}$

$94238.88 \mathrm{c}$

$94239.88 \mathrm{C}$

$94240.88 \mathrm{C}$

$94241.88 \mathrm{c}$

$94242.88 \mathrm{c}$

$95241.88 \mathrm{c}$

$95242.88 \mathrm{C}$

$95243.88 \mathrm{C}$

$96242.88 \mathrm{c}$

$96243.88 \mathrm{C}$

$96244.88 \mathrm{c}$

$96245.88 \mathrm{c}$

$96246.88 \mathrm{C}$

$43099.60 \mathrm{c}$

$53129.60 \mathrm{c}$

20

$92234.88 \mathrm{C}$

$92235.88 \mathrm{c}$

$92236.88 \mathrm{C}$

$92238.88 \mathrm{c}$

$93237.88 \mathrm{C}$

$94238.88 \mathrm{C}$

$94239.88 \mathrm{c}$

$94240.88 \mathrm{C}$

$94241.88 \mathrm{C}$

$94242.88 \mathrm{c}$

$95241.88 \mathrm{C}$

$95242.88 \mathrm{C}$

$95243.88 \mathrm{C}$

$96242.88 \mathrm{C}$
! Automatic tallies for mat\#11

! Automatic tallies for mat\#12 


\section{LA-14052-T}

$96243.88 \mathrm{C}$

$96244.88 \mathrm{c}$

$96245.88 \mathrm{c}$

$96246.88 \mathrm{C}$

$43099.60 \mathrm{c}$

$53129.60 \mathrm{C}$

20

$92234.88 \mathrm{c}$

$92235.88 \mathrm{C}$

$92236.88 \mathrm{c}$

$92238.88 \mathrm{C}$

$93237.88 \mathrm{C}$

$94238.88 \mathrm{c}$

$94239.88 \mathrm{c}$

$94240.88 \mathrm{C}$

$94241.88 \mathrm{c}$

$94242.88 \mathrm{c}$

$95241.88 \mathrm{c}$

$95242.88 \mathrm{C}$

$95243.88 \mathrm{C}$

$96242.88 \mathrm{c}$

$96243.88 \mathrm{C}$

$96244.88 \mathrm{c}$

$96245.88 \mathrm{c}$

$96246.88 \mathrm{c}$

$43099.60 \mathrm{c}$

$53129.60 \mathrm{C}$

20

$92234.88 \mathrm{C}$

$92235.88 \mathrm{C}$

$92236.88 \mathrm{C}$

$92238.88 \mathrm{C}$

$93237.88 \mathrm{C}$

$94238.88 \mathrm{C}$

$94239.88 \mathrm{c}$

$94240.88 \mathrm{C}$

$94241.88 \mathrm{c}$

$94242.88 \mathrm{c}$

$95241.88 \mathrm{C}$

$95242.88 \mathrm{C}$

$95243.88 \mathrm{C}$

$96242.88 \mathrm{c}$

$96243.88 \mathrm{C}$

$96244.88 \mathrm{c}$

$96245.88 \mathrm{c}$

$96246.88 \mathrm{C}$

$43099.60 \mathrm{c}$

$53129.60 \mathrm{C}$

! Automatic tallies for mat\#14

! Automatic tallies for mat\#15 


\section{Appendix G. Sample Monteburns Feed File for ADS (Concatenated to 15 Steps)}

\begin{tabular}{|c|c|c|c|c|c|c|c|c|}
\hline \multirow[b]{2}{*}{1.00000} & \multirow[b]{2}{*}{182.620} & \multirow[b]{2}{*}{1.00000} & \multicolumn{5}{|c|}{ grams/day } & \multirow[b]{2}{*}{1.0} \\
\hline & & & 1 & 0 & 0 & 0. & -1 & \\
\hline & & & 2 & 0 & 0 . & 0 . & 0 & 0. \\
\hline & & & 3 & 0 & 0 . & 0 . & 0 & 0. \\
\hline & & & 4 & 0 & 0 . & 0 . & 0 & 0 . \\
\hline & & & 5 & 0 & 0 . & 0 . & 0 & 0 . \\
\hline & & & 6 & 0 & 0 . & 0 . & 0 & 0 . \\
\hline & & & 7 & 0 & 0 . & 0 . & 0 & 0 . \\
\hline & & & 8 & 0 & 0. & 0. & 0 & 0 . \\
\hline & & & 9 & 0 & 0 . & 0 . & -1 & 1.0 \\
\hline & & & 10 & 0 & 0 . & 0 . & 0 & 0. \\
\hline & & & 11 & 0 & 0 . & 0 . & 0 & 0 . \\
\hline & & & 12 & 0 & 0 . & 0 . & 0 & 0 . \\
\hline & & & 13 & 0 & 0 . & 0 . & 0 & 0 . \\
\hline & & & 14 & 0 & 0 . & 0 . & 0 & 0 . \\
\hline & & & 15 & 0 & 0 & 0 & 0 & 0 . \\
\hline 2.00000 & 182.620 & 1.00000 & 1 & 1 & -2.0 & 800.00 & 0 & 0 . \\
\hline & & & 2 & 0 & 0 & 0 & -1 & 1.0 \\
\hline & & & 3 & 0 & 0 . & 0. & 0 & 0 \\
\hline & & & 4 & 0 & 0 . & 0 . & 0 & 0 . \\
\hline & & & 5 & 0 & 0 . & 0 . & 0 & 0 . \\
\hline & & & 6 & 0 & 0 . & 0 . & 0 & 0 . \\
\hline & & & 7 & 0 & 0 . & 0 . & 0 & 0 . \\
\hline & & & 8 & 0 & 0 & 0 & 0 & 0 . \\
\hline & & & 9 & 1 & -2.0 & 560.0 & 0 & 0. \\
\hline & & & 10 & 0 & 0 & 0 & -1 & 1.0 \\
\hline & & & 11 & 0 & 0 . & 0 . & 0 & 0. \\
\hline & & & 12 & 0 & 0 . & 0. & 0 & 0 . \\
\hline & & & 13 & 0 & 0 . & 0 . & 0 & 0 . \\
\hline & & & 14 & 0 & 0 . & 0 . & 0 & 0 . \\
\hline & & & 15 & 0 & 0 . & 0 . & 0 & 0 . \\
\hline 3.00000 & 182.620 & 1.00000 & 1 & 0 & 0 & 0 & 0 & 0 . \\
\hline & & & 2 & 1 & -2.0 & 680.00 & 00 & 0 \\
\hline & & & 3 & 0 & 0 & 0 & -1 & 1.0 \\
\hline & & & 4 & 0 & 0 . & 0 . & 0 & 0. \\
\hline & & & 5 & 0 & 0 . & 0 . & 0 & 0 . \\
\hline & & & 6 & 0 & 0 . & 0 . & 0 & 0 . \\
\hline & & & 7 & 0 & 0 . & 0 . & 0 & 0 . \\
\hline & & & 8 & 0 & 0 . & 0 . & 0 & 0 . \\
\hline & & & 9 & 0 & 0 & 0 & 0 & 0 . \\
\hline & & & 10 & 1 & -2.0 & 476.0 & 0 & 0. \\
\hline & & & 11 & 0 & 0 & 0 & -1 & 1.0 \\
\hline & & & 12 & 0 & 0 . & 0 . & 0 & 0. \\
\hline & & & 13 & 0 & 0 . & 0 . & 0 & 0 . \\
\hline & & & 14 & 0 & 0 . & 0 . & 0 & 0 . \\
\hline & & & 15 & 0 & 0 . & 0 . & 0 & 0 . \\
\hline 4.00000 & 182.620 & 1.00000 & 1 & 0 & 0 . & 0. & 0 & 0 . \\
\hline & & & 2 & 0 & 0 & 0 & 0 & 0. \\
\hline & & & 3 & 1 & -2.0 & 600.00 & 00. & 0.0 \\
\hline & & & 4 & 0 & 0 & 0 & -1 & 1.0 \\
\hline & & & 5 & 0 & 0 . & 0 . & 0 & 0. \\
\hline & & & 6 & 0 & 0 . & 0 . & 0 & 0 . \\
\hline & & & 7 & 0 & 0 . & 0 . & 0 & 0 . \\
\hline & & & 8 & 0 & 0 . & 0 . & 0 & 0 . \\
\hline & & & 9 & 0 & 0 . & 0 . & 0 & 0 . \\
\hline & & & 10 & 0 & 0 & 0 & 0 & 0 . \\
\hline & & & 11 & 1 & -2.0 & 420.0 & 0 & 0 \\
\hline & & & 12 & 0 & 0 & 0 & -1 & 1.0 \\
\hline
\end{tabular}




\section{LA-14052-T}

\begin{tabular}{|c|c|c|c|c|c|c|c|c|}
\hline & & & 13 & 0 & 0. & 0 . & 0 & 0. \\
\hline & & & 14 & 0 & 0 . & 0 . & 0 & 0 . \\
\hline & & & 15 & 0 & 0. & 0 . & 0 & 0 . \\
\hline 5.00000 & 182.620 & 1.00000 & 1 & 0 & 0 . & 0 . & 0 & 0. \\
\hline & & & 2 & 0 & 0. & 0 . & 0 & 0. \\
\hline & & & 3 & 0 & 0 & 0 . & 0 & 0 . \\
\hline & & & 4 & 1 & -2.0 & 550. & 0 & 0. \\
\hline & & & 5 & 0 & 0 & 0 & -1 & 1.0 \\
\hline & & & 6 & 0 & 0 & 0 . & 0 & 0 \\
\hline & & & 7 & 0 & 0 . & 0 . & 0 & 0. \\
\hline & & & 8 & 0 & 0. & 0. & 0 & 0. \\
\hline & & & 9 & 0 & 0. & 0 . & 0 & 0 . \\
\hline & & & 10 & 0 & 0. & 0 . & 0 & 0 . \\
\hline & & & 11 & 0 & 0 & 0. & 0 & 0. \\
\hline & & & 12 & 1 & -2.0 & 385.0 & 0 & 0 . \\
\hline & & & 13 & 0 & 0 & 0 & -1 & 1.0 \\
\hline & & & 14 & 0 & 0 . & 0 . & 0 & 0 \\
\hline & & & 15 & 0 & 0. & 0 . & 0 & 0 . \\
\hline 6.00000 & 182.620 & 1.00000 & 1 & 0 & 0 . & 0 . & 0 & 0 . \\
\hline & & & 2 & 0 & 0. & 0 . & 0 & 0 . \\
\hline & & & 3 & 0 & 0. & 0 . & 0 & 0 . \\
\hline & & & 4 & 0 & 0 & 0 & 0 & 0. \\
\hline & & & 5 & 1 & -2.0 & 510.0 & 0 & 0. \\
\hline & & & 6 & 0 & 0 & 0 & -1 & 1.0 \\
\hline & & & 7 & 0 & 0 . & 0 . & 0 & 0 \\
\hline & & & 8 & 0 & 0 . & 0 . & 0 & 0. \\
\hline & & & 9 & 0 & 0. & 0 . & 0 & 0 . \\
\hline & & & 10 & 0 & 0. & 0 . & 0 & 0 . \\
\hline & & & 11 & 0 & 0. & 0 . & 0 & 0 . \\
\hline & & & 12 & 0 & 0 & 0 & 0 & 0 . \\
\hline & & & 13 & 1 & -2.0 & 357.0 & 0 & 0 \\
\hline & & & 14 & 0 & 0 & 0 & -1 & 1.0 \\
\hline & & & 15 & 0 & 0 . & 0 . & 0 & 0 \\
\hline 7.00000 & 182.620 & 1.00000 & 1 & 0 & 0. & 0 . & 0 & 0. \\
\hline & & & 2 & 0 & 0. & 0 . & 0 & 0. \\
\hline & & & 3 & 0 & 0. & 0 . & 0 & 0 . \\
\hline & & & 4 & 0 & 0 . & 0 . & 0 & 0 . \\
\hline & & & 5 & 0 & 0 & 0 & 0 & 0 . \\
\hline & & & 6 & 1 & -2.0 & 500.0 & 0 & 0. \\
\hline & & & 7 & 0 & 0 & 0 & -1 & 1.0 \\
\hline & & & 8 & 0 & 0 . & 0 . & 0 & 0 \\
\hline & & & 9 & 0 & 0 . & 0 . & 0 & 0 . \\
\hline & & & 10 & 0 & 0 . & 0 . & 0 & 0 . \\
\hline & & & 11 & 0 & 0 . & 0 . & 0 & 0 . \\
\hline & & & 12 & 0 & 0 . & 0 . & 0 & 0 . \\
\hline & & & 13 & 0 & 0 & 0 & 0 & 0 . \\
\hline & & & 14 & 1 & -2.0 & 350.0 & 0 & 0 \\
\hline & & & 15 & 0 & 0 & 0 & -1 & 1.0 \\
\hline 8.00000 & 182.620 & 1.00000 & 1 & 0 & 0 . & 0 . & 0 & 0 \\
\hline & & & 2 & 0 & 0 . & 0 . & 0 & 0 . \\
\hline & & & 3 & 0 & 0 . & 0 . & 0 & 0 . \\
\hline & & & 4 & 0 & 0 . & 0 . & 0 & 0. \\
\hline & & & 5 & 0 & 0 . & 0 . & 0 & 0 . \\
\hline & & & 6 & 0 & 0 & 0 & 0 & 0 . \\
\hline & & & 7 & 1 & -2.0 & 497.0 & 0 & 0 \\
\hline & & & 8 & 0 & 0 & 0 & -1 & 1.0 \\
\hline & & & 9 & 0 & 0. & 0 . & -1 & 1.0 \\
\hline & & & 10 & 0 & 0 . & 0 . & 0 & 0. \\
\hline & & & 11 & 0 & 0 . & 0 . & 0 & 0. \\
\hline & & & 12 & 0 & 0 . & 0 . & 0 & 0. \\
\hline & & & 13 & 0 & 0. & 0 . & 0 & 0 . \\
\hline & & & 14 & 0 & 0 & 0 & 0 & 0. \\
\hline & & & 15 & 1 & -2.0 & 347.9 & 0 & 0. \\
\hline
\end{tabular}




\section{LA-14052-T}

\begin{tabular}{|c|c|c|c|c|c|c|c|c|}
\hline \multirow[t]{15}{*}{9.00000} & \multirow[t]{15}{*}{182.620} & \multirow[t]{15}{*}{1.00000} & 1 & 0 & 0 . & 0 . & -1 & 1.0 \\
\hline & & & 2 & 0 & 0 . & 0 . & 0 & 0 \\
\hline & & & 3 & 0 & 0 . & 0 . & 0 & 0 . \\
\hline & & & 4 & 0 & 0 & 0 . & 0 & 0 . \\
\hline & & & 5 & 0 & 0 . & 0 . & 0 & 0 . \\
\hline & & & 6 & 0 & 0 . & 0 . & 0 & 0 . \\
\hline & & & 7 & 0 & 0 & 0 & 0 & 0 . \\
\hline & & & 8 & 1 & -2.0 & 495.0 & 0 & 0 . \\
\hline & & & 9 & 1 & -2.0 & 346.5 & 0 & 0 \\
\hline & & & 10 & 0 & 0 & 0 & -1 & 1.0 \\
\hline & & & 11 & 0 & 0 . & 0 . & 0 & 0 \\
\hline & & & 12 & 0 & 0 . & 0 . & 0 & 0 . \\
\hline & & & 13 & 0 & 0 . & 0 . & 0 & 0 . \\
\hline & & & 14 & 0 & 0 . & 0 . & 0 & 0 . \\
\hline & & & 15 & 0 & 0 & 0 & 0 & 0 . \\
\hline \multirow[t]{15}{*}{10.00000} & \multirow[t]{15}{*}{182.620} & \multirow[t]{15}{*}{1.00000} & 1 & 1 & -2.0 & 494.0 & 0 & 0 \\
\hline & & & 2 & 0 & 0 & 0 & -1 & 1.0 \\
\hline & & & 3 & 0 & 0 . & 0 . & 0 & 0 \\
\hline & & & 4 & 0 & 0 . & 0 . & 0 & 0 . \\
\hline & & & 5 & 0 & 0 . & 0 . & 0 & 0 . \\
\hline & & & 6 & 0 & 0 . & 0 . & 0 & 0 . \\
\hline & & & 7 & 0 & 0. & 0 . & 0 & 0 . \\
\hline & & & 8 & 0 & 0 & 0 . & 0 & 0 . \\
\hline & & & 9 & 0 & 0 & 0 & 0 & 0 . \\
\hline & & & 10 & 1 & -2.0 & 345.8 & 0 & 0 \\
\hline & & & 11 & 0 & 0 & 0 & -1 & 1.0 \\
\hline & & & 12 & 0 & 0 . & 0 . & 0 & 0 \\
\hline & & & 13 & 0 & 0. & 0 . & 0 & 0 . \\
\hline & & & 14 & 0 & 0 & 0 . & 0 & 0 . \\
\hline & & & 15 & 0 & 0 . & 0 . & 0 & 0 . \\
\hline \multirow[t]{15}{*}{11.0000} & \multirow[t]{15}{*}{182.620} & \multirow[t]{15}{*}{1.00000} & 1 & 0 & 0 & 0 & 0 & 0 . \\
\hline & & & 2 & 1 & -2.0 & 494.0 & 0 & 0 \\
\hline & & & 3 & 0 & 0 & 0 & -1 & 1.0 \\
\hline & & & 4 & 0 & 0. & 0 . & 0 & 0 \\
\hline & & & 5 & 0 & 0. & 0 . & 0 & 0 . \\
\hline & & & 6 & 0 & 0 . & 0 . & 0 & 0 . \\
\hline & & & 7 & 0 & 0 . & 0 . & 0 & 0 . \\
\hline & & & 8 & 0 & 0 . & 0 . & 0 & 0 . \\
\hline & & & 9 & 0 & 0 . & 0 . & 0 & 0 . \\
\hline & & & 10 & 0 & 0 & 0 & 0 & 0 . \\
\hline & & & 11 & 1 & -2.0 & 345.8 & 0 & 0 \\
\hline & & & 12 & 0 & 0 & 0 & -1 & 1.0 \\
\hline & & & 13 & 0 & 0 . & 0 . & 0 & 0 \\
\hline & & & 14 & 0 & 0 . & 0 . & 0 & 0 . \\
\hline & & & 15 & 0 & 0 . & 0 . & 0 & 0 . \\
\hline \multirow[t]{15}{*}{12.0000} & \multirow[t]{15}{*}{182.620} & \multirow[t]{15}{*}{1.00000} & 1 & 0 & 0 . & 0 . & 0 & 0 . \\
\hline & & & 2 & 0 & 0 & 0 & 0 & 0 . \\
\hline & & & 3 & 1 & -2.0 & 494.00 & 0 & 0. \\
\hline & & & 4 & 0 & 0 & 0 & -1 & 1.0 \\
\hline & & & 5 & 0 & 0 . & 0 . & 0 & 0. \\
\hline & & & 6 & 0 & 0 . & 0 . & 0 & 0 . \\
\hline & & & 7 & 0 & 0 . & 0 . & 0 & 0 . \\
\hline & & & 8 & 0 & 0 . & 0 . & 0 & 0 . \\
\hline & & & 9 & 0 & 0 . & 0 . & 0 & 0 . \\
\hline & & & 10 & 0 & 0 . & 0 . & 0 & 0 . \\
\hline & & & 11 & 0 & 0 & 0 & 0 & 0 . \\
\hline & & & 12 & 1 & -2.0 & 345.8 & 0 & 0. \\
\hline & & & 13 & 0 & 0 & 0 & -1 & 1.0 \\
\hline & & & 14 & 0 & 0 . & 0 . & 0 & 0 \\
\hline & & & 15 & 0 & 0 . & 0 . & 0 & 0 . \\
\hline \multirow[t]{3}{*}{13.00000} & 182.620 & 1.00000 & 1 & 0 & 0 . & 0 . & 0 & 0 . \\
\hline & & & 2 & 0 & 0. & 0 . & 0 & 0 . \\
\hline & & & 3 & 0 & 0 & 0. & 0 & 0 . \\
\hline
\end{tabular}




\section{LA-14052-T}

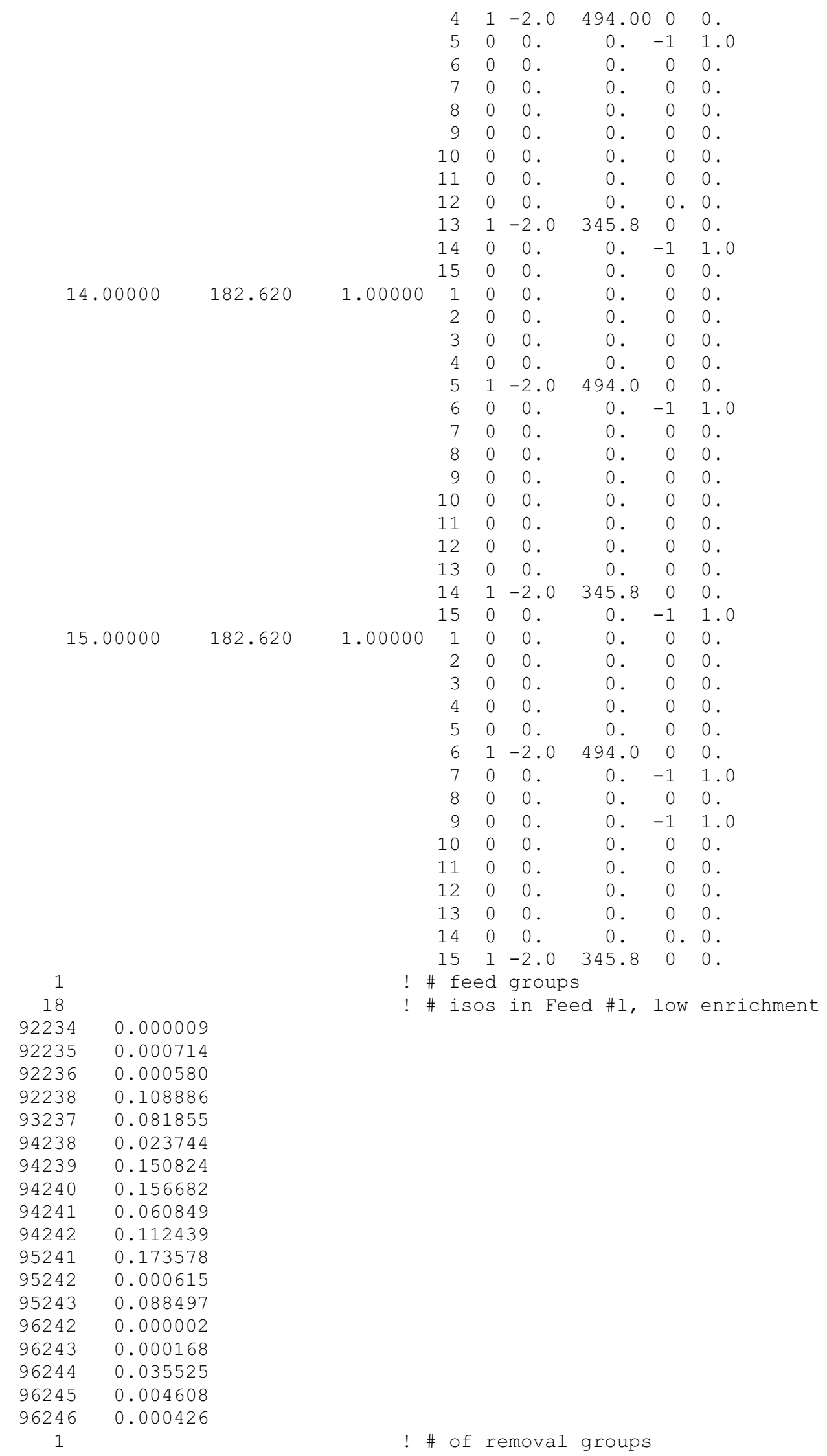


LA-14052-T

2

$-1 \quad-82$

$92 \quad 92$
! \# ranges for first removal group

! 1st range for Removal \#1 (negative=FPs only)

! 4th range for Removal \#1 
LA-14052-T 


\section{LA-14052-T}

\section{Appendix H. Excerpts from Sample Monteburns Output File for an ADS}

\begin{tabular}{|c|c|c|c|c|c|c|}
\hline \multicolumn{7}{|c|}{$\begin{array}{l}\text { Total Power }(\mathrm{MW})=8.40 \mathrm{E}+02 \\
\text { \# outer steps }=30, \quad \# \text { inner } \\
\text { Importance Fraction }=0.0010\end{array}$} \\
\hline \multicolumn{7}{|c|}{ Monteburns MCNP k-eff Versus Time } \\
\hline & days & $k-e f f$ & rel err & nu & avQfis & $k$-inf \\
\hline $0 \mathrm{~m}$ & 0.00 & 0.96402 & 0.00691 & 3.067 & 209.156 & 1.423 \\
\hline $1 \mathrm{~m}$ & 91.31 & 0.92653 & 0.00679 & 3.071 & 209.185 & 1.420 \\
\hline $1 e$ & 182.62 & 0.93548 & 0.00813 & 3.095 & & \\
\hline $2 \mathrm{~b}$ & 182.63 & 0.98186 & 0.00869 & 3.060 & & \\
\hline $2 m$ & 273.93 & 0.92405 & 0.00781 & 3.084 & 209.196 & 1.439 \\
\hline $2 e$ & 365.24 & 0.94296 & 0.00673 & 3.087 & & \\
\hline $3 b$ & 365.25 & 0.97199 & 0.00762 & 3.083 & & \\
\hline $3 m$ & 456.55 & 0.96251 & 0.01006 & 3.068 & 209.187 & 1.443 \\
\hline $3 e$ & 547.86 & 0.96044 & 0.00860 & 3.087 & & \\
\hline $4 \mathrm{~b}$ & 547.87 & 0.97615 & 0.01006 & 3.110 & & \\
\hline $4 m$ & 639.17 & 0.96683 & 0.00843 & 3.085 & 209.183 & 1.430 \\
\hline $4 e$ & 730.48 & 0.94068 & 0.00902 & 3.105 & & \\
\hline $5 b$ & 730.49 & 0.97408 & 0.00803 & 3.098 & & \\
\hline $5 \mathrm{~m}$ & 821.79 & 0.94538 & 0.00812 & 3.111 & 209.176 & 1.455 \\
\hline $5 e$ & 913.10 & 0.96057 & 0.00702 & 3.093 & & \\
\hline $6 \mathrm{~b}$ & 913.11 & 0.97892 & 0.00749 & 3.088 & & \\
\hline $6 \mathrm{~m}$ & 1004.41 & 0.96648 & 0.00971 & 3.120 & 209.192 & 1.441 \\
\hline $6 e$ & 1095.72 & 0.96900 & 0.00861 & 3.097 & & \\
\hline $7 \mathrm{~b}$ & 1095.73 & 0.99556 & 0.00904 & 3.111 & & \\
\hline $7 \mathrm{~m}$ & 1187.03 & 0.97734 & 0.00909 & 3.109 & 209.197 & 1.440 \\
\hline $7 e$ & 1278.34 & 0.96037 & 0.00762 & 3.091 & & \\
\hline $8 b$ & 1278.35 & 0.99030 & 0.00832 & 3.129 & & \\
\hline $8 m$ & 1369.65 & 0.95386 & 0.00800 & 3.091 & 209.200 & 1.455 \\
\hline $8 e$ & 1460.96 & 0.96317 & 0.00758 & 3.115 & & \\
\hline $9 b$ & 1460.97 & 0.97871 & 0.00845 & 3.117 & & \\
\hline $9 m$ & 1552.27 & 0.96957 & 0.00779 & 3.097 & 209.227 & 1.450 \\
\hline $9 e$ & 1643.58 & 0.95278 & 0.00876 & 3.123 & & \\
\hline $10 \mathrm{~b}$ & 1643.59 & 0.97210 & 0.00821 & 3.099 & & \\
\hline $10 \mathrm{~m}$ & 1734.89 & 0.96618 & 0.00829 & 3.114 & 209.252 & 1.465 \\
\hline $10 \mathrm{e}$ & 1826.20 & 0.94844 & 0.00912 & 3.144 & & \\
\hline $11 b$ & 1826.21 & 0.98497 & 0.00734 & 3.122 & & \\
\hline $11 \mathrm{~m}$ & 1917.51 & 0.97612 & 0.00747 & 3.121 & 209.271 & 1.473 \\
\hline $11 \mathrm{e}$ & 2008.82 & 0.93958 & 0.00827 & 3.097 & & \\
\hline $12 \mathrm{~b}$ & 2008.83 & 0.96731 & 0.00776 & 3.130 & & \\
\hline $12 \mathrm{~m}$ & 2100.13 & 0.96690 & 0.00863 & 3.124 & 209.305 & 1.461 \\
\hline $12 e$ & 2191.44 & 0.93658 & 0.00789 & 3.143 & & \\
\hline $13 b$ & 2191.45 & 0.97837 & 0.00873 & 3.127 & & \\
\hline $13 m$ & 2282.75 & 0.96307 & 0.00706 & 3.123 & 209.336 & 1.448 \\
\hline $13 e$ & 2374.06 & 0.95196 & 0.00841 & 3.105 & & \\
\hline $14 \mathrm{~b}$ & 2374.07 & 0.96939 & 0.00838 & 3.129 & & \\
\hline $14 \mathrm{~m}$ & 2465.37 & 0.96340 & 0.00918 & 3.070 & 209.355 & 1.443 \\
\hline $14 \mathrm{e}$ & 2556.68 & 0.96435 & 0.00818 & 3.111 & & \\
\hline $15 b$ & 2556.69 & 0.99748 & 0.00827 & 3.118 & & \\
\hline $15 \mathrm{~m}$ & 2647.99 & 0.93582 & 0.00717 & 3.092 & 209.383 & 1.449 \\
\hline $15 e$ & 2739.30 & 0.93446 & 0.00824 & 3.143 & & \\
\hline $16 \mathrm{~b}$ & 2739.31 & 0.97511 & 0.00978 & 3.139 & & \\
\hline $16 \mathrm{~m}$ & 2830.61 & 0.95517 & 0.00920 & 3.127 & 209.433 & 1.447 \\
\hline $16 e$ & 2921.92 & 0.93937 & 0.00818 & 3.117 & & \\
\hline $17 \mathrm{~b}$ & 2921.93 & 0.97666 & 0.00846 & 3.121 & & \\
\hline $17 \mathrm{~m}$ & 3013.23 & 0.95507 & 0.00896 & 3.131 & 209.462 & 1.458 \\
\hline $17 e$ & 3104.54 & 0.91408 & 0.00808 & 3.114 & & \\
\hline $18 \mathrm{~b}$ & 3104.55 & 0.96848 & 0.00763 & 3.135 & & \\
\hline
\end{tabular}




\section{LA-14052-T}

\begin{tabular}{|c|c|c|c|c|c|c|}
\hline $18 \mathrm{~m}$ & 3195.85 & 0.94602 & 0.00815 & 3.133 & 209.478 & 1.473 \\
\hline $18 e$ & 3287.16 & 0.91746 & 0.00757 & 3.141 & & \\
\hline $19 b$ & 3287.17 & 0.94992 & 0.00831 & 3.129 & & \\
\hline $19 m$ & 3378.47 & 0.94596 & 0.00759 & 3.127 & 209.521 & 1.463 \\
\hline $19 e$ & 3469.78 & 0.93210 & 0.00953 & 3.130 & & \\
\hline $20 b$ & 3469.79 & 0.94204 & 0.00823 & 3.132 & & \\
\hline $20 \mathrm{~m}$ & 3561.09 & 0.93844 & 0.00670 & 3.132 & 209.556 & 1.456 \\
\hline $20 e$ & 3652.40 & 0.91251 & 0.00765 & 3.135 & & \\
\hline $21 b$ & 3652.41 & 0.95428 & 0.00778 & 3.106 & & \\
\hline $21 \mathrm{~m}$ & 3743.71 & 0.93129 & 0.00957 & 3.155 & 209.603 & 1.466 \\
\hline $21 e$ & 3835.02 & 0.91437 & 0.00714 & 3.144 & & \\
\hline $22 \mathrm{~b}$ & 3835.03 & 0.95349 & 0.00808 & 3.108 & & \\
\hline $22 m$ & 3926.33 & 0.93240 & 0.00858 & 3.132 & 209.626 & 1.453 \\
\hline $22 e$ & 4017.64 & 0.92297 & 0.00821 & 3.122 & & \\
\hline $23 b$ & 4017.65 & 0.93418 & 0.00727 & 3.115 & & \\
\hline $23 m$ & 4108.95 & 0.91165 & 0.00759 & 3.122 & 209.639 & 1.458 \\
\hline $23 e$ & 4200.26 & 0.90716 & 0.00752 & 3.149 & & \\
\hline $24 b$ & 4200.27 & 0.94947 & 0.00847 & 3.128 & & \\
\hline $24 \mathrm{~m}$ & 4291.57 & 0.93650 & 0.00806 & 3.108 & 209.689 & 1.432 \\
\hline $24 e$ & 4382.88 & 0.92208 & 0.00863 & 3.169 & & \\
\hline $25 b$ & 4382.89 & 0.93404 & 0.00739 & 3.139 & & \\
\hline $25 m$ & 4474.19 & 0.92479 & 0.00860 & 3.184 & 209.718 & 1.475 \\
\hline $25 e$ & 4565.50 & 0.90541 & 0.00991 & 3.201 & & \\
\hline $26 b$ & 4565.51 & 0.93699 & 0.00898 & 3.161 & & \\
\hline $26 \mathrm{~m}$ & 4656.81 & 0.92430 & 0.00921 & 3.133 & 209.745 & 1.451 \\
\hline $26 e$ & 4748.12 & 0.88535 & 0.00748 & 3.145 & & \\
\hline $27 b$ & 4748.13 & 0.92704 & 0.00871 & 3.145 & & \\
\hline $27 \mathrm{~m}$ & 4839.43 & 0.91346 & 0.00704 & 3.102 & 209.767 & 1.439 \\
\hline $27 e$ & 4930.74 & 0.91567 & 0.00707 & 3.167 & & \\
\hline $28 b$ & 4930.75 & 0.92115 & 0.00764 & 3.146 & & \\
\hline $28 \mathrm{~m}$ & 5022.05 & 0.91144 & 0.00782 & 3.148 & 209.786 & 1.455 \\
\hline $28 e$ & 5113.36 & 0.89289 & 0.00950 & 3.148 & & \\
\hline $29 b$ & 5113.37 & 0.93214 & 0.00813 & 3.112 & & \\
\hline $29 \mathrm{~m}$ & 5204.67 & 0.89670 & 0.00798 & 3.117 & 209.827 & 1.426 \\
\hline $29 e$ & 5295.98 & 0.88668 & 0.00613 & 3.128 & & \\
\hline $30 \mathrm{~b}$ & 5295.99 & 0.91838 & 0.00679 & 3.169 & & \\
\hline $30 \mathrm{~m}$ & 5387.29 & 0.89499 & 0.00787 & 3.120 & 209.829 & 1.444 \\
\hline $30 e$ & 5478.60 & 0.88497 & 0.00805 & 3.154 & & \\
\hline
\end{tabular}

Monteburns Transport History for material 4

$\begin{array}{rlll}\text { material for actinide } & \\ \text { Qfis Slux SigmaF Power Pow.Den. Burnup namma }\end{array}$

total $\mathrm{n}$,fission fis/cap $\mathrm{n} 2 \mathrm{n}$ eta $\mathrm{n}$, gamma $\mathrm{n}$, fission fis/cap $\mathrm{n} 2 \mathrm{n}$

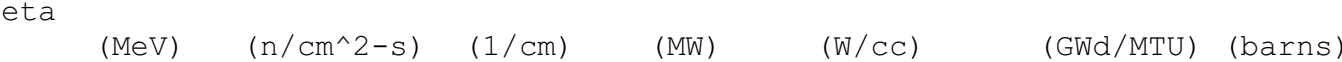
(barns) (barns) (barns) (barns) (barns) $\begin{array}{lllllllll}0 & 209.143 & 4.58 \mathrm{E}+15 & 5.44 \mathrm{E}-03 & 9.11 \mathrm{E}+01 & 8.344 \mathrm{E}+02 & 0.000 \mathrm{E}+00 & 1.30 \mathrm{E}-01\end{array}$ $\begin{array}{llllllll}1.27 \mathrm{E}-01 & 9.77 \mathrm{E}-01 & 2.92 \mathrm{E}-04 & 1.518 & 6.32 \mathrm{E}-01 & 6.91 \mathrm{E}-01 & 1.09 \mathrm{E}+00 & 6.30 \mathrm{E}-04\end{array}$ 1.603

$\begin{array}{llllllll}1 & 209.159 & 4.60 \mathrm{E}+15 & 5.35 \mathrm{E}-03 & 9.01 \mathrm{E}+01 & 8.250 \mathrm{E}+02 & 4.801 \mathrm{E}+01 & 1.22 \mathrm{E}-01\end{array}$ $\begin{array}{llllllll}1.25 \mathrm{E}-01 & 1.03 \mathrm{E}+00 & 2.67 \mathrm{E}-04 & 1.561 & 6.01 \mathrm{E}-01 & 6.98 \mathrm{E}-01 & 1.16 \mathrm{E}+00 & 6.84 \mathrm{E}-04\end{array}$ 1.651

$2 \quad 209.163 \quad 4.53 \mathrm{E}+15 \quad 5.02 \mathrm{E}-03 \quad 8.31 \mathrm{E}+01 \quad 7.611 \mathrm{E}+02 \quad 9.229 \mathrm{E}+01 \quad 1.19 \mathrm{E}-01$ $\begin{array}{llllllll}1.18 \mathrm{E}-01 & 9.93 \mathrm{E}-01 & 2.88 \mathrm{E}-04 & 1.539 & 6.06 \mathrm{E}-01 & 6.88 \mathrm{E}-01 & 1.13 \mathrm{E}+00 & 6.97 \mathrm{E}-04\end{array}$ 1.641

$\begin{array}{llllllll}3 & 209.158 & 4.37 \mathrm{E}+15 & 4.63 \mathrm{E}-03 & 7.39 \mathrm{E}+01 & 6.770 \mathrm{E}+02 & 1.317 \mathrm{E}+02 & 1.17 \mathrm{E}-01\end{array}$ $\begin{array}{llllllll}1.09 \mathrm{E}-01 & 9.27 \mathrm{E}-01 & 1.77 \mathrm{E}-04 & 1.478 & 6.13 \mathrm{E}-01 & 6.66 \mathrm{E}-01 & 1.09 \mathrm{E}+00 & 5.48 \mathrm{E}-04\end{array}$ 1.598

$4 \quad 209.128 \quad 4.33 \mathrm{E}+15 \quad 4.45 \mathrm{E}-03 \quad 7.05 \mathrm{E}+01 \quad 6.462 \mathrm{E}+02 \quad 1.693 \mathrm{E}+02 \quad 1.12 \mathrm{E}-01$ $\begin{array}{llllllll}1.05 \mathrm{E}-01 & 9.34 \mathrm{E}-01 & 2.19 \mathrm{E}-04 & 1.492 & 6.00 \mathrm{E}-01 & 6.69 \mathrm{E}-01 & 1.12 \mathrm{E}+00 & 5.69 \mathrm{E}-04\end{array}$ 1.628 


\section{LA-14052-T}

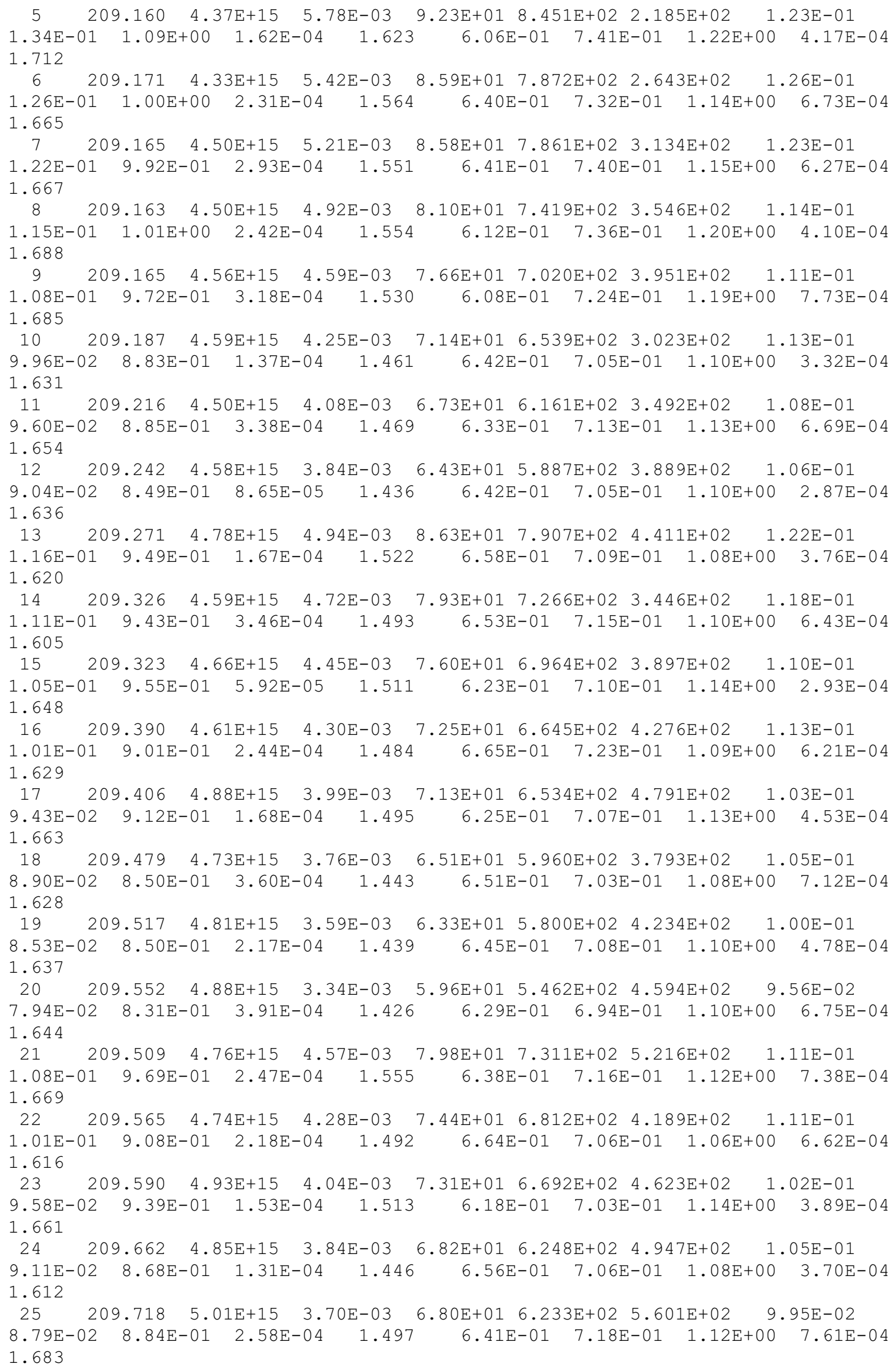




\section{LA-14052-T}

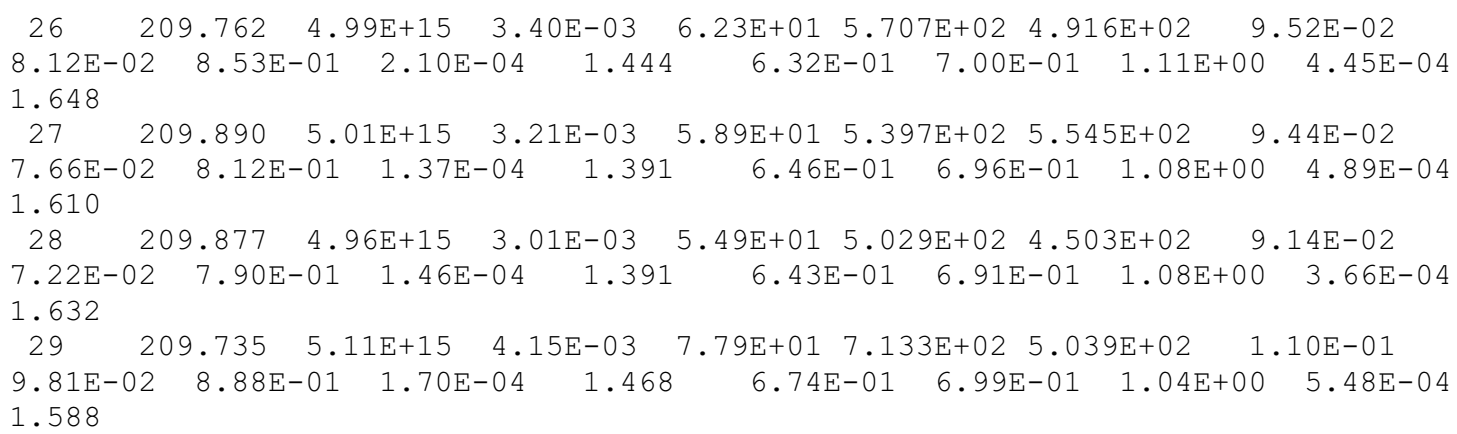

$\begin{array}{lr}<1 \mathrm{MeV} & <20 \mathrm{MeV} \\ 55.19 & 14.88 \\ 56.03 & 15.61 \\ 54.91 & 15.61 \\ 54.81 & 14.01 \\ 54.11 & 14.85 \\ 55.79 & 15.62 \\ 54.19 & 14.76 \\ 55.45 & 14.02 \\ 54.32 & 14.53 \\ 55.30 & 14.74 \\ 54.48 & 14.95 \\ 54.12 & 15.32 \\ 53.93 & 14.60 \\ 54.10 & 13.46 \\ 53.43 & 13.36 \\ 53.21 & 13.48 \\ 53.86 & 13.19 \\ 52.09 & 13.63 \\ 53.31 & 13.47 \\ 53.19 & 13.72 \\ 53.64 & 13.28 \\ 52.21 & 12.70 \\ 52.26 & 13.46 \\ 54.04 & 12.47 \\ 53.06 & 13.81 \\ 52.08 & 13.16 \\ 54.40 & 13.20 \\ 53.31 & 12.58 \\ 52.54 & 13.94 \\ 52.51 & 13.02 \\ 52.17 & 12.16 \\ 52.74 & 12.56 \\ 52.49 & 12.31 \\ 52.71 & 12.89 \\ & \\ 53 & \\ 53 & \\ 53 & \\ 53 & \end{array}$




\title{
Appendix I. FORTRAN77 Program Used to Generate MCNP Input Files for Safety
}

\section{Calculations}

\author{
program safety \\ character char $30 * 30$, char $80 * 80$ \\ This program generates additional MCNP input files for \\ further safety calculations \\ open (2, file='basecase', status='unknown') \\ open (3,file='Dopp1', status='unknown') \\ open (4,file='Dopp2', status='unknown') \\ open $\left(15, \mathrm{file}={ }^{\prime} \bmod 1\right.$ ', status='unknown' $)$ \\ open $(16, \mathrm{file}=$ 'mod2', status='unknown') \\ open ( 7 , file='boronl', status='unknown') \\ open ( 8 , file='boron2', status='unknown') \\ open (9,file='void', status='unknown') \\ open (17,file='control', status='unknown') \\ open (18,file='both', status='unknown') \\ open $(19, \mathrm{file}=$ ' shutdow', status='unknown' ) \\ 10 read $(2, '(a 80) ')$ char 80 \\ if (char80(1:4).eq.'81 0') then \\ write $(17, '(a 32, a 29)$ ') '81 $0 \quad-1310-1512$ ', \\ $\&$ \\ ' lat $=1$ \\ write $(17, *)$ ' \\ $\mathrm{u}=30$ imp: $\mathrm{n}=1^{\prime}$ \\ write $(17, *)$ ' \\ fill=0:7 $0: 9 \quad 0: 0$ ' \\ write $(17, *)$ ' \\ $\begin{array}{llllllll}20 & 12 & 22 & 12 & 22 & 11 & 21 & 13^{\prime}\end{array}$ \\ write $\left(17,{ }^{\star}\right)$ ' \\ $\begin{array}{llllllll}12 & 13 & 11 & 13 & 11 & 23 & 11 & 13^{\prime}\end{array}$ \\ write $(17, *)$ ' \\ $2211 \quad 12 \quad 12 \quad 13 \quad 11 \quad 12 \quad 13^{\prime}$ \\ $\begin{array}{lllllllll}12 & 13 & 12 & 22 & 11 & 22 & 11 & 13^{\prime}\end{array}$ \\ $\begin{array}{llllllll}22 & 11 & 13 & 11 & 22 & 11 & 12 & 18^{\prime}\end{array}$ \\ $\begin{array}{llllllll}11 & 23 & 11 & 22 & 11 & 12 & 13 & 18^{\prime}\end{array}$ \\ $\begin{array}{llllllll}21 & 11 & 12 & 11 & 12 & 13 & 18 & 18^{\prime}\end{array}$ \\ $\begin{array}{llllllll}13 & 13 & 13 & 13 & 18 & 18 & 18 & 18^{\prime}\end{array}$ \\ $\begin{array}{llllllll}18 & 18 & 18 & 18 & 18 & 18 & 18 & 18^{\prime}\end{array}$ \\ $\begin{array}{llllllll}18 & 18 & 18 & 18 & 18 & 18 & 18 & 18^{\prime}\end{array}$ \\ C \\ write $(17, *)$ \\ 1810 \\ $\begin{array}{llll}-13 & 10 & -15 & 12\end{array}$ \\ $£$ \\ write (18,' (a32,a29)') \\ $u=30$ imp: $n=1$ ' \\ write $(18, *)$ ' \\ fill=0:7 $0: 9 \quad 0: 0^{\prime}$ \\ write $(18, *)$ ' \\ write $(18, *)$ ' \\ $\begin{array}{llllllll}20 & 12 & 22 & 12 & 22 & 11 & 21 & 13^{\prime}\end{array}$ \\ $\begin{array}{llllllll}12 & 13 & 11 & 13 & 11 & 23 & 11 & 13^{\prime}\end{array}$ \\ $\begin{array}{llllllll}22 & 11 & 32 & 12 & 33 & 11 & 32 & 13^{\prime}\end{array}$ \\ $\begin{array}{llllllll}12 & 13 & 12 & 22 & 11 & 22 & 11 & 13^{\prime}\end{array}$ \\ write $(18, *)$ ' \\ write $(18, *)$ ' \\ $\begin{array}{llllllll}22 & 11 & 33 & 11 & 22 & 11 & 32 & 18^{\prime}\end{array}$ \\ write $(18, *)$ ' \\ $\begin{array}{llllllll}11 & 23 & 11 & 22 & 11 & 12 & 13 & 18^{\prime}\end{array}$ \\ write $(18, *)$ ' \\ write $(18, *)$ ' \\ write $(18, *)$ ' \\ $\begin{array}{llllllll}21 & 11 & 32 & 11 & 32 & 13 & 18 & 18^{\prime}\end{array}$ \\ $\begin{array}{llllllll}13 & 13 & 13 & 13 & 18 & 18 & 18 & 18^{\prime}\end{array}$ \\ $\begin{array}{llllllll}18 & 18 & 18 & 18 & 18 & 18 & 18 & 18^{\prime}\end{array}$ \\ write $(18, *)$ ' \\ $\begin{array}{lllllllll}18 & 18 & 18 & 18 & 18 & 18 & 18 & 18^{\prime}\end{array}$ \\ C \\ $\&$

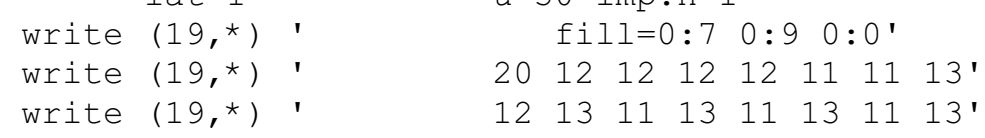




\section{LA-14052-T}

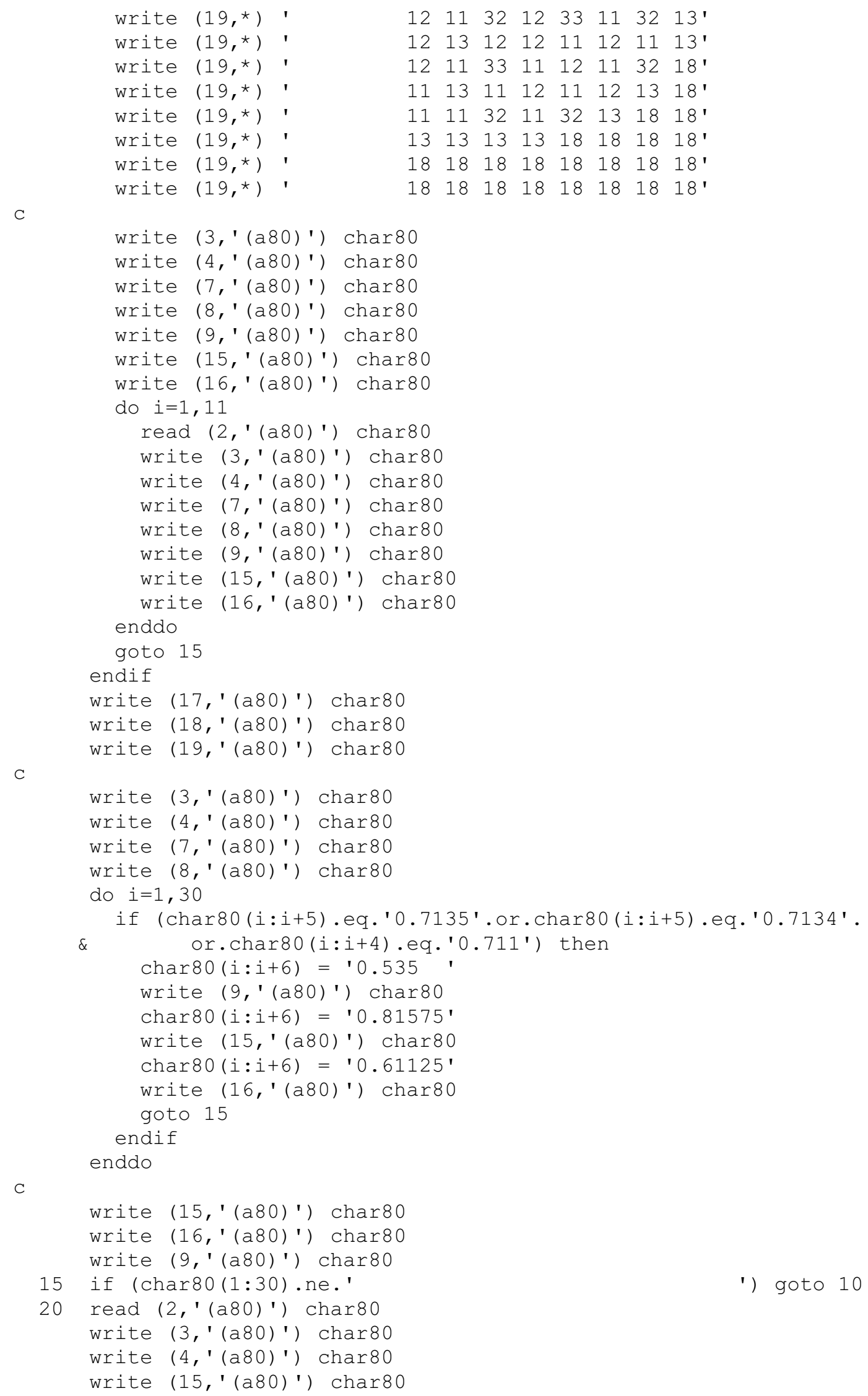




\section{LA-14052-T}

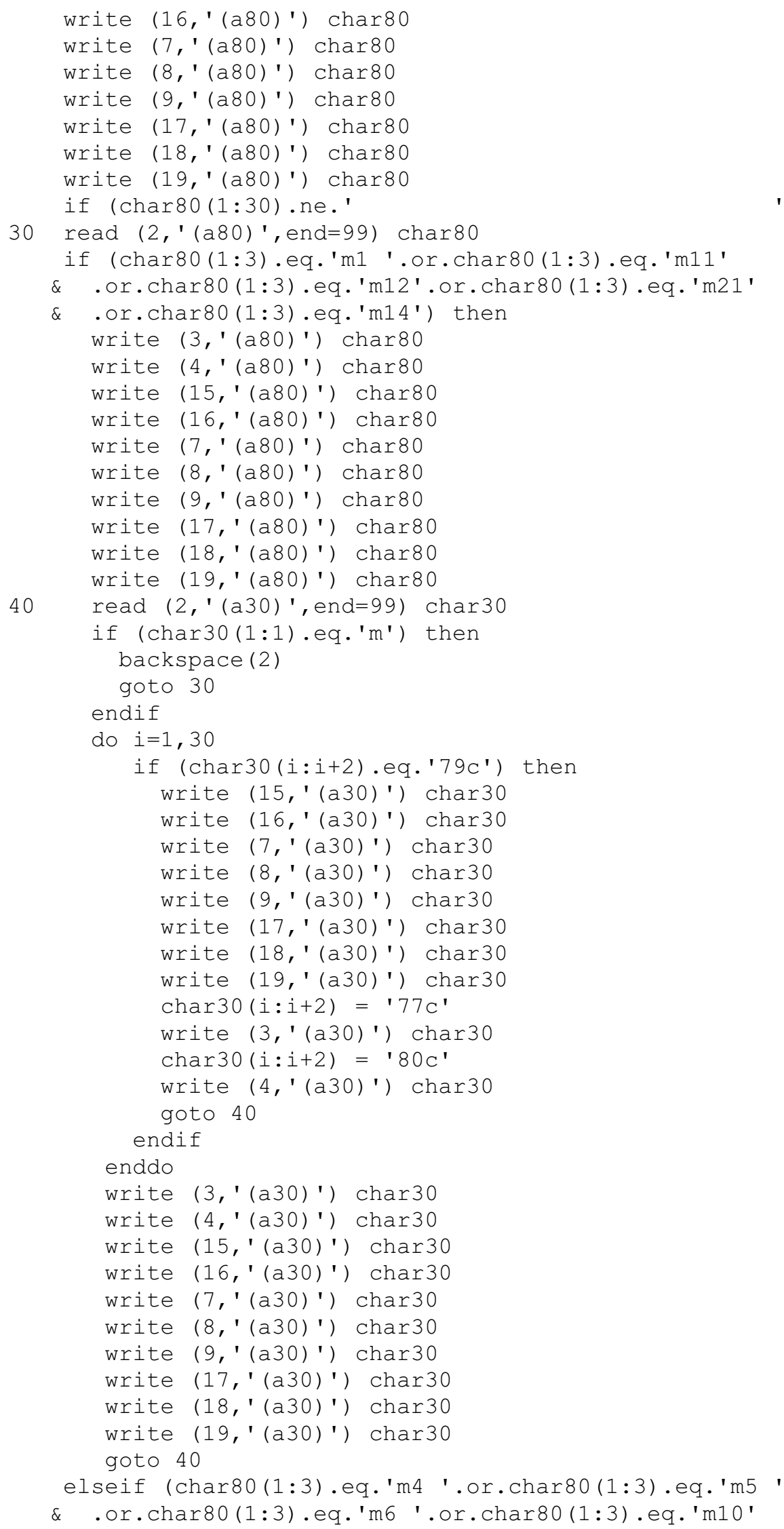




\section{LA-14052-T}

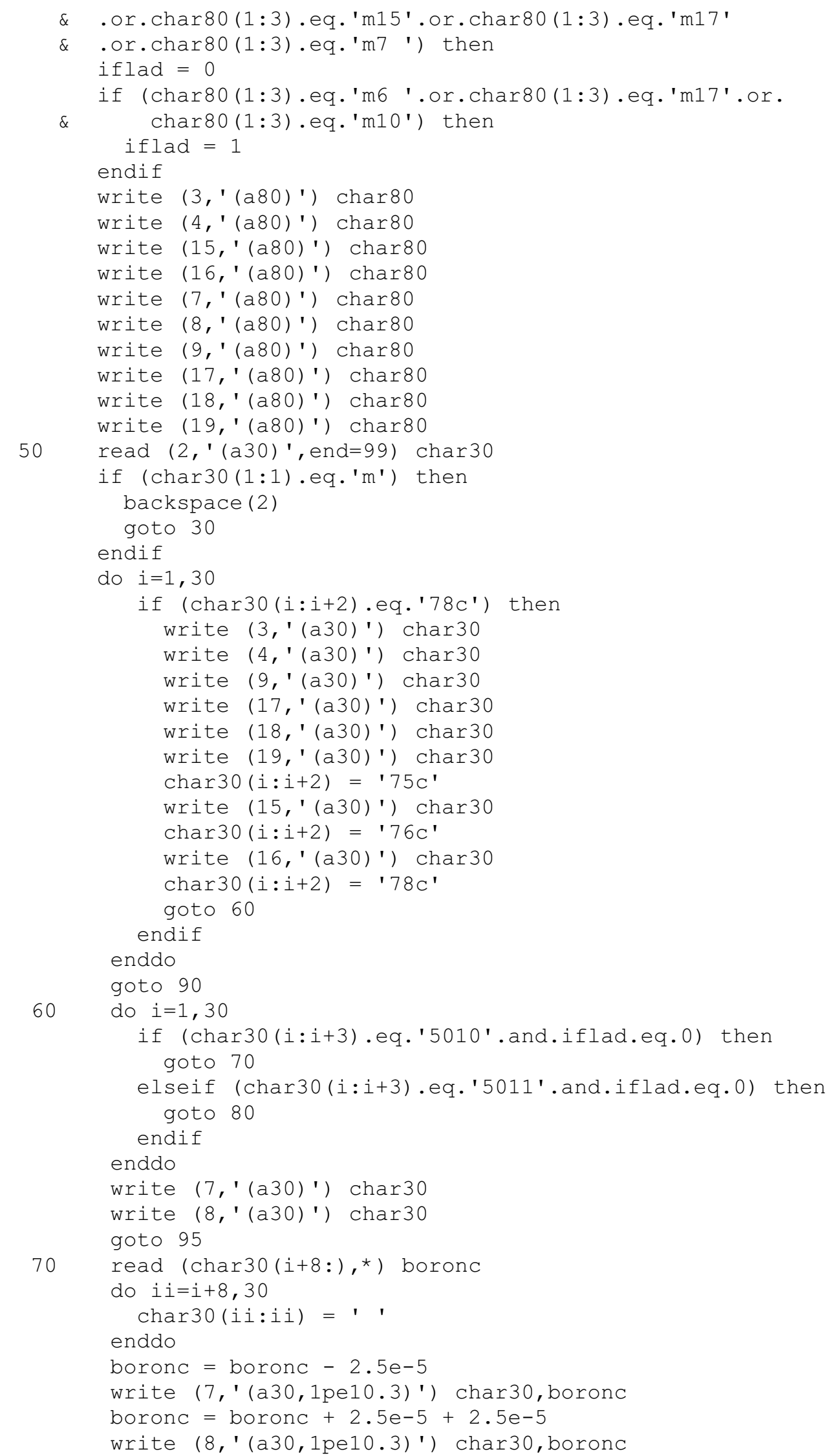




\section{LA-14052-T}

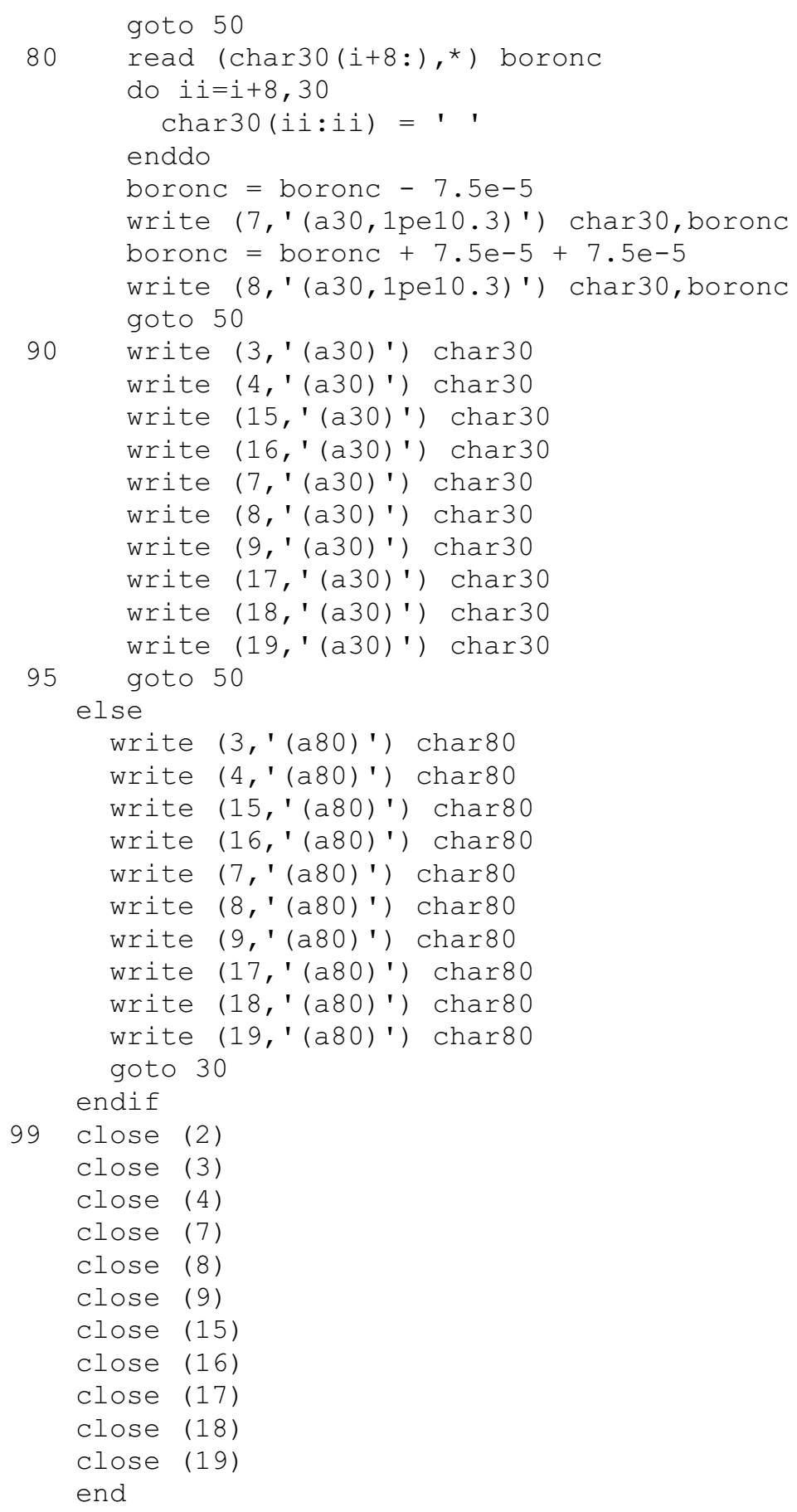


LA-14052-T 


\section{Appendix J. FORTRAN77 Program Used to Calculate Radiotoxicity of Spallation}

\section{Products from CINDER90 Output}

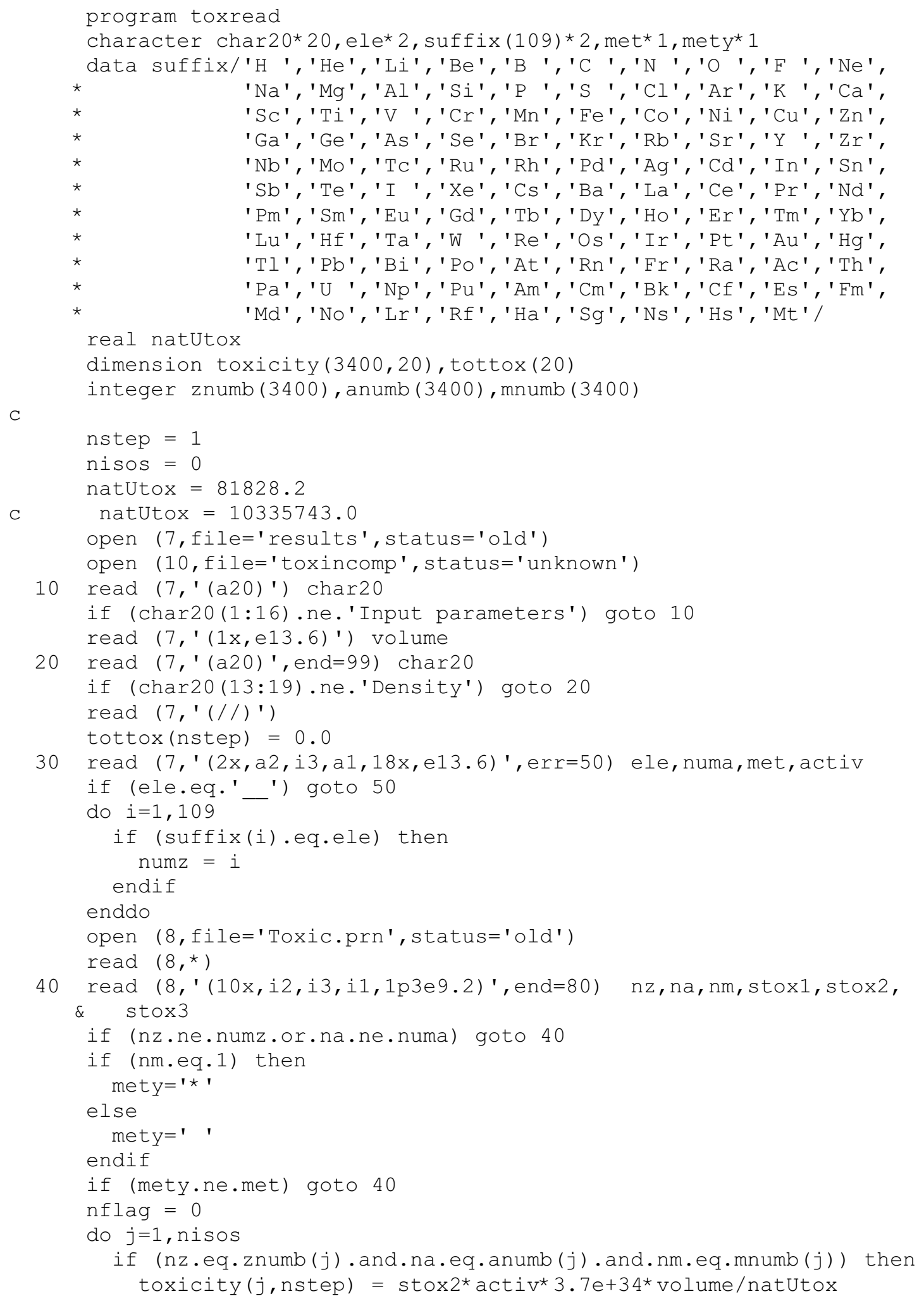




\section{LA-14052-T}

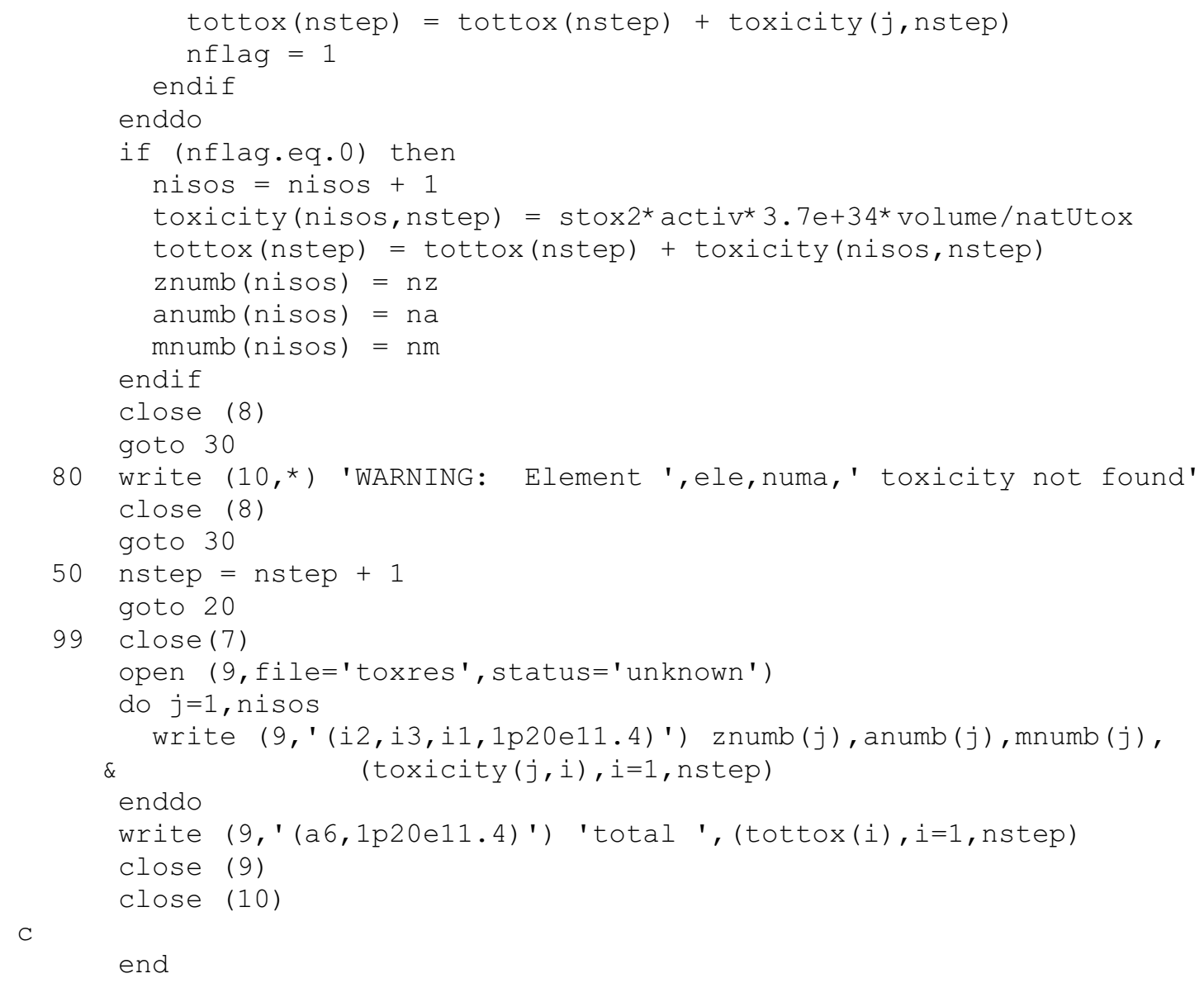

end 


\section{References:}

1. “CURE: Clean Use of Reactor Energy," WHC-EP-0268, Westinghouse Hanford Company, Richland, Washington (May 1990).

2. H. R. TRELlUE, E. J. PITCHER, P. CHODAK III, and D. BENNETT, “Two-Tiered Approach for Light-Water-Reactor Waste Disposition Using Existing Light-Water Reactors and a Minor Actinide Burner," LA-UR-01-1037, Los Alamos National Laboratory (February 2001).

3. G. J. VAN TUYLE, et al., "Candidate Approaches for an Integrated Nuclear Waste Management Strategy-Scoping Evaluations," LA-UR- 01-5572, Los Alamos National Laboratory (November 2001).

4. H. R. TRELLUE, and J. W. DAVIDSON, "Feasibility of Using Light Water Reactors to Transmute SNF," LA-UR-01-5692, Los Alamos National Laboratory (October 2001).

5. A. STANKOVSKY, et al., "Accumulation and Transmutation of Spallation Products in the Target of Accelerator-Driven System," Journal of Nuclear Science and Technology, 38, 7, pp. 503-510 (July 2001).

6. J. CARTER, "Nuclear Non-Proliferation," Presidential Decision Directive 8 (March 24, 1977).

7. R. P. RECHARD, L. C. SANCHEZ, H. R. TRELLUE, and C. T. STOCKMAN, "Unfavorable Conditions for Nuclear Criticality Following Disposal of Transuranic Waste at the Waste Isolation Pilot Plant," Nuclear Technology, 136, 1, pp. 99-128 (October 2001).

8. L. C. SANCHEZ, et al., "Nuclear Dynamics Consequences Analysis (NDCA) for the Disposal of Spent Nuclear Fuel in an Underground Geologic Repository, Volume 3: Appendices," INEEL/EXT-098-00996, SAND98-2208, Idaho National Engineering and Environmental and Sandia National Laboratories, (October 1998).

9. UNITED STATES DEPARTMENT OF ENERGY, Office of Civilian Radioactive Waste, "A Roadmap for Developing Accelerator Transmutation of Waste (ATW) Technology : A Report to Congress,” DOE $\backslash$ RW-0519 (October 1999).

10. “Total System Performance Assessment -Viability Assessment Analysis Technical Basis Report,” B00000000-01717-4301-00001, Rev. 01, Yucca Mountain Project (November 1998).

11. J. VERGNES, P. BARBRAULT, D. LECARPENTIER, et al., "Limiting Plutonium and Minor Actinides Inventory: Comparison Between Accelerator-Driven System (ADS) and Critical Reactor," Proceedings of the International Conference on Future Nuclear 
Systems, GLOBAL '99, Jackson Hole, Wyoming, American Nuclear Society, LaGrange Park, Illinois (August 1999).

12. C.M. BROEDERS, E. KIEFHABER, and H.W. WIESE, "Burning Transuranium Isotopes in Thermal and Fast Reactors," Nuclear Engineering and Design, 202, pp. 157$172(2000)$.

13. C. D. BOWMAN, "Once-Through Thermal-Spectrum Accelerator-Driven System for LWR Waste Destruction Without Reprocessing: Tier-1 Description,” ADNA/98-04, ADNA Corporation, Los Alamos, NM (1998).

14. H. R. TRELLUE, E. J. PITCHER, and D. I. POSTON, "Neutronics Studies of a Lead-Bismuth-Eutectic-Cooled Waste Transmuter," Proceedings of the Fourth International Topical Meeting on Nuclear Applications of Accelerator Technology, Washington D.C., American Nuclear Society, LaGrange Park, Illinois, pp. 81-88 (November 12-15, 2000).

15. T. MUKAIYAMA, "Partitioning and Transmutation Studies at JAERI Both Under OMEGA Program and High-Intensity Proton Accelerator Project," Intn. Seminar on Advanced Nuclear Systems toward Zero Release of Radioactive Wastes, Susono, Japan (November 2000).

16. S.R. GREENE, "Reactor-Based Plutonium Disposition: Opportunities, Options, and Issues,” ORNL\CP-102975 (also IAEA-SM-358/38), Oak Ridge National Laboratory (July 1999).

17. M. BENEDICT, T. H. PIGFORD, and H. W. LEVI, Nuclear Chemical Engineering, Second Edition, McGraw-Hill Inc., New York, pp. 76-78, 135-142, (1981).

18. E.J. DETILLEUX, W. HILD, and L. GEENS, "Reprocessing of Plutonium-Enriched Light Water Reactor Fuels,” Nuclear Technology, 61, pp. 398-402 (June 1983).

19. L. H. BAETSLE, and Ch. De RAEDT, "Limitations of Actinide Recycle and Fuel Cycle Consequences. A Global Analysis; Part 2: Recycle of Actinides in Thermal Reactors: Impact of High Burn Up LWR-UO $\mathrm{U}_{2}$ Fuel Irradiation and Multiple Recycle of LWR-MOX Fuel on the Radiotoxic Inventory," Nuclear Engineering and Design, 168, pp. 203-210 (1997).

20. C. R. FABER, and J. SEMMRICH, "Safety Aspects in Recycling Plutonium in LWR's: German Experience," Proceedings of the International Conference on Future Nuclear Systems, GLOBAL '99, Jackson Hole, Wyoming, American Nuclear Society, LaGrange Park, Illinois (August 1999).

21. J. NEDDERMAN, “100\% MOX cores?: Nearly no problem," Nuclear Engineering International, 41, 506, p. 28 (September 1996). 
22. L.H. BAETSLE, Ch. DE RAEDT, and G. VOLCKAERT, "Impact of Advanced Fuel Cycles and Irradiation Scenarios on Final Disposal Issues," Proceedings of the International Conference on Future Nuclear Systems, GLOBAL '99, Jackson Hole, Wyoming, American Nuclear Society, LaGrange Park, Illinois (August 1999).

23. J. W. STERBENTZ, "Neutronic Evaluation of a Non-Fertile Fuel for the Disposition of Weapons-Grade Plutonium in a Boiling Water Reactor," INEL-94/0079, Idaho National Engineering Laboratory (September 1994).

24. A. SHELLEY, et al., "Parametric Studies on Plutonium Transmutation Using Uranium-Free Fuels in Light Water Reactors," Nuclear Technology, 131, pp. 197-209 (August 2000).

25. H. AKIE, et al., "A New Fuel Material for Once-Through Weapons Plutonium Burning," Nuclear Technology, 107, 2, pp. 182-191 (1994).

26. A. PUILL and J. BERGERON, "Advanced Plutonium Fuel Assembly: An Advanced Concept for Using Plutonium in Pressurized Water Reactors," Nuclear Technology, 119, pp. 123-140 (August 1997).

27. S. L. EATON, et al., "Development of Nonfertile and Evolutionary Mixed Oxide Nuclear Fuels for Use in Existing Water Reactors," LA-UR-97-1359, Los Alamos National Laboratory (1997).

28. H.W. WIESE, "Investigation of the Nuclear Inventories of High-Exposure PWR Mixed-Oxide Fuels with Multiple Recycling of Self-Generated Plutonium," Nuclear Technology, 102, pp. 68-80 (April 1993).

29. K. HESKETH, et al., "The Physics of Plutonium Fuels - A Review of Organization for Economic Cooperation and Development/Nuclear Energy Agency Activities," Nuclear Technology, 131, pp. 385-394 (September 2000).

30. G. YOUINOU, et al., "Plutonium Management and Multirecycling in LWRs Using the Enriched Uranium Support," Proceedings of the International Conference on Future Nuclear Systems, GLOBAL '99, Jackson Hole, Wyoming, American Nuclear Society, LaGrange Park, Illinois (August 1999).

31. A. G. CROFF, J. O. BLOMEKE, and B. C. FINNEY, "Actinide PartitioningTransmutation Program Final Report," ORNL-5566, Oak Ridge National Laboratory, pp. 64-68 (June 1980).

32. A. PUILL and J. BERGERON, "Improved Plutonium Consumption in a Pressurized Water Reactor," Proceedings of the International Conference on Future Nuclear Systems, GLOBAL '95, Versailles, France, American Nuclear Society, LaGrange Park, Illinois (September 1995). 
33. B. ESTEVE, J. P. MARCON, and J. L. NIGON, "Irradiation Experience of MOX Fuel in EDF Reactors," Proceedings of the International Conference on Future Nuclear Systems, GLOBAL '95, Versailles, France, American Nuclear Society, LaGrange Park, Illinois (September 1995).

34. P. BARBRAULT, "A Plutonium-Fueled High-Moderated Pressurized Water Reactor for the Next Century," Nuclear Science and Engineering, 122, pp. 240-246 (1996).

35. K. SAKURADA, A. MOTOO, K. TAKASHI, et al., "Studies on Advanced LWR Cores for Effective Use of Plutonium and Analysis of MOX Physics Experiments," Proceedings of the International Conference on Future Nuclear Systems, GLOBAL '99, Jackson Hole, Wyoming, American Nuclear Society, LaGrange Park, Illinois (August 1999).

36. P. BARBRAULT, “A Plutonium-Fueled PWR 2000,” Mixed Oxide Fuel (MOX) Exploitation and Destruction in Power Reactors," NATO Advanced Science Institutes Series from NATO Advanced Research Workshop in Obninsk, Russia, October 16-19, 1994, Kluwer Academic Publishers, Dordrecht/Boston/London (1995).

37. R. MASUMI, and M. AOYAMA, "Minor Actinide Transmutation in BWR Cores for Multi-recycling Operation with Less Minor Actinide-to-Fissile Plutonium Amount Ratio," Journal of Nuclear Science and Technology, 32, 10, pp. 965-970 (October 1995).

38. G. MANENT, M. DELPECH, J.C. GARNIER, "Use of Plutonium in Reactors and Comparison of New Options Studied in France," Proceedings of the SPIE - The International Society for Optical Engineering, 2339, pp. 181-187 (1995).

39. G. YOUINOU, et al., "Heterogeneous Assembly for Plutonium Multirecycling in PWRs: The CORAIL Concept," Proceedings of the International Conference on Future Nuclear Systems, GLOBAL '99, Jackson Hole, Wyoming, American Nuclear Society, LaGrange Park, Illinois (August 1999).

40. G. ROUVIERE, G. B. BRUNA, J.L. GUILLET, and J. PELET, “1300 MWe PWR, A New Step in Full MOX Core Design," Proceedings of the International Conference on Future Nuclear Systems, GLOBAL '99, Jackson Hole, Wyoming, American Nuclear Society, LaGrange Park, Illinois (August 1999).

41. L. RESTEIGNE, "Utilization of MOX Fuel Assemblies in Belgian PWRs," Proceedings of the International Conference on Future Nuclear Systems, GLOBAL '95, Versailles, France, American Nuclear Society, LaGrange Park, Illinois (September 1995).

42. W. STOLL, "MOX Fuel: an Established Technology in Germany," Nuclear Europe, pp. 29-31 (1985). 
43. Y. KOO, D. SOHN, and B. VOLKOV, "A Comparative Analysis of $\mathrm{UO}_{2}$ and $\mathrm{MOX}$ Fuel Behavior Under Reactivity Initiated Accident," Annals of Nuclear Energy, 24, 11, pp. 859-870 (1997).

44. M. ROME, et al., "Plutonium Reload Experience in French Pressurized Water Reactors," Nuclear Technology, 94, pp. 87-98 (April 1991).

45. E. J. PITCHER, et al., "Neutronic design of the APT Target/Blanket," LA-UR-973627, Los Alamos National Laboratory (1997).

46. H. R. TRELLUE, E. J. PITCHER, and D. I. POSTON, "Sensitivity Studies on LeadBismuth Transmuter for Accelerator Transmutation of Waste," LA-UR-00-3285, Los Alamos National Laboratory (2000).

47. W. S. YANG, and H. S. KHALIL, "Reduction of Burnup Reactivity Loss in Accelerator Driven Transmutation Systems," Proceedings of the Fourth International Topical Meeting on Nuclear Applications of Accelerator Technology, Washington D.C., American Nuclear Society, LaGrange Park, Illinois, pp. 75-80 (November 12-15, 2000).

48. J. J. LAIDLER, "Separations Technology Supporting the Development of a Deployable ATW System," ANL\CMT \CP-100872, Argonne National Laboratory (January 2000).

49. J. J. LAIDLER, "Pyrochemical Separations Technologies Envisioned for the U.S. Accelerator Transmutation of Waste System," ANL\CMT \CP-101137, Argonne National Laboratory (March 2000).

50. "1990 Recommendations of the International Commission on Radiological Protection," ICRP Publication 60, Annals of the ICRP, 21, 1-3, Pergamon Press, Oxford (1991).

51. "Age-dependent Doses to Members of the Public from Intake of Radionuclides: Part 5 Compilation of Ingestion and Inhalation Dose Coefficients," ICRP Publication 72, Annals of the ICRP, 26, 1, Pergamon Press, Oxford (1979).

52. The ICRP Database of Dose Coefficients: Workers and Members of the Public, Task Force on Dose Calculations of Committee 2 of the International Commission on Radiological Protection, ISBN 0080427510 (1996).

53. J. E. TURNER, Atoms, Radiation, and Radiation Protection, McGraw-Hill, New York, p. 282 (1992).

54. Nuclear Regulatory Commission, Code of Federal Regulations, 10 CFR 20, Appendix B: Annual Limits on Intake (ALIs) and Derived Air Concentrations (DACs) of Radionuclides for Occupational Exposure; Effluent Concentrations; Concentrations for Release to Sewage, Washington D.C. (May 21, 1991). 
55. K. KAWAI, A. ENDO, and H. NOGUCHI, "Dose coefficients for Radionuclides Produced in High Energy Proton Accelerator Facilities: Coefficients for Radionuclides Not Listed in ICRP Publications," JAERI-Data/Code 2002-013, Japan Atomic Energy Research Institute (May 2002).

56. D. V. PANKRATOV, et al., "Radiological Properties of Heavy Liquid Metal Targets of Accelerator-Driven Systems," Materials Research Society Symposium Proceedings, 556, pp. 1215-1221 (1999).

57. Nuclides and Isotopes: Chart of Nuclides, Fifteenth Edition, General Electric Nuclear Energy, San Jose, California (1996).

58. J.F. BRIESMEISTER, ed., "MCNP - A General Monte Carlo N-particle Transport Code - Version 4B," LA-12625-M, Los Alamos National Laboratory (1997).

59. A. G. CROFF, “A User's Manual for ORIGEN2 Computer Code,” ORNL/TM-7175, Oak Ridge National Laboratory (July 1980).

60. D.I. POSTON and H.R. TRELLUE, “User's Manual, Version 2.0, for MONTEBURNS, Version 1.0," LA-UR-99-4999, Los Alamos National Laboratory (September 1999). Also known as RSICC code number P00455.

61. L. S. WATERS, ed., “MCNPX ${ }^{\mathrm{TM}}$ User's Manual, Version 2.1.5,” LA-UR 99-6058, Los Alamos National Laboratory (November 15, 1999).

62. R.E. PRAEL, H. LICHTENSTEIN, "Users Guide to LCS: The LAHET Code System," LA-UR-89-3014, Los Alamos National Laboratory (1989).

63. W. B. WILSON et al., "Recent Development of the CINDER'90 Transmutation Code and Data Library for Actinide Transmutation Studies," Proceedings of the International Conference on Future Nuclear Systems, GLOBAL '95, Versailles, France, American Nuclear Society, LaGrange Park, Illinois (September 1995).

64. R.E. MacFARLANE and D.W. Muir, "The NJOY Nuclear Data Processing System Version 91,” LA-12740-M, Los Alamos National Laboratory (October 1994).

65. N. BULTMAN, et al., "Los Alamos Next-Generation Spallation Source,” LA-UR95-4300, Los Alamos National Laboratory (1995).

66. H. R. TRELLUE, "Development of Monteburns: A Code That Links MCNP and ORIGEN2 in an Automated Fashion for Burnup Calculations," LA-13514-T, Los Alamos National Laboratory (December 1998).

67. O. W. HERMANN, S. M. BOWMAN, M. C. BRADY, and C. V. PARKS, "Validation of the Scale System for PWR Spent Fuel Isotopic Composition Analyses," ORNL/TM-12667, Oak Ridge National Laboratory (March 1995). 
68. OECD NUCLEAR ENERGY AGENCY, Working Party on Physics of Plutonium Recycling, "Physics of Plutonium Recycling," Vol. 2 and 3, OECD Document (1995).

69. W. BERNNAT, et al., "PWR Benchmarks from OECD Working Party on Physics of Plutonium Recycle," Proceedings of the International Conference on Future Nuclear Systems, GLOBAL '95, Versailles, France, American Nuclear Society, LaGrange Park, Illinois (September 1995).

70. O. W. HERMANN, "Benchmark of SCALE (SAS2H) Isotopic Predictions of Depletion Analyses for San Onofre PWR MOX Fuel," ORNL/TM-1999/326, Oak Ridge National Laboratory (February 2000).

71. D. BOULANGER and M. LIPPENS, “Actinide Research In A Nuclear Element-Final Report,” 0000253/221-B1, ARIANE International Programme, Belgonucleaire S.A. (December 2000).

72. T. O. BRUN, et al., "LAHET Code System/CINDER'90 Validation Calculations and Comparison with Experimental Data," Twelfth Meeting of the International Collaboration on Advanced Neutron Sources, (24-28 May 1993).

73. S. G. MASHNIK, et al., "Benchmarking Ten Codes Against the Recent GSI Measurements of the Nuclide Yields from ${ }^{208} \mathrm{~Pb},{ }^{197} \mathrm{Au}$, and ${ }^{238} \mathrm{U}+\mathrm{p}$ Reactions at 1 GeV/nucleon," LA-UR-01-5391, Los Alamos National Laboratory (2001).

74. J. L. ULLMANN, et al., "APT Radionuclide Production Experiment Technical Report," LA-UR-95-3327, Los Alamos National Laboratory, Appendix C-1 and C-2 (1995).

75. C. E. LAIRD, and D. H. MULLINS, “Analysis of Gamma-Ray Spectra from Foils Activated in a Range-Thick Lead Target by $800-\mathrm{MeV}$ Protons," Final Technical Report for Subcontract number 2045N0014-3C, Eastern Kentucky University, Richmond, KY (June 12, 1995).

76. D. BENNETT, et al., "Compendium of Initial System Point Designs for Accelerator Transmutation of Radioactive Waste," LA-UR-01-1817, Los Alamos National Laboratory (2001)

77. W. B. WILSON, et al., "Accelerator Transmutation Studies at Los Alamos with LAHET, MCNP and CINDER90," LA-UR-93-3080, Los Alamos National Laboratory (January 11, 1993).

78. S. G. MASHNIK, and A. J. SIERK, "Recent Developments of the Cascade-Exciton Model of Nuclear Reactions," LA-UR-01-5390, Los Alamos National Laboratory (2001) and Proc. Int. Conf. on Nuclear Data for Science and Technology (ND2001), October 712, 2001, Tsukuba, Ibaraki, Japan, 1; Journal of Nuclear Science and Technology,

Supplement 2, pp. 720-725 (2002). 
79. H. R. TRELLUE, “The Answer Is No: Does Transmutation of Spent Nuclear Fuel Produce More Hazardous Material Than It Destroys?" Radwaste Solutions, American Nuclear Society, LaGrange Park, Illinois, pp. 40-43, (July/August 2002).

80. B. D. MURPHY, "Characteristics of Spent Fuel from Plutonium Disposition Reactors, Vol. 3: A Westinghouse Pressurized-Water Reactor Design," ORNL/TM13170/V3, Oak Ridge National Laboratory, p. 4 (March 1996).

81. H. BERNARD, “Advanced Fuel Fabrication,” Journal of Nuclear Materials, 166, North Holland, Amsterdam, pp. 105-111 (1989).

82. H. BAIRIOT, and P. DERAMAIX, "MOX Fuel Development: Yesterday, Today, and Tomorrow," 188, North-Holland, pp. 10-18 (1992).

83. L. H. BAETSLE, and Ch. De RAEDT, "Limitations of Actinide Recycle and Fuel Cycle Consequences. A Global Analysis; Part 1: Global Fuel Cycle Analysis," Nuclear Engineering and Design, 168, pp. 191-201 (1997).

84. M. SALVATORES, "Transmutation and Innovative Options for the Back-End of the Fuel Cycle," Proceedings of the International Conference on Future Nuclear Systems, GLOBAL '99, Jackson Hole, Wyoming, American Nuclear Society, LaGrange Park, Illinois (August 1999). 
This report has been reproduced directly from the best available copy. It is available electronically on the Web (http://www.doe.gov/bridge).

Copies are available for sale to U.S. Department of Energy employees and contractors from:

Office of Scientific and Technical Information P.O. Box 62

Oak Ridge, TN 37831

(865) 576-8401

Copies are available for sale to the public from: National Technical Information Service

U.S. Department of Commerce

5285 Port Royal Road

Springfield, VA 22616

(800) 553-6847 
